Argonne

ANL/RERTR/TM-11-38 Rev. 3

\title{
A User Guide to PARET/ANL
}

Version 7.6

Nuclear Science and Engineering Division 


\section{About Argonne National Laboratory}

Argonne is a U.S. Department of Energy laboratory managed by UChicago Argonne, LLC under contract DE-AC02-06CH11357. The Laboratory's main facility is outside Chicago, at 9700 South Cass Avenue, Argonne, Illinois 60439. For information about Argonne and its pioneering science and technology programs, see www.anl.gov.

\section{DOCUMENT AVAILABILITY}

Online Access: U.S. Department of Energy (DOE) reports produced after 1991 and a growing number of pre-1991 documents are available free via DOE's SciTech Connect (http://www.osti.gov/scitech/)

\section{Reports not in digital format may be purchased by the public from the}

National Technical Information Service (NTIS):

U.S. Department of Commerce National Technical Information Service 5301 Shawnee Rd

Alexandria, VA 22312

www.ntis.gov

Phone: (800) 553-NTIS (6847) or (703) 605-6000

Fax: (703) 605-6900

Email: orders@ntis.gov

Reports not in digital format are available to DOE and DOE contractors from the Office of Scientific and Technical Information (OSTI):

U.S. Department of Energy

Office of Scientific and Technical Information

P.O. Box 62

Oak Ridge, TN 37831-0062

www.osti.gov

Phone: (865) 576-8401

Fax: (865) 576-5728

Email: reports@osti.gov

\section{Disclaimer}

This report was prepared as an account of work sponsored by an agency of the United States Government. Neither the United States Government nor any agency thereof, nor UChicago Argonne, LLC, nor any of their employees or officers, makes any warranty, express or implied, or assumes any legal liability or responsibility for the accuracy, completeness, or usefulness of any information, apparatus, product, or process disclosed, or represents that its use would not infringe privately owned rights. Reference herein to any specific commercial product, process, or service by trade name, trademark, manufacturer, or otherwise, does not necessarily constitute or imply its endorsement, recommendation, or favoring by the United States Government or any agency thereof. The views and opinions of document authors expressed herein do not necessarily state or reflect those of the United States Government or any agency thereof, Argonne National Laboratory, or UChicago Argonne, LLC. 
ANL/RERTR/TM-11-38 Rev. 3

\title{
A User Guide to PARET/ANL
}

\author{
Version 7.6
}

prepared by

A.P. Olson and M. Kalimullah

Nuclear Science and Engineering Division, Argonne National Laboratory

March 2019 
(This page left intentionally blank) 


\section{Abstract}

PARET was originally created in 1969 at what is now Idaho National Laboratory (INL), to analyze reactivity insertion events in research and test reactor cores cooled by light or heavy water, with fuel composed of either plates or pins. The use of PARET is also appropriate for fuel assemblies with curved fuel plates when their radii of curvatures are large with respect to the fuel plate thickness. The PARET/ANL version of the code has been developed at Argonne National Laboratory (ANL) under the sponsorship of the U.S. Department of Energy/NNSA since the inception of the Reactor Conversion Program. Since Reduced Enrichment for Research and Test Reactors (RERTR) began in 1978, PARET/ANL has been benchmarked to experimental data including SPERT testing, and used to determine the expected transient behavior of a large number of reactors regardless of enrichment both inside and outside the Reactor Conversion Program. This document provides the pertinent information for the use of PARET/ANL Version 7.6

PARET/ANL models the various fueled regions of a reactor core as channels. Each of these channels consists of a single flat fuel plate/pin (including cladding and, optionally, a gap) with water coolant on each side. In slab geometry the coolant channels for a given fuel plate are of identical dimensions (mirror symmetry), but they can be of different thickness in each channel. There can be many channels, but each channel is independent and coupled only through reactivity feedback effects to the whole core.

The time-dependent differential equations that represent the system are replaced by an equivalent set of finite-difference equations in space and time, which are integrated numerically. PARET/ANL uses fundamentally the same numerical scheme as RELAP5 for the time-integration of the point-kinetics equations.

The one-dimensional thermal-hydraulic model includes temperature-dependent thermal properties of the solid materials, such as heat capacity and thermal conductivity, as well as the transient heat production and heat transfer from the fuel meat to the coolant. Temperature- and pressure-dependent thermal properties of the coolant such as enthalpy, density, thermal conductivity, and viscosity are also used in determining parameters such as friction factors and heat transfer coefficients. The code first determines the steady-state solution for the initial state. Then the solution of the transient is obtained by integration in time and space. Multiple heat transfer, DNB and flow instability correlations are available.

The code was originally developed to model reactors cooled by an open loop, which was adequate for rapid transients in pool-type cores. An external loop model appropriate for Miniature Neutron Source Reactors (MNSR's) was also added to PARET/ANL to model natural circulation within the vessel, heat transfer from the vessel to pool and heat loss by evaporation from the pool. PARET/ANL also contains models for decay heat after shutdown, control rod reactivity versus time or position, time-dependent pump flow, and loss-of-flow event with flow reversal as well as logic for trips on period, power, and flow. Feedback reactivity effects from coolant density changes and temperature changes are represented by tables. Feedback reactivity from fuel heat-up (Doppler Effect) is represented by a four-term polynomial in powers of fuel temperature. Photo-neutrons produced in beryllium or in heavy water may be included in the point-kinetics equations by using additional delayed neutron groups. 


\section{Table of Contents}

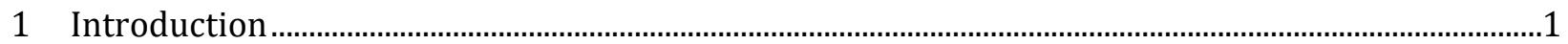

2 What is New in Version 7.6?

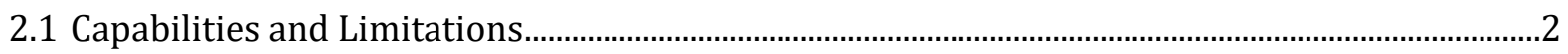

2.2 Flow Reversal Model .....................................................................................................................

2.3 Revised Power and Flow Edits By Channel............................................................................................

2.4 Revised CIAE Natural Convection Model ..............................................................................................

2.5 Change to Power Normalization and New Coolant Edits ...................................................................5

2.6 Computation of Coolant Energy Removal.............................................................................................

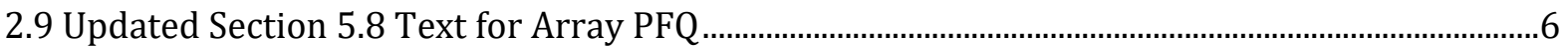

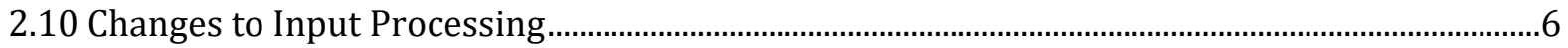

3 Description of the PARET/ANL Model - Theory and Empirical Correlations........................................

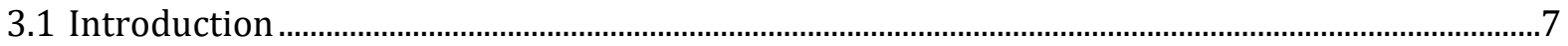

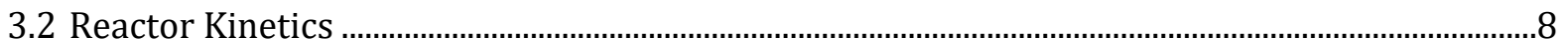

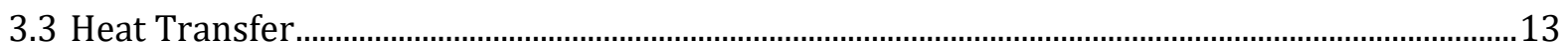

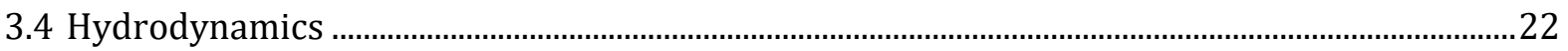

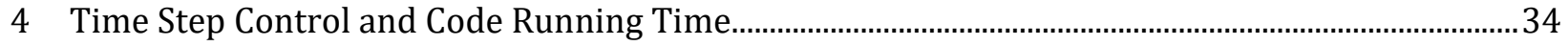

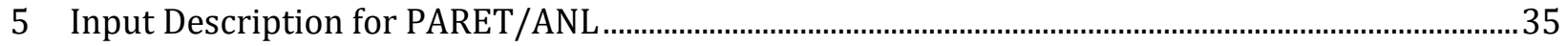

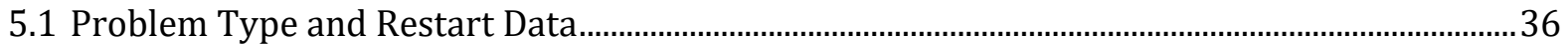

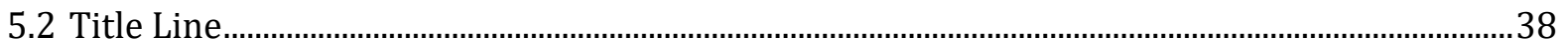

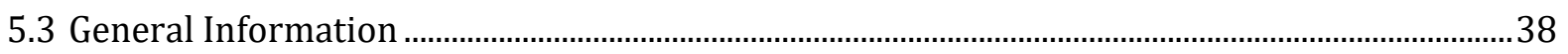

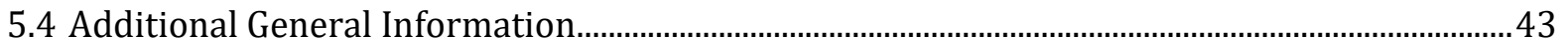

5.5 Thermal Properties of Fuel Element Materials ........................................................................................48

5.6 Radial or Half-Plate Thickness Description …….................................................................................

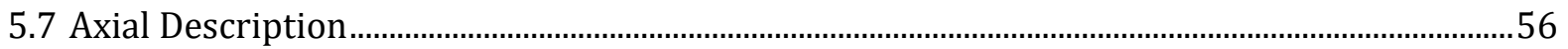

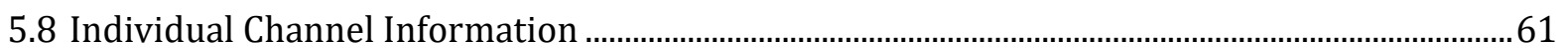

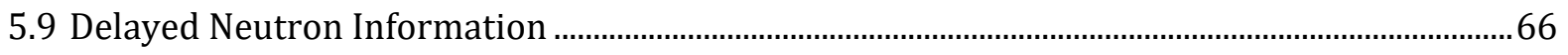

5.10 Power or Reactivity Versus Time (Table 9) .................................................................................67

5.11 Coolant Inlet Mass Flux Versus Time (Table 10) ………..............................................................69

5.12 Percent Linear Thermal Expansion of the Clad Versus Temperature (Table 11)..................69

5.13 Total Pressure Drop Versus Time (Table 12) ………………….................................................... 70

5.14 Table of Time Increment Versus Time (Table 14) [may be modified for restarts] ................ 70

5.15 Table of Print Frequency Versus Time (Table 16) [May Be Modified For Restarts] .............71 
5.16 Table of Pump Mass Flux Fraction Versus Time (Table 17) …………......................................... 73

5.17 Table of Rod Worth Versus Rod Location or Time (Table 18).....................................................74

5.18 Table of Coolant Reactivity Change with Temperature (Table 19) ........................................... 74

5.19 Table of Coolant Density/Void Reactivity Change (Table 20) ..................................................... 75

5.20 Table of Coolant Mixing After Flow Reversal (Table 21) .............................................................. 76

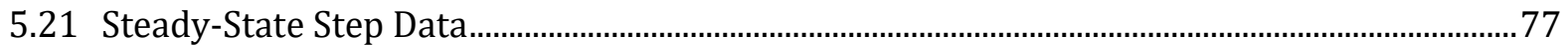

6 Files Used By PARET/ANL ..........................................................................................................................

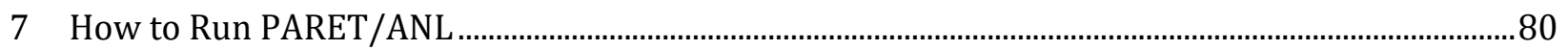

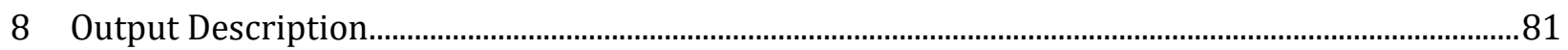

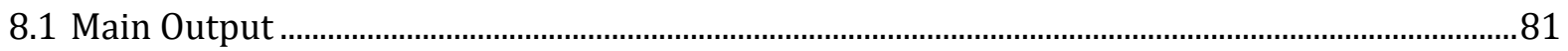

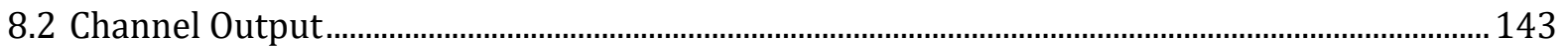

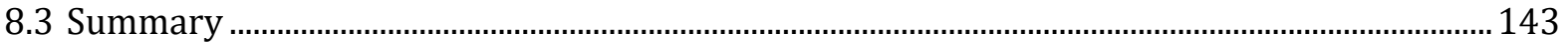

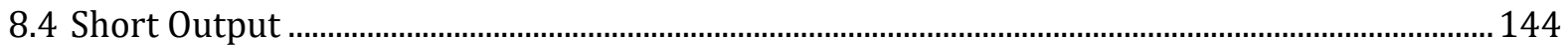

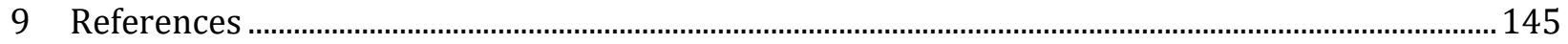

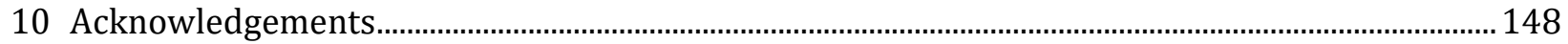

11 Appendix I Units, Constants and Conversion Factors........................................................................... 149

12 Appendix II Empirical Correlations …………………........................................................................ 150

13 Appendix III 10 MW IAEA Benchmark Reactor HEU Model .................................................................. 161

14 Appendix IV Use of Axial Power Profiles in PARET .............................................................................. 175

15 Appendix V Self-Consistency of Arrays BM and PFQ for PARET/ANL Channels and Normalization of Power Density Distribution............................................................................................................. 177

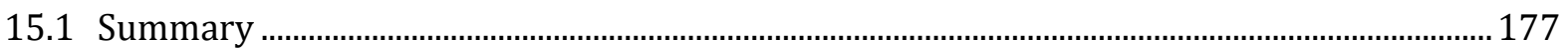

15.2 Demonstration Of The Self-Consistency Of Arrays BM And PFQ ............................................ 177

15.3 Channel-Wise Power Density In Fuel Meat...................................................................................... 182

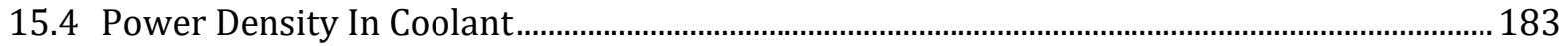

15.5 Check That Eq. (15-33) Is Consistent With Eq. (15-27)............................................................ 184

16 Appendix IV Energy Conservation in PARET ………........................................................................ 186

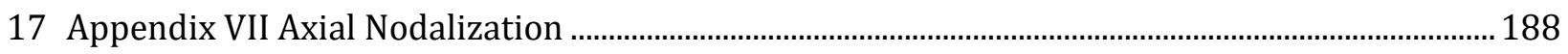

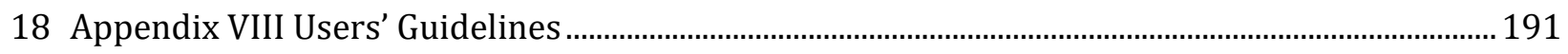

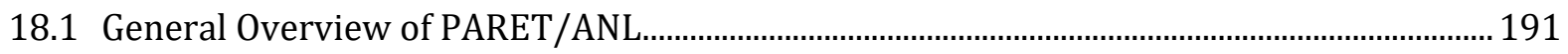

18.2 Lessons Learned From Comparisons With Reactivity Insertion Experiments In the SPERT

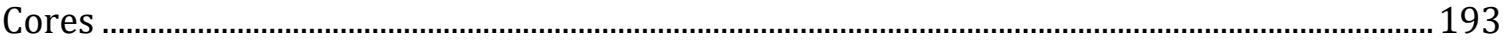

18.3 Lessons Learned From Comparisons With RELAP5 ……………........................................... 197

18.4 Recommendations For Selecting An Axial Nodalization .......................................................... 198 
18.5 Recommendations For Steady-State Initialization 198

18.6 Recommendations For Flow-Forced, Pressure-Drop-Forced Or Buoyancy Driven

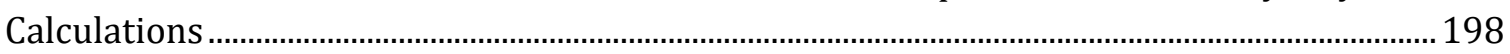

18.7 Recommendations For Selecting The Time Step Size .................................................................. 199

18.8 Recommendations About Output Verification................................................................................. 200

18.9 Recommendations About The Developmental Options .............................................................. 201

18.10Recommendations For Mass Flow Specification Using IGEOM=0 or 1 ................................. 201

18.11 Recommendations For Multi-Channel Core Partitioning......................................................... 201

18.12Clarification About Using The Decay Heat Model.............................................................................. 202

18.13Clarification About Water Property Tables ………………………................................................... 202

18.14Clarification on PARET/ANL Axial Nodalization Convention ................................................... 203

18.15Clarification About Specifying Flow Conditions.............................................................................. 203

18.16Discussion About Two-Phase Flow Heat Transfer Correlations And Transition Models. 203

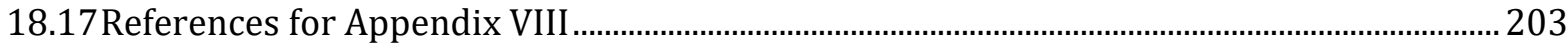

19 Appendix IX Coolant Properties Generators For PARET/ANL ………................................................ 205

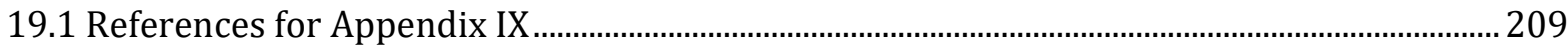

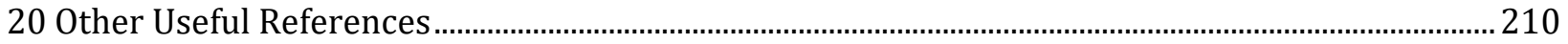




\section{LIST OF FIGURES}

Figure 3.1

Figure 3.2

Figure 3.3

Figure 5.1

Figure 5.2

Figure 13.1

Figure 15.1

Figure 16.1

Figure 16.2

Figure 17.1
Block diagram of PARET/ANL model 8

Example of radial subdivision for heat transfer calculations ........................................14

Radial mesh point pattern for thermal model ..................................................................17

Axial Node Model for NZ=11 ….......................................................................................58

Axial Geometry Used in PARET/ANL for Friction Pressure Loss Calculations ........60

Input listing for the IAEA 10 MW Benchmark HEU Reactor Core ...................................

Radial and Axial Mesh structure used by PARET/ANL in a Fuel Pin.........................185

Axial Power Shape in the Hot Channel (21 nodes) Small dots are interpolated points on the fitted curve through the large dots. 187

Axial Power Shape in the Hot Channel (41 nodes) Small dots are interpolated points on the fitted curve through the large dots........................................................................ 187

Effect of Increasing Axial Nodes on Energy Conservation. 


\section{LIST OF TABLES}

Table 2.1

Table 5.1

Table 11.1

Table 11.2

Table 12.1

Table 12.2

Table 14.1

Table 14.2

Table 16.1

Table 17.1

Table 17.2

Table 17.3

Table 19.1

Table 19.2

Table 19.3
Defined Capabilities of the PARET/ANL V7.6 Code ........................................................... 3

Print-Edit Increment Selection for Table 16 .....................................................................72

Conversion table between United States Customary units and SI units ................... 149

Constants defined and used by PARET/ANL .................................................................. 149

Heat Transfer Phenomena for the PARET/ANL options .............................................150

Heat Transfer Phenomena for the ATHENA (RELAP) Options ....................................160

Enthalpy Rise at time $t=0.1$ second for a null transient ..............................................175

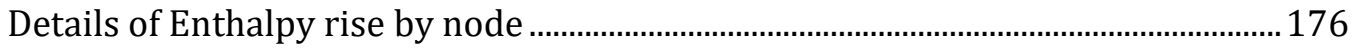

Energy Gain for Real Axial Power Profile (from P. Garner)......................................... 186

Fraction of Energy to Coolant; 1 Channel Test, Flat Axial Profile ................................189

Fraction of Energy to Coolant; 12 Channel Test, Flat Axial Profile.............................189

Fraction of Energy to Coolant, 1 Channel Test, Flat Axial Profile; Uniform Fluid Node

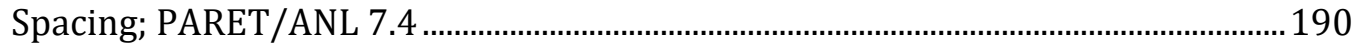

Saturation Temperature of Light and Heavy Water between NIST Data and the

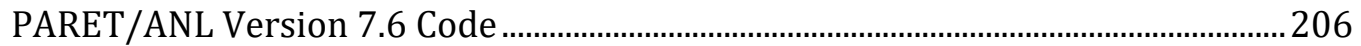

Comparison of Thermal Properties of $\mathrm{H}_{2} \mathrm{O}$ over 1 to 145 bar Pressure and 4 to 372 oC Temperature between PARET Version 7.6_r152_181129 and the NIST Data 207 Comparison Between ASME Steam Tables and NIST Data for $\mathrm{C}_{\mathrm{p}}$ and Viscosity of $\mathrm{H}_{2} \mathrm{O}$ 


\section{Introduction}

In order to quantitatively predict the course and consequences of a reactivity accident, the various physical processes that can occur during the accident and the interrelationships among them must be well understood. The development of information necessary for this understanding was an objective of the SPERT Project (Special Power Excursion Reactor Tests), which was conducted for the U.S. Atomic Energy Commission by Phillips Petroleum Company at the National Reactor Testing Station. As a result of experimental programs carried out at Spert and elsewhere, knowledge of certain of the processes that occur during a reactivity accident is thought to be sufficient for use in predicting the course of nondestructive accidents in small cores. To provide a comprehensive method for making such predictions, the development of a computer program, called PARET [1], was undertaken. PARET is an acronym for Program for the Analysis of REactor Transients.

The PARET/ANL code is the result of continuous improvement and modification applied to the original PARET code by the researchers at Argonne National Laboratory (ANL) over the course of four decades. It is intended primarily for the analysis of research and test reactors that use plate-type (flat) fuel elements or round fuel pins.

Over the code's lifetime, PARET/ANL been subjected to extensive comparisons with the SPERT I and SPERT II experiments [2, 3, 4] as well as other transient codes. These comparisons were quite favorable for a wide range of transients. A description of those comparisons is provided in the user's guidelines provided in 18. Favorable comparisons have also been made for TRIGA reactor pulses in pin geometry. The PARET/ANL code has been used by the RERTR Program for the safety evaluation of many candidate reactors for reduced enrichment

The following information is intended to provide all the pertinent details to the user who wishes to use PARET/ANL Version 7.6. Section 2 lists the modifications applied to the code since the last version. Section 3 describes the theory of reactor transient analysis and the model implemented in PARET/ANL. Section 4 provides guidelines on time step control and typical running time. Section 5 describes the input file format and entries item by item. Section 6 describes the files used by PARET/ANL. Section 7 describes how to run PARET/ANL. Section 8 describes the output from the code. References are given in Section 9. Sections 11 to 17 provide more details on specific topics that should be understood when preparing an analysis model. Section 18 provides additional guidance on transient analysis. Section 19 provides more information regarding coolant properties generators. 


\section{What is New in Version 7.6?}

\subsection{Capabilities and Limitations}

Work on software quality assurance regarding code verification and validation has been a major focus in preparing Version 7.6. The current users of PARET/ANL have identified the following key features based on their utilization of the code. For each item identified, the corresponding code capability of Table 2.1 is listed in parentheses.

\subsubsection{Capabilities Validated}

\section{Geometry}

- Multiple compositions in a plate with at least three materials (clad, zirconium, fuel) and multiple elements in a fuel assembly per core (Capability No. 2)

- Each channel and plate in a fuel element have different dimensions (Capability 7)

- Plates and pins with and without fins (Capability No. 13)

- Fuel pin with radial power profile in meat, plus a gas-filled gap, followed by clad and oxide layer on clad (Capabilities No. 4 and 7)

Problem characteristics

- Light or heavy water coolant, with temperature and pressure dependent thermal properties for liquid and vapor (density, viscosity, thermal conductivity, specific heat) (Capability No. 3)

- Forced upflow/downflow (Capabilities No. 1 and 2)

- Pressure specified at either inlet or outlet (pressure variation along channel is computed but not used to change coolant thermal properties) (Capabilities No. 1 and 2)

- Core total flow rate specified (code determines flow per channel under various options (flowforced, pressure-drop-forced, and buoyant forced) (Capabilities No. 1 and 2)

- Unique axial power profile for each channel (Capability No. 14)

- Laminar flow for $\operatorname{Re}<2300$ and transition flow between $2300<\operatorname{Re}<3700$ (Most test problems for capabilities of Table 2.1 are for turbulent flow) (Capability No. 5)

- Axial geometry can account for flow lengths above and below the core that provide pressure losses and buoyancy effects (Capability $\mathbf{1}$ )

- Reactivity feedback effects can be accounted for from fuel meat Doppler, coolant void, coolant temperature effects, and thermal expansion of the fuel (Capability No. 14)

- Model of control system: trip points, delay time after trip and before control rod motion begins, and reactivity worth vs. time as a table after control rods begin to move (Capability No. 10)

Numerical solution/options:

- Temperature-dependent thermal properties of the solids or gases in fuel rods or plates (Capability 4) 
- Radial and axial finite-difference iterated thermal solution (Capabilities No. 1 and 2)

- Point kinetics equations integrated numerically, if reactivity-driven (Capability No. 12)

- Power-driven mode when power vs. time is specified as input in a table (Capability No. 16) Correlations and safety parameters

- Dittus-Boelter (modified to include viscosity ratio) single-phase heat transfer coefficient (Capability No. 6)

- Bergles-Rosenhow for Onset of Nucleate Boiling (ONB) (Capability No. 6)

- Friction factor model (Capability No. 2 affecting buoyancy-driven flows)

- Entrance effects on the fluid flow solution, for $\operatorname{Re}<3700$, can be accounted for at option (Capability No. 5)

- Heat transfer correlations applicable to the following regimes: single-phase liquid, nucleate boiling, transition boiling, film boiling, bulk boiling, and pure vapor (Capability No. 6)

- Feedback reactivity effects from coolant density changes and temperature changes are represented by tables (Capability No. 14)

- Feedback reactivity from fuel heat-up (Doppler Effect) is represented by a four-term, sixcoefficient equation as a function of fuel temperature (Capability No. 14)

Table 2.1 Defined Capabilities of the PARET/ANL V7.6 Code

\begin{tabular}{|c|c|}
\hline Capability & Description \\
\hline 1 & Upflow and downflow \\
\hline 2 & Forced flow or buoyancy-driven flow \\
\hline 3 & Temperature-dependent and pressure-depend fluid properties (light water, heavy water) \\
\hline 4 & Temperature-dependent thermal properties for solid materials in the fuel plate \\
\hline 5 & Laminar, transition and turbulent flow regimes \\
\hline 6 & $\begin{array}{l}\text { Flow regime selection logic for heat transfer correlations, with or without consideration of a } \\
\text { period-dependent component, including entrance effects }\end{array}$ \\
\hline 7 & Use of different materials and different geometry for different channels (IGEOM=2 option) \\
\hline 8 & Models for reactor trips on period, power, and flow \\
\hline 9 & Model for decay heat after shutdown \\
\hline 10 & Model for control rod reactivity worth versus time or position, after trip plus delay time \\
\hline 12 & Solution of the Point Kinetics Equations \\
\hline 13 & Capability to account for fins on fuel plates or pins \\
\hline 14 & $\begin{array}{l}\text { Capability to account for axial dependence of power density; to account for coolant reactivity } \\
\text { feedback from void and temperature effects, and to account for fuel Doppler effects }\end{array}$ \\
\hline 16 & Capability to run in a "power driven" mode \\
\hline
\end{tabular}




\begin{tabular}{|l|l|}
\hline 19 & Simple friction factor model for laminar and turbulent flow \\
\hline 20 & Bundle effect on heat transfer coefficient caused by fuel in an infinite lattice \\
\hline 21 & Thermal expansion of clad model \\
\hline 22 & Steady-State initialization null transient duration and step size \\
\hline 23 & Nucleate Boiling Model \\
\hline
\end{tabular}

\subsubsection{Limitations}

- $\quad$ Not applicable for events where fuel failure occurs due to film boiling

- Power shape assumed fixed during event (basic assumption of point kinetics model)

- No transverse or axial heat transfer in the solid materials

- Perfect coolant mixing assumed within PARET/ANL coolant channel (sub-channels are permitted)

- All channels are independent thermally (no heat transfer between them) but coupled through reactivity feedback and through pressure boundary conditions

- $\quad$ Limited to light or heavy water in pressure range of approximately 1-150 bar

- In two-phase flow conditions, flow oscillations can occur if the void fraction becomes large and the reactivity feedback effects also are large

- All coolant properties except densities are evaluated at specified (inlet or outlet) pressure

\subsection{Flow Reversal Model}

PARET/ANL (Version 6.1, 2007 Rev.) introduced a simple approximation for establishing the coolant enthalpy to be used following flow reversal. This model is unchanged in Version 7.6. There was no primary loop simulation in PARET. The time of flow reversal is detected and saved for each channel. After flow reversal, the channel exit becomes the inlet. It was assumed that the reactor to be modeled was a pool-type system. The reactor core is immersed in a pool, with a complex flow path through the pool acting as a primary loop. It is assumed that there is no primary loop piping that confines the exit coolant. In this type of reactor, the exit coolant mixes with the pool water (possibly in a plenum), and is cooled. If the flow reverses, the coolant drawn back into the channel will initially be essentially at the same enthalpy as the coolant most recently discharged. After some time, the reversed flow will draw relatively unheated coolant from the pool. The model assumed that the enthalpy of that coolant well after flow reversal was the same as that of the coolant inlet enthalpy at the start of the calculation. It was assumed, quite arbitrarily, that the mixing would occur linearly over 5 seconds from the time of flow reversal. Some generalizations were added to PARET/ANL Version 7.5:

1. The time between flow reversal and the end of mixing is still 5.0 seconds unless a new Table 21 is provided. Then it can be anything.

2. The mixing process is linear if Table 21 is not provided. Variable ENTHHS is the enthalpy (or temperature) of the "heat sink" coolant that is drawn into the core well after flow reversal. If ENTHHS is not provided on Card 1116, or if ENTHHS is provided and it is the same as ENTHIN, then this option recovers the original model.

3. The mixing process is piece-wise linear in Table 21 if it is provided (up to 20 entries). 
4. The enthalpy (or temperature) of the pool coolant well after flow reversal, ENTHHS, can be specified on Card 1116. Changes to Coolant Properties Table Generation

Changes have been made to automatically adjust the pressure range and spacing used for the internally computed properties tables at a given pressure. There is now an internal table at exactly the user's input pressure, which eliminates some interpolation errors. The new logic creates more accurate tables than before, particularly at high pressure.

\subsection{Revised Power and Flow Edits By Channel}

Decay heat power is now edited in more detail in Version 7.6. In previous versions, there was a small error in total decay heat that was caused by the assumption that the production of decay heat came from prior operation (before time zero) and was "turned on" at time of trip. This assumption neglected what generally was a relatively tiny contribution to decay heat from power operation during the transient from time-zero to time of scram. A correction is made to the decay heat model to account for that contribution. This correction term is now edited also.

A new edit is provided of "COOLANT FLOW, kg/s, BY CHANNEL." It appears after major and minor edits. Inlet and outlet values are provided. A new edit of apparent power in the coolant is also provided which takes a snapshot of actual energy content of each coolant channel, assuming that the reactor is in steady-state. This edit can be used to examine "null-event" transients where steady-state is achieved. This edit shows how much power is delivered to the coolant by channel, and for the sum of all channels. New subroutines volpow and gain were added to compute necessary quantities.

\subsection{Revised CIAE Natural Convection Model}

The logic in using the CIAE correlation as part of the natural convection model for the Miniature Neutron Source Reactor (MNSR) is revised to be sure that its use is only in the laminar flow regime (V 7.6).

\subsection{Change to Power Normalization and New Coolant Edits}

Prior to Version 7.5 of PARET, there was no check by the code that the reactor was fully specified (or even over-specified) by the channel data provided. Version 7.5 introduced a check of actual power to be delivered by each channel, accounting for all of its diverse properties (different axial power profile, different core fraction (BM) that it represents, different power density, different meat thickness or width, and so on). If the core is not correctly represented, a correction is automatically made to the power density. This check was made for the IGEOM options 0 or 1 . Version 7.6 has refined this check to account for the IGEOM=2 option. The user will see "CHECK OF POWER NORMALIZATION" in the initialization process, showing a correction to the power density if it is needed. During the run, the user will also see an edit that has the title: "COOLANT POWER GAIN FROM INLET TO OUTLET = XXX MW IF IN STEADY STATE. This is followed by an edit of coolant flow in units of $\mathrm{kg} / \mathrm{s}$ at the inlet and outlet of each channel. These mass flows are for the core fraction that the user specified. If the user wishes to know the energy conservation error of his model, he can set up a null transient for power and flow conditions of interest, and run it for a few seconds of real time. If the energy loss is of concern, then he may be able to investigate the effect of this loss by changing the power delivered to the fuel. If the transient of interest is controlled by an over-power trip, then it would be best to change both the power and the over-power trip set point. 


\subsection{Computation of Coolant Energy Removal}

In Version 7.5, changes were made to the PARET/ANL program enabling it to calculate the coolant energy removal. The total flow area, $\mathrm{P}_{c}$, formerly read in on card number 1111 , is no longer used. This card follows the 100I cards and precedes the 200I cards in the data deck.

The coolant energy removal is calculated for each time step from the following equation

$$
C E R=\int \sum_{I=1}^{N C}\left(E N T_{X I} \cdot M F R_{X I}-E N T_{O I} \cdot M F R_{O I}\right) d t
$$

where

$N C$ is the number of channels

$E N T_{X I}$ is the exit enthalpy $(\mathrm{J} / \mathrm{kg})$ of channel I

$M F R_{X I}$ is the exit mass flow rate $(\mathrm{kg} / \mathrm{s})$ of channel I

$E N T_{O I}$ is the inlet enthalpy $(\mathrm{J} / \mathrm{kg})$ of channel I

$M F R_{O I}$ is the inlet mass flow rate $(\mathrm{kg} / \mathrm{s})$ of channel I

The resulting coolant energy removal (MWs) is printed just below the value of the energy every time a full time step printout occurs. These values depend on individual channel flow areas, core fractions represented by each channel, and $\mathrm{P}_{\mathrm{c}}$. Note that the mass flow rates depend in part on individual channel areas, K-losses, hydraulic diameters, core fraction represented by each channel, and total flow area. This logic is retained in PARET/ANL V7.6.

\subsection{Error Checking Of Input Tables}

Version 7.6 now examines every Table in the input file to verify that supplied data make physical sense. For example, many tables are of the form $\mathrm{y}_{\mathrm{i}}=\mathrm{f}\left(\mathrm{x}_{\mathrm{i}}\right)$. Prior code versions simply counted that the desired number of entries were read, and were of the correct form (integer or real), but did not examine the values according to specific rules for each type of data. Now the code eliminates the possibility of errors caused by data not being in correct order. For example, Table 18, Rod Worth Versus Rod Location, at option is supplied in time-ascending or in space-ascending order. This table is checked to confirm that it is in sequence in either space or time. If there are any issues detected with Tables, a fatal error is noted and the run is terminated.

\subsection{Updated Section 5.8 Text for Array PFQ}

The reactor orientation and flow description was confusing regarding the order in which array PFQ is to be supplied. This present User Guide removes that confusion.

\subsection{Changes to Input Processing}

The first input card (exception: if NLUP2=1, there are three cards) is processed as in prior code versions.. When using the IGEOM=2 option, the geometrical data on Card Type 3000 series is crosschecked with the data on the 5000 series. Variables RS, RC, and RF must agree within a relative tolerance of $1.0 \mathrm{E}-5$, or the job will terminate with an informative error message. The code also requires that $\mathrm{RPW}=\mathrm{RFW}=1.0$ when the $\mathrm{IGEOM}=2$ option is selected. 


\section{Description of the PARETIANL Model - Theory and Empirical Correlations}

\subsection{Introduction}

The reactor model assumed in PARET/ANL consists of a water-cooled core represented by fuel elements and their associated coolant channels. The core can be divided into up to 120 regions over its radial cross section, each having its own power generation, coolant flow rate, hydraulic parameter, etc., and each represented by a single fuel pin or plate, plus its associated coolant channel. One or more sub-channels may be represented also in this manner. For sub-channels, the results obtained will depend on the assumption that there is no cross-flow between channels. Each of these regions can be further subdivided into a maximum of 97 axial sections. The code is designed to represent the average behavior of each of the several regions into which the core is subdivided. A given fuel plate or pin is normally composed of a radial sequence of layers, such as an inert central pin (TRIGA), fuel meat, gap, clad, and oxide surface layer. Each of these layers can be subdivided radially. It is important to subdivide the meat radially if the meat is relatively thick and there is significant variation in power density or thermal conductivity. It is never necessary to subdivide a material layer that does not have a heat source, and has a fixed thermal conductivity, because the power profile and heat flux will be correct even with a single layer per material layer.

A transient problem can be forced through specification of externally inserted reactivity versus time or core power versus time (9000 card series). Specification of inlet mass flow rate as a function of time can also be used to force a problem. Either the pressure drop across a given region of the core (12000 card series) or the coolant inlet mass flux to that region must be specified with time (10000 card series). The program embodies continuous reactivity feedback from the known major feedback mechanisms (fuel rod expansion, coolant temperature and density effects, and fuel temperature (Doppler) effects), detailed heat transfer calculations (including boiling, as well as non-boiling, convective transfer), and hydrodynamic calculations allowing for coolant flow reversal. A block diagram illustrating the model is presented in Figure 3.1. Further details of the basic theory underlying the neutronics, heat transfer, and hydrodynamics calculations are presented in the following Sections of this chapter. 


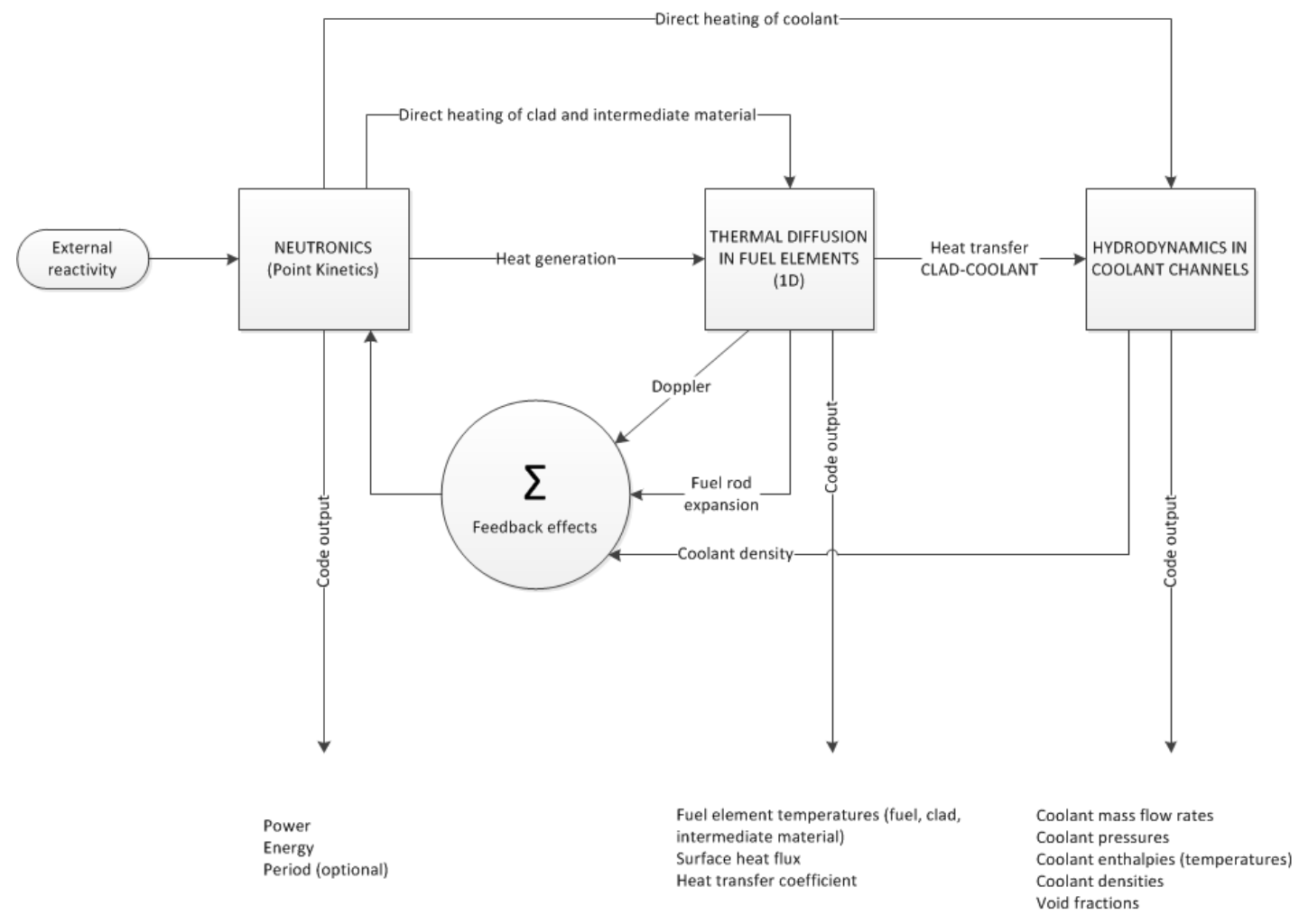

Figure 3.1 Block diagram of PARET/ANL model

\subsection{Reactor Kinetics}

The power behavior of the reactor is either specified as a function of time or is determined through a numerical solution of the point reactor kinetics equations [1] and [2]:

$$
\begin{gathered}
\frac{d \phi(t)}{d t}=\frac{[\rho(t)-\beta]}{\Lambda} \phi(t)+\sum_{i=1}^{I} \lambda_{i} C_{i}(t) \\
\frac{d C_{i}(t)}{d t}=\frac{\beta_{i}}{\Lambda} \phi(t)-\lambda_{i} C_{i}(t), i=1,2, \ldots, I
\end{gathered}
$$

where

$t=$ time

$\phi=$ reactor power

$\rho=$ reactivity of the system

$\beta=$ effective delayed neutron fraction

$\Lambda=$ prompt neutron generation time

$\lambda_{i}=$ decay constant for group $\mathrm{i}$

$\mathrm{C}_{\mathrm{i}}=$ concentration of delayed neutron precursors of group $\mathrm{i}$

$\beta_{i}=$ delayed neutron fraction for group i 
$I=$ number of delayed neutron groups

PARET uses the modified Runge-Kutta method of Cohen [5] for solution of these equations. The solution is computed subsequent to an estimation of the reactivity feedback from time zero up to the time node under consideration. In the reactivity-specified problem, the value of the externally inserted reactivity is specified as a function of time. The feedback reactivity is calculated as the sum of that fed back through the mechanisms of fuel rod expansion, coolant density effects, and fuel temperature effects. This feedback is calculated point-wise throughout each of the regions of the reactor. The point-wise contributions are then weighted volumetrically and summed to yield the total reactivity feedback. A detailed description of the reactivity feedback calculations is presented in Section 3.2.2.

\subsubsection{Reactor Kinetics Difference Equations}

Except in the case of a power level specified problem, the reactor kinetics equations must be solved at each time node to determine the reactor power level. Using the substitutions

$$
r(t)=\frac{\rho(t)}{\beta}
$$

and

$$
W_{i}(t)=C_{i}(t)\left(\frac{\Lambda \lambda_{i}}{\beta f_{i}}\right)
$$

the point kinetics Eqs. (1) and (2) become

$$
\begin{gathered}
\frac{\boldsymbol{d} \boldsymbol{\phi}(\boldsymbol{t})}{\boldsymbol{d} \boldsymbol{t}}=\frac{\boldsymbol{\beta}}{\boldsymbol{\Lambda}}\left([\boldsymbol{r}(\boldsymbol{t})-\mathbf{1}] \boldsymbol{\phi}(\boldsymbol{t})+\sum_{i=\mathbf{1}}^{\boldsymbol{I}} \boldsymbol{f}_{i} W_{\boldsymbol{i}}(\boldsymbol{t})\right) \\
\frac{d W_{i}(t)}{d t}=\lambda_{i} \phi(t)-\lambda_{i} W_{i}(t) . i=1, \ldots, I
\end{gathered}
$$

The various terms appearing in these equations are defined in conjunction with Eqs. (1) and (2). The energy release, $E(t)$, is determined from:

$$
\frac{d E(t)}{d t}=\phi(t)
$$

Equations (5), (6), and (7) are transformed for computation purposes through the following substitutions [7]:

$$
\begin{gathered}
a_{1}=\frac{\beta}{\Lambda}(r(0)-1) \\
a_{2}=0 \\
a_{j}=-\lambda_{i}, j=i+2, i=1, \ldots, I \\
R_{1}(\phi, t)=\frac{\beta}{\Lambda}\left(\left[\begin{array}{c}
\left.r(t)-r(0)] \phi(t)+\sum_{i=1}^{I} f_{i} W_{i}(t)\right) \\
R_{2}(E, t)=\phi(t)
\end{array}\right.\right.
\end{gathered}
$$




$$
R_{j}\left(W_{i}, t\right)=\lambda_{i} \phi(t), j=i+2, i=1, \ldots, I
$$

With these substitutions, the reactor kinetics equations take the form

$$
\begin{gathered}
\frac{d \phi(t)}{d t}=a_{1} \phi(t)+R_{1}(\phi, t) \\
\frac{d W_{i}(t)}{d t}=a_{j} W_{i}(t)+R_{j}\left(W_{i}, t\right), j=i+2, i=1, \ldots, I
\end{gathered}
$$

The energy equation becomes

$$
\frac{d E(t)}{d t}=a_{2} E(t)+R_{2}(E, t)
$$

By use of the integrating factor, $\exp \left(-a_{j} t\right)$, the solutions to Eqs. (14) - (16) can all be written in the form

$$
\xi_{j}(t)=\xi_{j}(0)+t \int_{0}^{1}\left[a_{j} \xi_{j}(0)+R_{j}\left(\xi_{j}, u\right)\right] \exp \left(a_{j} t(1-u)\right) d u, j=1, \ldots, I+2
$$

where

$$
\begin{gathered}
\xi_{1}(t)=\phi(t) \text { and } \xi_{1}(0)=\phi(0) \\
\xi_{2}(t)=E(t) \text { and } \xi_{2}(0)=E(0) \\
\xi_{j}(t)=W_{i}(t) \text { and } \xi_{j}(0)=W_{i}(0), j=i+2, i=1, \ldots, I
\end{gathered}
$$

The system of Equations (17) is solved in stages, according to a modified Runge-Kutta method [5], to yield the functions $\phi(t), E(t)$ and $W_{i}(t)$.

The error analysis included in the reactor kinetics calculations is based on the analysis carried out in the AIREK code [6]. In this scheme, the following quantities are evaluated

$$
\begin{aligned}
& \omega_{1}=\frac{1}{\phi(0)} \frac{d \phi(0)}{d t}, \text { instantaneous reciprocal period } \\
& \omega_{2}=\frac{1}{\phi(h)} \frac{d \phi(h)}{d t}, \text { instantaneous reciprocal period }
\end{aligned}
$$

where the quantity $h$ represents the time step across which the calculations are being made. Further definitions include

$$
\begin{gathered}
\bar{\omega}=\frac{1}{h} \ln \left[\frac{\phi(h)}{\phi(0)}\right], \text { average reciprocal period } \\
\delta=\max _{j}\left(\left|\frac{\xi_{j}\left(\frac{h}{2}\right)-\xi_{j}(0)}{\xi_{j}\left(\frac{h}{2}\right)}\right|\right) \\
Q=\frac{h C_{2}\left(a_{1} h\right)}{1+C_{1}\left(a_{1} h\right)}\left(\left|\omega_{1}-2 \bar{\omega}+\omega_{2}\right|\right)
\end{gathered}
$$

where 


$$
\begin{gathered}
C_{1}\left(a_{1} h\right)=\int_{0}^{1} \exp \left(a_{1} h(1-u)\right) d u \\
C_{2}\left(a_{1} h\right)=\int_{0}^{1} u \exp \left(a_{1} h(1-u)\right) d u
\end{gathered}
$$

The error analysis is based on the following considerations:

1. If $\delta \geq 2^{-20}$ and

1.1 If $Q>Q_{H}$, the time step is halved and the calculations repeated until the error is statisfied.

1.2 If $Q \leq Q_{H}$, the calculations are accepted and the same time-step size is used for the next advancement

2. If $\delta<2^{-20}$, the calculations are accepted and the same time step size is used for the next advancement

3. The time-step size is also halved and the calculations repeated if

$3.1 a_{j} h \geq 150.0$ for any $\mathrm{j}$

3.2 A negative or zero power is computed

3.3 A floating point overflow occurs during the calculation of any $a_{j}$ or $R_{j}\left(W_{i}, t\right)$, or during advancement of the solutions.

The quantity, $Q_{H}$ is specified as input to the code by the program user. The quantity $Q$ calculated in Eq. (25) can be printed out at the user's option.

\subsubsection{Reactivity Feedback}

Reactivity feedback is calculated as the sum of that fed back through the mechanisms of fuel rod expansion, coolant temperature and density changes, and fuel temperature changes (including Doppler broadening of resonance cross-sections).

\subsubsection{Reactivity Feedback Due to Fuel Rod Expansion}

The total reactivity feedback from time zero to time tm $^{\mathrm{m}}$ due to fuel rod expansion is given, in dollars, by

$$
r_{\mathrm{Rod}}^{m}=\frac{2}{V_{\mathrm{Mod}} \beta_{\mathrm{eff}}} \sum_{k=1}^{K} X_{k 2} \sum_{j=1}^{N Z} C_{j, k}\left(V_{\mathrm{Rod}}^{0}\right)_{j, k}\left(y_{c}\right)_{j, k}^{m}-r_{\mathrm{Rod}}^{0}
$$

where

$$
r_{\text {Rod }}^{0}=\frac{2}{V_{\text {Mod }} \beta_{\text {eff }}} \sum_{k=1}^{K} X_{k 2} \sum_{j=1}^{N Z} C_{j, k}\left(V_{\text {Rod }}^{0}\right)_{j, k}\left(y_{c}\right)_{j, k}^{0}
$$

The term, $V_{\text {Mod }}$ is calculated in PARET/ANL according to the equation

$$
V_{\text {Mod }}=\sum_{k=1}^{K} X_{k 2} \sum_{j=1}^{N Z}\left(V_{\text {Mod }}^{0}\right)_{j, k}
$$


where $\left(V_{\text {Mod }}^{0}\right)_{j, k}$ represents the volume of the coolant in axial increment $\Delta Z_{j, k}$. As mentioned in Chapter IV, 2.61 (5), it is convenient to set $X_{k 2}$ equal to the volume fraction of the core which is represented by channel (region) k. The quantity, $C_{j, k}$, represents the coolant density feedback coefficient appropriate to axial increment $\Delta Z_{j, k}$, in units of $\delta k$ per percent of the core voided [7]. This coefficient is arbitrarily broken down into the product

$$
C_{j, k}=C_{k} \delta_{j, k}
$$

where $C_{k}$ is constant over a given region, $\mathrm{k}$, of the core, and $\delta_{j, k}$ accounts for the axial dependence of $C_{j, k}$. The quantity $\left(y_{c}\right)_{j, k}^{m}$, represents the percent linear thermal expansion of the clad and is evaluated at $\left(\overline{u_{c}}\right)_{j, k}$, the volume-weighted, mean clad temperature in axial increment $\Delta Z_{j, k}$.

\subsubsection{Reactivity Feedback Due to Coolant Density Changes}

The total reactivity feedback from time zero to time tm due to coolant density changes is given, in dollars, by (subscript MD refers to "Moderator" which is actually coolant in PARET applications):

$$
r_{\mathrm{MD}}^{m}=\frac{100}{V_{\mathrm{Mod}} \beta_{\mathrm{eff}} \bar{\rho}_{\text {ref }}} \sum_{k=1}^{K} X_{k 2} \sum_{j=1}^{N Z} C_{j, k}\left(V_{\mathrm{Mod}}\right)_{j, k}\left(\bar{\rho}_{\mathrm{ref}}-\bar{\rho}_{j, k}^{m}\right)-r_{\mathrm{MD}}^{0}
$$

where

$$
r_{\mathrm{MD}}^{0}=\frac{100}{V_{\mathrm{Mod}} \beta_{\mathrm{eff}} \bar{\rho}_{\mathrm{ref}}} \sum_{k=1}^{K} X_{k 2} \sum_{j=1}^{N Z} C_{j, k}\left(V_{\mathrm{Mod}}\right)_{j, k}\left(\bar{\rho}_{\mathrm{ref}}-\bar{\rho}_{j, k}^{0}\right)
$$

In Eqs. (32) - (33), $\bar{\rho}$ represents a volume-weighted density defined by

$$
\bar{\rho}=\rho_{V} R+\rho_{l}(1-R)
$$

where $R$ represents vapor volume fraction and $\rho_{V}$ and $\rho_{l}$ represent the densities of the vapor and liquid phases, respectively. The quantity, $\bar{\rho}_{\text {ref, }}$ is the value of $\bar{\rho}$ at some reference condition of temperature and pressure.

\subsubsection{Reactivity Feedback Due to Fuel Temperature Changes}

The total reactivity feedback from time zero to time $\mathrm{t}^{\mathrm{m}}$ due to fuel temperature changes (primarily Doppler broadening) is given, in dollars, by

$$
r_{\text {Dop }}^{m}=\frac{1}{V_{\mathrm{MT}}} \sum_{k=1}^{K} X_{k 2} \sum_{j=1}^{N Z}\left(V_{\mathrm{M}}\right)_{j, k} D_{j, k}\left[\gamma_{0}+\gamma_{1} T_{j, k}^{m}+\gamma_{2}\left(T_{j, k}^{m}\right)^{2}+\gamma_{3}\left(T_{j, k}^{m}\right)^{n}\right]-r_{\text {Dop }}^{0}
$$

where

$$
\left.r_{\text {Dop }}^{0}=\frac{1}{V_{\mathrm{MT}}} \sum_{k=1}^{K} X_{k 2} \sum_{j=1}^{N Z}\left(V_{\mathrm{M}}\right)_{j, k} D_{j, k}\left[\gamma_{0}+\gamma_{1} T_{j, k}^{0}+\gamma_{2}\left(T_{j, k}^{0}\right)^{2}+\gamma_{3(} T_{j, k}^{0}\right)^{n}\right]
$$

Since the feedback represented in Eqs. (35) - (36) is due primarily to Doppler broadening in most cases of interest, it is referred to throughout the remainder of this document as Doppler feedback. The quantity, $\left(V_{\mathrm{M}}\right)_{j, k}$, represents the volume of fuel in axial increment $\Delta Z_{j, k}$ and $V_{\mathrm{MT}}$ is given by 


$$
V_{\mathrm{MT}}=\sum_{k=1}^{K} X_{k 2} \sum_{j=1}^{N Z-1}\left(V_{\mathrm{M}}\right)_{j, k}
$$

The quantities, $D_{j, k}$ (see Section 5.8, DOPPLR), are weighting factors for axial increment $\Delta Z_{j, k}$, and the $T_{j, k}^{m}$ are given by

$$
T_{j, k}^{m}=\left(\bar{u}_{\mathrm{M}}\right)_{j, k}^{m}+\gamma_{4}
$$

where $\left(\bar{u}_{\mathrm{M}}\right)_{j, k}^{m}$ represents the volumetric mean fuel temperature (in degrees Rankine) in axial increment $\Delta Z_{j, k}$, at time tm. The quantities $\gamma_{0}$ through $\gamma_{4}$, are constants which fit the temperature dependence of the Doppler feedback to the equation form given. The superscript, $n$, is an arbitrary power to which one of the $T_{j, k}^{m}$ is raised and is supplied as input to the code by the user. This allows one to use, for example, a square root temperature dependent Doppler feedback model. Calculation of the various coefficients appearing in Eq. (35) is illustrated in [8].

\subsubsection{Reactivity Feedback from Coolant Temperature Changes}

This feedback term, $\mathrm{rCool}^{\mathrm{m}}$, is based on a calculation similar to that of Section 3.2.2.1 for Fuel Doppler, except that only the linear term is accounted for in Eq. [35]. See input parameter DTMP in Section 5.8. Also see Table 19 in Section 5.18.

\subsubsection{Total compensated reactivity}

The total compensated reactivity, $r_{c}^{m}$, at time $t^{m}$, is given by

$$
r_{c}^{m}=r_{\mathrm{Rod}}^{m}+r_{\mathrm{MD}}^{m}+r_{\text {Dop }}^{m}+\mathrm{rCool}^{\mathrm{m}}
$$

Therefore the reactivity term, $r\left(t^{m}\right)$, used in solving the reactor kinetics Equations is

$$
r\left(t^{m}\right)=r_{\text {in }}\left(t^{m}\right)-r_{c}^{m}
$$

where $r_{\text {in }}\left(t^{m}\right)$ represents externally inserted reactivity (e.g. control rod induced), the value of which is obtained by linear interpolation from a table of such quantities (Table 9) ${ }^{1}$. Compensated reactivity can be calculated directly only at the end of a time step. Therefore, in order to provide reactivity values at advanced times, as is required by the point kinetics equations, an estimate of reactivity is obtained by extrapolation from previous values. The extrapolation procedure is based on a threepoint Lagrangian formula. At the end of each time step, the compensated reactivity is calculated and compared with the extrapolated value used in the immediately preceding kinetics calculations. If they do not agree within a specified limit, the calculations for that time step are repeated using the average of these two reactivity values. This process is repeated until two successive reactivity values agree to within the limit specified $(0.01 \$)$. The new total reactivity is then used at the next time node in obtaining an extrapolated reactivity value across the subsequent time step.

\subsection{Heat Transfer}

Heat transfer in each fuel element is determined on the basis of a one-dimensional conduction solution in each axial section. Additionally, the domain can be further subdivided in radial sections for the purpose of this calculation. The coolant in each axial section is not subdivided radially but is assumed to be adequately represented by an average bulk temperature and average fluid properties.

${ }^{1}$ Tables 9, 10,11, 12 and 14 are data tables supplied as input to the PARET/ANLcomputer code. 
A maximum of 10 material types (e.g. fuel, gas gap, clad, an inert central pin section, an oxide layer, etc.) are allowed in each fuel element. Radial subdivision of each axial section of each fuel element is illustrated in Figure 3.2.

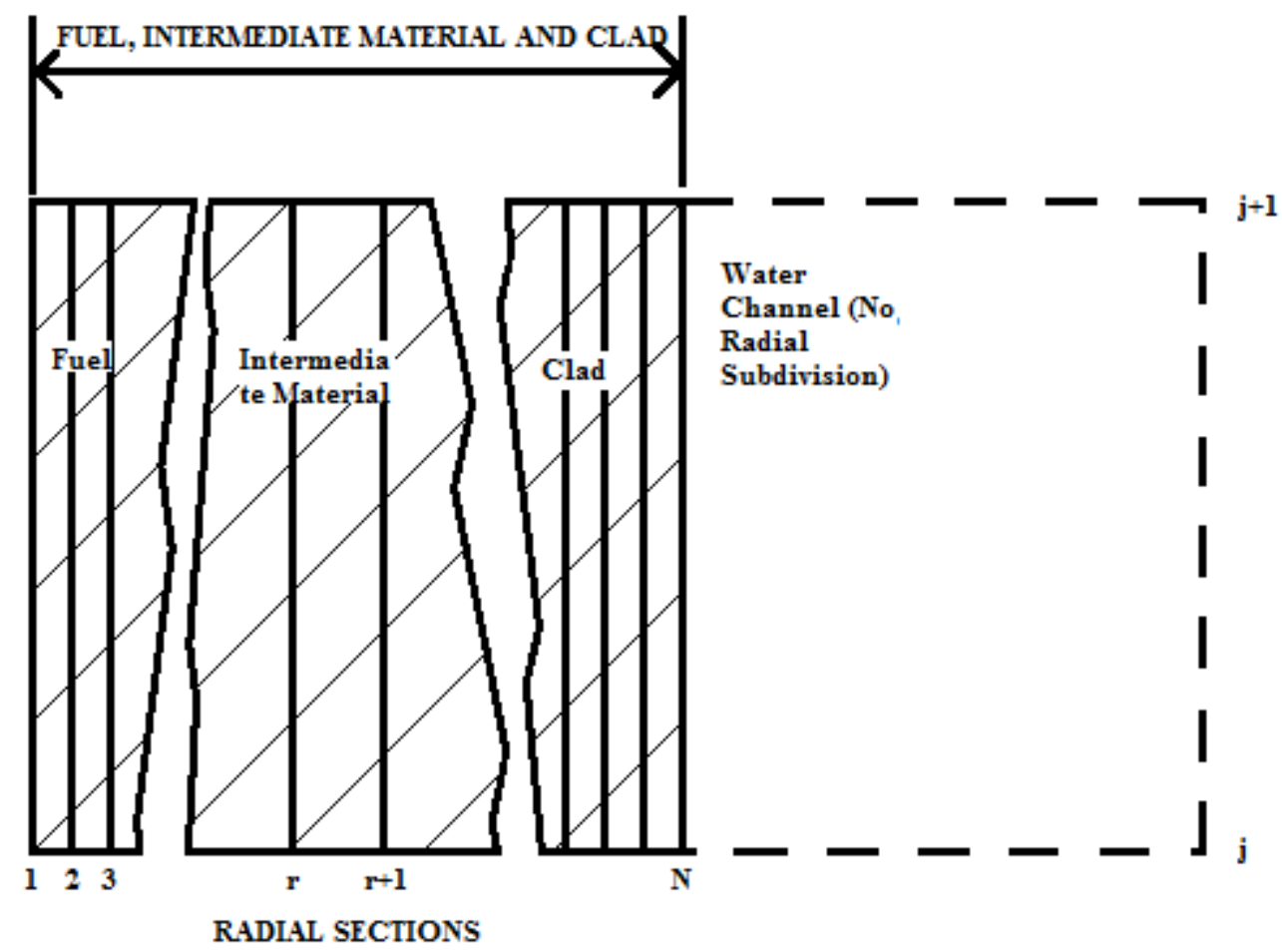

Figure 3.2 Example of radial subdivision for heat transfer calculations

The partial differential equation for diffusion of heat within each fuel element is

$$
\frac{\partial}{d t}[g(u, r) u(r, t)]=\nabla \cdot k(u, r) \nabla u(r, t)+S(r, t)
$$

where the symbol $u(r, t)$ represents temperature as a function of radial position, $r$, and time, $t$. Volumetric heat capacity and thermal conductivity are denoted by the symbols $g(u, r)$ and $k(u, r)$, respectively, and are treated as functions of both position and temperature. The heat source per unit volume, $S(r, t)$, is assumed to be a separable function of space and time. The magnitude of this local heat source is determined from the calculated or specified average core power level and pre-assigned axial and radial weighting factors. Provision is made for prompt energy generation within the coolant, as well as within each of the various fuel element materials. The particular scheme by which E (41) is solved within PARET/ANL is discussed in Section 3.3.1.

PARET/ANL employs empirical convective heat transfer correlations in estimating the rate of heat transfer at the clad-coolant interface. These correlations provide the boundary condition at this interface for use in solution of the heat conduction Eq. (41)) within the fuel elements. Which boundary condition is appropriate depends, of course, upon which heat transfer regime prevails at the particular node point under consideration. The various boundary conditions included in the code are presented in Section 3.3.2 and described in detail in Section 12. 
The scheme for assessing which of the several heat transfer regimes prevails at a given axial node point at any given time is based on the following primary considerations:

1. For clad surface temperatures less than the fluid saturation temperature, it is assumed that the non-boiling regime exists.

2. When the clad surface temperature, as calculated on the basis of a non-boiling boundary condition, exceeds the fluid saturation temperature, surface heat fluxes are calculated on the basis of both the non-boiling and nucleate boiling boundary conditions. If the nucleate boiling heat flux is greater than the forced convection heat flux, nucleate boiling is assumed to prevail. Otherwise, forced convection is assumed to prevail.

3. If the nucleate boiling heat flux exceeds the DNB heat flux, the possibility of being in either transition boiling or stable film boiling is considered. A clad surface temperature at departure from transition boiling $\left(\mathrm{u}_{\mathrm{s}}\right)_{\mathrm{DTB}}$, is then calculated by equating the film boiling and transition boiling surface heat fluxes and solving for the surface temperature. If the surface temperature calculated on the basis of the film boiling boundary condition is greater than $\left(\mathrm{u}_{\mathrm{s}}\right)_{\text {ртв, }}$, film boiling is assumed to prevail. Otherwise, it is assumed that transition boiling exists.

4. Saturated boiling can occur only for fluid enthalpies greater than the saturated liquid enthalpy, $\mathrm{H}_{\mathrm{f}}$.

5. The vapor regime exists only for fluid enthalpies equal to or greater than the saturated vapor enthalpy, $\mathrm{H}_{\mathrm{g}}$.

At the present time, PARET/ANL contains two options with respect to DNB calculations. In the first of these options, the point at which DNB occurs at any axial node is estimated on the basis of a steadystate DNB correlation. In this case, a DNB heat flux is calculated for each axial node at each time node. Since steady-state correlations are not generally valid under transient conditions, a second option provides for specification of a single DNB heat flux which is assumed to apply under transient conditions to each axial node over the duration of the transient. An estimate of a representative transient DNB heat flux can be obtained from Eq. (86). This correlation is based on Bernath's [9] steady-state correlation and Schrock's [10] transient heat transfer data.

\subsubsection{Thermal Diffusion Equation}

Eq. (41) for thermal diffusion within the fuel elements is solved for each axial level of each region into which the core is subdivided. For instance, if the core is divided into four regions with 19 axial increments (20 nodes) per region, then Eq. (41) is solved 80 times at each time node. The particular scheme through which the solution is effected is patterned after that employed in the HEAT-1 heat conduction code [11]. For this purpose, each axial increment is subdivided radially, as exemplified in part (a) of Figure 3.3, where $r_{n}$ represents the radial spatial variable.

To obtain the spatial difference approximation for the $\mathrm{n}^{\text {th }}$ interior mesh point, Eq. (41) is integrated over a volume indicated by the dashed lines in part (b) of Figure 3.3.

$$
\iiint \frac{\partial}{\partial t}[g(u, r) u(r, t)] d v=\iiint \nabla \cdot k(u, r) \nabla u(r, t) d v+\iiint S(r, t) d v
$$

Using a forward difference for the time derivative, Eq. (42) can be approximated by the following difference equation for the $\mathrm{n}^{\text {th }}$ interior mesh point at time node $(\mathrm{m}+1)$ : 


$$
a_{n} u_{n-1}^{m+1}+b_{n} u_{n}^{m+1}+c_{n} u_{n+1}^{m+1}=d_{n}
$$

where

$$
\begin{gathered}
a_{n}=\frac{-k_{\mathrm{pn}} h_{\mathrm{pn}}^{s} \Delta t}{2} \\
b_{n}=\sigma D_{n}-a_{n}-c_{n} \\
c_{n}=\frac{-k_{\mathrm{sn}} h_{\mathrm{sn}}^{s} \Delta t}{2} \\
d_{n}=-\sigma a_{n} u_{n-1}^{m}+\sigma\left(D_{n}+a_{n}+c_{n}\right) u_{n}^{m}-\sigma c_{n} u_{n+1}^{m}+\Delta t P_{f} \frac{\phi^{m+1}+\sigma \phi^{m}}{2} \\
+\left(Q_{\mathrm{pn}} h_{\mathrm{pn}}^{v}+Q_{\mathrm{sn}} h_{\mathrm{sn}}^{v}\right) \\
D_{n}=g_{\mathrm{pn}} h_{\mathrm{pn}}^{v}+g_{\mathrm{sn}} h_{\mathrm{sn}}^{v}
\end{gathered}
$$

In the above definitions, the quantity, $\sigma$, is set to unity for transient situations and to zero for steady state. Its function is simply to generalize Eq. (43), making it applicable to both situations. The quantities, $g$ and $k$, represent volumetric heat capacity and thermal conductivity, respectively. The subscripts pn and sn refer to average conditions existing between mesh points $n$ and $n-1$, and between $n+1$ and n, respectively, as illustrated in part (b) of Figure 3.3. Additional definitions include

$$
\left.\begin{array}{l}
Q_{\mathrm{pn}}=Q_{R}\left(r_{n}\right) \\
Q_{\mathrm{sn}}=Q_{R}\left(r_{n+1}\right)
\end{array}\right\}
$$

where $Q$ accounts for the radial dependence of the heat source (see Eq. (51)) and

$$
\left.\begin{array}{l}
h_{\mathrm{pn}}=r_{n}-r_{n-1} \\
h_{\mathrm{sn}}=r_{n+1}-r_{n} \\
h_{\mathrm{pn}}^{s}=\frac{1}{h_{\mathrm{pn}}}\left[2 \pi\left(r_{n}-\frac{h_{\mathrm{pn}}}{2}\right)^{\rho}\right] \\
h_{\mathrm{pn}}^{v}=\frac{h_{\mathrm{pn}}}{2}\left[2 \pi\left(r_{n}-\frac{h_{\mathrm{pn}}}{4}\right)^{\rho}\right]
\end{array}\right\}
$$

with $h_{\mathrm{sn}}^{s}$ and $h_{\mathrm{sn}}^{v}$ defined analogously. The quantity $r_{n}$ represents the radial spatial variable, as illustrated in Figure 3.3. For cylindrical geometry, the parameter, $\rho$, is set equal to unity and for slab geometry it is set to zero.

The heat source per unit volume, $S(r, t)$, is assumed to be a separable function of space and time and is given, for any axial level, by

$$
S(r, t)=P_{f} \phi(t) Q(r)
$$

Power levels at times $\mathrm{t}^{\mathrm{m}}$ and $\mathrm{t}^{\mathrm{m}+1}$ are represented by $\phi^{m}$ and $\phi^{m+1}$ respectively. 


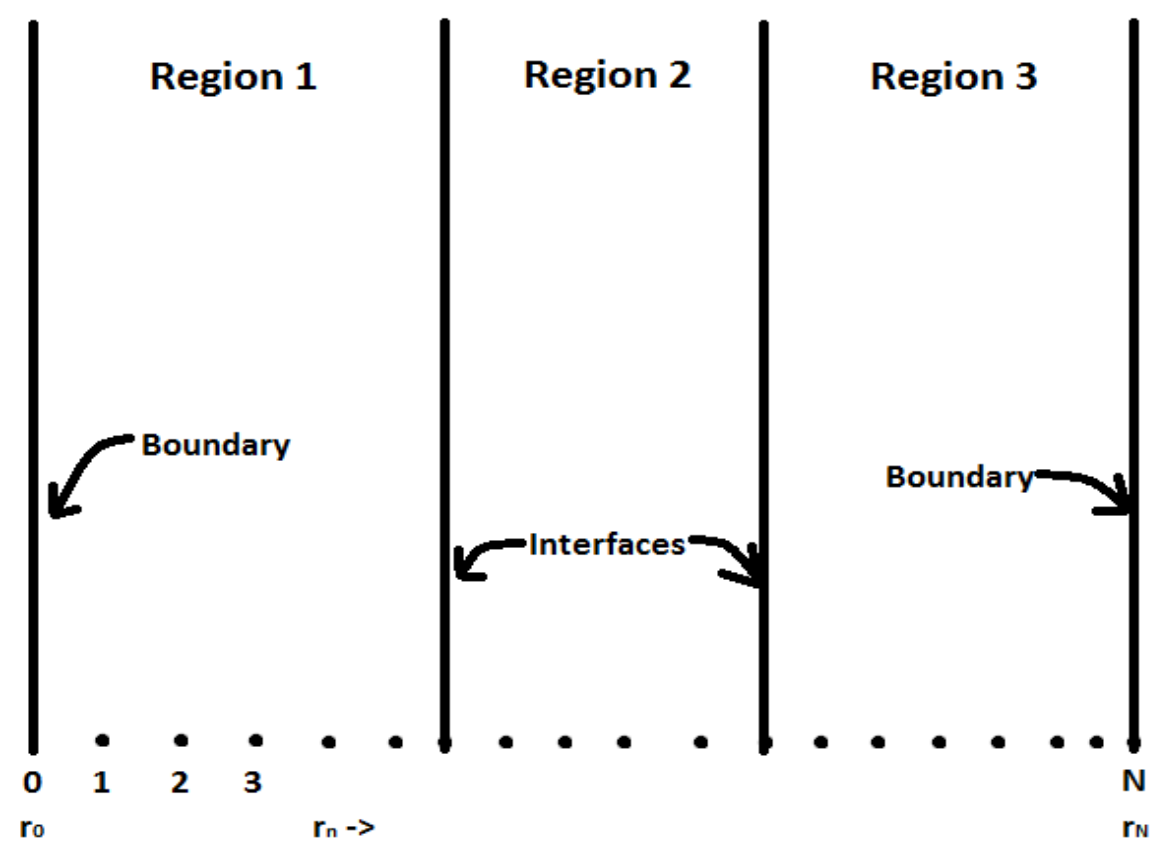

(a) RADIAL MESH POINT PATTERN

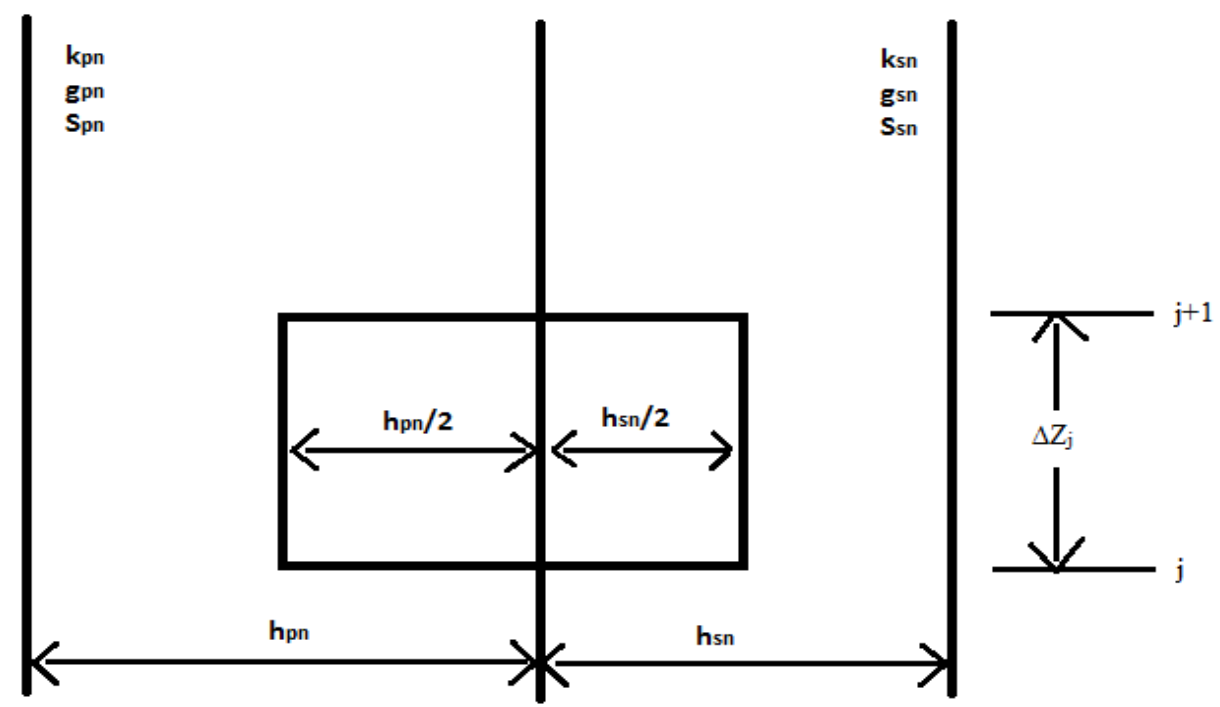

(b) TWO TYPICAL RADIAL INTERVALS

Figure 3.3 Radial mesh point pattern for thermal model

Allowable boundary conditions are of the generalized form 


$$
A(u) \cdot u+B(u) \frac{\partial u}{\partial r}=D(u) C(t)
$$

This equation is used to represent an adiabatic node at the center of the fuel and each of various convective boundary conditions at the clad-coolant interface. The boundary conditions for the cladcoolant interface are presented in Eqs. (65) - (76). Using a forward difference for the time derivative and substituting Eq. (52) into Eq. (42), the following difference equation can be derived for the inner boundary (at $r_{n}=r_{0}$ )

$$
b_{0} u_{0}^{m+1}+c_{0} u_{1}^{m+1}=d_{0}
$$

where

$$
\begin{gathered}
c_{0}=-B_{0} \frac{k_{\mathrm{s} 0} h_{\mathrm{s} 0}^{s} \Delta t}{2} \\
b_{0}=B_{0} \sigma g_{\mathrm{s} 0} h_{\mathrm{s} 0}^{v}-\frac{k_{\mathrm{s} 0} A_{0}\left(2 \pi r_{0}\right)^{\rho} \Delta t}{2}-c_{0} \\
d_{n}=-\sigma c_{0} u_{1}^{m}+\sigma\left(2 B_{0} g_{\mathrm{s} 0} h_{\mathrm{s} 0}^{v}-b_{0}\right) u_{0}^{m}-D_{0} k_{\mathrm{s} 0}\left(2 \pi r_{0}\right)^{\rho} \Delta t \frac{C_{0}^{m+1}+\sigma C_{0}^{m}}{2} \\
+\Delta t P_{f} B_{0} \frac{\phi^{m+1}+\sigma \phi^{m}}{2} Q_{\mathrm{s} 0} h_{\mathrm{s} 0}^{v}
\end{gathered}
$$

and $A_{0}, B_{0}, C_{0}$ and $D_{0}$ refer to values of $A(u), B(u), C(u)$ and $D(u)$ in Eq. (52) evaluated at the inner boundary $\left(r_{n}=r_{0}\right)$. Similarly, for the boundary at the clad surface $\left(r_{n}=r_{N}\right)$, the following difference equation can be derived:

$$
a_{N} u_{N-1}^{m+1}+b_{N} u_{N}^{m+1}=d_{N}
$$

where

$$
\begin{gathered}
a_{N}=-B_{N} \frac{k_{\mathrm{pN}} h_{\mathrm{pN}}^{s} \Delta t}{2} \\
b_{N}=B_{N} \sigma g_{\mathrm{pN}} h_{\mathrm{pN}}^{v}-\frac{k_{\mathrm{pN}} A_{N} \Delta \mathrm{t}\left(2 \pi r_{N}\right)^{\rho}}{2}-a_{N} \\
d_{n}=-\sigma a_{N} u_{N-1}^{m}+\sigma\left(2 B_{N} g_{\mathrm{pN}} h_{\mathrm{pN}}^{v}-b_{N}\right) u_{N}^{m}+D_{N} k_{\mathrm{pN}}\left(2 \pi r_{N}\right)^{\rho} \Delta t \frac{C_{N}^{m+1}+C_{N}^{m}}{2} \\
+\Delta t P_{f} B_{N} \frac{\phi^{m+1}+\sigma \phi^{m}}{2} Q_{\mathrm{pN}} h_{\mathrm{pN}}^{v}
\end{gathered}
$$

and $A_{N}, B_{N}, C_{N}$ and $D_{N}$ refer to values of $A(u), B(u), C(u)$ and $D(u)$ in Eq. (52) evaluated at the outer boundary $\left(r_{n}=r_{N}\right)$. Application of Eq. (43) to N-1 interior mesh points and Eqs. (53) and (57) to the two boundary mesh points leads to a tri-diagonal set of $\mathrm{N}+1$ simultaneous equations. This set of equations is solved by Gaussian elimination for the temperature distribution across a fuel element under both steady-state and transient situations.

Both thermal conductivity and volumetric heat capacity are considered to be temperature dependent and are represented by polynomials. Thermal conductivity is represented by

$$
k_{n+\frac{1}{2}}=\alpha_{1} T^{2}+\alpha_{2} T+\alpha_{3}+\frac{\alpha_{4}}{T}
$$

where 


$$
T=\frac{u_{n}^{m}+u_{n+1}^{m}}{2}+\alpha_{5}
$$

The quantity $u$ represents temperature and the alpha coefficients are constants. Volumetric heat capacity is given similarly by

$$
g_{n+\frac{1}{2}}=\beta_{1} T^{2}+\beta_{2} T+\beta_{3}+\frac{\beta_{4}}{T}
$$

where

$$
T=\frac{u_{n}^{m}+u_{n+1}^{m}}{2}+\beta_{5}
$$

The variable $\beta_{5}$ is an offset which used to change from degrees $\mathrm{F}$ to $\mathrm{R}$, or from $\mathrm{C}$ to $\mathrm{K}$.

\subsubsection{Boundary Conditions}

The clad-coolant boundary conditions employed in each of the various heat transfer regimes are presented below. The code selects from among the following numbered options based on the local conditions present at each time step.

1. Forced convection (FC) boundary condition [12]

$$
q_{\mathrm{FC}}^{\prime \prime}=h\left(u_{s}-u_{b}\right) ; q_{\mathrm{FC}}^{\prime \prime}>q_{\mathrm{NB}}^{\prime \prime}
$$

Where, for example,

$$
h=0.023 \frac{k}{\mathrm{De}} \operatorname{Re}^{0.8} \operatorname{Pr}^{0.4} ; \operatorname{Re}>6000
$$

Other correlations are available for $\mathrm{h}$.

2. Nucleate boiling (NC) boundary condition [13]

$$
\begin{gathered}
\left(q_{\mathrm{NB}}^{\prime \prime}\right)^{m+1}=\left(q_{\mathrm{NB}}^{\prime \prime}\right)^{m}\left[1+\frac{4\left(u_{s}^{m+1}-u_{s}^{\prime m}\right)}{u_{s}^{\prime m}-u_{\mathrm{sat}}}\right] \\
u_{s}>u_{\mathrm{sat}} \\
q_{\mathrm{DNB}}^{\prime \prime}>q_{\mathrm{NB}}^{\prime \prime}>q_{\mathrm{FC}}^{\prime \prime}
\end{gathered}
$$

where the superscript $\mathrm{m}$, refers to the $\mathrm{m}^{\text {th }}$ time node. This boundary condition is based on the JensLottes correlation [14]

$$
u_{s}^{\prime}=u_{\text {sat }}+60 \exp \left[\left(-\frac{p}{900}\right)\right]\left(\frac{q^{\prime \prime}}{10^{6}}\right)^{\frac{1}{4}}
$$

3. Transition boiling (TB) boundary condition [15]

$$
\begin{gathered}
q_{\mathrm{TB}}^{\prime \prime}=q_{\mathrm{DNB}}^{\prime \prime}-K_{T B}\left(u_{s}-\left(u_{s}\right)_{D N B}\right) \\
q_{\mathrm{TB}}^{\prime \prime}<q_{\mathrm{DNB}}^{\prime \prime} \\
u_{s}<\left(u_{s}\right)_{D T B}
\end{gathered}
$$

where $K_{T B}$ is a constant. 
4. Film boiling (FB) boundary condition [16]

$$
q_{\mathrm{FB}}^{\prime \prime}=h\left(u_{s}-u_{\mathrm{sat}}\right) ; u_{s}>\left(u_{s}\right)_{D T B}
$$

Where

$$
h=0.023 \frac{k_{g}}{\mathrm{De}} \operatorname{Re}_{g}{ }^{0.8} \operatorname{Pr}_{g}^{0.4} ; \operatorname{Re}>2000
$$

Note : at user option, h can also be obtained from the Groeneveld film boiling correlation [43].

5. Superheat (SH) boundary condition [16]

$$
q_{\mathrm{SH}}^{\prime \prime}=h\left(u_{s}-u_{\mathrm{b}}\right) ; H \geq H_{g}
$$

where the heat transfer coefficient, $h$, is given by Eq. (71)

6. Departure from nucleate boiling (DNB) correlations

a. Steady-state subcooled correlation [17]

$$
\begin{gathered}
q_{\mathrm{DNB}}^{\prime \prime}=\left(0.23 \times 10^{6}+0.094 G\right)\left[3.0+0.01\left(u_{\mathrm{sat}}-u_{b}\right)\right] \\
{\left[0.435+1.23 \exp \left(-0.0093 \frac{L}{\mathrm{De}}\right)\right]\left[1.7-1.4 e^{-a}\right]}
\end{gathered}
$$

where

$$
a=0.532\left[\frac{H_{f}-H_{I}}{H_{f g}}\right]^{\frac{3}{4}}\left(\frac{\rho_{f}}{\rho_{g}}\right)^{\frac{1}{3}}
$$

b. Steady-state saturated correlation [17]

$$
\begin{aligned}
\Delta H_{\mathrm{DNB}} & =0.529\left(H_{f}-H_{I}\right)+(0.825+2.36 \exp (-204 \mathrm{De})) H_{f g} \exp \left(\frac{-1.5 G}{10^{6}}\right) \\
& -0.41 H_{f g} \exp \left(-0.0048 \frac{L}{\mathrm{De}}\right)-1.12 H_{f g} \frac{\rho_{g}}{\rho_{f}}+0.548 H_{f g}
\end{aligned}
$$

c. Transient correlation [18]

$$
q_{\mathrm{DNB}}^{\prime \prime}=\left(12300+\frac{67 V}{\mathrm{De}^{0.6}}\right)\left[102.5 \ln p-97 \frac{p}{p+15}+32-u_{b}\right] \exp \left(\frac{4.25}{\tau}\right)
$$

where $\tau$ represents the initial asymptotic period of the excursion in msec. Eq. (76) is not an integral part of the PARET/ANL code, but is merely suggested here as a possible correlation for estimating a transient DNB flux.

\subsubsection{Natural convection (NC) heat transfer correlation}

$$
q_{\mathrm{NC}}^{\prime \prime}=h\left(u_{s}-u_{b}\right)
$$

where

$$
h=\frac{k}{\operatorname{De}} \operatorname{Re}^{0.45}\left(\frac{\xi}{k}\right)^{\frac{5}{6}} \mu^{\frac{2}{3}}\left(\frac{\mu}{\mu_{s}}\right)^{0.14} \delta\left(u_{s}-u_{b}\right)^{n}
$$


In Eq. (78), the $\delta$ and $n$ are constants. Parameter $\delta$ represents the ratio of the thin wire natural convection heat transfer coefficient for a thin horizontal cylinder at a value of $\left(\mathrm{u}_{\mathrm{s}}-\mathrm{u}_{\mathrm{b}}\right)$ of 1.0 , and the forced convection heat transfer coefficient evaluated from Eq. (78) when parameters $n$ and $\delta$ are both set to unity. The exponent $\mathrm{n}$ is obtained from:

$$
\begin{aligned}
& \mathrm{n}=1 / 4 \text { for } \mathrm{Gr}^{*} \operatorname{Pr}<10^{8} \text { (nominally laminar); } \\
& \mathrm{n}=1 / 3 \text { for } \mathrm{Gr}^{*} \operatorname{Pr}>10^{8} \text { (nominally turbulent). }
\end{aligned}
$$

Note that the Rayleigh Number is $\mathrm{Ra}=\mathrm{Gr} * \mathrm{Pr}$.

Gr is the Grashof number $\left(D^{3} g \beta\left[u_{s}-u_{b}\right] / v^{2}\right)$

Pr is the Prandtl number $\left(\mu \mathrm{C}_{\mathrm{p}} / \mathrm{k}\right)$.

$\mathrm{G}$ is the acceleration of gravity

$v$ is the kinematic viscosity

$\beta$ is the coefficient of thermal expansion of the coolant.

$\mu_{\mathrm{s}}$ represents coolant viscosity evaluated at the temperature of the heating surface

$\xi$ is given by

$$
\xi=k^{0.6}\left(\frac{C_{p}}{\mu}\right)^{0.4}
$$

The thin wire heat transfer coefficient was obtained in the original PARET code using

$$
\begin{aligned}
& \mathrm{h}=0.59(\mathrm{k} / \mathrm{De})\left(\mathrm{Gr}^{*} \operatorname{Pr}\right)^{0.25}, \text { for } 10^{4} \leq \mathrm{GR} * \operatorname{Pr} \leq 10^{8} \\
& \mathrm{~h}=0.129(\mathrm{k} / \mathrm{De})\left(\mathrm{Gr}{ }^{*} \operatorname{Pr}\right) 0.3333 \text {, for } 10^{8} \leq \mathrm{GR} * \operatorname{Pr} \leq 10^{14}
\end{aligned}
$$

These relations are undocumented but appear to be a very slight variation on the publication [M. Jakob and W. Linke, Phys Z $36: 267-280$ (1935)] that is referenced by S. K. S. Boetcher, Natural Convection from Circular Cylinders, SpringerBriefs in Thermal Engineering and Applied Science, DOI : 10.1007/978-3-319-08132-8_2. The only differences are as follows :

The Jakob and Linke work was based on horizontal cylinders, not vertical.

The constant of 0.59 was given as 0.555 by Jakob and Linke ;

The upper limit for Gr*Pr was $10^{12}$ instead of $10^{14}$.

In determining what values of $\delta$ and $n$ to use, one first must find GR*Pr to fix $n$. Then a value of $h$ can be obtained as above. There are many publications, both theoretical and experimental, that confirm the above choices for $\mathrm{n}$ for the above ranges of Gr*Pr. On the other hand, there is significant divergence on the value of the scale factor of 0.59 employed in PARET.

The Churchill-Chu correlation [41] is now well-accepted as the best correlation to use for vertical plates and vertical cylinders. 


\subsubsection{Transition model}

A transition model to fully developed two-phase heat transfer, as suggested by Bergles and Rohsenow [19], has been implemented in PARET/ANL as an option to the original model. The two-phase transition scheme at time step $\mathrm{m}+1$ may be expressed as

$\left(q^{\prime \prime}\right)^{m+1}=\left(q_{1 \phi}\right)^{m+1}\left\{1+\left[\frac{\left(q^{\prime \prime}{ }_{2 \phi}\right)^{m+1}}{\left(q^{\prime \prime}{ }_{1 \phi}\right)^{m+1}}\left(1-\frac{\left(q_{i}\right)^{m+1}}{\left(q^{\prime \prime}{ }_{2 \phi}\right)^{m+1}}\right)\right]^{2}\right\}^{1 / 2}$

where

$$
\begin{aligned}
& \mathbf{q}^{\prime 1 \phi} \text { is the single-phase heat flux } \sim \mathbf{h}_{1 \phi} \\
& \mathbf{q}^{\prime}{ }_{\mathbf{i}} \text { is the two-phase value } \sim\left(\mathbf{T}_{\mathbf{w i}}-\mathbf{T}_{\text {sat }}\right) \\
& \mathbf{q}^{\prime \prime}{ }_{2 \phi} \text { is the two-phase value } \sim\left(\mathbf{T}_{\mathbf{w}}-\mathbf{T}_{\text {sat }}\right)
\end{aligned}
$$

with the clad wall temperature at the onset of nucleate boiling (ONB) given by $\mathrm{T}_{\mathrm{wi}}=\left(\mathrm{q}_{\mathrm{ONB}}^{\prime} / 15.6 \mathrm{p}^{1.156}\right)^{\frac{\mathrm{p}^{0.0234}}{2.30}}+\mathrm{T}_{\text {sat }}$, the Bergles-Rohsenow correlation (B-R).

The two-phase correlation for $\mathrm{q}{ }_{\mathrm{i}}$ and $\mathrm{q}^{\prime}{ }_{2 \phi}$ may be chosen from the original Jens-Lottes (J-L) or the McAdams [14] correlation on option.

\subsection{Hydrodynamics}

The hydrodynamics calculations in PARET/ANL are based on a modified Momentum Integral Model [20] in which equations representing the laws of conservation of mass, momentum and energy are solved in each coolant channel at each time node.

$$
\begin{gathered}
\frac{\partial \bar{\rho}}{d t}=-\frac{\partial G}{\partial Z} \\
\frac{\partial G}{d t}+\frac{\partial}{\partial Z}\left(\frac{G^{2}}{\rho^{\prime}}\right)=-\frac{\partial p}{\partial Z}-\frac{f v|G| G}{2 D_{e}}-\overline{\rho g} \\
\rho^{\prime \prime} \frac{\partial H}{d t}+G \frac{\partial H}{\partial Z}=\frac{q}{r_{h}}
\end{gathered}
$$

where

$t=$ time

$Z=$ axial spatial variable

$\bar{\rho}=$ volume weighted two-phase density of coolant

$G=$ mass flow rate of coolant

$\rho^{\prime}=$ effective density of coolant for momentum considerations 
$p=$ pressure

$\mathrm{f}=$ friction factor

$v=$ specific volume of coolant

$D_{e}=$ equivalent diameter of coolant channel

$g=$ gravitational constant

$\rho^{\prime \prime}=$ effective slip flow density of coolant

$\mathrm{H}=$ enthalpy of coolant

$r_{h}=$ hydraulic radius of coolant channel

$\mathrm{q}=$ thermal energy gained by coolant

The dissipation term $\frac{f v|G| G}{2 D_{e}}$, as well as pressure changes with respect to both space and time, $G v \frac{\partial p}{\partial z}+$ $\frac{\partial p}{\partial t}$, have been neglected in Eq. (81). The solutions to Eqs. (79) - (81) yield the pressure drop across the core, as well as point-wise pressures, fluid enthalpies, and mass flow rates along the length of each channel. As in the case of the heat transfer calculations, this also is a one-dimensional treatment; i.e., variations in the fluid velocity and fluid properties are considered only in the direction of flow. The hydrodynamic description allows for coolant flow reversal, and the physical condition of the coolant is allowed to range from sub-cooled liquid through the two-phase region up to and including superheated steam.

A basic assumption of the Momentum Integral Model (MIM), upon which the PARET/ANL hydrodynamic model is based, is that all fluid properties, including density, can be evaluated at some single reference pressure. In PARET, however, this model has been modified to consider the dependence of fluid density upon local fluid pressure. The particular scheme through which this pressure dependence is accounted for is as follows. The code calculates local pressures along the length of each channel as a function of time. At any particular time node, however, the pressures calculated are appropriate to the immediately preceding time node. A Lagrangian extrapolation in then used to obtain pressures at the current time node and these extrapolated pressures are used as a basis for evaluating current fluid densities. The scheme includes an iteration on local fluid pressures (until extrapolated values are in agreement with the calculated values) and provision for decreasing the time-step size if the time rate of change of local fluid specific volume exceeds a specified value. Fluid properties are evaluated explicitly for the local conditions. The original PARET code exclusively used a table lookup process for fluid properties at the given system pressure. This process used linear interpolation in temperature. The code used a pre-existing binary library in the form of a fluid properties table. For the interpolation process, coolant density is considered to be a function of both temperature and pressure; the other fluid properties (viscosity $(\mu)$, heat capacity at constant pressure $\left(\mathrm{C}_{\mathrm{p}}\right)$ and thermal conductivity $\left.(\mathrm{k})\right)$ are evaluated as functions of temperature at the specified initial system temperature. More recent versions of PARET/ANL call explicit functions for fluid properties. For each channel (region) included in a problem, either the pressure drop across that channel or the coolant inlet mass flow rate must be specified as a function of time. In the latter case, the so-called flow-forced problem, the pressure drop across the channel is calculated, according to the conservation of momentum, as the sum of the frictional, elevation, spatial acceleration and transient acceleration pressure drops. As a result of integrating the equation for the conservation of momentum across the entire channel (Momentum Integral Model), the transient acceleration 
pressure drop must be determined on the basis of the time rate change of the channel average mass velocity, $\hat{G}$, between successive time nodes, where $\widehat{G}$ us given by

$$
\widehat{G}=\frac{1}{L} \int_{0}^{L} G d Z
$$

and $L$ represents the length of the channel. The time rate of change of this quantity is given by

$$
\frac{\partial \widehat{G}}{\partial t}=\frac{1}{L}[\Delta p-F]
$$

where $\Delta p$, the total channel pressure drop, and $F$, the sum of the frictional elevation, and spatial acceleration pressure drops, are

$$
\begin{gathered}
\Delta p=-\int_{0}^{L} \frac{\partial p}{\partial Z} d Z \\
\mathrm{~F}=\int_{0}^{L} \frac{f v|G| G}{2 D_{e}} d Z+\int_{0}^{L} \bar{\rho} g d Z+\left[\frac{G^{2}}{\rho^{\prime}}\right]_{N Z}-\left[\frac{G^{2}}{\rho^{\prime}}\right]_{1}
\end{gathered}
$$

The difference quantity $[\Delta p-F]$ in Eq. (83) represents the transient acceleration pressure drop. In the pressure-drop forced problem (in which case the total pressure drop across the channel is specified with time), a channel average mass velocity existing at the current time node is calculated on the basis of the average mass velocity at the previous time node and the transient acceleration pressure drop over the present time step (Eq. (83)). This current channel average mass velocity is used as a basis for evaluating the channel entrance mass velocity at the current time node, which effectively reduces the problem to a flow-forced problem. All succeeding mass velocities along the length of the channel are then determined from the equation for the conservation of mass. This entire scheme is discussed in detail in Section 3.4.1.

The enthalpy of the inlet coolant is assumed to be the same for each channel (except in the case of flow reversal) and must be specified. Succeeding enthalpies along the length of each channel are determined according to an Eq. for the conservation of energy in the channel, and on the basis of the enthalpy of the inlet coolant.

PARET/ANL includes the option of either estimating the vapor volume fraction formed during subcooled boiling, or assuming it to be zero for conditions other than saturated boiling. Vapor volume fraction calculations in the sub-cooled region are based on a simplified form of Zuber's [21] Eq.

$$
\frac{\partial R}{\partial t}+C_{2} V \frac{\partial R}{\partial Z}+\frac{R}{\tau}=\lambda K\left(q^{\prime \prime}\right)^{n}
$$

where the quantity $R$ represents the vapor volume fraction; $Z$ and $t$ are the position and time variables, respectively; $V$ represents the fluid linear velocity; $q^{\prime \prime}$ represents the surface heat flux; and $C_{2}, \tau, \lambda, K$ and $n$ are constants. The parameter $\tau$ represents the bubble collapse time and $\lambda$ represents the fraction of the clad surface heat flux which is utilized in producing vapor during boiling.

In the case of saturated boiling, the mass flow fraction of vapor is determined directly from the mixing-cup enthalpy. The vapor volume fraction is then obtained from a table lookup, according the revised Martinelli-Nelson [22] development.

PARET/ANL uses the Martinelli-Nelson method [23] to estimate two-phase pressure drop (in the case of saturated boiling) and relationships developed at Westinghouse [24] to evaluate sub-cooled two-phase pressure drop. The latter development is based on an equation of the form 


$$
f=\left(\frac{f}{f_{\text {iso }}}\right) f_{\text {iso }}
$$

where $f$ represents a two-phase friction factor and $f_{\text {iso }}$ represents a single-phase friction factor. The latter factor, $f_{\text {iso }}$, is correlated with the Reynolds number in the form

$$
f_{\text {iso }}=a_{0}(R e)^{a_{1}}
$$

where $a_{0}$ and $a_{1}$ are constants [see Eqs. (145) - (146)]. The ratio $\left(\frac{f}{f_{\text {iso }}}\right)$ is determined from empirical correlations based on experimental data obtained at Westinghouse. A detailed description of the friction factor correlations is presented in Chapter 3.4.1.

\subsubsection{Conservation of Mass}

Eq. (79) for the conservation of mass can be written in the form

$$
\frac{\partial G}{\partial Z}=-\frac{\partial \bar{\rho}}{\partial t}=-\frac{\partial \bar{\rho}}{\partial H} \frac{\partial \bar{H}}{\partial t}
$$

Evaluation of $\frac{\partial \bar{H}}{\partial t}$ from Eq. (81) and substitution into Eq. (89) yields

$$
\frac{\partial G}{\partial Z}=\frac{G}{\rho^{\prime \prime}} \frac{\partial \bar{\rho}}{\partial H} \frac{\partial \bar{H}}{\partial z}-\frac{q}{r_{h} \rho^{\prime \prime}} \frac{\partial \bar{\rho}}{\partial H}
$$

PARET/ANL employs the following explicit difference approximation to Eq. (90) for calculating the coolant mass flow rate, $G$, as a function of position and time (refer to Figure 3.3):

$$
G_{j}^{m}=\gamma_{j-\frac{1}{2}}^{m} G_{j-1}^{m}-\frac{\beta_{j-\frac{1}{2}}^{m}}{r_{h}} q_{j-\frac{1}{2}}^{m}
$$

where

$$
\begin{gathered}
\gamma_{j-\frac{1}{2}}^{m}=\frac{2+A_{j-\frac{1}{2}}^{m}}{2-A_{j-\frac{1}{2}}^{m}} \\
A_{j-\frac{1}{2}}^{m}=\frac{H_{j}^{m}-H_{j-1}^{m}}{\rho_{j-\frac{1}{2}}^{\prime \prime m}}\left(\frac{\partial \bar{\rho}}{\partial H}\right)_{j-\frac{1}{2}}^{m} \\
\beta_{j-\frac{1}{2}}^{m}=\frac{2 \Delta Z_{j}}{\rho_{j-\frac{1}{2}}^{\prime \prime m}} \frac{1}{2-A_{j-\frac{1}{2}}^{m}}\left(\frac{\partial \bar{\rho}}{\partial H}\right)_{j-\frac{1}{2}}^{m}
\end{gathered}
$$

and $q_{\frac{j-1}{2}}^{m}$ represents the sum of the surface heat flux, $q_{\frac{j-1}{2}}^{\prime \prime m}$, and the prompt energy generation within the coolant, expressed in terms of an equivalent flux.

The quantity $\rho^{\prime \prime}$, which is referred to as the "effective slip-flow density," is defined by

$$
\rho^{\prime \prime}=\bar{\rho} \frac{\partial \bar{H}}{\partial H}+(\bar{H}-H) \frac{\partial \bar{\rho}}{\partial H}
$$


where $\bar{H}$ represents a volume-weighted enthalpy and $H$ represents a flow-weighted or mixing-cup enthalpy. In the particular situation where both the liquid and vapor phases are saturated, Eq. (95) can be written in the form

$$
\rho^{\prime \prime}=\left[\rho_{f} X+\rho_{g}(1-X)\right] \frac{\partial R}{\partial X}
$$

where $R$ represents vapor volume fraction and $X$ represents the mass flow fraction of vapor. Since $\rho^{\prime \prime}$, as defined in Eq. (95) is very difficult to evaluate, it is assumed in PARET/ANL that Eq. (96) is applicable to the two-phase system under all conditions, saturated or otherwise. This greatly simplifies the evaluation of $\rho^{\prime \prime}$. The quantity, $\bar{\rho}$, is a volume-weighted density, defined by

$$
\bar{\rho},=\rho_{\mathrm{v}} \mathrm{R}+\rho_{\mathrm{l}}(1-\mathrm{R})
$$

In the flow-forced problem, the inlet mass flow rate, $G_{1}^{m}$, is specified as a function of time. All succeeding flow rates along the length of the channel are then calculated explicitly, according to Eq. (91). In the pressure-drop-forced problem, however, the inlet mass flow rate of the coolant is not specified and Eq. (91) therefore cannot be used directly. In this case, the computational scheme involves first computing a channel average mass flow rate, $\hat{G}_{T}^{m}$, on the basis of the flow rate, $\hat{G}_{T}^{m-1}$, at the previous time node and the transient acceleration pressure drop, $\left(\Delta p_{t a}\right)_{T}^{m-1}$, across the present time step. This $\hat{G}_{T}^{m}$ is then used in determining an inlet mass flow rate. Once the inlet mass flow rate has been determined, the pressure-drop-forced problem has been effectively reduced to a flowforced problem and is handled accordingly.

The equations involved in this scheme include an expression for the evaluation of $\widehat{G}_{T}^{m}$, derived from Eq. (83):

$$
\hat{G}_{T}^{m}=\hat{G}_{T}^{m-1}+\frac{g_{c} \Delta t^{m}}{L_{T}}\left(\Delta p_{t a}\right)_{T}^{m-1}
$$

where the quantity, $\left(\Delta p_{t a}\right)_{T}^{m-1}$, represents the transient acceleration pressure drop over time step $\Delta t^{m}$. After determining $\widehat{G}_{T}^{m}$ from Eq. (98), the channel inlet mass flow rate, $G_{1}^{m}$, is calculated from the expression

$$
G_{1}^{m}=\frac{L_{T} \hat{G}_{T}^{m}+L_{F} \hat{\delta}_{T}^{m}-\left(\alpha_{E} L_{E}+P_{E}\right) G_{N Z}^{m-1}}{L_{F} \hat{\sigma}_{T}^{m}+\left(\alpha_{I} L_{I}+P_{I}\right)}
$$

where

$$
\begin{gathered}
\hat{\delta}^{m}=\frac{1}{2 L_{F}} \sum_{j=2}^{N Z} \Delta Z_{j-1}\left(\delta_{j}^{m}+\delta_{j-1}^{m}\right) \\
\hat{\sigma}^{m}=\frac{1}{2 L_{F}} \sum_{j=2}^{N Z} \Delta Z_{j-1}\left(\sigma_{j}^{m}+\sigma_{j-1}^{m}\right) \\
\delta_{j}^{m}=\gamma_{j-\frac{1}{2}}^{m} \delta_{j-1}^{m}+\beta_{j-\frac{1}{2}}^{m} \frac{q_{j-\frac{1}{2}}^{m}}{r_{h}} \\
\sigma_{j}^{m}=\gamma_{j-\frac{1}{2}}^{m} \sigma_{j-1}^{m}
\end{gathered}
$$




$$
\left.\begin{array}{l}
\sigma_{1}^{m}=1 \\
\delta_{1}^{m}=0
\end{array}\right\}
$$

After determining $G_{1}^{m}$ from Eq. (99) for the pressure-drop-forced problem, Eq. (91) is used to calculate the other $G_{j}^{m}$ existing along the length of the channel.

In the flow-forced problem, the channel average mass velocity, $\widehat{G}_{T}^{m}$, is calculated from the equation:

$$
\hat{G}_{T}^{m}=\frac{1}{2 L_{T}}\left(2\left(\alpha_{I} L_{I}+P_{I}\right) G_{1}^{m}+\sum_{j=2}^{N Z} \Delta Z_{j}\left(G_{j}^{m}+G_{j-1}^{m}\right)+2\left(\alpha_{E} L_{E}+P_{E}\right) G_{N Z}^{m}\right)
$$

This average velocity is then used in conjunction with Eq. (98) to determine the transient acceleration pressure drop, $\Delta p_{t a}$.

\subsubsection{Conservation of Energy}

Fluid enthalpies at interior axial node points are calculated in the transient situation from a so-called "four points explicit" difference representation [25] of Eq. (81) for the conservation of energy in the coolant channel. This difference equation is given by

$$
\begin{aligned}
H_{j}^{m}=H_{j}^{m-1}+ & {\left[\frac{H_{j-1}^{m-1}-H_{j+1}^{m-1}}{\eta_{j}^{m-1}}\right]+\frac{D Z_{j}}{\eta_{j}^{m-1}}\left(\frac{2}{\eta_{j+\frac{1}{2}}^{m-1}} \frac{H_{j+1}^{m-1}-H_{j}^{m-1}}{\Delta Z_{j+1}}-\frac{2}{\eta_{j-\frac{1}{2}}^{m-1}} \frac{H_{j}^{m-1}-H_{j-1}^{m-1}}{\Delta Z_{j}}\right) } \\
& +\frac{\Delta t^{m}}{r_{h}}\left(\frac{1}{2 \eta_{j}^{m-1}}\left[\frac{q_{j}^{m-1}+q_{j-1}^{m-1}}{\left(\rho^{\prime \prime}\right)_{j-\frac{1}{2}}^{m-1}}-\frac{q_{j+1}^{m-1}+q_{j}^{m-1}}{\left(\rho^{\prime \prime}\right)_{j+\frac{1}{2}}^{m-1}}\right]\right. \\
& \left.+\frac{q_{j}^{m-1}}{\left(\rho^{\prime \prime}\right)_{j}^{m-1}}\left[\frac{\phi^{m}}{\phi^{m-1}}-1\right]\right) \frac{W_{F}}{2 W_{p}}
\end{aligned}
$$

where

$$
\begin{aligned}
& \eta_{j}^{m-1}=\frac{2 D Z_{j}\left(\rho^{\prime \prime}\right)_{j}^{m-1}}{\Delta t^{m} G_{j}^{m-1}} \\
& \eta_{j-\frac{1}{2}}^{m-1}=\frac{2 D Z_{j}\left(\rho^{\prime \prime}\right)_{j-\frac{1}{2}}^{m-1}}{\Delta t^{m} G_{j-\frac{1}{2}}^{m-1}} \\
& \eta_{j+\frac{1}{2}}^{m-1}=\frac{2 D Z_{j}\left(\rho^{\prime \prime}\right)_{j+\frac{1}{2}}^{m-1}}{\Delta t^{m} G_{j+\frac{1}{2}}^{m-1}} \\
& D Z_{j}=\frac{1}{2}\left(\Delta Z_{j}+\Delta Z_{j+1}\right)
\end{aligned}
$$

and $q_{j}^{m}$ is defined in conjunction with Eq. (91).

Equation (106) is stable [26] for 


$$
\left|\frac{2}{\eta_{j}^{m}}\right| \leq 1
$$

which imposes the hydrodynamic time step criterion:

$$
\Delta t^{m} \leq \min _{j=2, N Z}\left(\frac{\left(\rho^{\prime \prime}\right)_{j}^{m} D Z_{j}}{\left|G_{j}^{m}\right|}\right)
$$

This is the maximum time step that can be used if the enthalpy calculations are to remain stable.

Fluid enthalpies at the two end points of a channel are determined from:

$$
\begin{gathered}
\text { 1. } \mathbf{j}=\mathbf{1}, \boldsymbol{G}_{\mathbf{1}}^{\mathbf{m}-\mathbf{1}} \geq \mathbf{0} \\
H_{1}^{m}=\text { specified value } \\
\mathbf{2} \cdot \boldsymbol{j}=\mathbf{1}, \boldsymbol{G}_{\mathbf{1}}^{\mathbf{m}-\mathbf{1}}<\mathbf{0} \\
H_{1}^{m}=H_{1}^{m-1}-\frac{\Delta t^{m}}{2\left(\rho^{\prime \prime}\right)_{j+\frac{1}{2}}^{m-1}}\left(\frac{G_{1}^{m-1}+G_{2}^{m-1}}{\Delta Z_{2}}\left(H_{2}^{m-1}-H_{1}^{m-1}\right)\right. \\
\left.-\frac{q_{2}^{m-1}+q_{1}^{m-1}}{r_{h}}\left(\frac{\phi^{m}}{\phi^{m-1}}+1\right) \frac{W_{F}}{2 W_{p}}\right) \\
H_{N Z}^{m}=H_{N Z}^{m-1}-\frac{\Delta t^{m}}{2\left(\rho^{\prime \prime}\right)_{N Z-\frac{1}{2}}^{m-1}}\left(\frac{G_{N Z}^{m-1}+G_{N Z-1}^{m-1}}{\Delta Z_{N Z}}\left(H_{N Z}^{m-1}-H_{N Z-1}^{m-1}\right)\right. \\
\left.-\frac{q_{N Z}^{m-1}+q_{N Z-1}^{m-1}}{r_{h}}\left(\frac{\phi^{m}}{\phi^{m-1}}+1\right) \frac{W_{F}}{2 W_{p}}\right) \\
\mathbf{4} \cdot \boldsymbol{j}=\mathbf{N Z}, \boldsymbol{G}_{N Z}^{m-1} \leq \mathbf{0} \\
H_{N Z}^{m}=H_{N Z}^{m-1}
\end{gathered}
$$

In the special case of steady state, the original equation for conservation of energy reduces to

$$
G \frac{\partial H}{\partial Z}=\frac{q}{r_{h}}
$$

The difference equation reduces, accordingly to

$$
H_{j}^{0}=H_{j-1}^{0}+\frac{\Delta Z_{j}}{r_{h} G_{j}^{0}} \frac{q_{j}^{0}+q_{j-1}^{0}}{2} \frac{W_{F}}{W_{p}}, j=2, \ldots, N Z
$$

\subsubsection{Conservation of Momentum}

Local pressures and channel pressure drop are calculated from Eq. (80) for the conservation of momentum. This equation is represented in PARET/ANL by

$$
\Delta p_{T}^{m}=F+\left(\Delta p_{t a}\right)_{T}^{m}
$$


In Eq. (119), $\Delta p_{T}^{m}$ represents the total pressure drop across a channel at time node $\mathrm{m}$, and $\left(\Delta p_{t a}\right)_{T}^{m}$ represents the corresponding transition acceleration pressure drop. The latter of these two quantities is calculated on the basis of the change in channel average mass flow rate across the time step $\Delta t^{m}$, according to Eq. (98)

$$
\left(\Delta p_{t a}\right)_{T}^{m-1}=\frac{L_{T}}{g_{c} \Delta t^{m}}\left[\widehat{G}_{T}^{m}-\hat{G}_{T}^{m-1}\right]
$$

Calculation of $\hat{G}_{T}^{m}$ is illustrated in Eq. (105). The quantity F represents the sum of the frictional, elevation, and spatial acceleration pressure drops

$$
F=\left(\Delta p_{f}\right)_{T}^{m}+\left(\Delta p_{e l}\right)_{T}^{m}+\left(\Delta p_{s a}\right)_{T}^{m}
$$

where

$$
\begin{gathered}
\left(\Delta p_{f}\right)_{T}^{m}=\frac{1}{g_{c}}\left[\frac{1}{2} K_{c}+\frac{\alpha_{I}^{2} f_{I} L_{I}}{2(D e)_{I}}+\frac{f_{I} P_{I}}{2 D e}\right]\left[v_{1}^{m}\left|G_{1}^{m}\right| G_{1}^{m}\right] \\
+\frac{1}{4 D e g_{c}} \sum_{j=2}^{N Z} \Delta Z_{j}\left([f v|G| G]_{j}^{m}+[f v|G| G]_{j-1}^{m}\right) \\
+\frac{1}{g_{c}}\left[\frac{1}{2} K_{E}+\frac{\alpha_{E}^{2} f_{E} L_{E}}{2(D e)_{E}}+\frac{f_{E} P_{E}}{2 D e}\right]\left[v_{N Z}^{m}\left|G_{N Z}^{m}\right| G_{N Z}^{m}\right] \\
\left(\Delta p_{e l}\right)_{T}^{m}=\frac{g}{g_{c}} \bar{\rho}_{1}^{m}\left(L_{I}+P_{I}\right)+\frac{g}{g_{c}} \sum_{j=2}^{N Z} \Delta Z_{j}\left(\bar{\rho}_{j}^{m}+\bar{\rho}_{j-1}^{m}\right)+\frac{g}{g_{c}} \bar{\rho}_{N Z}^{m}\left(L_{E}+P_{E}\right) \\
\left(\Delta p_{s a}\right)_{T}^{m}=\frac{1}{2 g_{c}}\left(1-\alpha_{1}^{2}\right) v_{1}^{m}\left(G_{1}^{m}\right)^{2}-\frac{1}{g_{c}}\left(v^{\prime}\right)_{1}^{m}\left(G_{1}^{m}\right)^{2}-\frac{1}{2 g_{c}}\left(1-\alpha_{E}^{2}\right) v_{N Z}^{m}\left(G_{N Z}^{m}\right)^{2} \\
+\frac{1}{g_{c}}\left(v^{\prime}\right)_{N Z}^{m}\left(G_{N Z}^{m}\right)^{2}
\end{gathered}
$$

The quantity, $v^{\prime}$, appearing in Eq. (124), is an effective slip-flow specific volume for momentum considerations, and is given by

$$
\left(v^{\prime}\right)_{j}^{m}=\frac{\left(1-X_{j}^{m}\right)^{2}}{\left(\rho_{l}\right)_{j}^{m}\left(1-R_{j}^{m}\right)}+\frac{\left(X_{j}^{m}\right)^{2}}{\rho_{g} R_{j}^{m}}
$$

Intermediate pressures along the length of each channel are calculated on the basis of the known system pressure and appropriate calculated pressure differences.

\subsubsection{Estimation of Vapor Volume Fraction}

PARET/ANL contains the option of either estimating the vapor volume fraction formed during subcooled boiling or assuming it to be zero for conditions other than saturated boiling. The vapor volume fraction is estimated in the former case according to a simplified form of Zuber's Eq. [21]

$$
\frac{\partial R}{\partial t}+C_{2} V \frac{\partial R}{\partial Z}+\frac{R}{\tau}=\lambda K\left(q^{\prime \prime}\right)^{n}
$$

where $\mathrm{R}$ represents the vapor volume fraction; $\mathrm{Z}$ and $\mathrm{t}$ are the position and time variables, respectively; V represents the fluid linear velocity; q" represents the surface heat flux; and $C_{2}, \tau, \lambda, K$ and $n$ are constants. The parameter $\tau$ represents the bubble collapse time, and $\lambda$ represents 
the fraction of the clad surface heat flux which is utilized in producing vapor during boiling. Both of these parameters are supplied as input to the code by the user. Recommended values for use in both the highly subcooled and slightly subcooled regions are given in [25].

PARET/ANL employs a four point explicit difference representation of Eq. (126) for calculating the vapor volume fraction. This difference equation for the $\mathrm{j}^{\text {th }}$ interior node is given by

$$
\begin{aligned}
R_{j}^{m}=\frac{1}{1+\mu}\left(R_{j}^{m-1}\left[1-\mu-\beta_{j}^{m}\left(\gamma_{j+1}^{m-1}+\delta_{j}^{m-1}\right)\right]+R_{j-1}^{m-1} \beta_{j}^{m-1}\left[1-\mu+\delta_{j}^{m-1}\right]\right. \\
\quad+R_{j+1}^{m-1} \beta_{j}^{m-1}\left[\mu-1+\gamma_{j+1}^{m-1}\right] \\
\left.\quad+\frac{\lambda K \Delta t^{m}}{2}\left[\theta_{j}^{m}+\theta_{j}^{m-1}-\beta_{j}^{m-1}\left(\theta_{j+1}^{m-1}-\theta_{j-1}^{m-1}\right)\right]\right) ;, j=2, \ldots, N Z-1
\end{aligned}
$$

where

$$
\begin{gathered}
\mu=\frac{\Delta t^{m}}{2 \tau} \\
\beta_{j}^{m-1}=\frac{\mathrm{C}_{2} \mathrm{~V}_{\mathrm{j}}^{\mathrm{m}-1} \Delta t^{m}}{2 D Z_{j}} \\
\delta_{j}^{m-1}=\frac{\Delta t^{m} C_{2} V_{j-\frac{1}{2}}^{m-1}}{\Delta Z_{j}} \\
\gamma_{j+1}^{m-1}=\frac{\mathrm{C}_{2} \mathrm{~V}_{\mathrm{j}+\frac{1}{2}}^{\mathrm{m}-1} \Delta t^{m}}{\Delta Z_{j+1}} \\
\theta_{j}^{m-1}=\left[\left(q^{\prime \prime}\right)_{j}^{m-1}\right]^{n}
\end{gathered}
$$

The two extreme nodes at the entrance and exit to a channel $(j=1$ and $j=N Z$ ) require special consideration under transient conditions

$j=1, G_{1}^{m-1} \geq 0$

$$
\begin{gathered}
R_{1}^{m}=0 \\
\boldsymbol{j}=\mathbf{1}, \boldsymbol{G}_{\mathbf{1}}^{\mathbf{m - 1}}<\mathbf{0} \\
R_{1}^{m}=\frac{1}{1+\mu}\left(R_{1}^{m-1}\left[1-\mu-\eta_{1}^{m-1}\right]+\eta_{1}^{m-1} R_{2}^{m-1}+\frac{\lambda K \Delta t^{m}}{2}\left[\theta_{1}^{m}+\theta_{1}^{m-1}\right]\right) \\
\boldsymbol{j}=\mathbf{N Z}, \boldsymbol{G}_{N Z}^{\mathbf{m}-\mathbf{1}}>\mathbf{0} \\
R_{N Z}^{m}=\frac{1}{1+\mu}\left(R_{N Z}^{m-1}\left[1-\mu-\eta_{N Z}^{m-1}\right]+\eta_{N Z}^{m-1} R_{N Z-1}^{m-1}+\frac{\lambda K \Delta t^{m}}{2}\left[\theta_{N Z}^{m}+\theta_{N Z}^{m-1}\right]\right) \\
\boldsymbol{j}=\mathbf{N Z}, \boldsymbol{G}_{N Z}^{\mathbf{m}-\mathbf{1}} \leq \mathbf{0} \\
R_{N Z}^{m}=0
\end{gathered}
$$

where 


$$
\eta_{j}^{m-1}=\frac{C_{2} V_{j}^{m-1} \Delta t^{m}}{\Delta Z_{j}} \text { for } \mathrm{j}=1 \text { and NZ }
$$

For the special case of steady state, vapor volume fractions are calculated from

$$
R_{j}^{0}=\frac{\tau C_{2} V_{j}^{0} R_{j-1}^{0}+\lambda K \tau \Delta Z_{j} \theta_{j}^{0}}{\tau C_{2} V_{j}^{0}+\Delta Z_{j}}
$$

In the steady-state situation, it is assumed that the value of the vapor volume fraction at the channel entrance is zero.

Having calculated the value of $\mathrm{R}$, the mass flow fraction of vapor, $\mathrm{X}$, is obtained by table lookup, on the basis of the Martinelli-Nelson correlation [22].

In the case of saturated boiling, the mass flow fraction of vapor is obtained directly from the mixingcup enthalpy, according to the Eq. (140):

$$
X=\frac{H-H_{f}}{H_{f g}}
$$

In this case, having calculated $\mathrm{X}$, the vapor volume fraction is obtained by table lookup, on the basis of the Martinelli-Nelson correlation [22].

\subsubsection{Friction Factor Correlations}

PARET/ANL uses the Martinelli-Nelson method [23] to predict two-phase pressure drop in the case of saturated boiling and relationships developed at Westinghouse [24] to evaluate subcooled twophase and single-phase pressure drop. The various relationships employed in evaluating the friction factor are given below.

Liquid heating and cooling, Re $<2000$, for IGEOM=1. Note that the coefficient in Eq.(140 becomes 96 for IGEOM=0 or 2 .

$$
f=\frac{64}{\operatorname{Re}}
$$

where

$$
\operatorname{Re}=\frac{\operatorname{De}|G|}{\mu}
$$

A correction factor, fhw, is computed that scales $\mathrm{f}$ for $\mathrm{Re}<2000$. It is obtained from the following equation in which " $w$ " refers to the wall temperature, and " $b$ " refers to the bulk coolant temperature.

$$
\text { fhw }=(\mu \mathrm{w} / \mu \mathrm{b}) 0^{.54}
$$

\subsubsection{Liquid heating and cooling, $\operatorname{Re}>2000$

$$
f=\left(\frac{f}{f_{\text {iso }}}\right) f_{\text {iso }}
$$

where 


$$
\begin{gathered}
f_{\text {iso }}=1-a_{5} \Delta u_{f} \\
\Delta u_{f}=a_{6} \frac{q^{\prime \prime}}{h} \\
f_{\text {iso }}=a_{0} R e^{a_{1}}, \text { for } \operatorname{Re}<a_{2} \\
f_{\text {iso }}=a_{3} R e^{a_{4}, \text { for } \operatorname{Re} \geq a_{2}}
\end{gathered}
$$

\subsubsection{Subcooled nucleate boiling}

Use Eqs. (142), (145), (146) and the minimum of Eqs. (147) and (148)

$$
\begin{gathered}
\left(\frac{f}{f_{\text {iso }}}\right)=1+a_{8} \frac{a_{9} \Delta u_{f}-u_{s}^{\prime}+u_{b}}{a_{9} \Delta u_{f}-u_{s}^{\prime}+u_{\text {sat }}} \\
\left(\frac{f}{f_{\text {iso }}}\right)=a_{10}
\end{gathered}
$$

\subsubsection{Subcooled transition and film boiling}

Use Eqs. (142), (145), (146) and the minimum of Eqs. (148) and (149)

$$
\left(\frac{f}{f_{\text {iso }}}\right)=1+a_{8} \frac{u_{s}-u_{s}^{\prime}}{u_{s}-u_{s}^{\prime}+u_{s a t}-u_{b}}
$$

\section{Saturated boiling, low qualities $\left(X<a_{11}\right)$}

Use the maximum of Eqs. (150) and (151)

$$
\begin{aligned}
& f=\left(f_{\text {iso }}\right)_{s a t} \phi_{L 0}^{2} \\
& f=\left(f_{\text {iso }}\right)_{\text {sat }} a_{10}
\end{aligned}
$$

In Eqs. (150) - (151), $\left(f_{\text {iso }}\right)_{\text {sat }}$ is calculated according to Eqs. (145) - (146) for $f_{\text {iso, }}$, except that the Reynolds number is calculated, in this case from

$$
\operatorname{Re}=\frac{\operatorname{De}|G|}{\mu_{\text {sat }}}
$$

where $\mu_{\text {sat }}$ is the viscosity of the saturated liquid.

Saturated boiling, intermediate qualities $\left(\boldsymbol{a}_{11} \leq X \leq \boldsymbol{a}_{12}\right)$

$$
f=\left(f_{\text {iso }}\right)_{s a t} \phi_{L 0}^{2}
$$

Saturated boiling, high qualities ( $\boldsymbol{X}>\boldsymbol{a}_{\mathbf{1 2}}$ where $\boldsymbol{a}_{\mathbf{1 2}}$ is the highest quality in the $\boldsymbol{\phi}_{\boldsymbol{L} \mathbf{0}}^{2}$ table)

$$
\begin{gathered}
f=\left(f_{\text {iso }}\right)_{\text {sat }}\left(\phi_{L 0}^{2} a_{12}-\left[\phi_{L 0}^{2} a_{12}-\frac{\rho_{f}}{\rho_{g}}\left(\frac{\mu_{f}}{\mu_{g}}\right)^{a_{1}}\right] \frac{X-a_{12}}{1.0-a_{12}}\right), \\
\text { for } \operatorname{Re}<a_{2}\left(\operatorname{Re} \text { based on } \mu_{\text {sat }}\right)
\end{gathered}
$$




$$
\begin{gathered}
f=\left(f_{\text {iso }}\right)_{\text {sat }}\left(\phi_{L 0}^{2} a_{12}-\left[\phi_{L 0}^{2} a_{12}-\frac{\rho_{f}}{\rho_{g}}\left(\frac{\mu_{f}}{\mu_{g}}\right)^{a_{4}}\right] \frac{X-a_{12}}{1.0-a_{12}}\right), \\
\text { for } \operatorname{Re} \geq a_{2}\left(\operatorname{Re} \text { based on } \mu_{\text {sat }}\right)
\end{gathered}
$$

where $\phi_{L 0}^{2}$ is evaluated at $X=a_{12}$.

\section{Superheated vapor}

$$
f=f_{\text {iso }}
$$

where $f_{\text {iso }}$ is evaluated from Eqs. (145) - (146) using

$$
R e=\frac{D e|G|}{\mu_{v}}
$$

and $\mu_{v}$ represents the viscosity of the superheated vapor.

In all the above correlations containing $\phi_{L 0}^{2}$, this quantity (a function of $\mathrm{X}, \mathrm{G}$, and $\mathrm{p}$ ) is obtained by table lookup.

The various constants appearing in the foregoing pressure drop correlations have the following values in PARET:

$$
\begin{array}{ll}
a_{0}=0.2108160 & a_{7}=60 \\
a_{1}=-0.213727 & a_{8}=\left(\phi_{L O}^{2} \text { at } 4.2 \% \text { quality }\right)-1 \\
a_{2}=10^{5} & a_{9}=1.0 \\
a_{3}=0.1137 & a_{10}=\phi_{L O}^{2} \text { at } 4.2 \% \text { quality } \\
a_{4}=-0.160608 & a_{11}=0.50 \\
\mathrm{~A}_{5}=0.0013 & a_{12}=1.0 \\
a_{6}=0.766 &
\end{array}
$$

According to Westinghouse [24], the foregoing correlations provide a reasonable estimate of the friction factor, but their development has indicated the following primary areas of uncertainty:

Transition boiling and film boiling

Condensing of steam and vapor

Carryover of vapor and liquid upon entering and leaving the two-phase region

Superheating and de-superheating with high film temperature drops

They point out further that the acquisition of sufficient data to resolve the problem areas will probably require extensive steady-state and transient experimental work. 


\section{Time Step Control and Code Running Time}

Table 14 provides for specification of time increment as a function of time. At each time node, a comparison is made between this input-specified time step and the maximum time step allowed by the hydrodynamics (Eq. (112)). The code will always use the smaller of the two in order to maintain stability of the enthalpy calculations. The neutron kinetics calculations are carried out using whichever of these two time steps is accepted. If a neutronics error criterion is violated using this time step (see Eqs. (21) - (27) and succeeding discussion), it is automatically halved and the neutron kinetics calculations repeated. This procedure is continued until the error criterion is satisfied. If the original time step must be reduced for the neutron kinetics calculations, this reduced time step may be used for the thermal and hydrodynamics calculations as well. Or, at the user's option, the neutron kinetics calculations may be repeated a number of times sufficient for spanning the input-specified or hydrodynamics-specified time step. 


\section{Input Description for PARETIANL}

The FORTRAN input processor routine imposes certain restrictions on the input and requires an additional scratch file (FORTRAN Unit 2) to contain each card image as it is processed. The card input following the card type number (a four or five digit number followed by a comma) must be blocked in fields of 12 columns beginning with column 7. Each field may contain either one floating point number (E12.5 format) or up to two integers (2I6 format). All floating point numbers must include a decimal point. For mixtures of floating point numbers and single or odd numbers of integer entries, a blank field of 6 column must be added with the single or last integer so that the next floating point number starts in the next proper field of 12. Each card can contain a maximum of 6 floating point numbers or 12 fixed point numbers through column 78. Embedded blank fields are allowed unless further restrictions are imposed and in some cases required as noted above. The card input format is further structured to some extent by card type (See sample problem input, APPENDIX V). The initial integer entries on the 1000 series cards must be entered on card types 1001 and 1002 (card type 1002 must be omitted if all 12 integers are on card 1001), and the floating entries for the 1000 series start on 1003 and continue on additional cards in the series as needed. The 1112 card type must have 5 integer entries (with the odd number of integers a blank field of 6 must be imbedded) followed by 3 floating point numbers. The 4000 series cards must have pairs of entries consisting of one floating point number with a maximum of three sets per card. The $5 \mathrm{~N} 00$ card(s) present special problems.

The second entry may be either an integer number or a floating point number depending on the problem specified.

The amount of data in the fixed format scheme requires a second card.

Thus, if the second entry is an integer, the usual packing rules apply and five floating point numbers follow with three floating point numbers entered on an additional $5 \mathrm{~N} 00$ card. However, if the second entry is floating point, a blank field of 6 must follow the integer entry and again five floating point entries follow but now the second card must contain four floating point entries. Embedded blank fields, unless required, are not allowed on the $5 \mathrm{~N} 00$ cards. The remaining card types may be entered following only the general rules described above.

For user convenience, an input file pre-processor was created to permit placing comment lines anywhere in the input file. Simply place an exclamation mark (!) in column 1, and any text following that line will be ignored. One can also place the exclamation mark at any column. Then the card image is copied up to the exclamation mark, and the remainder is treated as blanks. This feature can be used to identify key variables, or to denote changes from other similar runs. It makes an input file much easier to review and verify. The pre-processor creates a temporary copy of the user's input file, without the comment lines or comments.

An example of the modified input format and the IAEA benchmark problem with SI units is shown in Section 13.

The following is an item-by-item description of the input file. It is arranged in 16 sections plus a restart Section. The user may choose between SI or English units. Variables with dimensions of length only are to be assumed to be in feet (ft) or meters (m). Units for all other dimensioned input variables are given below in both systems. 


\subsection{Problem Type and Restart Data}

Any problem begins with this data card. The restart option is functional since V7.5. Since many arrays are now variably dimensioned, it is now necessary upon restart to supply card type 1001 with NCHN, $\mathrm{NZ}$, and NR on it ahead of 14000 cards (or 14000 plus 16000 cards). The user must supply all cards from 1001 to 1099 . Then, if desired, supply the 14000 , or 14000 and 16000 cards.

First input card (precedes the "* title" card) must be provided exactly in the identified format in order for default values to be assigned:

IRSTRT,IFREQ,ICHNG,NFILE, TTIME,IFLUID,INAME,JPROP,NLUP2,IDBL,INORM,IOPT

Format $(4 \mathrm{I} 6, \mathrm{E} 12.4,7 \mathrm{I} 6)$

\begin{tabular}{|c|c|c|}
\hline \multirow[t]{2}{*}{ IRSTRT } & 0 & Initial problem (default) \\
\hline & 1 & Restart problem \\
\hline \multirow[t]{2}{*}{ IFREQ } & 0 (or blank) & Write restart file every 50000 steps (default) \\
\hline & $\mathrm{N}$ & Write restart file every n steps \\
\hline \multirow[t]{3}{*}{ ICHNG } & 0 (or blank) & No table changes (default) \\
\hline & 1 & Time step data revision (Table 14 input follows) \\
\hline & 2 & $\begin{array}{l}\text { Time step and edits data revised (Table } 14 \text { and } \\
\text { Table } 16 \text { input follows) }\end{array}$ \\
\hline \multirow[t]{3}{*}{ NFILE } & Blank & Default (IRSTRT $=0$ ) \\
\hline & 12 or 14 & Desired file number (IRSTRT $=1$ ) \\
\hline & & $\begin{array}{l}\text { Restart data is alternately written to units } 12 \\
\text { (RESTRT1) and } 14 \text { (RESTRT2). (default 12) }\end{array}$ \\
\hline TTIME & & New time limit for transient (optional); reset if $>0$. \\
\hline \multirow[t]{4}{*}{ IFLUID } & $0, \mathrm{H}_{2} \mathrm{O}$ & $\begin{array}{l}\text { Automatic generation of coolant library tables for } \\
\text { light water (default }=0 \text { ) }\end{array}$ \\
\hline & $1, \mathrm{D}_{2} \mathrm{O}$ & $\begin{array}{l}\text { Automatic generation of coolant library tables for } \\
\text { heavy water }\end{array}$ \\
\hline & $2, \mathrm{H}_{2} \mathrm{O}$ & Use existing file H2O.lib \\
\hline & $3, \mathrm{D}_{2} \mathrm{O}$ & Use existing file D20.lib \\
\hline \multirow[t]{2}{*}{ INAME } & 0 & Old input format type \\
\hline & 1 & NAMELIST format type (not available) \\
\hline JPROP & 0 & This parameter is no longer used. \\
\hline NLUP2 & $0 / 1$ & $\begin{array}{l}1 \text { if an external coolant loop is to be modeled; else } \\
0 \text {. (see further down for additional cards required } \\
\text { by the external coolant loop model) }\end{array}$ \\
\hline IDBL & 0 & This parameter is no longer used \\
\hline INORM & 0 & run the problem, renormalizing power if needed \\
\hline
\end{tabular}


check power normalization and run without normalization if the error < 1.E-4; issue a warning if the error is between 1.E-4 and 1.E-2, renormalize, and run; otherwise terminate.

IOPT

do not optimize axial mesh

If NLUP2=1, the following external loop data are needed: Format (6E12.5)

\begin{tabular}{|l|l|}
\hline VLUP & Volume of primary loop water, $\mathrm{m}^{3}$ \\
\hline ALUP & Area of contact between primary and secondary loop or pool, $\mathrm{m}^{2}$ \\
\hline V2LUP & Volume of secondary loop or pool, $\mathrm{m}^{3}$ \\
\hline ASURF & Area of secondary pool, $\mathrm{m}^{2}$ \\
\hline T2LUP & Bulk temperature of secondary pool, C \\
\hline T2AIR & Air temperature over pool, C \\
\hline
\end{tabular}

If NLUP2=1, the following external loop data are needed: Format (5E12.5)

\begin{tabular}{|l|l|}
\hline VAIR & Velocity of air over pool, ft/s \\
\hline HUM & Humidity of air over pool, \% \\
\hline WALLH & $\begin{array}{l}\text { Heat transfer coefficient for heat flow from primary to secondary } \\
\text { loop, } \\
\mathrm{W} / \mathrm{m}^{2} \mathrm{~K}\end{array}$ \\
\hline PR2LUP & $\begin{array}{l}\text { Pressure (nominal) of primary and secondary external loops, Pa } \\
\text { Feactivity, } \$ / \text { degree } \mathrm{C}, \text { from bulk heatup of the radial reflector } \\
\text { (assumed to be at the bulk temperature of the primary loop, T1LSI). } \\
\text { DKPRIM=FBREF*(T1LSI-TINLET1) }\end{array}$ \\
\hline
\end{tabular}

For the initial problem only a blank card image is required if the default frequency for writing a restart file every 50000 steps is desired. For a restart problem, only IRSTRT=1 must be set. Restart data will be taken either from unit 12 or from unit 14 with no changes imposed, and no other input is required.

If TTIME is non-zero, the transient time is reset to that value at restart. IFREQ may also be changed at restart.

If $I C H N G=0$, no further input data is required.

If ICHNG is non-zero, card type 1001 must first be provided. Then Table 14 data must be provided (even if no change is made in the time step data). If ICHNG is 2, Table 16 data must also be provided. The format for these tables is identical to the original 14000 and 16000 series PARET/ANL input data. 
At this time no other input data may be changed at restart. For multiple cases, only one Restart card is expected. Succeeding cases begin with a new Title Line.

\subsection{Title Line}

A title line must precede each problem set of data. The format of the title line is as follows:

(1) An asterisk $\left(^{*}\right)$ in column 1.

(2) An identifying title in columns 2 through 60.

\subsection{General Information}

The data lines immediately following the title line are of the format (80 columns):

$10 Y Y, X_{1}, X_{2}, \ldots, X_{n}$ where $Y Y=01,02, \ldots, 99$ and $X_{i}, i=1,2, \ldots, n$ are the data (items)

Notes: (a) Each line must contain at least one word (item) in addition to the line number.

(b) Data must be listed in required order (1 through 12 must be integers, and 13 through 47 must be floating point.)

(c) Data may be followed by a comment. Simply place an asterisk $\left({ }^{*}\right)$ after the last data entry, and use the remainder of the line for any text comment. See Section 7 for all input rules.

(d) See Section 5 for detailed Input Description rules that apply to all subsequent input parameters and Card Types.

$\begin{array}{ll}\text { ITEM } & \text { FORTRAN } \\ & \text { VARIABLE } \\ 1 & \text { NCHN }\end{array}$

DESCRIPTION

The number of channels, NCHN, where $1 \leq \mid$ NCHN $\mid \leq 120$. This is the number of regions into which the core is subdivided. If NCHN is positive, the code assumes all input to follow will be in United States Customary units $\left(\mathrm{ft}, \mathrm{lb}_{\mathrm{m}}, \mathrm{Btu}, \mathrm{psi},{ }^{\circ} \mathrm{F}, \mathrm{hr}\right)$. If negative, SI units are assumed $(\mathrm{m}, \mathrm{kg}, \mathrm{J}$, $\left.\mathrm{Pa},{ }^{\circ} \mathrm{K}, \mathrm{s}\right)$. Power is always in megawatts. Internal calculations are carried out in United States Customary units but output is printed in the same units as the input data. Thus if United States Customary units are used, input data are converted to SI units after the input data is echoed and output data is converted back to United States Customary units for printing. United States Customary units are assumed to be: time in hours when part of a complex unit such as mass flux and viscosity (e.g. lb/hr $\mathrm{ft}^{2}$; lb/ft $\mathrm{hr}$ ); length in $\mathrm{ft}$; mass in lb; pressure in psia; energy in Btu; temperature in $\mathrm{F}$.

$2 \quad \mathrm{NZ} \quad$ The number of axial node points, NZ, where $1 \leq \mathrm{NZ} \leq 97$. Type $5 \mathrm{k} 00$ logic as presently coded prevents NZ>97.

3 NR The number of radial node points, NR, in meat, gap and cladding combined in a fuel pin or half-plate where $2 \leq \mathrm{NR} \leq 43$. 
IGEOM

IPROP

IRXSWT

IPOP

(1)

10

ISUPPR
The geometry code: 0 for slab and 1 for cylindrical geometry; 2 for slab geometry with channels having more variability than for IGEOM=0.

The operation code: 0 for power-level-specified and 1 for reactivityspecified (see Table 9000 definition). If 0, omit Table 6000.

Vapor fraction and quality option. A zero indicates the assumption that subcooled $\mathrm{R}=\mathrm{X}=0$ where $\mathrm{R}$ and $\mathrm{X}$ are the void fraction and quality, respectively. An entry of 1 allows the code to calculate values of $R$ and $X$ in both the sub-cooled and saturation regions.

Coolant pressure code: 0 for the inlet pressure level being specified (see item 15), and 1 for outlet pressure level being specified. Affects only the pressure values being reported in the output. These values are for information purpose only since they are not used as part of the solution.

Kinetics time step parameter: 0 for reduce and expand, 1 for reduce only, and -1 for reduce only and force printout. In the zero option, the time step is reduced, when necessary, for the neutron kinetics calculations and then expanded to the input-specified or hydrodynamics-specified time step, whichever controls. An integral number of neutron kinetics time steps are contained in each inputspecified or hydrodynamics-specified time step. In the 1 option, the time step is reduced for the neutron kinetics calculations, whenever necessary, and this same time step is used for the other calculations (thermal and hydrodynamic), as well. The -1 option is the same as the 1 option except that the printout is forced whenever time step reduction is affected. Reactivity feedback to the neutronics is computed in conjunction with the thermal-hydraulics calculations, and the first estimate of feedback at any particular time node is necessarily based on an extrapolation (since the value is needed prior to the thermalhydraulics calculations). Therefore, at any time node at which only neutronics calculations are made (zero option), the value of the reactivity is obtained by extrapolation rather than direct calculation. Therefore, the zero option should be used with caution. A value of 2 may also be used for slow reactivity insertion transients that show some irregularity in the kinetics solution.

The number of delayed neutron groups, where $1 \leq$ IDLYGP $\leq 30$.

Kinetics print parameter: 0 for no intermediate printout, 1 for printout after every input-specified or NPOFQ-th (see Section 7.15 describing Table 16 for definition of NPOFQ) hydrodynamics-specified time step, and -1 for printout by subroutine TRANSS includes time, reactor power, reactivity, the maximum outlet flow rate of all channels, and average reactor period.

Average temperature printout option. A zero yields no average temperature printout. For an entry of $>0$, average temperatures for each of the various regions (e.g. fuel, gap or insulator, and clad) are printed for each axial node of each channel at every ISUPPR time node. These temperatures represent the volumetric average temperatures averaged radially for each of the axial sections, and their printout precedes the 
12 MAXHCC

13 POWER

14 PF

15 PRESUR

16

ENTHIN

17

18

19

$20 \quad$ PW

$21 \quad$ FW

22

23
AL

RS

$\mathrm{RF}$

RC

PW
FW

ALDDIN detailed printout for the time node to which they apply. If ISUPPR $>0$, output file TBAR.out can be very large. Try using 1000 .

The maximum number of iterations through the heat transfer calculations at each axial node at any given time node. If MAXHCC $\leq 0$, the problem will terminate when the heat code iterations exceed $\mid$ MAXHCC $\mid$ at any axial node. If MAXHCC $>0$ and the heat code iterations exceed MAXHCC at any particular axial node, the problem continues, but the temperature printout at that node is accompanied by an asterisk (*). Furthermore, a printout is forced in such cases. This indicates a possible need for a finer radial mesh.

Initial reactor power, megawatts (>0). See card 1113 (OPT, POW0)

Total volume of fuel meat in the core.

Operating pressure (inlet or outlet), in pounds per square inch (formerly limited to between 14.7 and 50.0) or in Pa (1.0E5 and 3.4E5) for the default binary library. This is absolute pressure. The library is extended to higher pressure as needed, automatically. The nominal limits are $16.608 \mathrm{MPa}$ for $\mathrm{H}_{2} \mathrm{O}$, and 16.327 $\mathrm{MPa}$ for $\mathrm{D}_{2} \mathrm{O}$. Verification up to $14.5 \mathrm{MPa}$ is satisfactory for $\mathrm{H}_{2} \mathrm{O}$, and to $15.0 \mathrm{MPa}$ for $\mathrm{D}_{2} \mathrm{O}$.

Enthalpy of inlet coolant in units of Btu/lb or J/ $\mathrm{kg}(>0)$. At the users option, the inlet coolant temperature ( $\mathrm{C}$ or ${ }^{\circ} \mathrm{F}$ ) may be used in lieu of its enthalpy by entering the negative of that temperature. The code converts the temperature into the corresponding enthalpy and proceeds as usual. If the flow is negative or becomes negative (i.e., from top of core to bottom), the code senses this and estimates from the previous time step what the prescribed bottom value must be to obtain the desired value of the enthalpy at the top. This can lead to inaccurate inlet values when rapid changes occur such as the commencement of boiling in the channel.

Fuel pin radius or plate half-thickness (including clad).

Fuel radius or half-thickness. Items 17 and 18 must be in agreement with the radial description given on the 3000 series lines (Section 5.6).

Radial distance to inner surface of the clad or, for slab geometry, the half-distance to the inner surface of the clad. This is the same as item 18, unless another material (e.g. gas gap) lies between fuel and clad.

Plate width. Set to zero for cylindrical geometry.

Fuel width. Set to zero for cylindrical geometry. Items 20 and 21 must both be greater than zero for slab geometry and item 20 greater than or equal to item 21 .

Active fuel length must be in agreement with the axial description given on the 4000 series lines (Section 5.7).

Inlet non-fueled section length $(\geq 0)$.

Note: full hydraulic length $=$ ALPPIN + ALDDIN + AL+ALDDEX+ALPPEX 
$24 \quad$ ALDDEX

$25 \quad$ BBEFF

$26 \quad$ EL

$27 \quad$ GRAV

$28 \quad$ QW

Outlet non-fueled section length $(\geq 0)$. Items 23 and 24 refer to end sections of the fuel elements which contain no active fuel.

Effective delayed neutron fraction, $\beta(>0)$.

Prompt neutron generation time, $\mathrm{l}_{\mathrm{p}}$, in seconds $(>0)$.

Acceleration due to gravity, in units of $\mathrm{ft} / \mathrm{sec}^{2}$ or $\mathrm{m} / \mathrm{s}^{2}$

Heat source description for coolant (dimensionless and $\geq 0$ ). This parameter is the fraction of the heat generated in the coolant multiplied by the ratio of the fuel meat volume to the coolant volume. The heat is assumed to be deposited instantaneously (e.g. gamma heating). It is in addition to the power otherwise specified. To be consistent, one can use $\mathrm{QR}<1$ to place fraction $\mathrm{QR}$ of the heat generation in the fuel meat, and adjust QW such that

$\mathrm{QR}+\mathrm{QW} \cdot($ coolant volume $) /($ meat volume $)=1$.

Example: Direct Heating to the Coolant

Assume that fraction 0.06 of fission heat is delivered directly and instantaneously to the coolant. The following input parameters are defined:

IGEOM=0; $\mathrm{NCHN}=-2 ; \mathrm{AL}=0.5 \mathrm{~m}$

$\mathrm{RF}=0.0004 \mathrm{~m}$

$\mathrm{RC}=0.0004 \mathrm{~m}$

$\mathrm{RS}=0.0009 \mathrm{~m}$

$\mathrm{RN}($ channel 1$)=0.0019 \mathrm{~m} ; \mathrm{BM}($ channel 1$)=0.01$

$\mathrm{RN}($ channel 2) $=0.0020 \mathrm{~m} ; \mathrm{BM}($ channel 2$)=0.99$

$\mathrm{PW}=\mathrm{FW}=3.375 \mathrm{~m}$

$\mathrm{PF}=1.3500 \mathrm{E}-3 \mathrm{~m}^{3}$

Then the water volumes are $3.375 \mathrm{E}-3 \mathrm{~m}^{3}$ in channel 1 , and $3.7125 \mathrm{E}-3$ $\mathrm{m}^{3}$ in channel 2 . When scaled by BM, the water volumes in the reactor core are $3.375 \mathrm{E}-5$ and $3.675376 \mathrm{E}-3 \mathrm{~m}^{3}$. Hence the "TOTAL WATER VOLUME" edited by PARET/ANL is $3.70912 \mathrm{E}-3 \mathrm{~m}^{3}$. From these volumes one obtains

$$
\mathrm{QW}=0.06^{*}(1.3500 \mathrm{E}-3 / 3.70912 \mathrm{E}-3)=0.021838 \text {. }
$$

29 TRANST

Transient time, in seconds $(\geq 0)$. This is the total reactor time interval (not computation time) over which it is desired to investigate the transient. If zero, only a steady-state calculation will be made. IONEP=1, 2 , or 4 requires TRANST $>0$ before wall temperature effects can be computed.

30 RXXCON A constant, $\mathrm{C}_{2}$ (dimensionless), in the void volume generation Eq. (86) (recommended value 0.8) 
$31 \quad$ RXXEXP

RHOREF

33

34

35

36

37

38

39

40

41 TAUUNB

42 TAUUTB

$43 \quad$ ALAMNB

$44 \quad$ ALAMTB

45
GAMMA0

GAMMA1

GAMMA2

GAMMA3

GAMMA4

DOPPN

EPS3

DNBQDP

ALAMNB

ALAMTB

ALAMFB
An exponent, $\mathrm{n}$ (dimensionless), in Eq. (86). (recommended value 1.0)

Coolant reference density, in units of $\mathrm{lb} / \mathrm{ft}^{3}$ or $\mathrm{kg} / \mathrm{m}^{3}(>0)$. This represents the density of the coolant at the initial reactor conditions. If $\mathrm{I}_{\mathrm{k}}=3$ or 4 , see Section 5.8 item $2 \mathrm{a}$, then this value is overridden within the code to assure accurate density difference calculations in natural convection. The new value is printed out to make the user aware of this.

This term will have no effect in any problem other than to change the level of temperature feedback at $t=0$. Set it to zero.

Coefficients for the fuel temperature feedback equation. See Eq. (35) See also Section 3.2.2.3 of this document.

$\rho(\$)=\gamma_{0}+\gamma_{1} \mathrm{~T}+\gamma_{2} \mathrm{~T}^{2}+\gamma_{3} \mathrm{~T}^{\mathrm{n}} ; \mathrm{T}(\mathrm{C})=\mathrm{T}(\mathrm{K})-273.15$ if $\gamma_{4}=-273.15$

$\mathrm{T}(\mathrm{F})=\mathrm{T}(\mathrm{R})-459.67$ if $\gamma_{4}=-459.67$

Note: the code operates in R if NCHN is positive; else in K. Use of $\gamma_{4}$ as shown converts to $\mathrm{F}$ or $\mathrm{C}$.

Example: suppose that the fuel temperature feedback equation is:

$$
[0.001548+1.76 \mathrm{E}-5 \mathrm{~T}], \${ }^{\circ} \mathrm{C}
$$

This is equivalent to:

$$
[1.161 \mathrm{E}-5+1.32 \mathrm{E}-7 \mathrm{~T}], \Delta \mathrm{k} / \mathrm{k} /{ }^{\circ} \mathrm{C}
$$

The exponent, n, used in the fuel temperature feedback Eq. referred to above, items 33-37.

Upper limit for kinetics time step test, $\mathrm{Q}_{\mathrm{H}}$ (dimensionless). (see Section 3.2.1) Recommend 0.001.

Transient DNB heat flux. If a value of zero is entered here, the code uses steady-state DNB heat flux values calculated internal to the code for each axial node at each time node. If a nonzero value is entered, this value is used as the DNB heat flux for each axial node at each time node.(see Section 3.3)

Nucleate boiling bubble collapse time, $\tau_{\mathrm{NB}}$ (in seconds). See Eq. (126) Recommend 0.001

Transition boiling bubble collapse time, $\tau_{\mathrm{NB}}$ (in seconds). See Eq. (126). Recommend 0.001

Fraction of the clad surface heat flux, $\lambda_{\mathrm{NB}}$, which is utilized in producing vapor in the sub-cooled nucleate boiling region. See Eq. (126) The fraction $\left(1-\lambda_{\mathrm{NB}}\right)$ would be used in heating the bulk liquid rather than in producing vapor. Recommend 0.05

$\lambda_{\mathrm{TB}}$; analogous to item 43 , except that it applies to transition boiling. Recommend 0.05

$\lambda_{\mathrm{FB}}$; analogous to item 43 , except that it applies to film boiling. Recommend 0.05 
$46 \quad$ HTTCON

Natural convection heat transfer constant No. $1(\delta)$, (see Eq. (78)). Only used when the Reynolds number is less than 2300 and IHT $=0$. Alternatively this is laminar flow Nusselt No. when IHT $\geq 1$ (see 1112 card for loss-of-flow transients). The original PARET code used 1.4.

$47 \quad$ HTTEXP

Natural convection heat transfer constant No. 2: exponent (n), (see Eq. (78)). Only used when the Reynolds number is less than 2300 and $\mathrm{IHT}=0$. The original PARET code used 0.33 .

\subsection{Additional General Information}

\section{ITEM FORTRAN DESCRIPTION}

VARIABLE

1a PSUBC

2a $\quad$ FACT2 (120)

1b IONEP
Data required for revisions that have been made to the PARET/ANL code are included in the 111X lines:

$\rightarrow$ 1111, PSUBC, FACT2(1), ...., FACT2(NCHN)

Total cross Sectional area of all flow channels in core. (no longer used; provide a value as a place holder)

Flux weighting factor; NCHN values entered on the type 1111 line. FACT2(I) is a factor along with the reactivity feedback weighting factor (Section 5.8 item 5a) of the coolant energy and coolant energy removed which are outputs on the header page of major edits. FACT2(I) has no effect on code calculations or results. Its physical significance is not clear and has been taken as unity in ANL calculations. If less than NCHN2 values are supplied, the code defaults to 1.0 for all values. If $\mathrm{NCHN}>4$, supply only 2 values.

The PARET/ANL code supports a selection of heat transfer, flow instability, and DNB correlations and includes a tabulation of decay heat power based on the ANS curve for fission product decay heat. The code also provides a simulation of control rod reactivity insertion with rate and delay time settings, trip points for low flow, period, and over-power, and leg lengths for natural convection effects. The required input for the types 1112, 1113, and 1114 lines follow:

$\rightarrow$ 1112, IONEP, ITWOP, IMODE, ICHF, IHT, QAVE, ETA, CP

Single-phase correlation flag

0 - original Dittus - Boelter [27]; the Rosenthal \& Miller option is selected if it is the largest heat transfer coefficient.

\pm 1 - Sieder - Tate [28]

\pm 2 - Petukhov - Popov (Must have IHT=0, see 5b) [29] and [37]

\pm 3 - Colburn [30]

\pm 4 - Russian

\pm 5 - China Inst. of Atomic Energy MNSR correlation [31] to replace the PARET/ANL natural circulation model 
\pm 6 - Dittus-Boelter modified by ANL, scaled by a factor of $\left[\mu_{\mathrm{b}} / \mu_{\mathrm{w}}\right]^{0.11}$

\pm 7 - original Dittus - Boelter

Note: IONEP can be negative or positive. If positive, the Rosenthal \& Miller transient heat transfer coefficient can be selected if it is the large heat transfer coefficient (this typically occurs when the reactor is on a very short period). If negative, it is never selected. It is calculated from: $\mathrm{h}=\left[\mathrm{k \rho C}_{\mathrm{p}} / \mathrm{T}\right]^{1 / 2}$

where $k, \rho$, and $C_{p}$ are the coolant thermal conductivity, density, and specific heat, and $\mathrm{T}$ is the reactor period in seconds.

IONEP is not used when the ATHENA options are selected.

$2 b \quad$ ITWOP

Two-phase correlation flag

0 - original Jens - Lottes [14]

1 - McAdams [12]

2 - No longer available (see USERS' GUIDELINES, Section VIII-16)

3b IMODE

Transient two-phase scheme

0 - original model

1 - transition model, single-phase to two-phase (calls htran2)

2 - ATHENA [32] options for heat transfer; selects 'ORNL ANS 102' options [37] (developed for the Advanced Neutron Source Reactor). This option uses the Rosenthal and Miller transient $h$ when it is larger than other choices.

The Churchill-Chu correlation is used for natural convection.

The Chen correlation is used for nucleate boiling and for transition boiling.

It uses the Gambill-Weatherhead model for CHF under high mass flow conditions for mass flux $>8000 \mathrm{~kg} / \mathrm{m}^{2} / \mathrm{s}$ (the Groeneveld table goes up to $8000 \mathrm{~kg} / \mathrm{m}^{2} / \mathrm{s}$ ).

3 - Like 2, but uses Groeneveld film boiling table.

4 - Uses ATHENA 101 options; uses Sellars correlation for laminar flow and Elenbaas correlation for natural convection. The Chen correlation is used for nucleate boiling and transition boiling.

5 - Like 4 but uses Groeneveld film boiling table.

Options 2-5 will in future yield CHF margin based on 2006 Groeneveld CHF table. They are not yet validated.

The ATHENA options select the largest applicable heat transfer correlation given choices from Dittus-Boelter, Churchill-Chu, Sellars (laminar), and Elenbaas that apply for forced turbulent flow, forced laminar flow, and free (natural) convection. 
IMODE for the ATHENA options (2-5) can be set to a negative value in order to not use the Rosenthal \& Miller transient heat transfer correlation as one of the options.

For the ATHENA IMODE options $(-2,-3,-4,-5,2,3,4,5)$ the code ignores the parameters IHT and IONEP. These options are not yet validated.

$4 \mathrm{~b}$

ICHF

$5 b$

IHT

6b QAVE

$7 \mathrm{~b} \quad \mathrm{ETA}$

$8 b$
DNB and flow instability correlations

0 - original DNB from Tong [19]

1 - Bernath DNB [9]

2 - Mirshak DNB [33]

The following options are not appropriate for use with IMODE=2-5:

3 - Forgan FIR (Plate geometry only-code checks)

4 - CEA FIR (Plate geometry only-code checks)

5 - Lund DNB (cylindrical pin geometry only)

6 - Lund DNB (as option 5, but with bowed pin included)

7 - Groeneveld 2006 CHF lookup table (this option is not available. The code will stop with a fatal error message if used)

Single-phase heat transfer subroutine selection

0 - original; uses subroutine htran 0 and use variables HTTCON and HTTEXP for natural convection heat transfer.

1 - revised, without entrance effects for h; code uses subroutine htran2 (assumes fully-developed flow). Code use variable HTTCON as the laminar flow Nusselt Number $(\mathrm{h}=[\mathrm{k} / \mathrm{De}]$ HTTTCON ). It does not use HTTEXP.

2 - revised, with entrance effects for simultaneously developing velocity and thermal profiles for $\mathrm{h}$ when $\mathrm{Re} \leq \mathrm{RET} \mathrm{T}$; code uses subroutine htran2. See card 1114 for RET_T. Code uses HTTCON as laminar flow Nusselt Number.

IHT is not used when the ATHENA options are selected.

Average (core) heat flux used with ICHF $=3 \& 4\left[\mathrm{Btu} / \mathrm{hr} \mathrm{ft}^{2}\right.$ or $\left.\mathrm{W} / \mathrm{m}^{2}\right]$

Bubble detachment flow instability parameter for $\mathrm{ICHF}=3$ (recommended is 25. But note that 32.5 will yield a 95\% confidence interval that $95 \%$ of the rectangular channel data measured in future will not exceed 32.5 .

Specific heat used with ICHF $=3 \& 4$ [Btu/lb - of or J/kg - $\left.{ }^{\circ} \mathrm{K}\right]$ (if blank, default is 1.0 for US Customary units or 4186.8 for SI units)

$\rightarrow$ 1113, RDRATE, TDLAY, POWTP, FLOTP, OPT, POW0 


$\begin{array}{ll}\text { 1c } & \text { RDRATE } \\ \text { 2c } & \text { TDLAY } \\ 3 \mathrm{c} & \text { POWTP } \\ 4 \mathrm{c} & \text { FLOTP } \\ 5 \mathrm{c} & \text { OPT } \\ & \\ 6 \mathrm{c} & \text { POW0 }\end{array}$

1d HNCTOP

2d HNCBOT

3d REL_T

4d RET_T

5d FINF

6d PHI
Constant rate for control rod movement (with scram or withdrawal) [ft/sec or m/sec] or if set to -1.0 , Table 18 sets the rate of motion (see Table 18) (recommend 0.0 if no trip data supplied)

Delay time before rod starts in after trip [sec] (recommend 36000. sec if one wishes to not have a trip)

Overpower trip point [MW] (recommend10000. MW if one wishes to not have an overpower trip)

Low flow trip point [\%] (recommend $0.0 \%$ if one wishes to not have a low flow trip; not $<0$ )

Previous operation time of reactor - Used in decay heat level after scram [days] (depends on core operating history. set to 1.E-20 to essentially zero any decay heat). Recommended: 24.0 days.

Previous operating power of the reactor - Used in decay heat power after scram [MW] (recommended - initial power input for startup of transient). Decay heat power is checked against initial power. If decay heat exceeds initial power, it is added to POWER and a message is written to notify of the change. The decay heat contribution is held constant at the value at time zero, until a trip occurs. Then the decay heat contribution begins to decay at time $\mathrm{T}_{\text {trip }}+\mathrm{T}_{\text {delay }}$.

$\rightarrow 1114$, HNCTOP, HNCBOT, REL_T, RET_T, FINF, PHI

Height above reactor core fuel meat for natural convection effects.

Height below reactor fuel meat for natural convection effects.

If both HNCTOP and HNCBOT in line 1114 are 0.0 , no output is printed for them. These lengths would include the non-fueled section length, Section 5.3 items 23 (ALDDIN) and 24 (ALDDEX), and any plenum above or below the core.

Reynolds number lower limit for entrance effects (2300. is recommended but must be $\leq 3000$.)

Reynolds number below which entrance effects are computed per IHT flag (3700. is recommended but must be < 4000.)

Fin heat transfer enhancement factor from clad to coolant (h with fins divided by h without fins). (If no fins, set to 1.0). One correlation that is used to calculate FINF is the one created by Carnavos $[48,49]$. It is limited to turbulent flow for $10,000<\operatorname{Re}<100,000$. There are other geometrical limits on it as well. For PARET, a check is made on the local Reynolds Number. If not in the above range, a WARNING is issued, but the calculation is not terminated and the user-supplied value of FINF is used as given. Note: $0<\mathrm{FINF}<5$.

Laminar flow friction factor correction factor: $f_{x} R e=64 / P H I$

Used for $\mathrm{Re}<2200$. Recommended: $2 / 3$ for flat plates and 1.0 for cylindrical fuel rods. 
$\rightarrow$ 1115, PERTP, PTDLAY

1e PERTP

Period trip point, seconds (In order to not have a period trip, set it to $0.0001 \mathrm{~s}$ ). This trip applies only to positive periods. It is initiated by the period becoming less than this value. Recommended value is $0.0001 \mathrm{~s}$.

2e PTDLAY Delay time before control rod motion begins after trip, seconds (In order to not have a period trip cause rod insertion, set it to 36000 . sec). Recommended value is 36000 . seconds.

This card can be omitted if both default values are appropriate.

$$
\rightarrow \text { 1116, SUTOL(1), SUTOL(2), SUTOL(3), SUTOL(4), ENTHHS }
$$

SUTOL(1) Shortened channel output file filter tolerance (recommend value=0.5 C) for peak fuel temperature

SUTOL(2) Shortened channel output file filter tolerance (recommend value $=0.5 \mathrm{C}$ ) for peak clad temperature

SUTOL(3) Shortened channel output file filter tolerance (recommend value $=0.5 \mathrm{C}$ ) for peak coolant temperature

SUTOL(4) Shortened channel output file filter tolerance (recommend value $=0.5 \mathrm{C}$ ) for peak coolant exit temperature

ENTHHS Enthalpy of inlet coolant after flow reversal in units of BTU $/ \mathrm{lb}$ or J/kg $(>0)$. At user option, the inlet temperature ( $\mathrm{C}$ or $\mathrm{F}$ ) may be used in lieu of enthalpy by entering the negative of that temperature. Recommended: ENTHIN.. See input for Table 21.

\section{$\rightarrow$ 1117, IDKOPT,EPFU5,TSHUT0}

IDKOPT(1) 0, Recommended value to select ANSI/ANS 2005 decay heat model

1, Select 1973 ANS decay heat model

EPFU5(2) Energy per fission, MeV. Recommended value is 200.0.

TSHUT0(3) Shutdown time, days (set to 0.0 is recommended) 


\subsection{Thermal Properties of Fuel Element Materials}

\subsubsection{When Using Option IGEOM = 0 or IGEOM = 1}

These data are input on a pair of lines in the form

Items 1 - 5, [ALPHA1 (10), ..., ALPHA5 (10)] $\rightarrow \underline{\mathbf{2 0 0 X}_{1}}, \boldsymbol{\alpha}_{1}, \boldsymbol{\alpha}_{2}, \boldsymbol{\alpha}_{3}, \boldsymbol{\alpha}_{4}, \boldsymbol{\alpha}_{5}$

Items 6 - 10, [BETA1 (10), ..., BETA5 (10)] $\rightarrow \underline{\mathbf{2 0 0 X}}_{\underline{2}} \boldsymbol{\beta}_{1}, \boldsymbol{\beta}_{2}, \boldsymbol{\beta}_{3}, \boldsymbol{\beta}_{4}, \boldsymbol{\beta}_{5}$

Description

Notes:

(a) There is one pair of lines per material, the number of materials being no more than

10. The fuel meat, by convention, must be the first material. The clad must be the last material.

(b) $\quad X_{2}=X_{1}+1$

(c) $X_{1}=1$ for the first material, 3 for the second, and 5 for the third, etc., up to $19(X 2=2$, $4,6, \ldots 20)$.

(d) The $\alpha_{n},(n=1,2, \ldots, 5)$ are the thermal conductivity coefficients of the material for an equation of the form

$$
\mathrm{k}_{\mathrm{n}+1 / 2}^{\mathrm{m}}=\alpha_{1} \mathrm{~T}^{2}+\alpha_{2} \mathrm{~T}+\alpha_{3}+\alpha_{4} / \mathrm{T}
$$

Temperature is determined as follows:

Define ubar $=0.5\left[\mathrm{u}_{\mathrm{n}}{ }^{\mathrm{m}}+\mathrm{u}_{\mathrm{n}}{ }^{\mathrm{m}+1}\right]$, where:

$u_{n}{ }^{m}$ is the temperature of the material at the $n_{\text {th }}$ spatial (radial, axial) node at the $m_{\text {th }}$ time node. Because internal temperatures in PARET/ANL are in Fahrenheit, the $u_{n}$ are in $\mathrm{F}$ and so is ubar.

If the user requested SI units (by setting $\mathrm{NCHN}<0$ ), $\mathrm{T}^{\prime}$ is set to the equivalent temperature to ubar on the Kelvin scale. Then $\alpha_{5}$ is added $\mathrm{T}=\mathrm{T}^{\prime}+\alpha_{5}$ to either leave $\mathrm{T}$ in $\mathrm{K}$ (Kelvin), if $\alpha_{5}$ is zero, or in C (Celsius) if $\alpha_{5}$ is -273.15 .

If the user requested United States Customary units $(\mathrm{NCHN}>0)$, $\mathrm{T}^{\prime}$ is set to ubar and is in Fahrenheit.

$\mathrm{T}^{\prime}=\mathrm{ubar}$

$\mathrm{T}=\mathrm{T}^{\prime}+\alpha_{5}$

Then $\alpha_{5}$ is added to either leave T in F, if $\alpha_{5}$ is zero, or in R (Rankine) if $\alpha_{5}$ is +459.67 . 
$\mathrm{k}_{\mathrm{n}+1 / 2}^{\mathrm{m}}$ is the thermal conductivity of the material between the $\mathrm{n}_{\text {th }}$ and $\mathrm{n}+1^{\text {st }}$ radial nodes, in units of $\frac{\mathrm{Btu}}{\mathrm{hr}-\mathrm{ft}-{ }^{\circ} \mathrm{F}}$ or $\frac{\mathrm{w}}{\mathrm{m}^{0} \mathrm{~K}}$

Note: the above units for $\mathrm{k}$ should be replaced: $\mathrm{R}$ for $\mathrm{F}$, or $\mathrm{C}$ for $\mathrm{K}$, if those options are used.

(e) The $\beta_{n}(n=1,2, \ldots 5)$ are the volumetric heat capacity coefficients of the material for an equation of the form

$$
\mathrm{g}_{\mathrm{n}+1 / 2}^{\mathrm{m}}=\beta_{1} \mathrm{~T}^{2}+\beta_{2} \mathrm{~T}+\beta_{3}+\beta_{4} / \mathrm{T}
$$

$g_{n+1 / 2}^{m}$ is the volumetric heat capacity of the material between the $\mathrm{n}^{\text {th }}$ and $\mathrm{n}+1^{\text {st }}$ radial nodes, in units of

$\frac{\text { Btu }}{\mathrm{ft}^{3}-{ }^{\circ} \mathrm{F}}$ or $\frac{\mathrm{J}}{\mathrm{m}^{3}-{ }^{0} \mathrm{~K}}$

\subsubsection{When Using Option IGEOM = 2}

These data are input on a pair of lines in the form

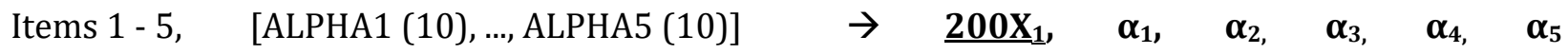

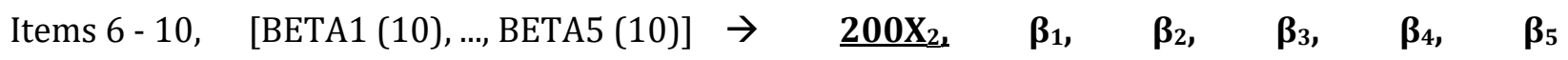

Description

Notes:

(a) There is one pair of lines per material, the number of materials being no more than 10 . The fuel meat, by convention, must be the first material. The clad must be the last material.

(b) $\mathrm{X}_{2}=\mathrm{X}_{1}+1$

(c) $\mathrm{X}_{1}=1$ for the first material, 3 for the second, and 5 for the third, etc.

(d) The $\alpha_{n},(n=1,2, \ldots, 5)$ are the thermal conductivity coefficients of the material for an equation of the form

$$
\mathrm{k}_{\mathrm{n}+1 / 2}^{\mathrm{m}}=\alpha_{1} \mathrm{~T}^{2}+\alpha_{2} \mathrm{~T}+\alpha_{3}+\alpha_{4} / \mathrm{T}
$$

Temperature is determined as follows:

1. Define ubar $=0.5\left[u_{n}{ }^{m}+u_{n}{ }^{m+1}\right]$, where:

$\mathrm{u}_{\mathrm{n}}{ }^{\mathrm{m}}$ is the temperature of the material at the $\mathrm{n}_{\text {th }}$ spatial (radial, axial) node at the $\mathrm{m}_{\text {th }}$ time node. Because internal temperatures in PARET/ANL are in Fahrenheit, the $\mathrm{u}_{\mathrm{n}}$ are in $\mathrm{F}$ and so is ubar. 
2. If the user requested SI units $(\mathrm{NCHN}<0)$, $\mathrm{T}^{\prime}$ is set to the equivalent temperature to ubar on the Kelvin scale. Then $\alpha_{5}$ is added:

$\mathrm{T}=\mathrm{T}^{\prime}+\alpha_{5}$

to either leave T in $\mathrm{K}$ (Kelvin), if $\alpha_{5}$ is zero, or in C (Celsius) if $\alpha_{5}$ is -273.15 .

3. If the user requested United States Customary units (NCHN $>0$ ), T' is set to ubar and is in Fahrenheit.

$\mathrm{T}^{\prime}=\mathrm{ubar}$

$\mathrm{T}=\mathrm{T}^{\prime}+\alpha_{5}$

Then $\alpha_{5}$ is added to either leave T in F, if $\alpha_{5}$ is zero, or in R (Rankine) if $\alpha_{5}$ is +459.67 .

$\mathrm{k}_{\mathrm{n}+1 / 2}^{\mathrm{m}}$ is the thermal conductivity of the material between the $\mathrm{n}_{\mathrm{th}}$ and $\mathrm{n}+1^{\text {st }}$ radial nodes, in units of $\frac{\mathrm{Btu}}{\mathrm{hr}-\mathrm{ft}-{ }^{\circ} \mathrm{F}}$ or $\frac{\mathrm{w}}{\mathrm{m}^{0} \mathrm{~K}}$

Note: the above units for $\mathrm{k}$ should be replaced: $\mathrm{R}$ for $\mathrm{F}$, or $\mathrm{C}$ for $\mathrm{K}$, if those options are used.

(e) The $\beta_{n}(n=1,2 \ldots 5)$ are the volumetric heat capacity coefficients of the material for an equation of the form

$\mathrm{g}_{\mathrm{n}+1 / 2}^{\mathrm{m}}=\beta_{1} \mathrm{~T}^{2}+\beta_{2} \mathrm{~T}+\beta_{3}+\beta_{4} / \mathrm{T}$

$g_{n+1 / 2}^{m}$ is the volumetric heat capacity of the material between the $\mathrm{n}^{\text {th }}$ and $\mathrm{n}+1^{\text {st }}$ radial nodes, in units of

$\frac{B t u}{f t^{3}-{ }^{o} F}$ or $\frac{J}{m^{3}-{ }^{0} K}$

Note: the above units for g should be replaced: $\mathrm{R}$ for $\mathrm{F}$, or $\mathrm{C}$ for $\mathrm{K}$, if those options are used. See item (d) above for the definition of temperature.

In order to accommodate two or more quite different classes of "channels" containing different materials, the IGEOM=2 option reads the composition data in an alternative manner.

This data (for this beta version) is not read by the standard input processor. Instead, it is read in a new subroutine (inlkb) expecting fixed-format data. Checks are made that card id's are in sequence, and that NCLASS, NMAT, NLO, and NHI are acceptable (non-zero, and not over its own limit). If not, a fatal error occurs and an error message is issued.

When all assignments of the input to channels are complete, a final check is made that no channel is left without material assignments.

The formats used are the same as those used by the standard input processor, when the input is in most compact form.

CARD 1: NCARD,NCLASS

FORMAT(I4,2X,I6) 
NCARD is the card id, which must be 2001 (it is checked).

NCLASS is the number of classes of CHANNELS (1 ... NCHN)

Note: NCLASS is 1 if all channels are alike regarding the number, sequence from plate centerline, and properties of materials in the fuel plate. In that event, the user only supplies one set of data, which is expanded out to all channels. NCLASS is NCHN if all channels are different regarding the sequence and properties of materials in the fuel plate.

FOR EACH CLASS FROM 1...NCLASS, SUPPLY THE FOLLOWING:

CARD TYPE 2: NCARD,NMAT

FORMAT(I4,2X,I6)

NCARD is the card id, expected to be in sequence after CARD 1 value.

NMAT is the number of materials in this class of fuel plate. For each material, two input cards are read: types 3 and 4 .

CARD TYPE 3: NCARD, ALPHA1,...ALPHA5 $\rightarrow \underline{\mathbf{2 0 0 X}} \underline{1}, \boldsymbol{\alpha}_{1}, \boldsymbol{\alpha}_{2,}, \boldsymbol{\alpha}_{3}, \boldsymbol{\alpha}_{4}, \boldsymbol{\alpha}_{5}$

FORMAT(I4,2X,5E12.5)

CARD TYPE 4: NCARD, BETA1,...BETA5 $\rightarrow \underline{\mathbf{2 0 0} \underline{X}_{2}} \boldsymbol{\beta}_{1}, \boldsymbol{\beta}_{2}, \boldsymbol{\beta}_{3}, \boldsymbol{\beta}_{4}, \boldsymbol{\beta}_{5}$

FORMAT(I4,2X,5E12.5)

Note 1: The code will number the materials in the order provided, from 1 to MNAT. This numbering begins again from 1 ...NMAT for each class.

Note 2: All values of NCARD are checked that they are in sequence. If not, a fatal error occurs and an error message is issued.

EXAMPLE: NCHN=6, BUT TWO CLASSES OF FUEL PLATES

Class 1 consists of two materials in the fuel plate.

Class 2 consists of three materials in the fuel plate.

\begin{tabular}{|c|c|c|c|c|c|}
\hline 2001, & 2 & & & & \\
\hline 2002, & 2 & & & & \\
\hline 2003 & $\odot .0$ & 0.0 & 151.53 & $\odot . \odot$ & $\odot . \odot$ \\
\hline 2004, & 0.0 & 1014.0 & $2.01140+6$ & 0.0 & 0.0 \\
\hline 2005 & 0.0 & 0.0 & 183.11 & $\odot . \odot$ & 0.0 \\
\hline 2006, & 0.0 & 1243.4 & $2.07090+6$ & $\odot . \odot$ & $\odot . \odot$ \\
\hline 2007, & 3 & & & & \\
\hline 2008, & 0.0 & $\Theta . \odot$ & 151.53 & $\Theta . \odot$ & $\odot .0$ \\
\hline 2009, & 0.0 & 0.0 & $3.00000+6$ & 0.0 & 0.0 \\
\hline 2010 & 0.0 & 0.0 & 200.00 & $\odot .0$ & $\odot . \odot$ \\
\hline 2011 & $\odot . \odot$ & $\odot . \odot$ & $2.50 \odot \odot \odot+6$ & $\odot . \odot$ & 0.0 \\
\hline 2002, & 0.0 & 0.0 & 100.00 & 0.0 & 0.0 \\
\hline 2013, & 0.0 & $\odot .0$ & $1.00000+6$ & 0.0 & $\odot . \odot$ \\
\hline
\end{tabular}




\subsection{Radial or Half-Plate Thickness Description}

The radial description refers to cylindrical geometry and half-plate thickness (symmetry assumed) to slab geometry. Each line is of the form

\subsubsection{When Using Option IGEOM = 0 or IGEOM =1 \\ ITEM FORTRAN DESCRIPTION \\ VARIABLE \\ $\rightarrow 3 X X X, Y, I, J, Z, K$ \\ where XXX = 001, 002, .., 999 \\ $1 \quad$ AINCR \\ $\mathrm{Y}$ is the Radial increment length, $(>0)$ \\ $2 \quad \mathrm{KK}$ \\ $3 \quad$ ICOMP \\ I is the radial node out to which the increment applies (integer and $>0$ ) \\ Note: the first card, type 3001 , must have I $\geq 2$ in order to define the zero radius point \\ J is the composition code represented by one of the 10 integers $1,2, \ldots 10$. The composition code begins at the center; i.e., the fuel is composition 1 , the next material is composition 2, etc. The clad is the last composition (so the code will know which is clad, even if the clad is not the outermost material next to coolant) and the maximum number of materials is 10 . If there are more than one meat layers, assign the outermost meat layer to composition 1. This enables satisfying an error check on meat outer radius. \\ $4 \quad$ QR \\ $\mathrm{Z}$ is the radial source description $(\geq 0)$. The heat source is assumed to be separable into a function of time, a function of radius, and a function of axial position. QR is dimensionless, as it is with reference to the core average power density. If the radially averaged value of $Q R=1$., one obtains the full output power from the fuel meat retained in the meat for conduction. If the radially averaged value of $\mathrm{QR}<1.0$, then there should be direct heating to the coolant to compensate (see item $28, \mathrm{QW}$, in Section 5.3). The function of axial position is specified on card type $5 \mathrm{k} 00$ as variable PFQ.}

Notes:

(a) On line $3001(\mathrm{XXX}=001)$ the first I -1 radial increment will be represented (I > 2) all of length Y, composition J (see 2000 series lines), and radial heat source magnitude $\mathrm{Z}$.

(b) On each succeeding line the $\mathrm{Y}, \mathrm{I}, \mathrm{J}$, and $\mathrm{Z}$ values apply to radial increments following those covered by the previous line, up to I - 1 from the new line.

(c) When either the radial increment, the composition code, or the radial source description changes from one node point to the next, a new line must be input for the next node point or node points. 
(d) The 3000 - series lines describe the pin or plate from the centerline to the outer surface of the clad. The node point at the fuel centerline is node point number one (not zero).

(e) The sum of the increment lengths between successive pairs of node points must be equal to the pin radius or plate half-thickness given in Section 5.3 item 17; also, the dimensions given in items 18 and 19 must bear a correct correspondence to the dimensions given on these 3000 series lines.

(f) If QR of a node is zero in a fuel meat node, the contribution to Doppler feedback will be zero.

$5 \quad$ ICLAD

$\mathrm{K}$ is the node point (interface) number to be edited as "CLAD TEMPERATURE" in edits of peak clad temperature. Any node point can be selected: $1 \leq \mathrm{K} \leq \mathrm{NR}$. The code assumes that node point 1 is the fuel centerline (slab) or axis (cylindrical). Caution: if IGEOM=0, the user MUST put ICLAD on the last type-3000 card.

Geometry Example 1: (meat + clad + oxide). The rules are (for slab geometry):

\#18 RF = fuel plate meat half thickness

\#19 RC = RF as fuel meat is in contact with clad

\#17 RS = RF + clad thickness + oxide thickness

card 3000 series:

card 3001: choose AINCR $=$ RF $/($ KK-1)

card 3002: choose AINCR $=($ clad thickness $) / \mathrm{KK}$

card 3003: choose ANICR $=$ (oxide thickness) $/ \mathrm{KK}$

Geometry Example 2: (meat + gap + clad + oxide layer). The rules are (for slab

geometry):

\#18 RF = fuel plate meat half thickness

\#19 RC = RF + gap thickness as fuel meat is not in contact with clad

\#17 RS = RF + gap thickness + clad thickness + oxide layer thickness

Card 3000 series:

card 3001: fuel: choose AINCR $=\mathrm{RF} /(\mathrm{KK}-1)$

card 3002: gap: choose AINCR $=$ (gap thickness) $/ \mathrm{KK}$

card 3003: oxide layer: choose AINCR = (oxide thickness) $/ \mathrm{KK}$

card 3004: clad: choose AINCR $=($ clad thickness $) / \mathrm{KK}$ (clad must be the last

material)

\subsubsection{When Using Option IGEOM = 2}

This input is generalized to enable having classes of channels, where each channel in a given class has identical radial mesh and composition descriptions. But within that class, the other channeldependent characteristics still are available. There can be up to 120 classes of channels (i.e. every channel in the problem can be unique radially). The purpose of this is to enable having different types of fuel such as LEU and HEU, or different burnup, in the same core model. The input data provided by class is expanded to define the radial data for every channel. A check is made to confirm that all channels are defined.

$\begin{array}{lll}\text { ITEM FORTRAN } & \text { DESCRIPTION } \\ \text { VARIABLE }\end{array}$


$\rightarrow$ NNNN, I $\quad$ Format(I4,2x,I6)

1 NNNN 3001, The first card of this series

2 NCLASS Number of classes of channels, each class potentially having different numbers of radial nodes and compositions

For each class (1...NCLASS) provide the following sets of data:

$\rightarrow$ LLLL, I, J, K, L, M

1 LLLL The next card of this series

2 NLO Lowest channel number to which this class applies

3 NHI Highest channel number to which this class applies

$4 \quad$ NMAT Number of materials in this class

$5 \quad$ NR Number of radial nodes in this class

6 ICLAD Radial node at which peak temperature is desired. $\mathrm{M}$ is the node point (interface) number to be edited as "CLAD TEMPERATURE" in edits of peak clad temperature. Any node point can be selected: $1 \leq \mathrm{K} \leq \mathrm{NR}$. The code assumes that node point 1 is the fuel centerlineICLAD need not be the same in all classes.

For each class, the radial definition data is of the form

\begin{tabular}{|c|c|c|}
\hline \multirow[t]{3}{*}{ ITEM } & $\begin{array}{l}\text { FORTRAN } \\
\text { VARIARLE }\end{array}$ & DESCRIPTION \\
\hline & & $\rightarrow$ LLLL,Y,I,J,Z \\
\hline & & where \\
\hline 1 & AINCR & $\mathrm{Y}$ is the radial increment length, $(>0)$ \\
\hline \multirow[t]{2}{*}{2} & KK & I is the radial node out to which the increment applies (integer and $>0$ ) \\
\hline & & $\begin{array}{l}\text { Note: the first card, type } 3001 \text {, must have I } \geq 2 \text { in order to define the zero } \\
\text { radius point }\end{array}$ \\
\hline 3 & ICOMP & $\begin{array}{l}\text { J is the composition code represented by one of the } 10 \text { integers } 1,2, \ldots 10 \text {. } \\
\text { The composition code begins at the center; i.e., the fuel is composition } 1 \text {, } \\
\text { the next material is composition } 2 \text {, etc. The clad is the last composition } \\
\text { (so the code will know which is clad, even if the clad is not the outermost } \\
\text { material next to coolant) and the maximum number of materials is } 10 \text {. } \\
\text { The meat can be anywhere in the pin, but it must have the lowest } \\
\text { composition number. For example, the innermost part of the pin can be } \\
\text { a non-fissionable material. The composition data supplied on type-2000 } \\
\text { series input are generalized to be by fuel type number. A simple problem } \\
\text { with all channels identical will have NCLASS=1. If more than one fuel } \\
\text { meat layer is present, then make the outermost (radially) meat } \\
\text { composition be number } 1 \text { in order to satisfy a radial mesh check } \\
\text { comparing with RF. }\end{array}$ \\
\hline
\end{tabular}


$\mathrm{Z}$ is the radial distribution of power density in fuel meat averaged over the radial increment $(\geq 0)$. The heat source is assumed to be separable into a function of time, a function of radius, and a function of axial position. QR is dimensionless, as it is with reference to the core average power density. If the average $Q R=1$, one obtains the full output power from the fuel meat retained in the meat for conduction. If the average $\mathrm{QR}<1$, then there will be direct heating to the coolant to compensate. The function of axial position is specified on card type $5 \mathrm{k} 00$ as variable PFQ.

Notes:

(a) On line $3001(\mathrm{XXX}=001)$ the first I-1 radial increment will be represented ( $\mathrm{I}>2$ ) all of length $\mathrm{Y}$, composition J (see 2000 series lines), and radial heat source magnitude $\mathrm{Z}$.

(b) On each succeeding line the Y, I, J, and Z values apply to radial increments following those covered by the previous line, up to I-1 from the new line.

(c) When either the radial increment, the composition code, or the radial source description changes from one node point to the next, a new line must be input for the next node point or node points.

(d) The 3000 - series lines describe the plate from the centerline to the outer surface of the clad. The node point at the fuel centerline is node point number one (not zero).

(e) The sum of the increment lengths between successive pairs of node points must be equal to the plate half-thickness given in Section 5.3 item 17; also, the dimensions given in items 18 and 19 must bear a correct correspondence to the dimensions given on these 3000 - series lines.

(f) If $\mathrm{QR}$ of a node is zero in a fuel meat node, the contribution to Doppler feedback will be zero.

Geometry Example 1: (meat + clad + oxide). The rules are (for slab geometry):

$\# 18 \mathrm{RF}$ = fuel plate meat half thickness

$\# 19 \mathrm{RC}=\mathrm{RF}$ as fuel meat is in contact with clad

$\# 17 \mathrm{RS}=\mathrm{RF}+$ clad thickness + oxide thickness

Card 3000 series:

card 3001: choose AINCR $=$ RF $/($ KK-1)

card 3002: choose AINCR $=($ clad thickness $) / \mathrm{KK}$

card 3003: choose ANICR $=$ (oxide thickness) $/ \mathrm{KK}$

Geometry Example 2: (meat + gap + clad + oxide layer). The rules are (for slab geometry):

\#18 RF = fuel plate meat half thickness

\#19 RC = RF + gap thickness as fuel meat is not in contact with clad

$\# 17 \mathrm{RS}=\mathrm{RF}+$ gap thickness + clad thickness + oxide layer thickness

Card 3000 series:

card 3001: fuel: choose AINCR $=$ RF $/($ KK-1) 
card 3002: gap: choose AINCR $=$ (gap thickness) $/ \mathrm{KK}$

card 3003: oxide layer: choose AINCR = (oxide thickness) $/ \mathrm{KK}$

card 3004: clad: choose AINCR = (clad thickness)/KK (clad must be the last material, defined, but it is not necessarily the last material assigned to the outermost radial material; for example, there could be an oxide layer)

A sample input for 2 classes of channels follows.

It is known from other input that there are 6 channels in the model. Class 1 covers channels 1 and 2 , and has three compositions in 7 radial nodes. Class 2 covers channels 3 to 6 , and has 2 compositions in 6 radial nodes. Note that the ICOMP $=1$ specified for class 1 is NOT the same composition as ICOMP=1 for class 2 .

\begin{tabular}{|c|c|c|c|c|}
\hline ! & JCLASS & & & \\
\hline 3001, & 2 & & & \\
\hline ! & NLO & NMAT & NR & ICLAD \\
\hline $30 \odot 2$, & 1 & 3 & 7 & 7 \\
\hline 3003 & 4. $00000 \mathrm{E}-3$ & 5 & 1 & 0.980 \\
\hline 3004, & $9.00000 \mathrm{E}-4$ & 6 & 2 & 0.000 \\
\hline 3005, & $5.00000 \mathrm{E}-5$ & 7 & 3 & 0.980 \\
\hline 3006, & $\begin{array}{ll}3 & 6\end{array}$ & 2 & 6 & 6 \\
\hline 3007, & $6.00000 \mathrm{E}-3$ & 5 & 1 & 0.960 \\
\hline 3008 & $7.0000 \odot \mathrm{E}-4$ & 6 & 2 & $\odot . \odot \odot \odot$ \\
\hline
\end{tabular}

\subsection{Axial Description}

ITEM FORTRAN

VARIABLE

$$
\begin{gathered}
\rightarrow \\
4 X X X, Y_{1}, I_{1}, Y_{2}, I_{2}, \ldots, Y_{i}, I_{i}, \ldots Y_{n}, I_{n} \\
\text { where XXX }=001,001, \ldots, 999
\end{gathered}
$$

$1 \quad \mathrm{DZ}(97)$

$2 \quad \mathrm{KJ}$$$
Y_{i} \text { is the axial region length }(>0)
$$

\section{DESCRIPTION}

$I_{i}$ is the region through which the length $Y_{i}$, applies, subject to the conditions

$\mathrm{I}_{1} \geq 1$ and $\mathrm{I}_{\mathrm{i}} \geq \mathrm{I}_{\mathrm{i}-1}$

\section{Notes:}

(a) If there are $\mathrm{NZ}$ axial regions, there will be $\mathrm{NZ}$ axial node points and NZ -1 axial increments, $\Delta Z_{j}$, as the illustration in Figure 5.1, Except for the node points 1 and NZ, all axial node points are located at the center of regions I of length Y. Node 1, however, is located at the one end of the fuel and node NZ at the other end of the fuel, rather than at the center of regions 1 and NZ. Thus

$$
\begin{aligned}
& \Delta \mathrm{Z}_{1}=\mathrm{R}_{1}+1 / 2 \mathrm{R}_{2} \\
& \Delta \mathrm{Z}_{\mathrm{j}}=1 / 2\left(\mathrm{R}_{\mathrm{j}}+\mathrm{R}_{\mathrm{j}+1}\right) ; 1<\mathrm{j}<\mathrm{NZ}-1 \\
& \Delta \mathrm{Z}_{\mathrm{NZ}-1}=1 / 2 \mathrm{R}_{\mathrm{NZ}-1}+\mathrm{R}_{\mathrm{NZ}}
\end{aligned}
$$


where $\Delta \mathrm{Z}_{\mathrm{j}}$ represents the distance between node point J and J +1 , and $\mathrm{R}_{\mathrm{i}}$ represents the length of region j. A maximum of 97 axial regions is allowed.

(b) The 4000 - series lines describe the axial spacing in the active fuel only, beginning at the bottom of the active fuel and proceeding to the top.

(c) The sum of the axial increments must be equal to the active fuel length given in Section 5.3 item 22.

(d) The information, $Y_{i}$ and $I_{i}$, must be in pairs; a pair may not be split between two lines. 
Standard PARET

Axial Mesh

Power Node Fluid Node

(11 nodes)

(10 nodes)

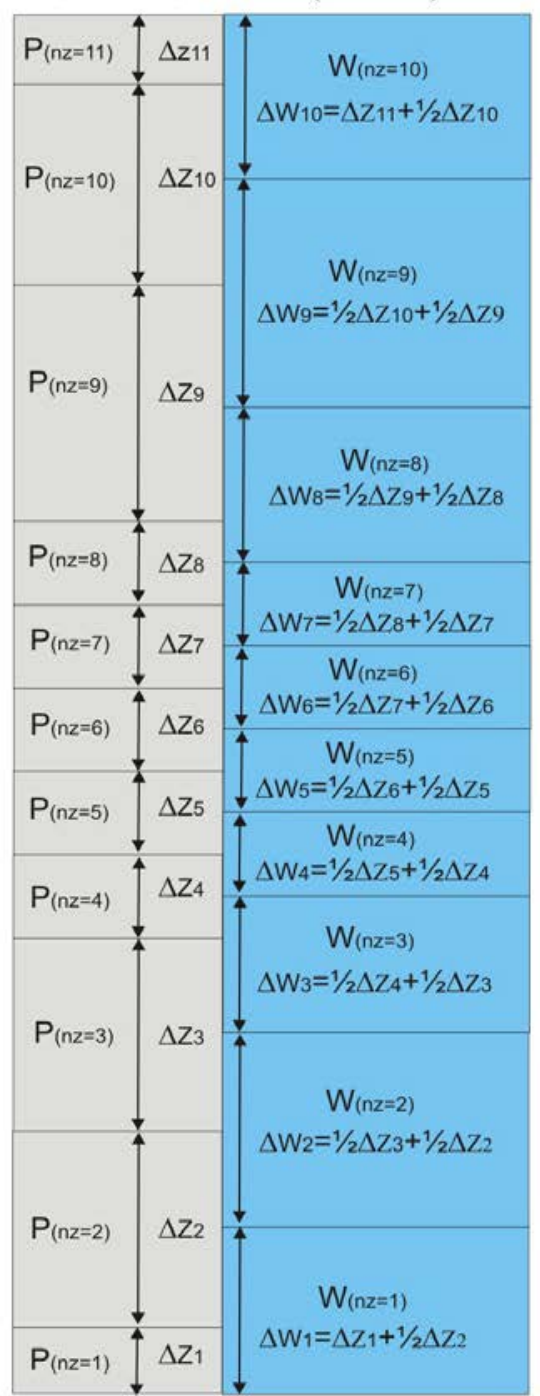

Optimum PARET Axial Mesh

Power Node Fluid Node

(11 nodes) (10 nodes)

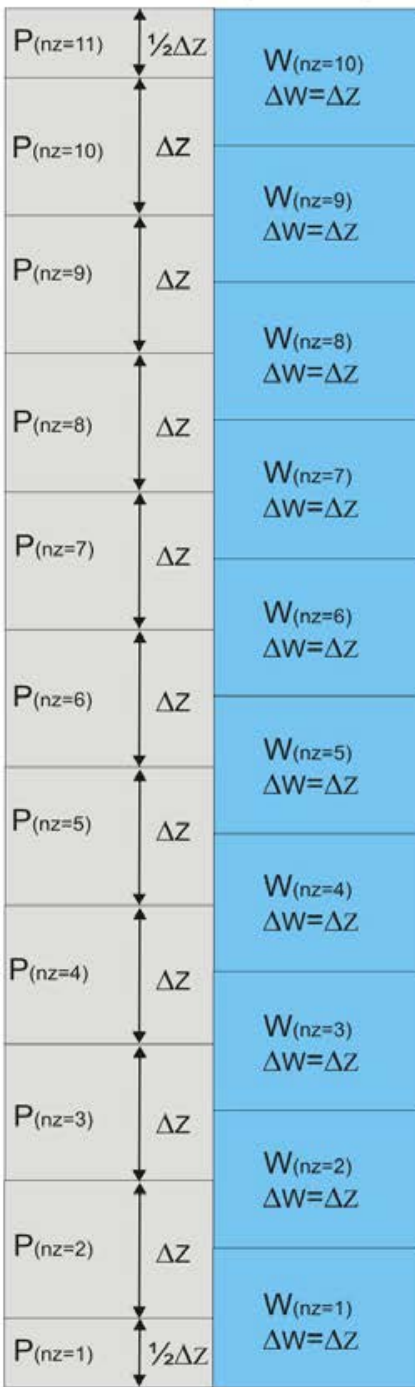

Figure 5.1 Axial Node Model for $\mathrm{NZ}=11$

The fluid mesh of region 1 is all of power node $1+$ half of power node 2 .

The fluid mesh of region 2 is half of power node $2+$ half of power node 3 .

The fluid mesh of region $\mathrm{j}$ is half of power node $\mathrm{j}+$ half of power node $\mathrm{j}+1 ; \mathrm{j}<\mathrm{NZ}-2$.

The fluid mesh of region NZ-1 is half of power node NZ-1 + all of power node NZ.

Notes:

1. Temperatures and enthalpies are edited on the Interfaces. 
2. An optimal axial mesh has first and last power nodes half the length of all of the other equal-length power nodes. This makes all fluid nodes equal-length. See Figure 5.1.

3. Figure 5.2 illustrates the axial geometry used for friction pressure loss calculations. 


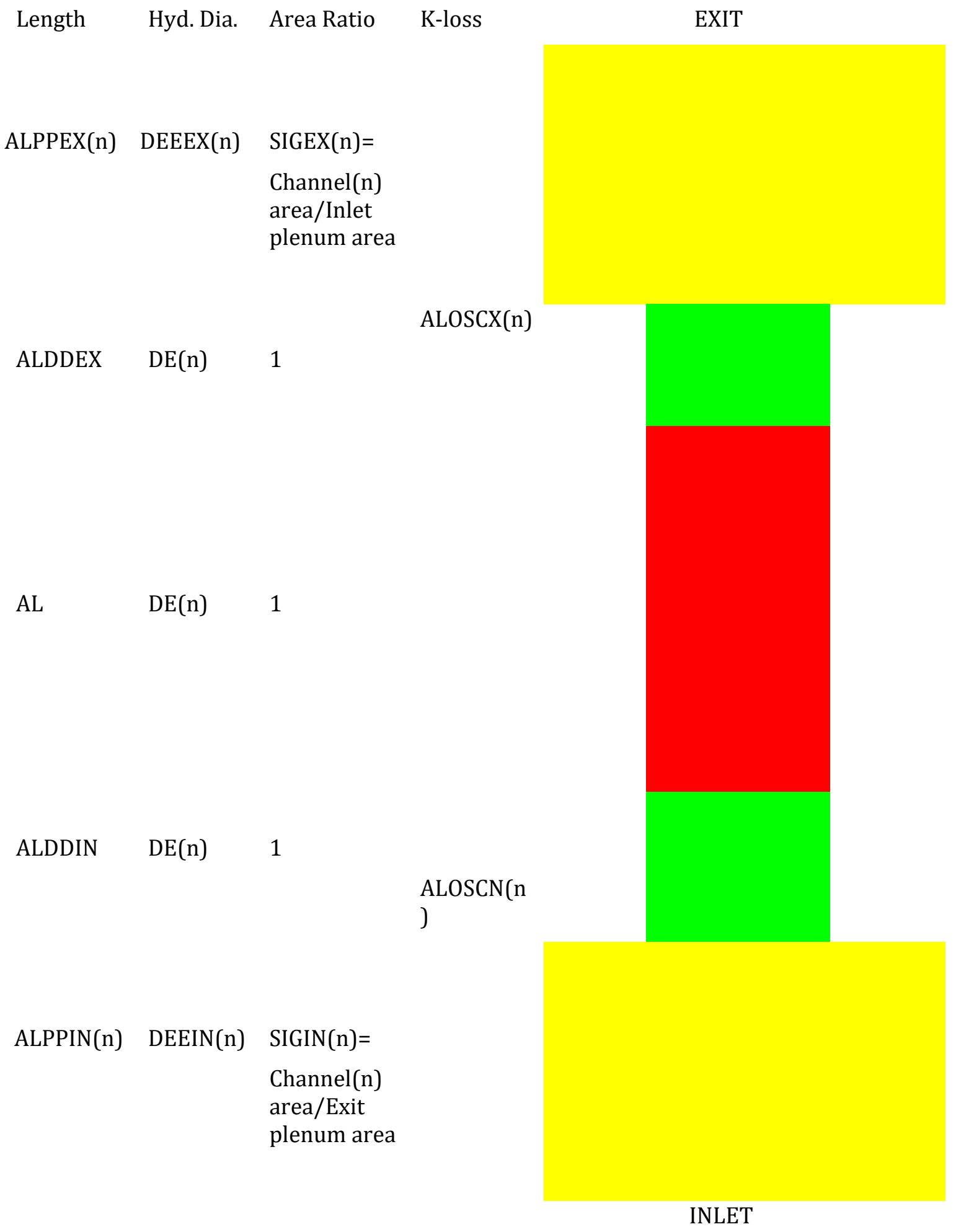

Figure 5.2 Axial Geometry Used in PARET/ANL for Friction Pressure Loss Calculations

Notes: 
1. AL, ALDDIN, ALDDEX are the same for all $\mathrm{n}$ channels.

2. Area and hydraulic diameter used in ALDDIN and ALDDEX are those for length AL and do not depend on INLET vs. EXIT location.

3. There is wall friction in all 5 length segments.

4. K-type pressure loss occurs with velocity based on conditions in axial node 1 or NZ of meat.

5. There are other pressure change effects (e.g., gravity) in PARET.

6. This Figure is drawn for up-flow (Table 10, AMFRIN $>0$ ).

7. "IN" refers to inlet; "EX" refers to exit.

8. HNCTOP is the sum of ALPPEX + ALDDEX.

9. HNCBOT is the sum of ALPPIN + ALDDIN.

\subsection{Individual Channel Information}

ITEM FORTRAN DESCRIPTION

The data for each channel are input in the form

$$
\rightarrow 5 \mathrm{k} 00, \mathrm{I}_{\mathrm{k}}, \mathrm{L}_{\mathrm{k}}, \mathrm{X}_{\mathrm{k} 1}, \mathrm{X}_{\mathrm{k} 2}, \mathrm{X}_{\mathrm{k} 3}, \mathrm{X}_{\mathrm{k} 4}, \mathrm{X}_{\mathrm{k} 5}, \mathrm{X}_{\mathrm{k} 6}, \mathrm{X}_{\mathrm{k} 7}, \mathrm{X}_{\mathrm{k} 8}
$$

or, if there are more than 9 channels:

$$
\rightarrow 5 \mathrm{kk} 00, \mathrm{I}_{\mathrm{k}}, \mathrm{L}_{\mathrm{k}}, \mathrm{X}_{\mathrm{k} 1}, \mathrm{X}_{\mathrm{k} 2}, \mathrm{X}_{\mathrm{k} 3}, \mathrm{X}_{\mathrm{k} 4}, \mathrm{X}_{\mathrm{k} 5}, \mathrm{X}_{\mathrm{k} 6}, \mathrm{X}_{\mathrm{k} 7}, \mathrm{X}_{\mathrm{k} 8}
$$

Note: place the " 50000 " series in the input file after any data of lesser number; i.e. at the end of the input file.

$1 \mathrm{a} \quad \mathrm{k}$ $\mathrm{k}=1$ for the first channel, 2 for the second, etc. If a problem includes several channels, some of which are flow-forced and some pressuredrop-forced, the flow-forced channels must be numbered lower than the pressure-drop-forced channels unless the pressure drop is obtained from Table 12. This is necessary because the pressure drop across the flow-forced channels must be calculated before it can be imposed across the pressure-drop-forced channels.

2a IFLOW(120) $\quad \mathrm{I}_{\mathrm{k}}$ is the flow parameter.

(a) 1 for flow-forced channel (flow is specified in Table 10).

(b) 2 for pressure-drop-forced-channel (pressure drop is specified in Table 12 or in item $3 a$ (b) below). This option is not functional. (c) 3 for buoyant forced flow (in all channels) with pump coast down superimposed from Table 17. Initial flow rate is computed from pressure drop given in next entry.

(d) 4, same as 3 except initial flow taken from value at zero time in Table 10. If a problem includes some channels which are flow-forced 
and some which are pressure-drop-forced, then the flow-forced channels must be first. Otherwise, channel ordering is unimportant.

(e) 5 , no pump; buoyancy only

3a DELP(120) $\quad \mathrm{L}_{\mathrm{k}}$ is

(a) Zero if $\mathrm{I}_{\mathrm{k}}=1$

(b) Either the pressure drop (lb / in..$^{2}$ or $\mathrm{Pa}$ ), or a channel number if $\mathrm{I}_{\mathrm{k}}$ $=2$ (must be positive or nonzero). In the former case, the pressure drop as a function of time is given in Table 12, but the initial pressure drop must be given here. In the latter case, the channel number given is the number of a flow-forced channel across which the pressure drop is calculated as a function of time. This same pressure drop is then automatically imposed across the pressure-drop-forced channel at corresponding times. The initial pressure drop is specified by DELP for $\mathrm{I}_{\mathrm{k}}=3$. If $\mathrm{I}_{\mathrm{k}}=4$ the floating point number provided affects the initial mass flow direction. If the first entry in Table 10 is positive, set DELP positive. If negative, set DELP negative (it is needed as a place holder) but a zero value should not be specified (DELP $\neq 0.0$ ).

$4 \mathrm{a} \quad \mathrm{RN}(120)$

Rod geometry: $\mathrm{X}_{\mathrm{k} 1}$ is the radial distance from the center of the rod to the node in the center of the water channel. $\mathrm{RN}$ is the radius enclosing the heated water per rod.

Plate geometry: $\mathrm{X}_{\mathrm{k} 1}$ is the radial distance from the center of the plate to the node in the center of the water channel. $\mathrm{RN}$ is the perpendicular distance from the fuel meat centerline to the center of the coolant channel. Note that the channels on either side of the plate are symmetric.

RN must be positive and greater than RS (the pin surface radius or slab half-thickness).

$\mathrm{X}_{\mathrm{k} 2}$ is the overall reactivity feedback weighting factor for channel $\mathrm{k}$. It is applied to four effects:

1. fuel meat reactivity change with temperature;

2. coolant reactivity change with temperature;

3. coolant reactivity change with void production or loss;

4. coolant reactivity change with clad expansion treated as equivalent void. It is assumed that, during a rapid transient, the clad may expand, whereas the lattice pitch or plate separation remains fixed. If Table 11 data are active, clad expansion will displace coolant just as void does.

Set $\mathrm{BM}(\mathrm{k})$ equal to the fraction of the core meat volume represented by channel $\mathrm{k}$. If IGEOM=0, this is the same as the fraction of plate width in channel $\mathrm{k}$ relative to the total plate width. All channels have the same meat and clad radial dimensions (RF, RC, RS), and axial length, but may have different water channel dimensions related to RN. In effect, $B M(k)$ is the fraction of core channels that are of type k. For IGEOM=1, all fuel 
pins are identical. $\mathrm{BM}(\mathrm{K})$ is the fraction of fuel pins that are represented by channel k. For IGEOM=2, the meat, clad, and coolant radial dimensions and widths can be different in different channels.

The sum of the $X_{k 2}$ summed over the NCHN channels must be unity. .

Note that input cards 5k00 provide, for each channel, values DVOID and DTMP. Input cards $5 \mathrm{kXX}$ provide for each axial node $\mathrm{m}$ in channel $\mathrm{k}$ the Doppler feedback equation coefficients DOPPLR, the coolant density feedback weighting factor VOIDVC, and the coolant temperature feedback weighting factor TEMPC. For example, the final feedback values (\$) obtained for axial node $m$ in channel $\mathrm{k}$ at time $\mathrm{t}$ from Doppler feedback is the product:

$\Delta \rho_{\text {dop }}(\mathrm{k}, \mathrm{m})=\mathrm{BM}(\mathrm{k}) \cdot[\mathrm{DOPPLR}(\mathrm{k}, \mathrm{m})] \cdot \mathrm{V}_{\text {fuel }}(\mathrm{j}) \cdot\left[\rho_{\mathrm{D}}(\mathrm{t}) \rho_{\mathrm{D}}\left(\mathrm{t}_{0}\right)\right] /$

$\mathrm{PF}$. The total volume of fuel in the core is PF.

Index $\mathrm{j}=(\mathrm{k}-1) * \mathrm{NZ}+\mathrm{m}$, where $1 \leq \mathrm{m} \leq|\mathrm{NCHN}|$;

$\mathrm{V}_{\text {fuel }}(\mathrm{j})$ is fuel volume in node $\mathrm{j}$;

$\rho_{D}(t)=\gamma_{0}+\gamma_{1} T+\gamma_{2} T^{2}+\gamma_{3} T^{n}$ at time $t$.

DOPPLR(k,m)] is variable $D_{j k}$ of Eq. (35).

6a $\quad \operatorname{ALOSCN}(120)$

$\mathrm{X}_{\mathrm{k} 3}$ is an unrecoverable pressure loss coefficient for abrupt change in the area at the inlet to the channel $\mathrm{k}(>0)$. This change is the proportionality constant between the pressure change across the abrupt area change and the fluid kinetic energy, where $\Delta \mathrm{p}=$ Loss coef. ${ }^{*} \rho v^{2} / 2 \mathrm{~g}$.

7a $\quad \operatorname{ALOSCX(120)~} \quad \mathrm{X}_{\mathrm{k} 4}$ is the outlet unrecoverable pressure loss coefficient analogous to $\mathrm{X}_{\mathrm{k} 3}$ in item $6 a(>0)$.

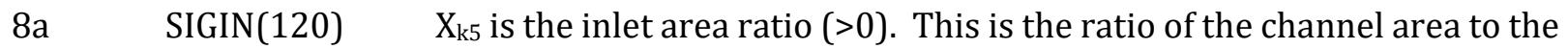
area of the associated inlet plenum.

9a SIGEX(120) $\quad \mathrm{X}_{\mathrm{k} 6}$ is the outlet area ratio (>0). This is the ratio of the channel area to the area of the associated outlet plenum.

10a DVOID(120) $\quad \mathrm{X}_{\mathrm{k} 7}$ is an overall density/void coefficient. The product of $\mathrm{X}_{\mathrm{k} 7}$ and $\mathrm{Z}_{\mathrm{kXx}}$ given in item $3 c$ below is the value of the local density/void coefficient at the axial node XX of channel $\mathrm{k}$. The product must be in $\$ / \%$ of core voided. If Table 20000 is present, it provides a scale factor. Note: the code assumes that this feedback is a negative term. Therefore enter DVOID $>0$ to create a negative feedback, assuming that VOIDVC is positive. If Table 20 is used, values of VCOWTH also should be positive because the final result is the product of DVOID*VOIDVC*[Table 20 interpolated value].

11a DTMP(120) $\quad \mathrm{X}_{\mathrm{k} 8}$ is the coolant temperature coefficient. The product of $\mathrm{X}_{\mathrm{k} 8}$ and TEMPC $_{\mathrm{kXx}}$ given in item $5 \mathrm{c}$ below is the value of the local coolant temperature coefficient at axial node XX of channel $\mathrm{k}$. The product must be $\$ /{ }^{\circ} \mathrm{F}$ or $\$ / C$. If Table 19000 is present, it provides a scale factor. Note: the code assumes that this feedback is a negative term. Therefore enter 
12a $\quad \mathrm{DE}(120)$

DTMP $>0$ to create a negative feedback, assuming that TEMPC is positive. If Table 19 is used, values of TCOWTH also should be positive because the final result is the product of DTMP*TEMPC*[Table 19 interpolated value].

$\mathrm{X}_{\mathrm{k} 9}$ is the equivalent hydraulic diameter of the channel, if supplied. Computed from other data if not supplied. The standard equation for hydraulic diameter is $\mathrm{D}_{\mathrm{h}}=4$ (Flow Area)/[Wetted Perimeter].

The $5 \mathrm{k} 01$ lines are input in the format

$\rightarrow 5 \mathrm{k} 01, \mathrm{~L}_{\mathrm{I}}, \mathrm{L}_{\mathrm{E}},(\mathrm{De})_{\mathrm{I}},(\mathrm{De})_{\mathrm{E}}, \mathrm{RFW}, \mathrm{RPW}$

Where

1b ALPPIN(120) $\mathrm{L}_{\mathrm{I}}$ is the length of the inlet plenum, $(\geq 0)$.

2b ALPPEX(120) $L_{E}$ is the length of the outlet plenum, $(\geq 0)$.

3b DEEIN(120)

4b DEEEX(120)

$(D e)_{I}$ is the inlet plenum equivalent hydraulic diameter, $(\geq 0)$.

$(\mathrm{De})_{\mathrm{E}}$ is the outlet plenum equivalent hydraulic diameter, $(\geq 0)$. Items (1), (2), (3), and (4) refer to the inlet and outlet plena to and from the coolant flow channels.

The following items are needed if IGEOM=2:

5b $\quad$ RFW(120)

Ratio of fuel meat width to FW (card 10YY \#21). Must be set to 1.0

6b RPW(120)

Ratio of plate width to PW (card 10YY \#20); used for calculation of hydraulic diameter. Must be set to 1.0

Begin a new input line here. The 5k02 lines are input in the format:

$\rightarrow$ 5k02, RFLOW,ZQW,RS,RF, RC, FACT3

7b RFLOW(120)

Scale factor on mass flow rate per unit area; used to match velocity.

The following 5 items are needed if IGEOM=2:

$8 b \quad$ ZQW

Heat source description for coolant (dimensionless and $\geq 0$ ). This parameter is the fraction of the heat deposited in the coolant of each channel. Its definition is not the same as that of $\mathrm{QW}$, which is used when IGEOM $=0$.The heat is assumed to be deposited instantaneously (e.g. gamma heating). To be consistent, one can use $\mathrm{QR}<1$ to place fraction QR of the heat generation in the fuel meat, and adjust QW such that

$\mathrm{QR}+\mathrm{QW}=1$ for each channel.

$9 \mathrm{~b} \quad \mathrm{RS} \quad$ Plate half thickness for this channel.

10b RF $\quad$ Fuel meat half thickness for this channel.

11b RC Half distance to inner surface of the clad.

12b FACT3 Set to 1.0 in current version of the code.

The following 6 items are needed if IGEOM=2: 
13b GAMA0K This term will have no effect in any problem other than to change the level of temperature feedback at $\mathrm{t}=0$. Set it to zero.

14b GAMA1K

15b GAMA2K

16b GAMA3K

17b GAMA4K

18b DOPPNK

5b PDR(120)

6b BOWPDR (120)

$1 c$

2c
Coefficients for the fuel temperature feedback for channel $\mathrm{k}$.

See Eq. (35) and also Section 3.2.2.3 item 4c of this document.

$\rho(\$)=\gamma_{0}+\gamma_{1} \mathrm{~T}+\gamma_{2} \mathrm{~T}^{2}+\gamma_{3} \mathrm{Tn} ; \mathrm{T}(\mathrm{C})=\mathrm{T}(\mathrm{K})-273.15$ if $\gamma_{4}=-273.15$

$\mathrm{T}(\mathrm{F})=\mathrm{T}(\mathrm{R})-459.67$ if $\gamma_{4}=-459.67$

Note: the code operates in R if NCHN is positive; else in K. Use of $\gamma_{4}$ as shown converts to $\mathrm{F}$ or $\mathrm{C}$.

Example: suppose that the fuel temperature feedback equation is:

$$
[0.001548+1.76 \mathrm{E}-5 \mathrm{~T}], \${ }^{\circ} \mathrm{C}
$$

This is equivalent to:

$$
[1.161 \mathrm{E}-5+1.32 \mathrm{E}-7 \mathrm{~T}], \Delta \mathrm{k} / \mathrm{k} /{ }^{\circ} \mathrm{C}
$$

The exponent, $n$, used in the fuel temperature feedback equation referred to above, items $13 \mathrm{~b}-17 \mathrm{~b}$

The following two items are needed (place after item $4 \mathrm{~b}$ above) if cylindrical pin geometry (IGEOM =1), IMODE is 0 or 1 , and ICHF is 5 or 6:

Pitch to diameter ratio

Bowed pitch to diameter ratio (only if $\mathrm{ICHF}=6$ )

The remaining 5000 - series lines $(X X \geq 02)$ are in the format

$\rightarrow 5 \mathrm{kXX}, \mathrm{Y}_{\mathrm{kXx}}, \mathrm{Z}_{\mathrm{kXx}}, \mathrm{DOPPLR}_{\mathrm{kXx}}, \mathrm{TEMPC}_{\mathrm{kXX}}$

Where

$\mathrm{k}$ is defined in Section 5.8 item $1 \mathrm{a}$ above. For IGEOM=0 or $1, \mathrm{XX}$ is 02 for the first line, 03 for the second, etc. For IGEOM=2, XX=04, 05, etc.

PFQ(120*97) $\quad Y_{\mathrm{kXx}}$ is the axial source description for axial node (XX-1). This parameter is the value of the ratio of the local fission power density to the coreaverage fission power density. The PFQ(K,J) array for each channel K must be normalized so that the axial average of PFQ satisfies the following constraint where PTOT(K) is the total power of channel $\mathrm{K}$ and POWER is total reactor power (input item 13 of Section 5.3). See [14] for details.

$$
\overline{\mathrm{PFQ}}(\mathrm{K})=\frac{\mathrm{PTOT}(\mathrm{K})}{\mathrm{POWER} \times \mathrm{BM}(\mathrm{K})}
$$

The axial average of PFQ for a channel is defined as 


$$
\overline{\mathrm{PFQ}}(\mathrm{K})=\frac{\sum_{\mathrm{J}=1}^{\mathrm{NZ}} \mathrm{PFQ}(\mathrm{K}, \mathrm{J}) \times \Delta \mathrm{Z}(\mathrm{J})}{\sum_{\mathrm{J}=1}^{\mathrm{NZ}} \Delta \mathrm{Z}(\mathrm{J})}
$$

The orientation of the axial power profile is as follows:

Table 10000 value at time zero is $>0$ (up flow) implies PFQ(1) is at the core bottom (inlet) for $\mathrm{XX}-1=1$;

Table 10000 value at time zero is $<0$ (downflow) implies PFQ(1) is at the core bottom (outlet) for $\mathrm{XX}-\mathrm{l}=1$

Note: For the downflow case, this last statement has been revised to resolve conflicting statements found in previous versions of the manual but does not reflect any change to the code itself. PFQ(1) corresponds to axial node 1 which is always at the bottom of the PARET/ANL channel, i.e., at the bottom of a coolant channel, fuel assembly or reactor core modeled.

3c VOIDVC $(120 * 97)$

4c DOPPLR

$(120 * 97)$

5c TEMPC $(120 * 97)$
$\mathrm{Z}_{\mathrm{kXx}}$ is the coolant density feedback weighting factor for axial node (XX1).

DOPPLR $_{k x x}$ represents the $D_{j, k}$ parameter in the feedback fuel temperature equation. Refer to Eq. (46) of [1].

$$
\left(\mathrm{R}_{\mathrm{D}}\right)_{\mathrm{j}, \mathrm{k}}=\mathrm{D}_{\mathrm{j}, \mathrm{k}}\left[\gamma_{0}+\gamma_{1}\left(\overline{\mathrm{u}}_{\mathrm{M}}+\gamma_{4}\right)+\gamma_{2}\left(\overline{\mathrm{u}}_{\mathrm{M}}+\gamma_{4}\right)^{2}+\gamma_{3}\left(\overline{\mathrm{u}}_{\mathrm{M}}+\gamma_{4}\right)^{\mathrm{n}}\right]
$$

The above $(\mathrm{Rd})_{\mathrm{jk}}$ must be scaled by $\left(\mathrm{VFj}_{\mathrm{k}} / \mathrm{PF}\right.$ in order to get its contribution to core reactivity. Here $\mathrm{VF}_{\mathrm{jk}}$ is the fuel volume in a particular channel $\mathrm{k}$ and axial node $\mathrm{j}$.

The units of the products $D_{j, k} \times \gamma_{i}(i=0,1,2,3)$ must be consistent with the units of $\left(R_{D}\right)_{j, k}$, which is dollars. In this equation the units of the mean temperature of the fuel, $\overline{\mathrm{u}}_{\mathrm{M}}$, may be in units of of or $\mathrm{C}$ and $\gamma_{4}$ may be used to convert to degrees Rankine or $\mathrm{K}$.

${ }^{T E M P C} C_{k x x}$ is the dimensionless coolant temperature feedback weighting factor for axial node (XX-1). See ANL revisions.

\subsection{Delayed Neutron Information}

[Type 6XXX data must not be provided for a power-level-specified problem. See Section 7.3 item 5: IPROP. A fatal error will be identified and the run will terminate.]

ITEM FORTRAN DESCRIPTION

VARIABLE

This information is input in the following format: 
$\rightarrow 6 X X X, Y_{1}, Z_{1}, Y_{2}, Z_{2}, \ldots, Y_{i}, Z_{i}, \ldots, Y_{n}, Z_{n}$

where $\mathrm{XXX}$ is 001 for the first line, 002 for the second, etc.

FRACT(30) $\quad Y_{i}$ is the delayed neutron fraction for group $i: Y_{i}=\beta_{i} / \beta(>0)$

$2 \quad \operatorname{DECAY}(30)$

$\mathrm{Z}_{\mathrm{i}}$ is the delayed neutron decay constant $\lambda_{\mathrm{i}}$ for group i (positive, nonzero, and units of sec-1).

(a) Number of pairs, $n$, is given in Section 5.3 item 9 as IDLYGP.

(b) Must be in pairs; a pair may not be split between two lines.

Notes: $\quad$ (c) Sum of all $Y_{i}$ must be in unity within a small tolerance of 0.001 ; i.e.

$$
\sum_{i=1}^{n} Y_{i}=1.0 \text {, or } \sum_{i=1}^{n} \beta_{i}=\beta \text {. }
$$

\subsection{Power or Reactivity Versus Time (Table 9) \\ ITEM FORTRAN DESCRIPTION \\ VARIABLE}

$1 \mathrm{a}$

NTBL9

This table is input in the following format:

$\rightarrow 9000, \mathrm{~N}$

where $\mathrm{N}$ is the number of pairs of entries in the table, $2 \leq \mathrm{N} \leq 100$.

The succeeding lines are of the form

$\rightarrow$ 9XXX, $Y_{1}, Z_{1}, Y_{2}, Z_{2}, \ldots, Y_{i}, Z_{i}, \ldots, Y_{n}, Z_{n}$

where $\mathrm{XXX}$ is 001 for the first line, 002 for the second, etc.

1b REACC(100) $\quad Y_{i}$ is

(a) Power (in megawatts) if Section 5.3 item 5 is zero

(b) Reactivity (in dollars) if Section 5.3 item 5 is unity

This is the reactivity which is externally inserted (i.e., not compensated reactivity). The first reactivity entry in the table, $\mathrm{Y}_{1}$, must be negative or zero. 
2b TBL9(100) $\quad Z_{\mathrm{i}}$ is the time (in seconds) associated with $\mathrm{Y}_{\mathrm{i}}$.

Notes:

(a) The information must be in pairs; a pair may not be split between two lines.

(b) The data must be in ascending order $\left(Z_{i} \leq Z_{i+1}\right)$ with $Z_{1}=0$ and the last value of $Z$ greater than the total transient time given in Section 5.3 item 29 (TRANST).

(c) There must be at least two pairs of table entries. The first entry $Y_{1}$ at time $\mathrm{t}=0$ can be precisely 0.0 if the problem begins with zero reactivity, or it can be a pure step if non-zero. The step can be either positive or negative. Subprogram table9 detects an error when the desired time $(\geq 0)$ is less than the given TBL9(1) beginning point, or when the desired time is greater than the last time point,

TBL9(NTBL9). 


\subsection{Coolant Inlet Mass Flux Versus Time (Table 10) \\ ITEM FORTRAN DESCRIPTION \\ VARIABLE \\ $1 \mathrm{a}$ \\ NTBL10 \\ This table is input according to the following format: \\ $\rightarrow 10000, \mathrm{~N}$ \\ where $\mathrm{N}$ is the number of pairs of entries in the table, $2 \leq \mathrm{N} \leq 100$. \\ Subsequent lines are in the form \\ $\rightarrow 10 X X X, Y_{1}, Z_{1}, Y_{2}, Z_{2}, \ldots, Y_{n}, Z_{n}$ \\ where $\mathrm{XXX}$ is 001 for the first line, 002 for the second, etc. \\ 1b AMFRIN(100) $\quad \mathrm{Y}_{\mathrm{i}}$ is the inlet mass flux $\left(\mathrm{kg} / \mathrm{s} / \mathrm{m}^{2}\right.$ or $\left.\mathrm{lb} / \mathrm{hr} / \mathrm{ft}^{2}\right)$; positive for up-flow, or negative for downflow. \\ 2b TBL10(100) $\quad Z_{\mathrm{i}}$ is the time (in seconds) associated with $\mathrm{Y}_{\mathrm{i}}$. \\ Notes: (a) The information must be in pairs; a pair may not be split between two lines. \\ (b) The data must be in ascending order $\left(\mathrm{Z}_{\mathrm{i}} \leq \mathrm{Z}_{\mathrm{i}+1}\right)$ with $\mathrm{Z}_{1}=0$ and the last value of $\mathrm{Z}$ greater than the total transient time given in Section 5.3 item 29. \\ (c) There must be at least two pairs of table entries. \\ (d) Subprogram tabl10 detects an error when the desired time ( $\geq 0$.) is less than the given TBL10(1) beginning point, or when the desired time is greater than the last time point, TBL10(NTBL10).}

\subsection{Percent Linear Thermal Expansion of the Clad Versus Temperature (Table 11) \\ ITEM FORTRAN DESCRIPTION \\ VARIABLE}

This table is input in the following format:

1a $\quad$ NTBL11 $\rightarrow 11000, \mathrm{~N}$

where $\mathrm{N}$ is the number of pairs of entries in the table, $2 \leq \mathrm{N} \leq 100$.

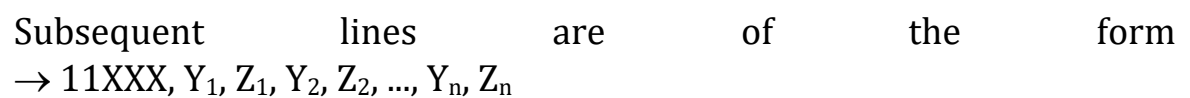
where $\mathrm{XXX}$ is 001 for the first line, 002 for the second, etc. 
1b YYCLAD(100) Yi is the percent linear thermal expansion of the clad (\%).

2b YCTEMP(100) $\quad \mathrm{Z}_{\mathrm{i}}$ is the temperature (K or ${ }^{\circ} \mathrm{F}$ ) associated with $\mathrm{Y}_{\mathrm{i}}$.

Notes:

(a) The information must be in pairs; a pair may not be split between two

lines.

(b) The data must be in ascending order $\left(Z_{i} \leq Z_{i+1}\right)$ and must include the maximum and minimum average temperatures of the clad to be encountered throughout the course of the problem. (c) There must be at least two pairs of table entries.

\subsection{Total Pressure Drop Versus Time (Table 12) \\ ITEM FORTRAN DESCRIPTION}

VARIABLE

This table is input in the following format:

$1 \mathrm{a}$

NTBL12

$\rightarrow 12000, \mathrm{~N}$

where $\mathrm{N}$ is the number of pairs of entries in the table, $2 \leq \mathrm{N} \leq 100$.

Subsequent lines are of the form $\rightarrow 12 X X X, Y_{1}, Z_{1}, Y_{2}, Z_{2}, \ldots, Y_{n}, Z_{n}$

where $\mathrm{XXX}$ is 001 for the first line, 002 for the second line, etc.

1b PRESSP(100) $\quad Y_{\mathrm{i}}$ is the total pressure drop, $\Delta \mathrm{p}_{\mathrm{T}}\left[\mathrm{N} / \mathrm{m}^{2}\right.$ (Pascal) or psi], across the channel.

2b TBL12(100) $\quad \mathrm{Z}_{\mathrm{i}}$ is the time (in seconds) associated with $\mathrm{Y}_{\mathrm{i}}$.

Notes:

(a) The information must be in pairs; a pair may not be split between two

lines.

(b) The data must be in ascending order $\left(Z_{i} \leq Z_{i+1}\right)$ with $Z_{1}=0$ and the last value of $\mathrm{Z}$ greater than the total transient time given in Section 5.3 item

29.

(c) There must be at least two pairs of table entries.

(d) Subprogram tabl12 detects an error when the desired time ( $\geq 0$.) is less than the given TBL12(1) beginning point, or when the desired time is greater than the last time point, TBL12(NTBL12).

\subsection{Table of Time Increment Versus Time (Table 14) [may be modified for restarts] \\ ITEM FORTRAN DESCRIPTION \\ VARIABLE}

This table is input in the following format:

1a $\quad$ NTBL14 $\rightarrow 14000, N$ 
where $\mathrm{N}$ is the number of pairs of entries in the table, $2 \leq \mathrm{N} \leq 10$.

Subsequent lines are of the form

$\rightarrow 14 X X X, Y_{1}, Z_{1}, Y_{2}, Z_{2}, \ldots, Y_{n}, Z_{n}$

where $\mathrm{XXX}$ is 001 for the first line, 002 for the second, etc.

1b TINCRR(10) $Y_{i}$ is the time increment (in seconds)

2b TBL14(10) $\quad \mathrm{Z}_{\mathrm{i}}$ is the reactor time at which time-step increment is to go into effect ( $\mathrm{Z}_{1}$ must be zero).

Notes:

(a) The information must be in pairs; a pair may not be split between two lines.

(b) The data must be in ascending order $\left(Z_{i} \leq Z_{i+1}\right)$, with $Z_{1}=0$. There must be at least two pairs of table entries.

(c) If two pairs of zeros are entered into Table 14, the code will calculate its own time step on the basis of the hydrodynamics.

\subsection{Table of Print Frequency Versus Time (Table 16) [May Be Modified For Restarts] \\ ITEM FORTRAN DESCRIPTION \\ VARIABLE}

This table is input in the format:

1a $\quad$ NTBL16 $\rightarrow 16000, N$

where $\mathrm{N}$ is the number of sets of entries in the table, $1 \leq \mathrm{N} \leq 10$.

Subsequent lines are of the form

$\rightarrow 16 X X X, Y_{1}, M_{1}, Z_{1}, Y_{2}, M_{2}, Z_{2}, \ldots, Y_{n}, M_{n}, Z_{n}$

where $\mathrm{XXX}$ is 001 for the first line, 002 for the second, etc.

1b TOPFQ(10) $\quad Y_{\mathrm{i}}$ is the print time increment (in seconds) for major output edits.

2b NPOFQ(10) $\quad \mathrm{M}_{\mathrm{i}}$ is the frequency of intermediate printout (i.e., every $\mathrm{M}_{\mathrm{i}}$ steps). $\mathrm{M}_{\mathrm{i}}$ is also the frequency of writing lines of key variables to files named like "abc.out chnn" on output units $40+\mathrm{nn}, 1 \leq \mathrm{nn} \leq|\mathrm{NCHN}|$.

3b TBL16(10) $\quad Z_{\mathrm{i}}$ is the reactor time at which print time increment is to go into effect ( $\mathrm{Z}_{1}$ must be zero).

Notes: 
(a) Major output edits will occur at

$0, Y_{1}, 2 Y_{1}, \ldots, Z_{1}, Z_{1}+Y_{2}, Z_{1}+2 Y_{2}, \ldots, Z_{2}, Z_{2}+Y_{3}, \ldots$, etc.

(b) Intermediate output edits will occur ever $\mathrm{M}_{\mathrm{i}}$ steps when $\mathrm{Z}_{\mathrm{i}}<$ time $<$ $\mathrm{Z}_{\mathrm{i}+1}$ ***

(c)The information must be in triplets; a triplet may not be split between two lines.

(d) The data must be in ascending order $\left(Z_{i} \leq Z_{i+1}\right)$, with $Z_{1}=0$.

(e) In addition to the output indicated in Section 7.3 item 10, the minimum burnout ratio, the minimum bubble detachment parameter (ETA), the maximum temperature in the coolant, clad, and fuel, and the nucleate (1), transition (2), film (3), and bulk (4) boiling point indicators are printed at each intermediate output time.

*** See the attached tabulation of increment choices by time step size (Table 5.1Table 5.1).

Table 5.1

Print-Edit Increment Selection for Table 16

\begin{tabular}{|l|l|l|l|l|l|l|}
\hline $\begin{array}{l}\text { Time Step, } \\
\text { seconds }\end{array}$ & $\begin{array}{l}\text { Major Edit } \\
\text { Increments }\end{array}$ & \multicolumn{2}{l}{$\begin{array}{l}\text { Number of Minor Edits per Increment } \\
\mathrm{M}_{\mathrm{i}}\end{array}$} & \multicolumn{2}{l|}{} \\
\hline Table 14 & $\mathrm{Y}_{\mathrm{i}}$ & 1 & 5 & 10 & 20 & 50 \\
\hline 0.05 & 2.0 & 40 & 8 & 4 & 2 & - \\
& 1.0 & 20 & 4 & 2 & 1 & - \\
& 0.5 & 10 & 2 & 1 & - & - \\
\hline 0.01 & 1.0 & 100 & 20 & 10 & 5 & 2 \\
& 0.5 & 50 & 10 & 5 & 2 & 1 \\
& 0.1 & 10 & 2 & 1 & - & - \\
\hline 0.005 & 1.0 & 200 & 40 & 20 & 10 & 4 \\
& 0.5 & 100 & 20 & 10 & 5 & 2 \\
& 0.1 & 20 & 4 & 2 & 1 & - \\
\hline 0.001 & 1.0 & 1000 & 200 & 100 & 50 & 20 \\
$(1 \mathrm{~ms})$ & 0.5 & 500 & 100 & 50 & 25 & 10 \\
& 0.1 & 100 & 20 & 10 & 5 & 2 \\
& 0.05 & 50 & 10 & 5 & 2 & - \\
\hline 0.0005 & 0.5 & 1000 & 200 & 100 & 50 & 20 \\
& 0.1 & 200 & 40 & 20 & 10 & 4 \\
& 0.05 & 100 & 20 & 10 & 5 & 2 \\
& 0.01 & 20 & 4 & 2 & 1 & - \\
\hline
\end{tabular}




\begin{tabular}{|l|l|l|l|l|l|l|}
\hline 0.0001 & 0.1 & 1000 & 200 & 100 & 50 & 20 \\
& 0.05 & 500 & 100 & 50 & 25 & 10 \\
& 0.01 & 100 & 20 & 10 & 5 & 2 \\
& 0.005 & 50 & 10 & 5 & 2 & 1 \\
\hline 0.00005 & 0.05 & 1000 & 200 & 100 & 50 & 20 \\
& 0.01 & 200 & 40 & 20 & 10 & 4 \\
& 0.005 & 100 & 20 & 10 & 5 & 2 \\
& 0.001 & 20 & 4 & 2 & 1 & - \\
\hline 0.000001 & 0.001 & 1000 & 200 & 100 & 50 & 20 \\
$(1 \mu \mathrm{s})$ & 0.0005 & 500 & 100 & 20 & 25 & 10 \\
& 0.0001 & 100 & 20 & 10 & 5 & 2 \\
& 0.00005 & 50 & 10 & 5 & 2 & - \\
\hline 0.0000005 & 0.0005 & 1000 & 200 & 100 & 50 & 20 \\
& 0.0001 & 200 & 40 & 20 & 10 & 4 \\
& 0.00005 & 100 & 20 & 10 & 5 & 2 \\
& 0.00001 & 20 & 4 & 2 & 1 & - \\
\hline
\end{tabular}

\subsection{Table of Pump Mass Flux Fraction Versus Time (Table 17)}

ITEM FORTRAN DESCRIPTION
VARIABLE

This table is input in the format

1a $\quad$ NTBL17 $\rightarrow 17000, \mathrm{~N}$

where $\mathrm{N}$ is the number of pairs of entries in the table, $2 \leq \mathrm{N} \leq 20$.

Subsequent lines are of the form

$\rightarrow 17 X X X, Y_{1}, Z_{1}, Y_{2}, Z_{2}, \ldots, Y_{n}, Z_{n}$

where $\mathrm{XXX}$ is 001 for the first line, 002 for the second, etc.

1b FLOWRT(20) $Y_{i}$ is the mass flux fraction of the coolant in the channel to its initial value ( $\mathrm{Y}_{1}$ must be 1.0).

2b TBL17(20) $\quad Z_{\mathrm{i}}$ is the reactor time corresponding to $\mathrm{Y}_{\mathrm{i}}\left(\mathrm{Z}_{1}\right.$ must be zero).

Notes:

(a) The information must be in pairs; a pair may not be split between two lines.

(b) The data must be in ascending order $\left(\mathrm{Z}_{\mathrm{i}} \leq \mathrm{Z}_{\mathrm{i}+1}\right)$, with $\mathrm{Z}_{1}=0$.

(c) There must be at least two pairs of table entries.

(d) This table is used in conjunction with $\mathrm{I}_{\mathrm{k}}=3$ or 4 only, as specified in Section 5.8 item 2a (IFLOW). 


\subsection{Table of Rod Worth Versus Rod Location or Time (Table 18)}

$\begin{array}{ll}\text { ITEM } & \text { FORTRAN } \\ \text { VARIABLE }\end{array}$

DESCRIPTION

This table is input in the format:

$1 \mathrm{a}$

NTBL18

$\rightarrow 18000, \mathrm{~N}$

where $\mathrm{N}$ is the number of pairs of entries in the table, $2 \leq \mathrm{N} \leq 20$.

Subsequent lines are of the form

$\rightarrow 18 X X X, Y_{1}, Z_{1}, Y_{2}, Z_{2}, \ldots Y_{n}, Z_{n}$

where $\mathrm{XXX}$ is 001 for the first line, 002 for the second, etc.

1b RODWTH(20) $\quad Y_{i}$ is the reactivity (\$) associated with the control rod. Negative values should be entered for a control rod which reduces reactivity.

$2 b \quad \operatorname{RODLOC}(20) \quad \mathrm{Z}_{\mathrm{i}}$ is either the rod position ( $\mathrm{ft}$ or $\mathrm{m}$ ) corresponding to $\mathrm{Y}_{\mathrm{i}}$ where the rate of motion is specified by RDRATE in Card 1113, or the time (sec) corresponding to $Y_{i}$ where RDRATE is set to -1.0 in Card 1113. If time

Notes: data is used, the values are relative to the start of rod motion.

Notes:

(a) The information must be in pairs; a pair may not be split between two lines.

(b) There must be at least two pairs of table entries.

\subsection{Table of Coolant Reactivity Change with Temperature (Table 19)}

\section{ITEM \\ FORTRAN}

VARIABLE

$1 \mathrm{a}$

NTBL19

\section{DESCRIPTION}

This table is input in the format:

$\rightarrow 19000, \mathrm{~N}$

where $\mathrm{N}$ is the number of pairs of entries in the table, $2 \leq \mathrm{N} \leq 10$.

Subsequent lines are of the form

$\rightarrow$ 19XXX, $Y_{1}, Z_{1}, Y_{2}, Z_{2}, \ldots Y_{n}, Z_{n}$

where $\mathrm{XXX}$ is 001 for the first line, 002 for the second, etc. 
TCOWTH(10) $\quad \mathrm{Y}_{\mathrm{i}}$ is the reactivity $(\$ /$ degree $\mathrm{K})$ associated with the paired temperature in TCOLOC.

2b TCOLOC $(10)$

$\mathrm{Z}_{\mathrm{i}}$ is the temperature in Kelvin or $\mathrm{F}$ corresponding to $\mathrm{Y}_{\mathrm{i}}$.

Note: The information must be in pairs; a pair may not be split between two lines. There must be at least two pairs of table entries, and no more than 10 pairs. The first reactivity entry applies for any temperature up to $\mathrm{Zi}$; the second applies between $\mathrm{Z}_{1}$ and $\mathrm{Z}_{2}$, and so on. The resulting integral reactivity worth is a piece-wise linear, continuous function.

This table may be omitted if Card 5k00 item 11a, DTMP, is sufficient (the coefficient is not temperature-dependent).

If this table is supplied, DTMP may be used to make the resulting reactivity change channel-dependent.

If T>TCOLOC(NTBL19), the last entry TCOWTH(NTBL19) is used to extrapolate the worth table.

\subsection{Table of Coolant Density/Void Reactivity Change (Table 20)}

$\begin{array}{ll}\text { ITEM } & \text { FORTRAN } \\ \text { VARIABLE }\end{array}$

DESCRIPTION

This table is input in the format:

1a $\quad$ NTBL20 $\rightarrow 20000, N$

where $\mathrm{N}$ is the number of pairs of entries in the table, $2 \leq \mathrm{N} \leq 10$.

Subsequent lines are of the form

$\rightarrow 20 X X X, Y_{1}, Z_{1}, Y_{2}, Z_{2}, \ldots Y_{n}, Z_{n}$

where $\mathrm{XXX}$ is 001 for the first line, 002 for the second, etc.

1b VCOWTH(10) $\quad Y_{i}$ is the reactivity (\$ per \% void) associated with the paired void \% in VCOLOC.

2b VCOLOC(10) $\quad \mathrm{Z}_{\mathrm{i}}$ is the void \% corresponding to $\mathrm{Y}_{\mathrm{i}}$.

Note: The information must be in pairs; a pair may not be split between two lines. There must be at least two pairs of table entries, and no more than 20 pairs.

The first reactivity entry applies for any void up to $\mathrm{Zi}$; the second applies between $\mathrm{Z}_{1}$ and $\mathrm{Z}_{2}$, and so on. The resulting integral reactivity worth is a piece-wise linear, continuous function. 
This table may be omitted if Card 5k00 item 10a, DVOID, is sufficient. If this table is supplied, DVOID may be used to make the resulting reactivity change channel-dependent.

VCOWTH(M) applies between VCOLOC(M)-VCOLOC(M+1)

If VOID \%>VCOLOC(NTBL20), the last entry VCOWTH(NTBL20) is used to extrapolate the worth table.

Example (void worth is always $\$ 0.1 / \%$ void):

$20000 \quad 2$

$200010.1 \quad 0.0$

$200020.1 \quad 100$.

\subsection{Table of Coolant Mixing After Flow Reversal (Table 21) \\ ITEM FORTRAN DESCRIPTION \\ VARIABLE}

This table is input in the format:

1a NTBL21

$\rightarrow 21000, \mathrm{~N}$

where $\mathrm{N}$ is the number of pairs of entries in the table, $2 \leq \mathrm{N} \leq 20$.

Subsequent lines are of the form

$\rightarrow 21 X X X, Y_{1}, Z_{1}, Y_{2}, Z_{2}, \ldots Y_{n}, Z_{n}$

where $\mathrm{XXX}$ is 001 for the first line, 002 for the second, etc.

1b TIME21(20) $\quad Y_{i}$ is the time after flow reversal (s) associated with the paired enthalpy mixing fraction of coolant last leaving the channel, in ENTH21. The first time entry should be 0 .

2b ENTH21(20) $\quad Z_{\mathrm{i}}$ is the bulk pool enthalpy mixing fraction corresponding to $Y_{i}$. At time $\mathrm{Y}_{1}=0, \mathrm{Z}_{1}$ should be 0 . The last entry, $\mathrm{Z}_{\mathrm{NTBL} 21}$, should be 1.0. If the last entry is 1.0, then the inlet enthalpy will be ENTHHS for time exceeding TIME21(NTBL21)+t(flow reversal).

The information must be in pairs; a pair may not be split between two lines. There must be at least two pairs of table entries, and no more than 20 pairs. The second applies between $Y_{1}$ and $Y_{2}$, and so on. The resulting mixing curve is a piece-wise linear, continuous function. See card type 1116, variable ENTHHS. 
If this table is omitted, the original 5-second linear mixing model will be used. Note: if card 1116 variable ENTHHS is supplied, the original 5second linear mixing model is modified to use ENTHHS instead of ENTHIN.

Example (this is a tabular version of the original 5-second model):

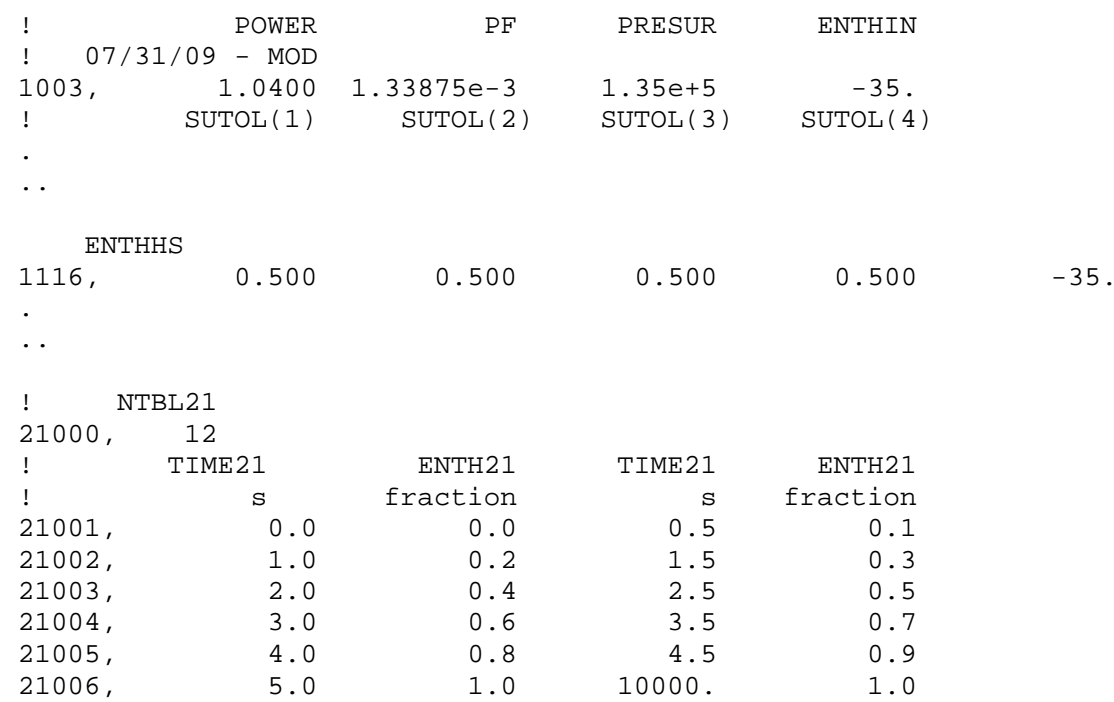

NOTE: The "missing" Table 13 is quality vs. vapor fraction, which is supplied in the coolant T-H properties input binary file.

\subsection{Steady-State Step Data}

The radial description refers to cylindrical geometry and half-plate thickness (symmetry assumed) to slab geometry. Each line is of the form
ITEM FORTRAN
DESCRIPTION
VARIABLE
$\rightarrow 22000, \mathrm{Y}, \mathrm{Z}$
y TIMSS Null transient duration. Recommended value is $100.0 \mathrm{sec}$ for forced flow (IFLOW=1 or 2) and $300.0 \mathrm{sec}$ for buoyancy driven forced flow (IFLOW $=3$ or 4 )
z DTSS
Null transient step size, sec. Recommended value is 0.001 . If set to 0 ., the steady-state iteration is bypassed.
To not perform the steady-state initialization, set both TIMSS and DTSS to 0.0 . Select this choice only to see the approximate starting point solution for all temperatures and flows. Unless the transient solution begins with a null transient (such as zero reactivity for the first second) the result will be unreliable. 


\title{
6 Files Used By PARETIANL
}

\author{
UNIT \\ NAME \\ DESCRIPTION \\ 1 (NIN) abc.inp \\ 2 (NSCAN) input.scan \\ user-created; supplied to PARET; up to 127 characters \\ (must end in inp) \\ $3 \quad$ abc.kin \\ $4 \quad$ groenfilm2.bin \\ 5 (NCOPY) input.short \\ 6 abc.out \\ 8 (N8)

$-$ \\ 8 (N8) H2O.lib or D20.lib \\ scratch file used for detection of illegal characters \\ such as tabs in the input file \\ automatically created; uses Unit 1 name supplied \\ to PARET; up to 127 characters; (automatically ends \\ with .kin). \\ film boiling heat transfer tables from Groeneveld, \\ in binary format \\ created by PARET/ANL from input.inp minus all comment \\ lines with ! in column 1 \\ created by PARET/ANL as standard output. Must not exist \\ prior to a computer run. \\ a scratch file containing water properties tables, \\ generated automatically at the start of a run \\ (light or heavy water, provided that IFLUID $=0$ or 1 ) \\ an "OLD" file containing water properties tables, \\ generated previously by a stand-alone properties \\ generator (light or heavy water, provided that IFLUID $=2$ \\ or 3) \\ 9 groen2006.2.bin CHF lookup tables from Groeneveld, in binary format \\ 10 (NSU) SUMMARY a binary output file of key time-dependent results: \\ 11 (NSU+1) SUMMARY.short a shortened version of the SUMMARY file containing \\ key time-dependent results, thinned from file SUMMARY \\ using a temperature tolerance of $0.5 \mathrm{C}$ recommended, but \\ user-selectable) \\ TIMES,POWER,REAC,(AMFR(I),I=1,NCHN),(BRM(I),I=1,NCHN), \\ (TCOOL(I),I=1,NCHN),(TCLAD(I),I=1,NCHN),(TCNTR(I),I=1,NCHN), \\ TCOUT(I),I=1,NCHN) \\ where

$\begin{array}{ll}\text { TIMES } & =\text { current time point, } \mathrm{s} \\ \text { POWER } & =\text { total power, } \mathrm{MW} \\ \text { REAC } & =\text { net reactivity, } \$ \\ \text { AMFR } & =\text { mass flux, } \mathrm{kg} / \mathrm{m}^{2} / \mathrm{s} \\ \text { BRM } & =\text { minimum burnout ratio }\end{array}$ \\ TCOUT =coolant outlet temperature
}


The following temperatures are peak values located anywhere along a channel:

TCOOL $=$ coolant temperature

TCLAD =clad surface temperature

TCNTR =fuel centerline temperature

12

14

15

20

41

$40+n n$

$\leq \mathrm{NCHN}$

91

92

101

101.short

$100+$ nn $\quad 1 n n . s h o r t$ a restart file

a second restart file

contains core average fuel meat temperature, average clad temperature, etc. vs. time. The output is created if ISUPPR $>0$

a debug output file of selected edits turned on at compilation by setting flag IDEBUG to 1

ASCII output like the SUMMARY file but specifically for channel 1, as a function of time, of key variables like unit 41; characters nn are the channel number,

External loop time vs. temperature results (ASCII); created only if NLUP2 $>0$

This is a shortened version of file external.out. Data are saved only if temperatures change at least 0.1 degree since the last saved data. This makes a much smaller file for use in any plotting program. This file is created after a successful run has reached completion.

Like unit 41, but shortened. ASCII output specifically for channel 1, as a function of time, of key variables (a shortened version of file 41 based on temperature changes being $\geq$ SUTOL from card 1116). That is, the differences between the present time point temperatures and the last saved time point temperatures are all at least SUTOL, for all four saved temperatures. Peak values are also collected for fuel, clad, coolant, and exit temperatures. In addition, the minimum positive period is also collected.

Like unit $40+n n$, but shortened. Characters nn are the channel number: $1 \leq \mathrm{nn} \leq \mathrm{NCHN}$. 


\section{How to Run PARETIANL}

Open a Linux window (or DOS window). Create a working directory (e.g. run) in which to run the code. Copy the executable file (for example, paret76.x or paret76win.exe) to directory run. One can alternatively use the linux command $\ln -\mathrm{s}$ to make a symbolic link to the executable file, rather than creating a copy in directory run.

Go to that working directory. Copy an input file of the form "abc.inp" in that directory. To run from the command line, in directory run, simply type the name of executable on your system.

Remember that the code will not overwrite a pre-existing file named abc.out, or abc.kin, but will check if it already exists. If so, it will terminate the run immediately. File abc.kin contains a limited edit of information at major edit time points. Files debug.out, input.short, and external.out are opened with status=unknown, so it is not essential that they be deleted prior to a run because they will be automatically deleted before new information is written. Files RESTRT1 and RESTRT2 are checked for existence prior to being reopened. Hence they need not be deleted, but will be overwritten when used. 


\section{Output Description}

\subsection{Main Output}

PARET/ANL generates several output files during each run. The main output file contains virtually all information produced by the code and requested by the user. Channel-specific output files contain tabulated data for a given channel at every time step.

The primary output file (unit 6) begins with date, time, and code version information. It then lists the input file. Next, the various input processor routines list the interpreted and expanded problem description derived from the input file.

Here is a sample output file (which is self-explanatory), starting with an input file listing:

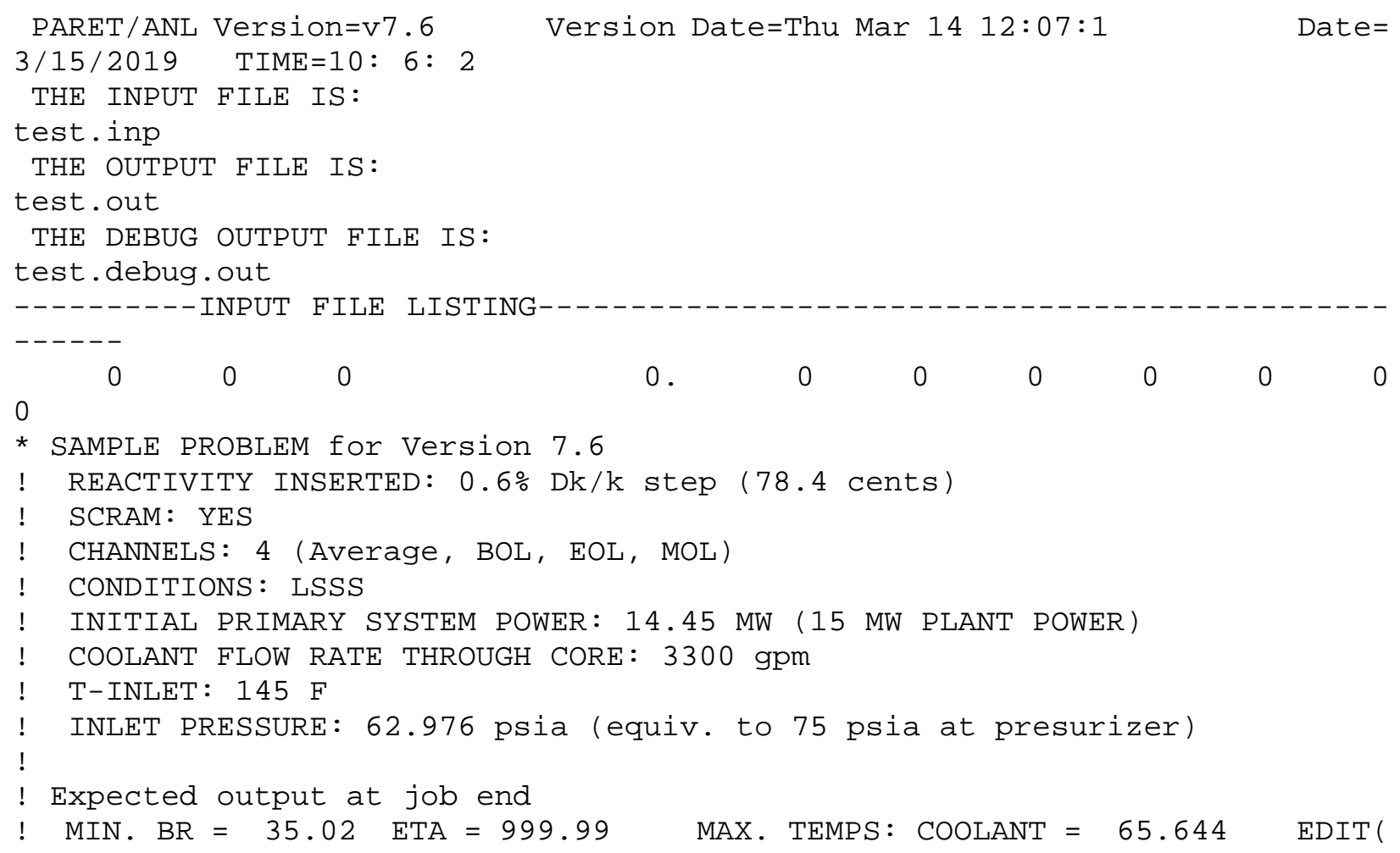


! power reduced at $t=0$ to prevent premature trip ! aaaaa11111111111122222222222233333333333344444444444455555555555566666666 6666

1003, $\quad 14.00 \quad 3.985 \mathrm{E}-3 \quad 4.342 \mathrm{E}+5 \quad-62.78 \quad 5.616 \mathrm{E}-4 \quad 2.396 \mathrm{E}-$

4

! RC $\quad$ PW (4) FW (5) AL ALDDIN (6) ALDDEX

1004, 2.650E-4 7.640E-2 7.284E-2 $6.096 \mathrm{E}-1 \quad 1.905 \mathrm{E}-2 \quad 1.905 \mathrm{E}-$

2

! BBEFF (7) EL (8) GRAV QW (9) TRANST RXXCON

$\begin{array}{lllllll}1005, & 7.650 \mathrm{E}-3 & 3.87 \mathrm{E}-5 & 9.80 \mathrm{E}+\odot & 0.00 \mathrm{E}+\odot & 2.2000 & 8.0 \mathrm{E}-\end{array}$

1

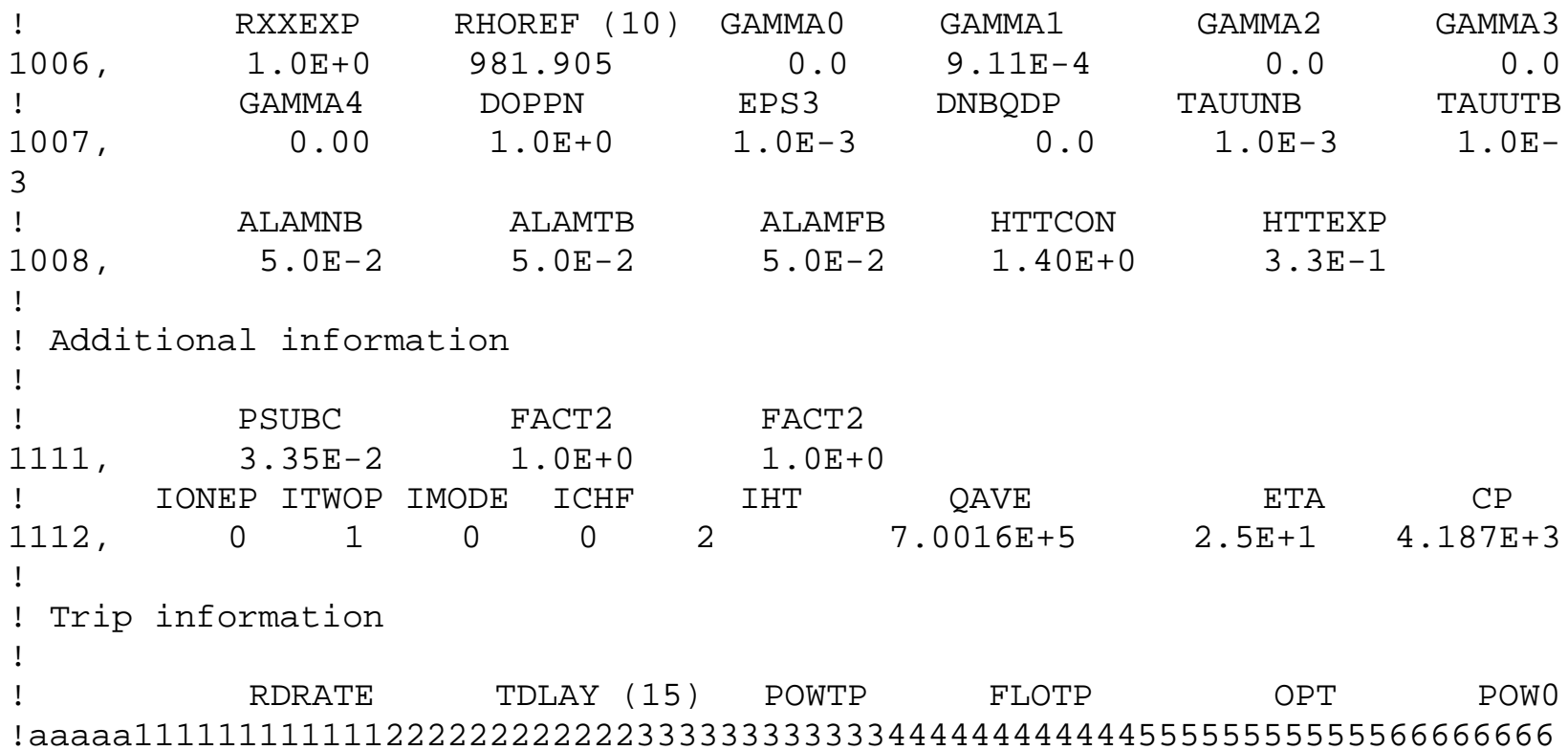
6666

$\begin{array}{lrrrrrr}1113, & -1 . \odot & 1.5 E-2 & 14.46 \odot & 8.55 E+1 & 6.5 E+\odot & 14.45 \\ ! & \text { HNCTOP } & \text { HNCBOT } & \text { REL_T } & \text { RET_T } & \text { FINF } & \text { PHI } \\ 1114, & 1.83 E+\odot & 7.10 E-1 & 2.30 E+3 & 3.99 E+3 & 1.0 & 0.66667\end{array}$

!

! Thermal properties

!

! Four classes of fuel plates -

! (1) Average plate, 1.25e21 f/cc; 4 materials (fuel, $\mathrm{Zr}, 6061-\mathrm{Al}$, oxide)

! (2) Peak heat flux, fresh; 4 materials (fuel, $\mathrm{Zr}, 6061-\mathrm{Al}$, oxide (nil))

! (3) Peak heat flux, EOL plate $(2.6 e 21 \mathrm{f} / \mathrm{Cc}) ; 4$ materials (fuel, $\mathrm{Zr}$, 6061Al, 0

! (4) Peak heat flux, MoL plate (1.4e21 f/cc); 4 materials (fuel, Zr, 6061Al, 0

!

2001, $\quad 4$

2002, $\quad 4$

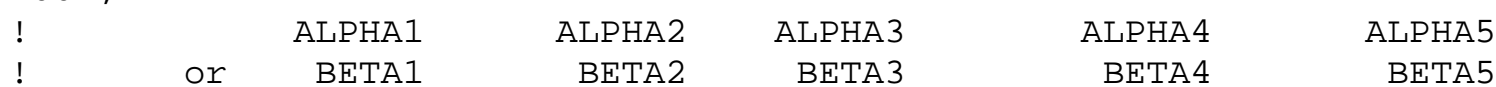

! Class 1, Fuel (1.25e21 f/cc)

2003, $\quad 0.0 \quad 2.379 \mathrm{E}-2$

2004, $\quad 0.0 \quad 1199.9$

! Class 1, Zr

$\begin{array}{rrr}11.412 & 0 . \odot & -273.15 \\ 1.923 E+6 & 0 . \odot & 0.0\end{array}$




\begin{tabular}{|c|c|c|c|c|c|}
\hline $\begin{array}{l}2005, \\
2006, \\
\text { ! Class }\end{array}$ & $\begin{array}{r}2.533 \mathrm{E}-6 \\
\Theta . \Theta \\
1, \text { oxide }\end{array}$ & $\begin{array}{r}7.082 \mathrm{E}-3 \\
739.2\end{array}$ & $\begin{array}{r}8.843 \\
1.859 \mathrm{E}+6\end{array}$ & $\begin{array}{r}2.992 \mathrm{E}+3 \\
0.0\end{array}$ & $\begin{array}{r}0.0 \\
-273.15\end{array}$ \\
\hline 2007, & 0.0 & $\odot . \odot$ & 2.25 & $\Theta .0$ & 0.0 \\
\hline $\begin{array}{l}2008, \\
! \text { Class }\end{array}$ & $\begin{array}{r}0.0 \\
1, \quad 6061-A 1\end{array}$ & $\Theta . \odot$ & 1.0 & $\odot . \odot$ & 0.0 \\
\hline 2009 & $-2.616 \mathrm{E}-4$ & 0.1792 & 147.8 & $0 . \odot$ & -273.15 \\
\hline $\begin{array}{l}\text { 2010, } \\
!\end{array}$ & 2.214 & -2685.0 & $4.252 E+6$ & $-3.774 \mathrm{E}+8$ & 0.0 \\
\hline $\begin{array}{l}2011 \\
! \text { Class }\end{array}$ & $\begin{array}{ll} & 4 \\
2, & \text { Fresh Fuel }\end{array}$ & & & & \\
\hline 2012, & $\odot . \odot$ & 3. $090 \mathrm{E}-2$ & 14.821 & $\odot . \odot$ & -273.15 \\
\hline $\begin{array}{l}2013, \\
! \text { Class }\end{array}$ & $2, \mathrm{Zr} \quad 0.0$ & 1199.9 & $1.923 E+6$ & 0.0 & 0.0 \\
\hline 2014 & $2.533 E-6$ & $7.082 E-3$ & 8.843 & $2.992 E+3$ & 0.0 \\
\hline $\begin{array}{l}2015, \\
! \text { Class }\end{array}$ & 2, oxide $^{\ominus .0}$ & 739.2 & $1.859 E+6$ & $0 . \odot$ & -273.15 \\
\hline 2016, & $\odot . \odot$ & $\odot . \odot$ & 2.25 & $\odot . \odot$ & 0.0 \\
\hline $\begin{array}{l}\text { 2017, } \\
\text { ! Class }\end{array}$ & $\begin{array}{r}0.0 \\
2, \quad 6061-A 1\end{array}$ & $\odot . \odot$ & 1.0 & $\odot . \odot$ & $\odot . \odot$ \\
\hline 2018, & $-2.616 \mathrm{E}-4$ & 0.1792 & 147.8 & 0.0 & -273.15 \\
\hline $\begin{array}{l}\text { 2019, } \\
!\end{array}$ & 2.214 & -2685.0 & $4.252 E+6$ & $-3.774 \mathrm{E}+8$ & ०. 0 \\
\hline $\begin{array}{l}2020, \\
! \quad \text { Class }\end{array}$ & $\begin{array}{l}4 \\
3, \text { EOL Fuel }\end{array}$ & $(2.6 \mathrm{E} 21 \mathrm{f} / \mathrm{cc})$ & & & \\
\hline 2021, & 0.0 & $2.009 \mathrm{E}-2$ & 9.633 & 0.0 & -273.15 \\
\hline $\begin{array}{l}2022, \\
! \quad \text { Class }\end{array}$ & $3, \mathrm{Zr} \quad 0.0$ & 1199.9 & $1.923 \mathrm{E}+6$ & $\odot . \odot$ & $0 . \Theta$ \\
\hline 2023, & $2.533 E-6$ & $7.082 E-3$ & 8.843 & $2.992 E+3$ & 0.0 \\
\hline $\begin{array}{l}2024, \\
\text { ! Class }\end{array}$ & 3, oxide $^{\ominus . \odot}$ & 739.2 & $1.859 \mathrm{E}+6$ & $\odot . \odot$ & -273.15 \\
\hline 2025 & 0.0 & $\odot . \odot$ & 2.25 & $\odot . \odot$ & 0.0 \\
\hline $\begin{array}{l}2026, \\
\text { ! Class }\end{array}$ & $\begin{array}{r}0.0 \\
3, \quad 6061-A 1\end{array}$ & $\odot . \odot$ & 1.0 & $\odot . \odot$ & $\odot . \odot$ \\
\hline 2027 & $-2.616 \mathrm{E}-4$ & 0.1792 & 147.8 & 0.0 & -273.15 \\
\hline 2028, & 2.214 & -2685.0 & $4.252 E+6$ & $-3.774 E+8$ & 0.0 \\
\hline $\begin{array}{l}2029, \\
! \quad \text { Class }\end{array}$ & $\begin{array}{l}4 \\
4, \quad \text { MOL Fuel }\end{array}$ & $(1.4 \mathrm{E} 21 \mathrm{f} / \mathrm{cc})$ & & & \\
\hline 2030 & $0 . \odot$ & $2.318 \mathrm{E}-2$ & 11.116 & 0.0 & -273.15 \\
\hline $\begin{array}{l}\text { 2031, } \\
\text { ! Class }\end{array}$ & $4, \mathrm{Zr} \quad 0.0$ & 1199.9 & $1.923 E+6$ & 0.0 & 0.0 \\
\hline 2032, & $2.533 E-6$ & $7.082 \mathrm{E}-3$ & 8.843 & $2.992 \mathrm{E}+3$ & 0.0 \\
\hline $\begin{array}{l}2033, \\
! \text { Class }\end{array}$ & 4, oxide $^{\ominus .0}$ & 739.2 & $1.859 \mathrm{E}+6$ & 0.0 & -273.15 \\
\hline 2034 & $0 . \odot$ & $\odot . \odot$ & 2.25 & $\odot . \odot$ & 0.0 \\
\hline $\begin{array}{l}2035, \\
! \text { Class }\end{array}$ & $\begin{array}{r}0.0 \\
4, \quad 6061-\mathrm{Al}\end{array}$ & $\odot . \odot$ & 1.0 & 0.0 & 0.0 \\
\hline 2036, & $-2.616 \mathrm{E}-4$ & 0.1792 & 147.8 & $\Theta . \odot$ & -273.15 \\
\hline $\begin{array}{l}2037 \\
!\end{array}$ & 2.214 & -2685.0 & $4.252 E+6$ & $-3.774 \mathrm{E}+8$ & $\odot . \odot$ \\
\hline ! Radi & 1 Plate Descri & iptions & & & \\
\hline
\end{tabular}


! Four classes of fuel plates -

! (1) Average plate, 1.25e21 f/cc; 4 materials (fuel, $\mathrm{Zr}, 6061-\mathrm{Al}$, oxide)

! (2) Peak heat flux, fresh; 4 materials (fuel, $\mathrm{Zr}, 6061-A l$, oxide (nil))

! (3) Peak heat flux, EOL plate $(2.6 \mathrm{e} 21 \mathrm{f} / \mathrm{cc}) ; 4$ materials (fuel, Zr, 6061Al, o

! (4) Peak heat flux, MOL plate $(1.4 \mathrm{e} 21 \mathrm{f} / \mathrm{cc}) ; 4$ materials (fuel, $\mathrm{Zr}, 6061$ Al, 0

$$
\text { ! }
$$

$\begin{array}{rc}4 & 12 \\ \text { KK } & \text { ICOMP }\end{array}$

\section{79287E-5} 2. 5400E-5 7. 41293E- 5 $1.4986 \mathrm{E}-5$

$6 \quad 1$

$7 \quad 2$

114

123
11

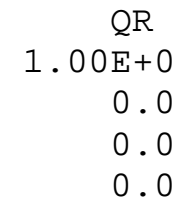

11

1. $\odot \odot E+\odot$

$\odot .0$

$\odot .0$

$\odot .0$

!

! Class 3

3012 ,

3013 ,

$\begin{array}{lr}3 & 3 \\ 4.3180 E-5\end{array}$

412

11

3014 ,

2. $5400 \mathrm{E}-5$

9. $5250 \mathrm{E}-5$

6

7

1

1. $\odot \odot E+\odot$

$\odot . \odot$

0.0

0.0

$3016, \quad 2.3622 \mathrm{E}-5 \quad 12$

!

! Class 4

\begin{tabular}{|c|c|c|c|c|}
\hline 3017, & $\begin{array}{ll}4 & 4\end{array}$ & 4 & 12 & 11 \\
\hline 3018, & $4.3180 E-5$ & 6 & 1 & $1.00 \mathrm{E}+\odot$ \\
\hline 3019, & $2.5400 \mathrm{E}-5$ & 7 & 2 & 0.0 \\
\hline 3020, & $9.5250 \mathrm{E}-5$ & 11 & 4 & 0.0 \\
\hline 3021, & $1.6002 \mathrm{E}-5$ & 12 & 3 & 0.0 \\
\hline
\end{tabular}

!

! Axial plate description

$!$

! 4001, $\quad 2.903 \mathrm{E}-2^{\mathrm{KJ}} 21$

$4001, \quad 2.540 \mathrm{E}-2 \quad 24$

!

! Individual channel information

!

! Channel 1 (Average Channel)

\begin{tabular}{|c|c|c|c|c|c|c|}
\hline & IFLOW DELP & RN (22) & BM & ALOSCN & ALOSCX & SIGIN \\
\hline 5100 & $1 \quad 0$ & $1.7011 \mathrm{E}-3$ & 0.99901 & $\odot . \odot \mathrm{E}+\odot$ & $\odot . \odot E+\odot$ & 1.0 \\
\hline 5100 & $\begin{array}{r}1.0 \\
\text { 1. }\end{array}$ & $3.04 \mathrm{E}-1$ & $1.630 \mathrm{E}-3$ & 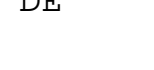 & 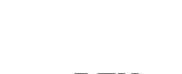 & \\
\hline
\end{tabular}




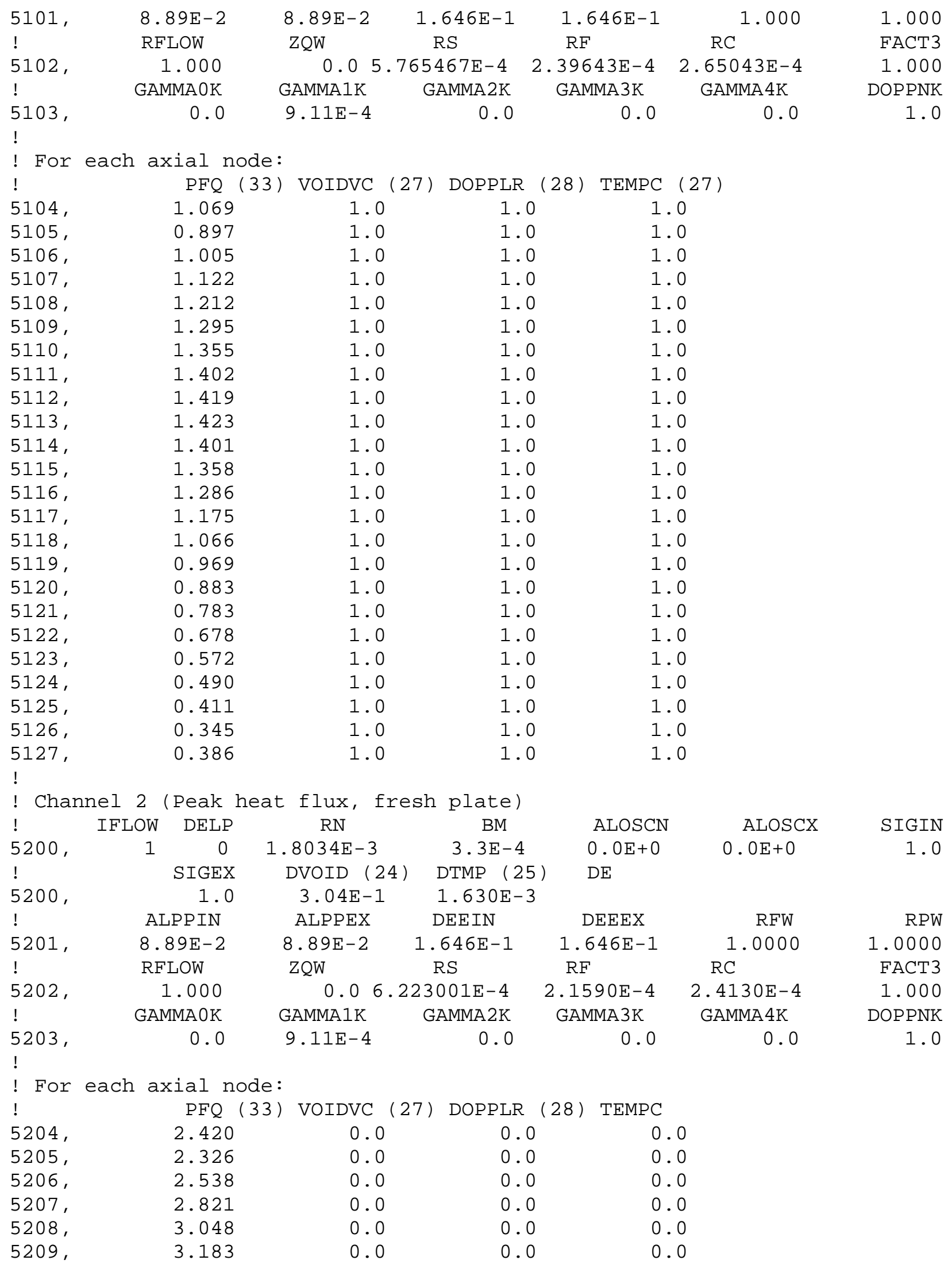




\begin{tabular}{|c|c|c|c|c|}
\hline 5210, & 3.367 & $\odot .0$ & $\odot . \odot$ & $\odot . \odot$ \\
\hline 5211, & 3.445 & 0.0 & $\Theta . \odot$ & 0.0 \\
\hline 5212, & 3.508 & 0.0 & $\Theta . \Theta$ & 0.0 \\
\hline 5213, & 3.461 & 0.0 & $\odot . \odot$ & 0.0 \\
\hline 5214, & 3.398 & 0.0 & $\odot . \odot$ & 0.0 \\
\hline 5215, & 3.241 & 0.0 & 0.0 & 0.0 \\
\hline 5216, & 2.958 & 0.0 & 0.0 & 0.0 \\
\hline 5217, & 2.451 & 0.0 & 0.0 & 0.0 \\
\hline 5218, & 1.990 & 0.0 & $\Theta . \odot$ & 0.0 \\
\hline 5219, & 1.758 & 0.0 & $\Theta . \Theta$ & 0.0 \\
\hline 5220, & 1.537 & 0.0 & $\Theta . \Theta$ & 0.0 \\
\hline 5221, & 1.299 & 0.0 & $\Theta .0$ & 0.0 \\
\hline 5222, & $1.0 \odot \odot$ & $\odot . \odot$ & $\odot . \odot$ & 0.0 \\
\hline 5223, & $\odot .727$ & 0.0 & $\odot . \odot$ & $\odot . \odot$ \\
\hline 5224, & 0.599 & 0.0 & $\odot .0$ & 0.0 \\
\hline 5225, & 0.494 & 0.0 & $\odot .0$ & 0.0 \\
\hline 5226, & $\odot .426$ & $\odot . \odot$ & $\odot . \odot$ & $\odot .0$ \\
\hline 5227, & 0.417 & $\odot . \odot$ & 0.0 & 0.0 \\
\hline
\end{tabular}

! Channel 3 (Peak heat flux, EOL plate)

\begin{tabular}{|c|c|c|c|c|c|c|}
\hline$!$ & IFLOW & RN & BM & ALOSCN & ALOSCX & SIGIN \\
\hline 5300, & $\begin{array}{l}0 \\
0\end{array}$ & $1.7254 \mathrm{E}-3$ & $3.3 E-4$ & $\odot . \odot \mathrm{E}+\odot$ & $\odot . \odot \mathrm{E}+\odot$ & 1.0 \\
\hline & SIGEX & DVOID (24) & DTMP (25) & $\mathrm{DE}$ & & \\
\hline 5300, & 1.0 & 3. 04E-1 & $1.630 \mathrm{E}-3$ & & & \\
\hline$!$ & ALPPIN & ALPPEX & DEEIN & DEEEX & RFW & RPW \\
\hline $\begin{array}{l}5301, \\
!\end{array}$ & $\begin{array}{l}8.89 E-2 \\
\text { RFLOW }\end{array}$ & $\begin{array}{l}\text { 8.89E-2 } \\
\text { ZQW }\end{array}$ & $\begin{array}{c}\text { 1. } 646 \mathrm{E}-1 \\
\mathrm{RS}\end{array}$ & $\begin{array}{l}1.646 \mathrm{E}-1 \\
\mathrm{RF}\end{array}$ & $\mathrm{RC}^{1.0000}$ & $\begin{array}{r}1.0000 \\
\text { FACT3 }\end{array}$ \\
\hline 5302, & 1.000 & 0.06 .4 & $59220 E-4$ & $2.1590 E-4$ & $2.4130 \mathrm{E}-4$ & 1.000 \\
\hline$!$ & GAMMAOK & GAMMA1K & GAMMA2K & GAMMA3K & GAMMA4K & DOPPNK \\
\hline 5303, & 0.0 & $9.11 \mathrm{E}-4$ & 0.0 & 0.0 & 0.0 & 1.0 \\
\hline
\end{tabular}

!

! For each axial node:

! PFQ (33) VOIDVC (27) DOPPLR (28) TEMPC

\begin{tabular}{|c|c|c|c|c|}
\hline 5304, & 1.921 & $\odot . \odot$ & 0.0 & 0.0 \\
\hline 5305, & 1.852 & $\odot . \odot$ & $\odot . \odot$ & $\odot .0$ \\
\hline 5306, & 2.024 & $\odot . \odot$ & $\odot . \odot$ & 0.0 \\
\hline 5307, & 2.216 & $\odot . \odot$ & $\odot . \odot$ & 0.0 \\
\hline 5308, & 2.336 & $\odot . \odot$ & $\odot . \odot$ & 0.0 \\
\hline 5309, & 2.496 & $\odot . \odot$ & $\odot . \odot$ & 0.0 \\
\hline 5310, & 2.549 & $\odot . \odot$ & $\odot . \odot$ & 0.0 \\
\hline 5311, & 2.642 & 0.0 & $\odot .0$ & 0.0 \\
\hline 5312, & 2.610 & 0.0 & 0.0 & 0.0 \\
\hline 5313, & 2.640 & 0.0 & 0.0 & 0.0 \\
\hline 5314, & 2.601 & $\odot . \odot$ & $\odot . \odot$ & 0.0 \\
\hline 5315, & 2.542 & $\odot . \odot$ & $\odot . \odot$ & 0.0 \\
\hline 5316, & 2.501 & $\odot . \odot$ & $\odot . \odot$ & 0.0 \\
\hline 5317, & 2.364 & $\odot . \odot$ & $\odot . \odot$ & 0.0 \\
\hline 5318, & 2.161 & 0.0 & 0.0 & 0.0 \\
\hline 5319, & 1.940 & $\odot . \odot$ & $\odot . \odot$ & 0.0 \\
\hline 5320, & 1.776 & 0.0 & 0.0 & 0.0 \\
\hline 5321, & 1.446 & 0.0 & $\odot .0$ & 0.0 \\
\hline 5322, & $\odot .952$ & 0.0 & $\odot .0$ & 0.0 \\
\hline 5323, & 0.537 & 0.0 & 0.0 & 0.0 \\
\hline
\end{tabular}




$\begin{array}{lllll}5324, & 0.425 & 0.0 & 0.0 & 0.0 \\ 5325, & 0.339 & 0.0 & 0.0 & 0.0 \\ 5326, & 0.299 & 0.0 & 0.0 & 0.0 \\ 5327, & 0.302 & 0.0 & 0.0 & 0.0\end{array}$

! Channel 4 (Peak heat flux, MOL plate, $96 \mathrm{MWd}$ )

\begin{tabular}{|c|c|c|c|c|c|c|}
\hline & IFLOW & $\mathrm{RN}$ & BM & ALOSCN & ALOSCX & SIGIN \\
\hline & 1 & $1.7652 \mathrm{E}-3$ & $3.3 E-4$ & $\odot . \odot \mathrm{E}+\odot$ & $\odot . \odot \mathrm{E}+\odot$ & 1.0 \\
\hline & SIGEX & DVOID (24) & DTMP (25) & $\mathrm{DE}$ & & \\
\hline 5400, & 1.0 & 3. $04 \mathrm{E}-1$ & $1.630 \mathrm{E}-3$ & & & \\
\hline$!$ & ALPPIN & ALPPEX & DEEIN & DEEEX & RFW & RPW \\
\hline 5401, & $8.89 E-2$ & $8.89 E-2$ & $1.646 \mathrm{E}-1$ & $1.646 \mathrm{E}-1$ & 1.0000 & 1.0000 \\
\hline ! & RFLOW & ZQW & RS & RF & $\mathrm{RC}$ & FACT3 \\
\hline 5402, & 1.000 & 0.0 & $38302 \mathrm{E}-4$ & $2.1590 \mathrm{E}-4$ & $2.4130 \mathrm{E}-4$ & 1.000 \\
\hline ! & GAMMAOK & GAMMA1K & GAMMA2K & GAMMA3K & GAMMA4K & DOPPNK \\
\hline 5403 & $\odot . \odot$ & $9.11 \mathrm{E}-4$ & $\odot . \odot$ & $\odot . \odot$ & $0 . \odot$ & 1.0 \\
\hline
\end{tabular}

!

! For each axial node:

\begin{tabular}{|c|c|c|c|c|}
\hline ! & PFQ (33) & VOIDVC (27) & DOPPLR (28) & TEMPC \\
\hline 5404, & 2.027 & 0.0 & 0.0 & 0.0 \\
\hline 5405, & 1.976 & ๑. 0 & 0.0 & $\odot . \odot$ \\
\hline 5406, & 2.184 & $\odot . \odot$ & 0.0 & 0.0 \\
\hline 5407, & 2.409 & 0.0 & $\odot . \odot$ & 0.0 \\
\hline 5408, & 2.570 & 0.0 & 0.0 & 0.0 \\
\hline 5409, & 2.755 & $\odot .0$ & 0.0 & $\odot .0$ \\
\hline 5410, & 2.885 & $\odot . \odot$ & $\odot . \odot$ & 0.0 \\
\hline 5411, & 2.981 & $\odot . \odot$ & $\odot . \odot$ & 0.0 \\
\hline 5412, & 3.019 & $\odot . \odot$ & $\odot . \odot$ & 0.0 \\
\hline 5413, & 3.045 & $\odot .0$ & 0.0 & 0.0 \\
\hline 5414, & 3.038 & $\odot . \odot$ & $\odot . \odot$ & $\odot . \odot$ \\
\hline 5415, & 2.990 & $\odot . \odot$ & $\odot . \odot$ & $\odot . \odot$ \\
\hline 5416, & 2.881 & 0.0 & $\Theta .0$ & 0.0 \\
\hline 5417, & 2.712 & 0.0 & $\Theta .0$ & 0.0 \\
\hline 5418, & 2.479 & $\odot .0$ & 0.0 & $\odot .0$ \\
\hline 5419, & 2.242 & $\odot .0$ & 0.0 & 0.0 \\
\hline 5420, & 1.993 & $\odot . \odot$ & $\odot .0$ & $\odot .0$ \\
\hline 5421, & 1.653 & $\odot . \odot$ & 0.0 & 0.0 \\
\hline 5422, & 1.073 & 0.0 & $\Theta .0$ & 0.0 \\
\hline 5423, & 0.610 & 0.0 & 0.0 & 0.0 \\
\hline 5424, & 0.473 & 0.0 & 0.0 & 0.0 \\
\hline 5425, & 0.386 & 0.0 & $\Theta . \Theta$ & 0.0 \\
\hline 5426, & 0.322 & 0.0 & $\Theta .0$ & 0.0 \\
\hline 5427, & 0.331 & $\odot . \odot$ & 0.0 & 0.0 \\
\hline
\end{tabular}

! Delayed neutron information (29)

!

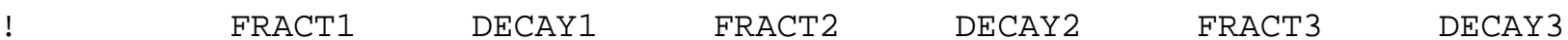
6001, 3.293E-2 1.240E-2 2.190E-1 $3.05 \mathrm{E}-2 \quad 1.962 \mathrm{E}-1 \quad 1.110 \mathrm{E}-$ 1

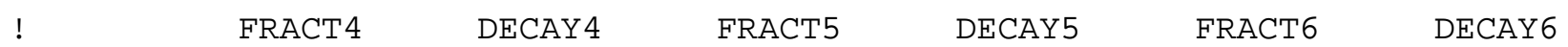
6002, $3.948 \mathrm{E}-1 \quad 3.010 \mathrm{E}-1 \quad 1.152 \mathrm{E}-1 \quad 1.14 \mathrm{E}+\Theta \quad 4.187 \mathrm{E}-2 \quad 3.010 \mathrm{E}+\odot$ !

! Reactivity insertion over $60 \mathrm{~ms}$ 


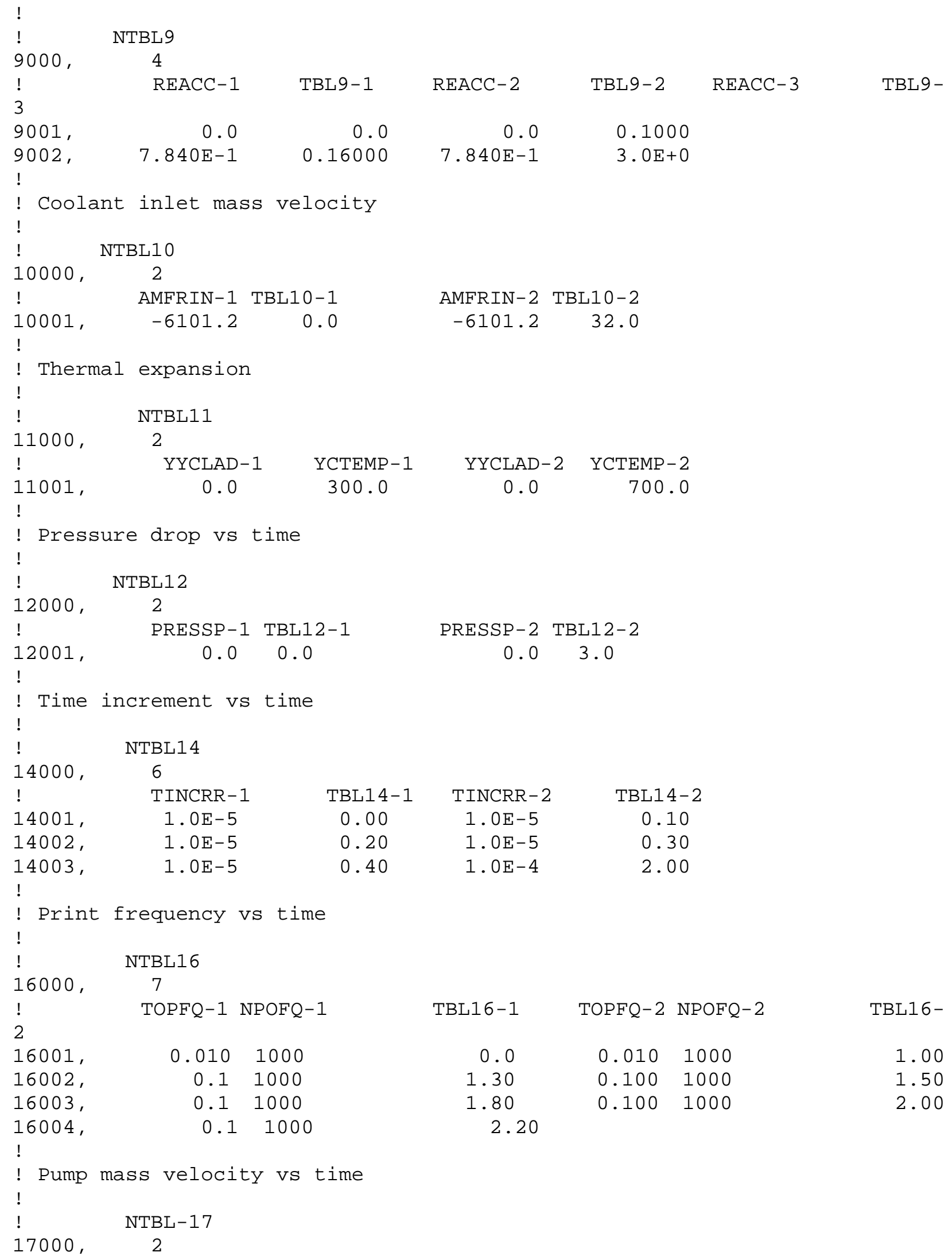




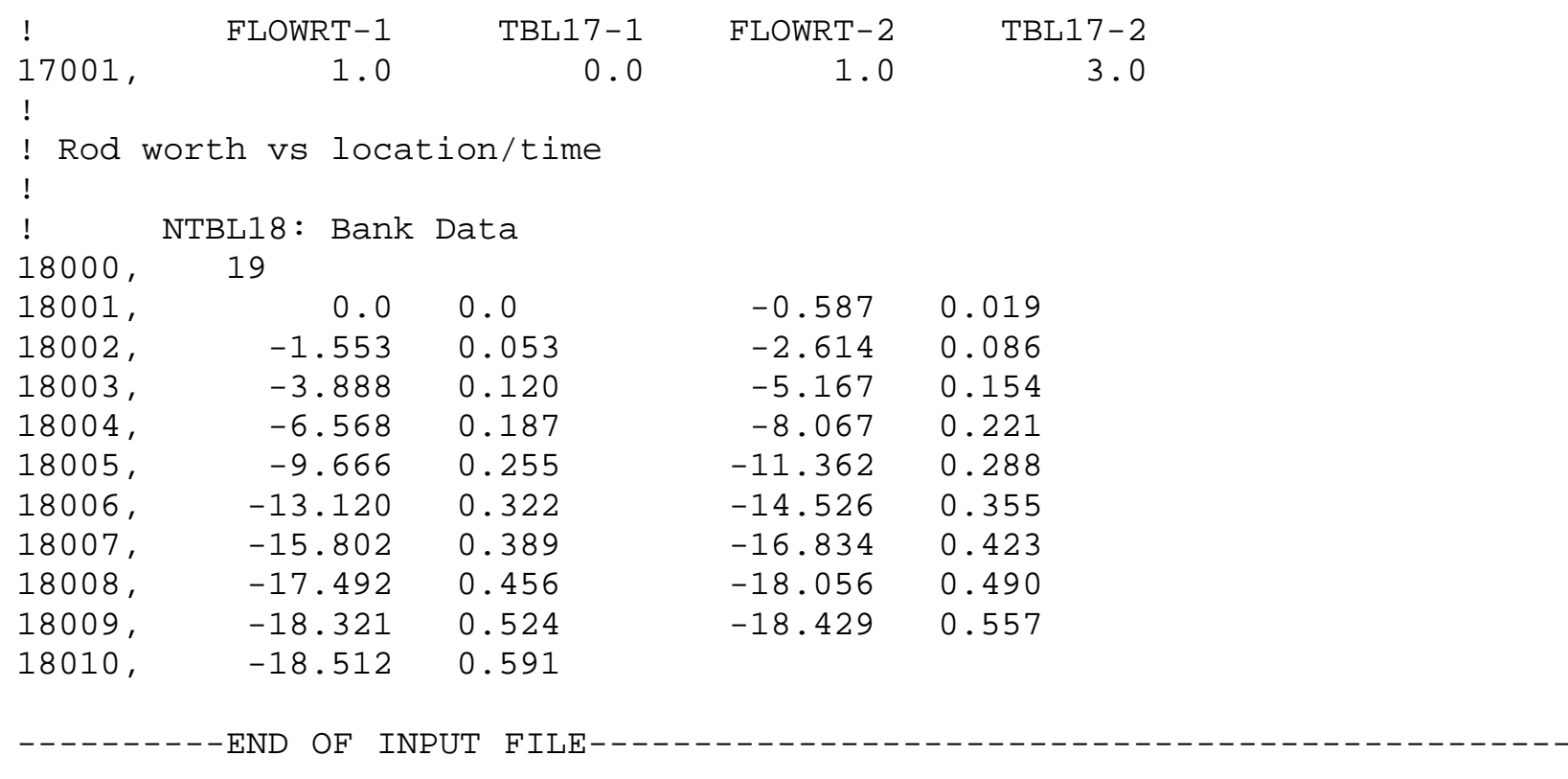

This section shows results from processing Type 1000 input:

$\begin{array}{lccccc}\text { no bad characters found } & & & \\ \text { IRSTRT }= & \odot \text { IFREQ }= & \odot \text { ICHNG }= & \odot \text { NFILE= } & \odot \text { TTIME= }= & \odot . \odot \odot \odot \odot E+\odot \odot \\ \text { IFLUID }= & \odot \text { INAME }= & \odot \text { JPROP }= & \odot \text { NLUP2 }= & \odot \text { IDBL }= & 1 \text { INORM }= \\ \odot \text { IOPT }= & \odot & & & \end{array}$

JPROP IS A DUMMY PLACEHOLDER (NOT USED ANYMORE)

ONLY DOUBLE PRECISION OF PARET/ANL IS NOW SUPPORTED (IDBL IS A DUMMY PLACEHOLDER)

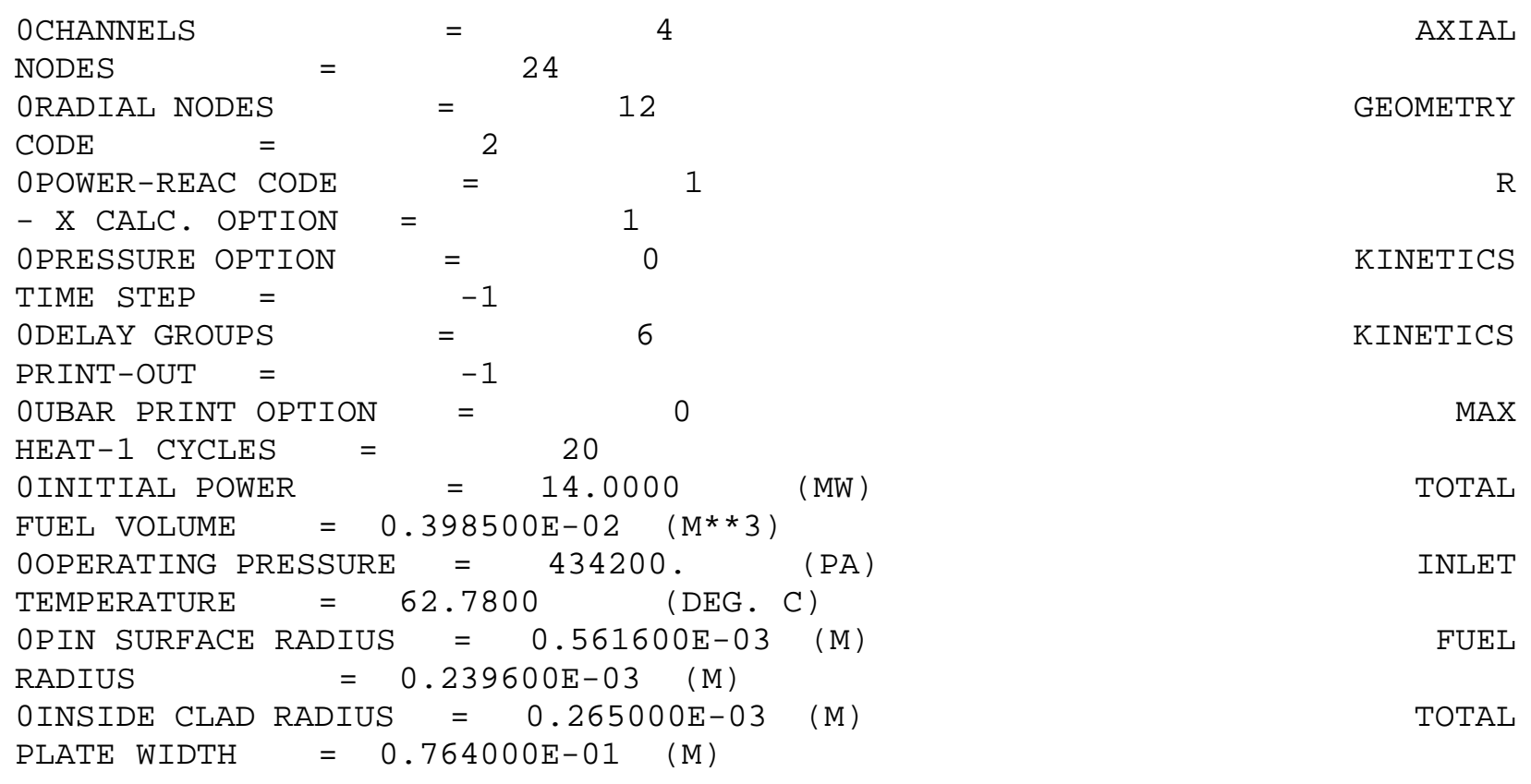




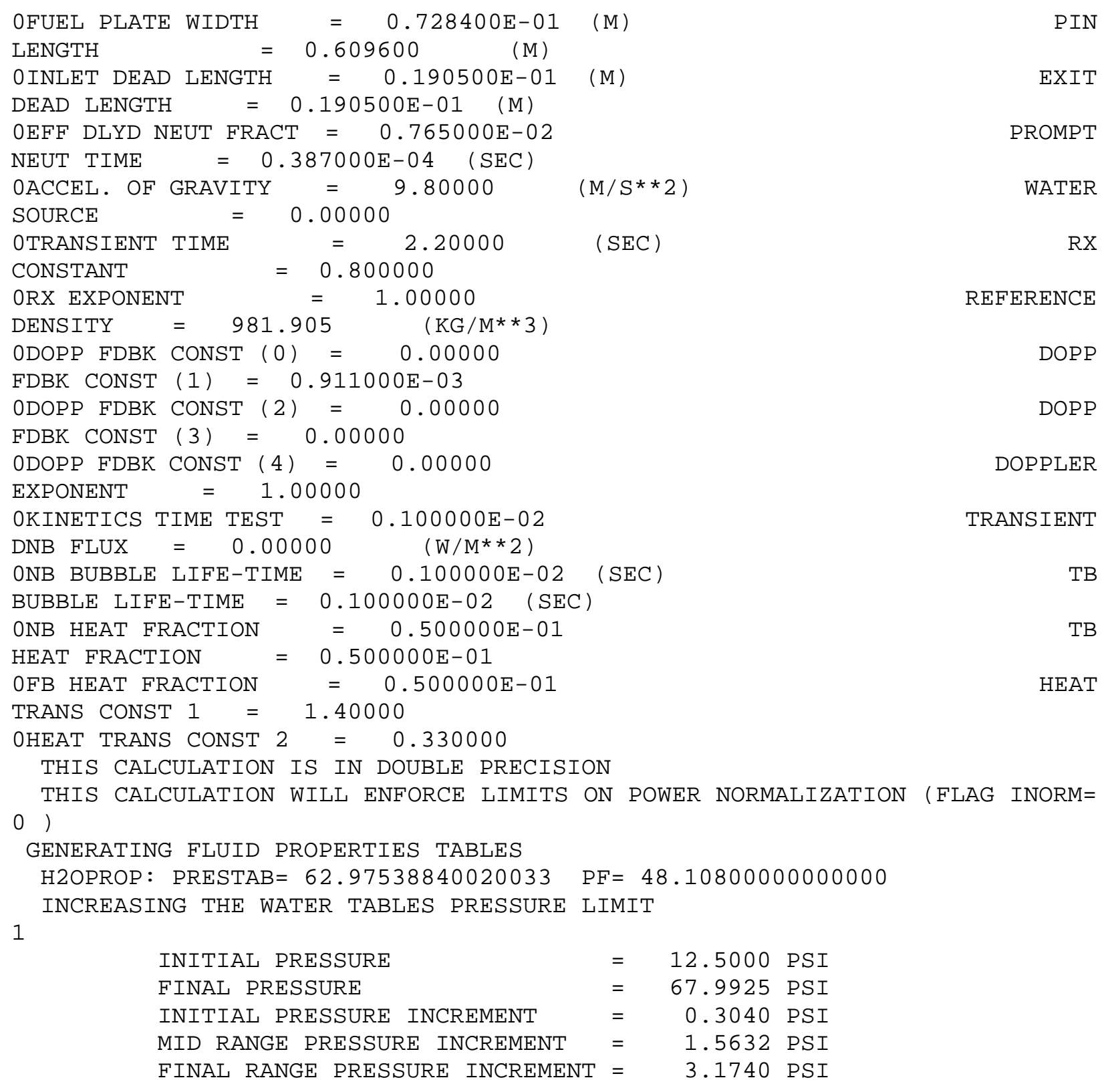

(M) PIN

$\begin{array}{ll}\text { (M) } & \text { EXIT }\end{array}$ 


$\begin{array}{ll}10 & 25.3099 \\ 11 & 26.8731 \\ 12 & 28.4364 \\ 13 & 29.9996 \\ 14 & 31.5628 \\ 15 & 33.1261 \\ 16 & 34.6893 \\ 17 & 36.2526 \\ 18 & 39.4266 \\ 19 & 42.6006 \\ 20 & 45.7745 \\ 21 & 48.9485 \\ 22 & 52.1225 \\ 23 & 55.2965 \\ 24 & 58.4705 \\ 25 & 61.6445 \\ 26 & 62.9754 \\ 27 & 67.9925 \\ \text { FRICTION FACTOR }\end{array}$

FRICTION FACTOR DATA ON RECORD 56

$A(1)=1.000000000000000 \quad A(1412)=1800.000000000000$ $\mathrm{RECORD}=57: \mathrm{A}(\mathrm{I}), \mathrm{I}=1,2160$

$A(1)=12.50000000000000 \quad A(2160)=6.388089962855990$

LIGHT WATER FLUID PROPERTIES HAVE BEEN GENERATED

OTHE FOLLOWING CARD IS NOT A TITLE CARD AS WAS EXPECTED, SKIPPING TO NEXT TITLE CARD.

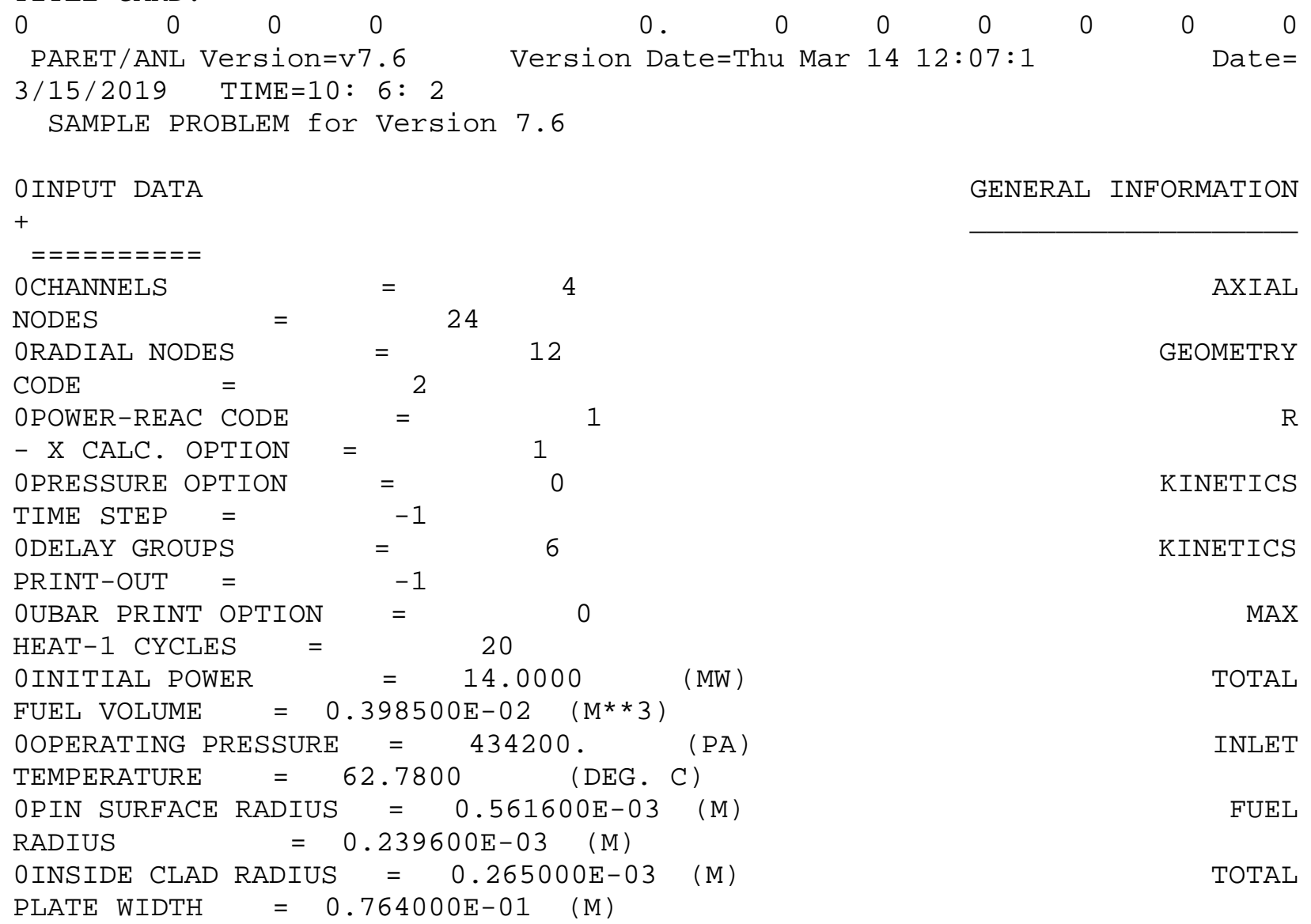




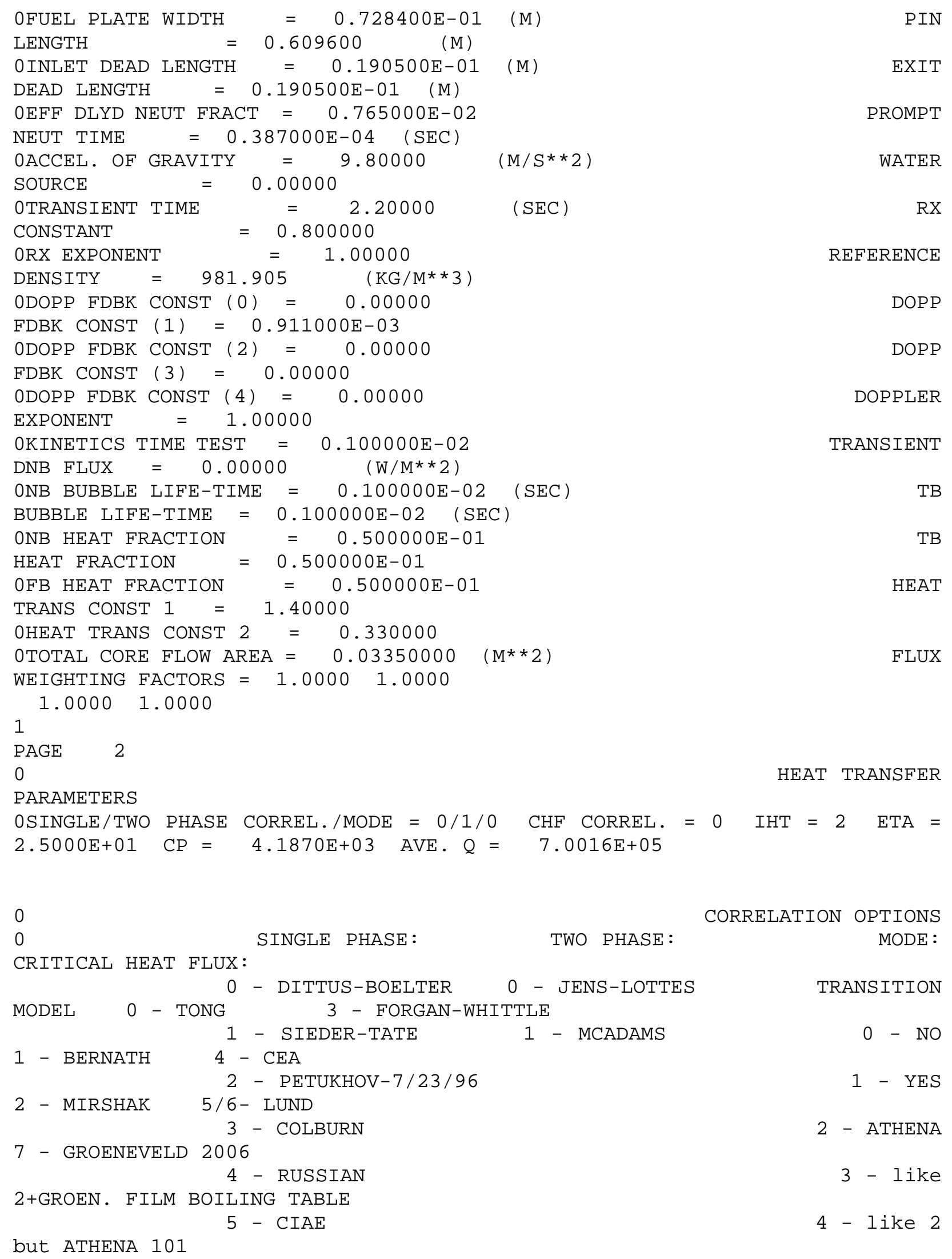


6 - DB-MOD.

5 - like 3

but ATHENA 101

IDENTIFIER， JHT :

FLOW AND HEAT TRANSFER REGIME

- NUCLEATE BOILING

- TRANSITION BOILING

1 - LAMINAR 5

2 - NATURAL CONVECTION 6

$\begin{array}{ll}3 \text { - TURBULENT } & 7\end{array}$

- FILM BOILING

- USING HTRANO(IHT=@)

4 - TRANSIENT 8

REVISED SINGLE PHASE HEAT TRANSFER COEFFICIENT SUBROUTINE USED: $\quad \mathrm{NU}=1.400$ FOR LAMINAR FLOW.

ENTRANCE EFFECTS WITH LAMINAR FLOW ARE INCLUDED.

$\odot$

CONTROL

TRIP SET POINTS

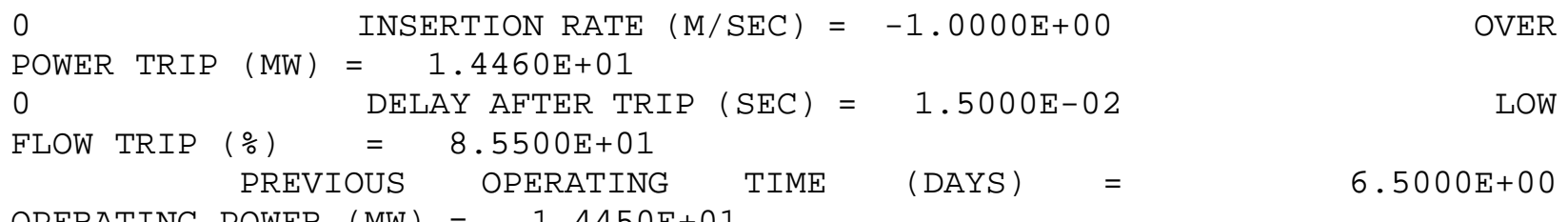

OPERATING POWER $(\mathrm{MW})=1.4450 \mathrm{E}+01$

INLK SETTING REL_T $=2300.000000000000 \quad$ RET_T $=3990.0000000000000 \quad$ FINF= $1.000000000000000 \quad \mathrm{PHI}=0.6666700000000000$

$\odot$

CONVECTION EFFECTS

ACTIVE CORE $=7.1000 \mathrm{E}-01 \mathrm{M}$

ABOVE ACTIVE CORE $=1.8300 \mathrm{E}+00 \mathrm{M}$

LAMINAR TO TURBULENT TRANSITION REYNOLDS NUMBER RANGE:

2300. T0 3990.

$=6.66670 \mathrm{E}-01$

CARD TYPE 1115 IS NOT PRESENT; THEREFORE A PERIOD TRIP CANNOT BE ACTUATED CARD TYPES 1116 \& 1117 ARE NOT PRESENT; SUTOL SET TO DEFAULT OF 0.5 C FILTER; DECAY HEAT MODEL DEFAULT SET TO 2005

CARD TYPE 1117 IS NOT PRESENT; IDKOPT SET TO DEFAULT OF $\odot$ FOR 2005 ANSI/ANS

5.1 DECAY HEAT

DEFAULT MEV/FISSION SET TO 200.000000000000९

FINAL FLOW REVERSAL INLET ENTHALPY ENTHHS $=262567.8253173828 \mathrm{~J} / \mathrm{kg}$

1

PAGE 3 


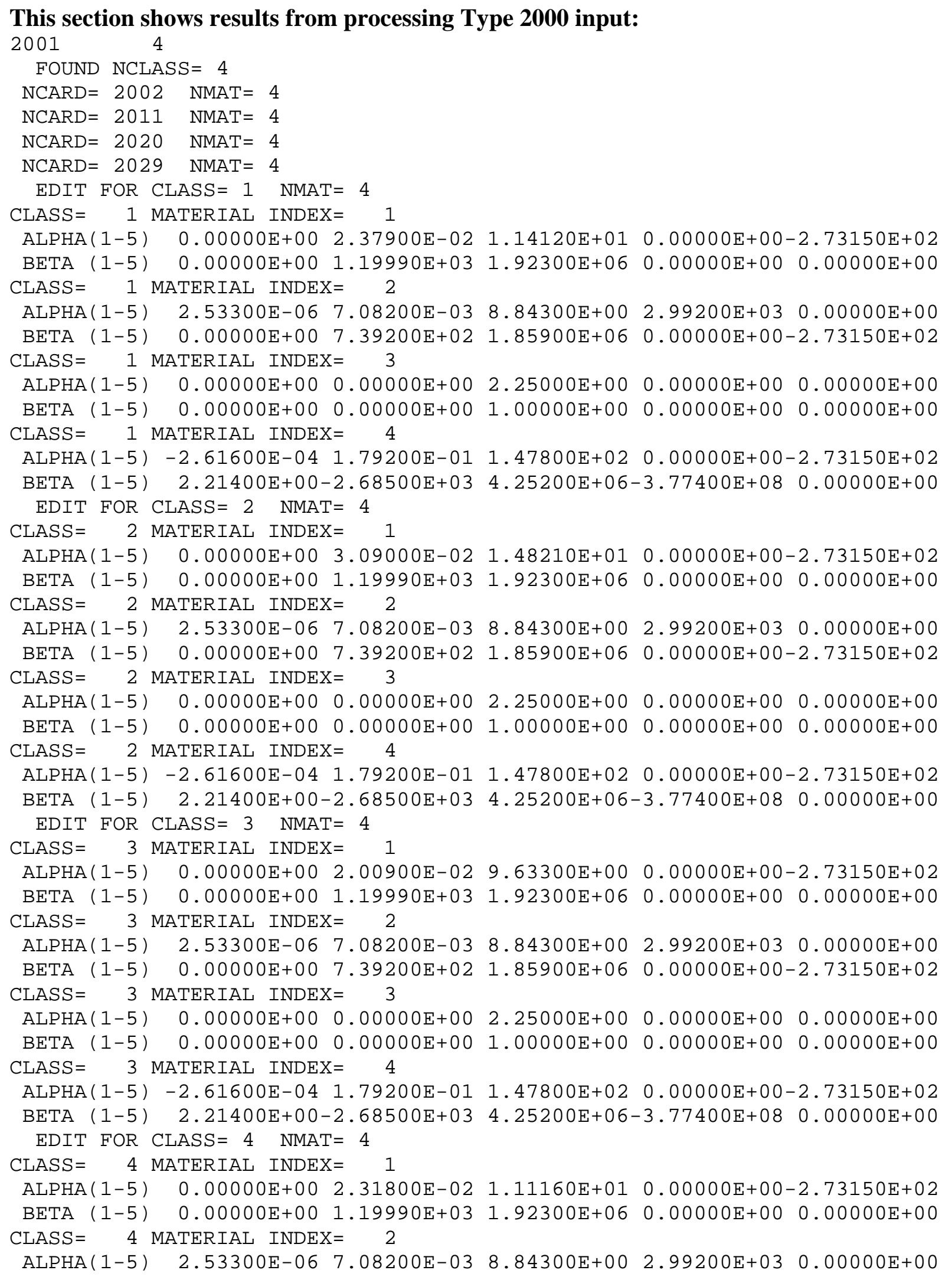


BETA (1-5) $\quad 0.00000 \mathrm{E}+00 \quad 7.39200 \mathrm{E}+02$ 1.85900E+@6 $0.00000 \mathrm{E}+00-2.73150 \mathrm{E}+\odot 2$ CLASS $=4$ MATERIAL INDEX $=3$

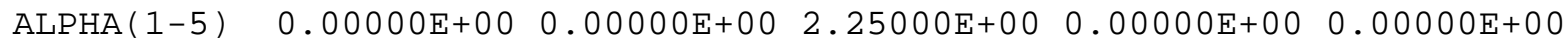

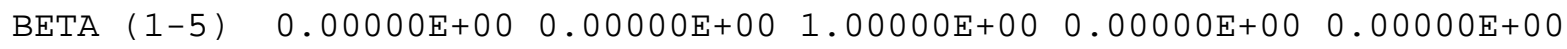
CLASS $=4$ MATERIAL INDEX $=4$

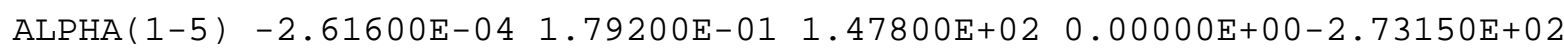
BETA (1-5) 2.21400E+00-2.68500E+@3 4.25200E+06-3.77400E+08 $0.00000 \mathrm{E}+00$ THE NUMBER OF 2000-SERIES MATERIALS PROCESSED $=16$

This section shows processing of card type 3000:

SUPPLIED LENGTHS ARE IN SI

THREEK FOUND NCLASS $=4$

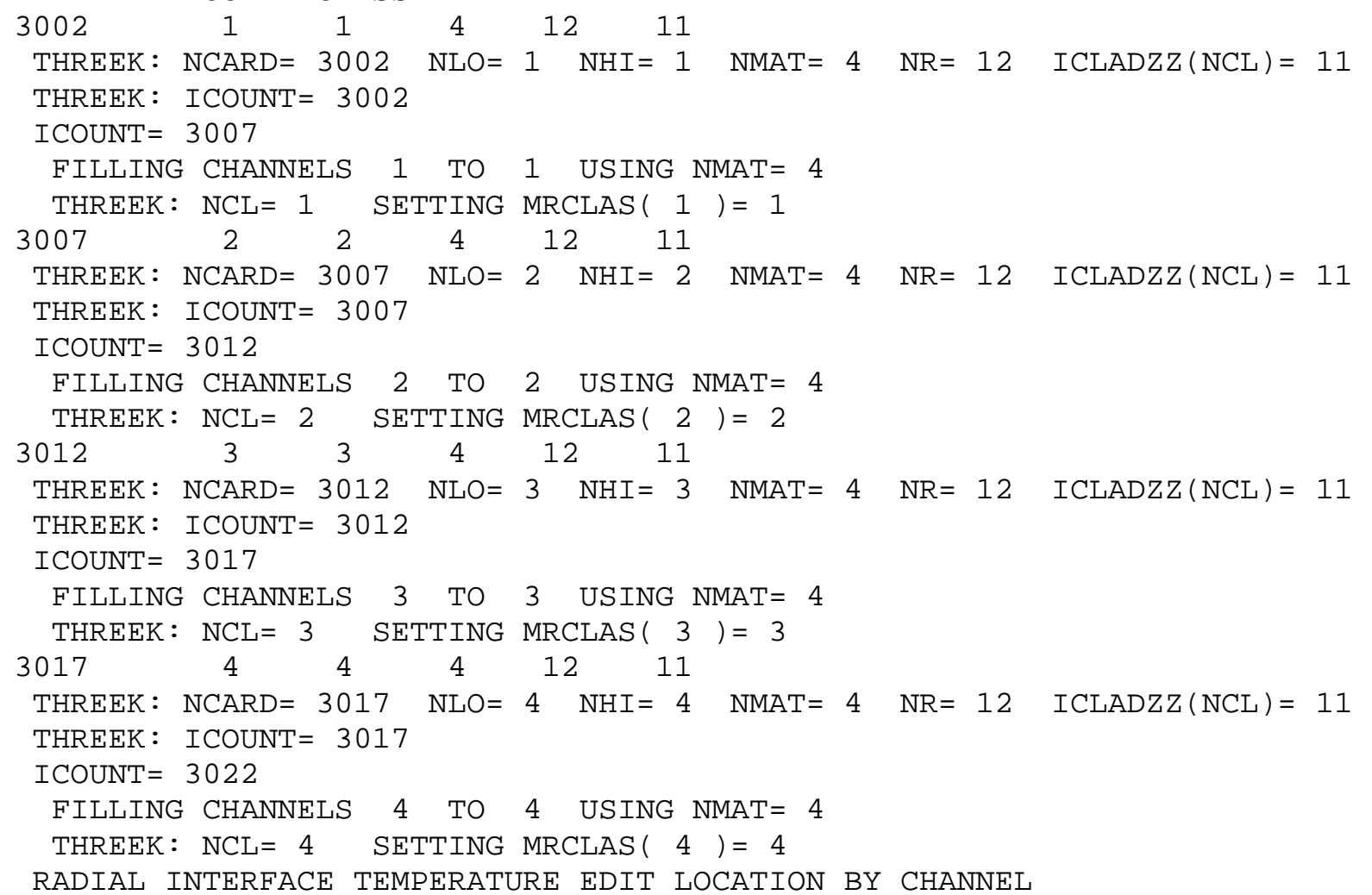

RADIAL INTERFACE TEMPERATURE EDIT LOCATION BY CHANNEL CHANNEL INTERFACE

\begin{tabular}{|c|c|c|c|c|}
\hline \\
\hline 1 & 11 & & & \\
\hline 2 & 11 & & & \\
\hline 3 & 11 & & & \\
\hline 4 & 11 & & & \\
\hline CHANNEL $=1 \mathrm{NO}$. & OF RADIAL NODES= & 12 & & \\
\hline RAD . INTERFACE & RAD . INCREMENT & & COMPOS. CODE & RADIAL QR \\
\hline$\odot . \odot \odot \odot \odot \odot E+\odot \odot$ & $\odot . \odot \odot \odot \odot \odot Е+\odot \odot$ & & $\odot$ & $\odot . \odot \odot \odot \odot \odot E+\odot \odot ~ S I$ \\
\hline$\odot .47929 E-04$ & $\odot .47929 E-\odot 4$ & & 1 & $\odot .10000 \mathrm{E}+01 \mathrm{SI}$ \\
\hline$\odot .95857 \mathrm{E}-\odot 4$ & $\odot .47929 E-\odot 4$ & & 1 & $\odot .10000 \mathrm{E}+01 \mathrm{SI}$ \\
\hline$\odot .14379 \mathrm{E}-03$ & $\odot .47929 E-\odot 4$ & & 1 & $\odot .10000 \mathrm{E}+01 \mathrm{SI}$ \\
\hline$\odot .19171 \mathrm{E}-03$ & $\odot .47929 E-\odot 4$ & & 1 & $\odot .10000 \mathrm{E}+01 \mathrm{SI}$ \\
\hline$\odot .23964 \mathrm{E}-03$ & $\odot .47929 E-\odot 4$ & & 1 & $\odot .10000 \mathrm{E}+01 \mathrm{SI}$ \\
\hline$\odot .265 \odot 4 \mathrm{E}-\odot 3$ & $\odot .2540 \odot \mathrm{E}-\odot 4$ & & 2 & $\odot . \odot \odot \odot \odot \odot E+\odot \odot S I$ \\
\hline
\end{tabular}




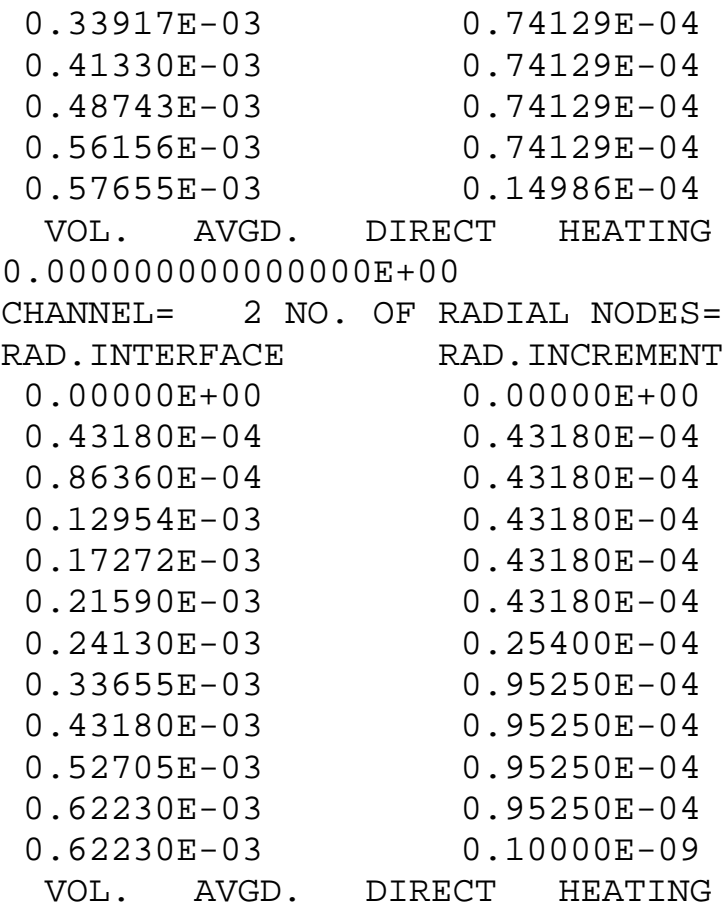

๑. . $000000000000000 \mathrm{E}+0 \odot$

CHANNEL $=3$ NO. OF RADIAL NODES $=$ RAD . INTERFACE

$0.00000 \mathrm{E}+00$

$\odot .43180 \mathrm{E}-04$

$\odot .86360 \mathrm{E}-04$

$\odot .12954 \mathrm{E}-03$

$\odot .17272 \mathrm{E}-03$

$0.21590 \mathrm{E}-03$

$\odot .24130 \mathrm{E}-03$

$\odot .33655 \mathrm{E}-03$

$\odot .43180 \mathrm{E}-03$

$\odot .52705 \mathrm{E}-03$

$\odot .62230 \mathrm{E}-03$

$\odot .64592 \mathrm{E}-03$

VOL. AVGD. $\odot . \odot \odot \odot \odot \odot \odot \odot \odot \odot \odot \odot \odot \odot \odot \odot Е+\odot \odot$

CHANNEL $=4$ NO. OF RADIAL NODES= RAD . INTERFACE

$\odot .00000 \mathrm{E}+00$

$\odot .43180 \mathrm{E}-04$

$\odot .86360 \mathrm{E}-04$

$0.12954 \mathrm{E}-03$

$\odot .17272 \mathrm{E}-03$

$\odot .21590 \mathrm{E}-03$

$\odot .24130 \mathrm{E}-03$

$\odot .33655 \mathrm{E}-03$

$\odot .43180 \mathrm{E}-03$

$\odot .52705 \mathrm{E}-03$

$0.62230 \mathrm{E}-03$

$\odot .63830 \mathrm{E}-03$
RAD . INCREMENT

$\odot .00000 \mathrm{E}+0 \odot$

$\odot .43180 \mathrm{E}-04$

$\odot .43180 \mathrm{E}-04$

$\odot .43180 E-04$

$\odot .43180 \mathrm{E}-04$

$\odot .43180 \mathrm{E}-04$

$\odot .25400 \mathrm{E}-04$

$\odot .95250 \mathrm{E}-04$

$\odot .95250 \mathrm{E}-04$

$\odot .95250 \mathrm{E}-04$

$\odot .95250 \mathrm{E}-04$

$\odot .23622 \mathrm{E}-04$
DIRECT HEATING

RADIAL NODES=
RAD. INCREMENT

○. $00000 \mathrm{E}+\odot \odot$

$\odot .43180 \mathrm{E}-04$

$\odot .43180 \mathrm{E}-04$

$\odot .43180 \mathrm{E}-04$

$\odot .43180 \mathrm{E}-04$

$\odot .43180 \mathrm{E}-04$

$\odot .25400 \mathrm{E}-04$

$\odot .95250 \mathrm{E}-04$

$\odot .95250 \mathrm{E}-04$

$\odot .95250 \mathrm{E}-04$

$\odot .95250 \mathrm{E}-04$

$\odot .16002 \mathrm{E}-04$

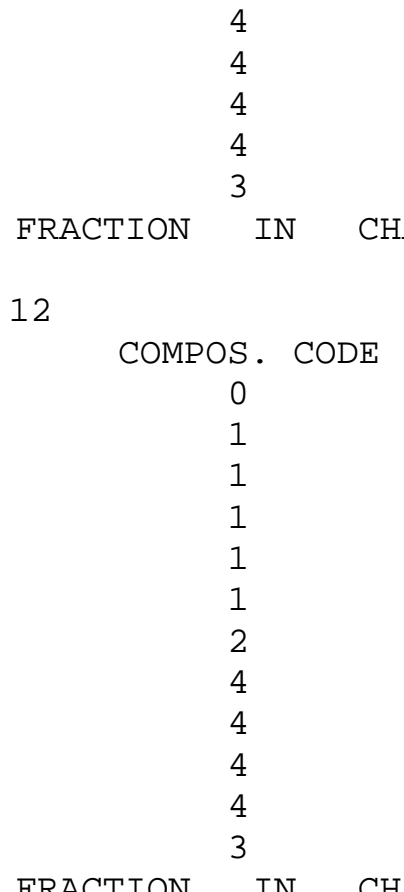

$\odot .000 \odot \odot E+\odot \odot S I$

$\odot .00000 \mathrm{E}+0 \odot \mathrm{SI}$

$\odot .00000 \mathrm{E}+00 \mathrm{SI}$

$\odot .00000 \mathrm{E}+0 \odot \mathrm{SI}$

$\odot .00000 \mathrm{E}+0 \odot \mathrm{SI}$

CHANNEL $\mathrm{N}=1$

IS

FRACTION

12

COMPOS. CODE

$\begin{array}{cc}\text { COMPOS. CODE } & \text { RADIAL QR } \\ 0 & 0.0000 \odot \mathrm{E}+\odot \odot \mathrm{SI} \\ 1 & 0.1000 \odot \mathrm{E}+01 \mathrm{SI} \\ 1 & 0.1000 \odot \mathrm{E}+\odot 1 \mathrm{SI} \\ 1 & 0.1000 \odot \mathrm{E}+01 \mathrm{SI} \\ 1 & 0.1000 \odot \mathrm{E}+\odot 1 \mathrm{SI} \\ 1 & 0.1000 \odot \mathrm{E}+\odot 1 \mathrm{SI} \\ 2 & 0.00 \odot \odot \odot \mathrm{E}+\odot \odot \mathrm{SI} \\ 4 & 0.00 \odot \odot \odot \mathrm{E}+\odot \odot \mathrm{SI} \\ 4 & 0.00 \odot \odot \odot \mathrm{E}+\odot \odot \mathrm{SI} \\ 4 & 0.00 \odot \odot \odot \mathrm{E}+\odot \odot \mathrm{SI} \\ 4 & 0.00 \odot \odot \odot \mathrm{E}+\odot \odot \mathrm{SI} \\ 3 & 0.00 \odot \odot \odot \mathrm{E}+\odot \odot \mathrm{SI}\end{array}$
$\odot .10000 \mathrm{E}+01 \mathrm{SI}$
$0.10000 \mathrm{E}+01 \mathrm{SI}$
$0.10000 \mathrm{E}+01 \mathrm{SI}$
$0.10000 \mathrm{E}+01 \mathrm{SI}$
$\odot .10000 \mathrm{E}+01 \mathrm{SI}$
$\odot .00000 \mathrm{E}+0 \odot \mathrm{SI}$
$\odot .00 \odot \odot \odot E+\odot \odot ~ S I$
$\odot .00000 \mathrm{E}+0 \odot \mathrm{SI}$
$\odot .000 \odot \odot E+\odot \odot ~ S I$
$\odot .00000 \mathrm{E}+0 \odot \mathrm{SI}$
$\odot .00000 \mathrm{E}+0 \odot \mathrm{SI}$

IS

FRACTION IN CHANNEL N= 3

IS

12
RADIAL QR

$\odot . \odot \odot \odot \odot \odot E+\odot \odot ~ S I$

$0.10000 \mathrm{E}+01 \mathrm{SI}$

$0.10000 \mathrm{E}+01 \mathrm{SI}$

$0.10000 \mathrm{E}+01 \mathrm{SI}$

$0.10000 \mathrm{E}+01 \mathrm{SI}$

$0.10000 \mathrm{E}+01 \mathrm{SI}$

$\odot .000 \odot \odot E+\odot \odot S I$

$\odot .00 \odot \odot \odot E+\odot \odot ~ S I$

$\odot . \odot \odot \odot \odot \odot E+\odot \odot ~ S I$

$\odot .00000 \mathrm{E}+0 \odot \mathrm{SI}$

$\odot .00000 \mathrm{E}+\odot \odot$ SI

$\odot . \odot \odot \odot \odot \odot E+\odot \odot ~ S I$ 
VOL. AVGD. DIRECT HEATING FRACTION IN CHANNEL $N=\begin{aligned} & 4 \\ & \text { IS }\end{aligned}$ $\odot .000000000000000 \mathrm{E}+00$

This section processes the axial geometry on card type 4000:

$\odot$

$+$

AXIAL NODE

INTERVAL

1

01

$\odot .3810000 \mathrm{E}-01$

01

๑. 2540000E-01

01

๑. 2540000E-01

01

๑. 2540000E-01

01

๑. 2540000E-01

01

๑. 2540000E-01

01

๑. 2540000E-01

01

๑. 2540000E-01

01

๑. 2540000E-01

01

5

8

9
AXIAL INTERVAL

AXIAL LENGTH

CALC .
AXIAL DESCRIPTION

๑. 2540000E-

๑. 2540000E -

$\odot .6350000 \mathrm{E}-01$

๑. 2540000E -

$\odot .8890000 \mathrm{E}-01$

๑. 2540000E -

0.1143000

๑. 2540000E -

$\odot .139700 \odot$

๑. 2540000Е -

$\odot .1905000$

๑. 2540000E -

๑. 2540000E -

$\odot .1651000$

O.2540000E-

$\odot .2159000$

$\odot .2540000 \mathrm{E}-$

$\odot .2413000$

$\odot .2540000 \mathrm{E}-$ 
$\odot .2540000 \mathrm{E}-01$

$\odot .266700 \odot$

$\odot .2540000 \mathrm{E}-$

01

๑. 2540000E-01

$\odot .292100 \odot$

$\odot .2540000 \mathrm{E}-$

01

$\odot .2540000 \mathrm{E}-01$

01

$\odot .3175000$

๑. 2540000E -

$\odot .2540000 \mathrm{E}-01$

14

$\odot .3429000$

$\odot .2540000 \mathrm{E}-$

01

๑ . 25400९०E-๑1

$\odot .3683000$

๑. 2540000E-

01

$\odot .2540000 \mathrm{E}-01$

01

$\odot .3937000$

๑. 2540000E -

๑. 254000०E- 01

$\odot .4191000$

๑. 2540000E-

01

๑ . 2540000E- 01

01

0.4445000

๑. 2540000E-

๑. 2540000E-01

19

$\odot .4699000$

๑. 2540000E -

01

๑ . 25400००E-๑1

$\odot .4953000$

๑. 2540000E -

01

๑. 2540000E-01

01

$\odot .5207000$

๑. 2540000E -

๑ . 2540000E- 01

22

0.5461000

๑. 25400000E-

01

๑ . 25400९०E - 01

01

$\odot .571500 \odot$

๑. 2540000०E- 
$0.3810000 \mathrm{E}-01$

$\odot .609600 \odot$

$0.2540000 \mathrm{E}-$

01

FLAG IOPT IS 0 ; THE AXIAL MESH WILL BE CHECKED TO SEE IF IT NEEDS TO BE OPTIMIZED

INFORMATIONAL NOTE: THE GIVEN AXIAL MESH IS NOT OPTIMAL FOR ENERGY CONSERVATION OF THE FLUID MESH SOLUTION.

A NEW OPTIMAL AXIAL MESH WILL BE CONSTRUCTED.

AXIAL POWER PROFILE DATA ON 5000 CARDS WILL BE RECONSTRUCTED

DZ IS THE ORIGINAL AXIAL MESH FOR PFQ

ZORIG IS THE ORIGINAL AXIAL MESH FOR PFQ

ZREV IS THE INTERPOLATED AXIAL MESH FOR PFQ

OPTIMAL AXIAL MESH

N DELZN ZZNEW DZ DELZ

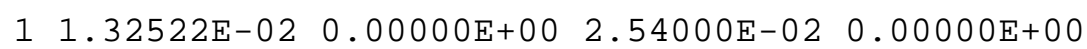

2 2.65043E-02 2.65043E-@2 2.54000E-๑2 3.8100९E-02

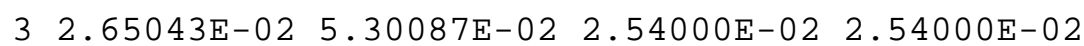

4 2.65043E-@2 7.95130E-@2 2.54000E-@2 2.5400९E-๑2

5 2.65043E-02 1.06017E-01 2.54000E-02 2.54000E-02

6 2.65043E-02 1.32522E-01 2.54000E-02 2.54000E-02

7 2.65043E-02 1.59026E-01 2.54000E-02 2.54000E-02

8 2.65043E-02 1.85530E-01 2.54000E-02 2.54000E-02

9 2.65043E-02 2.12035E-01 2.54000E-02 2.54000E-02

$102.65043 \mathrm{E}-02 \quad 2.38539 \mathrm{E}-01 \quad 2.54000 \mathrm{E}-02 \quad 2.54000 \mathrm{E}-02$

$112.65043 \mathrm{E}-02$ 2.65043E-01 2.54000E-๑2 2.54000E-๑2

$122.65043 \mathrm{E}-02 \quad 2.91548 \mathrm{E}-01 \quad 2.54000 \mathrm{E}-02 \quad 2.54000 \mathrm{E}-02$

$132.65043 \mathrm{E}-02 \quad 3.18052 \mathrm{E}-01 \quad 2.54000 \mathrm{E}-02 \quad 2.54000 \mathrm{E}-02$

$142.65043 \mathrm{E}-02 \quad 3.44557 \mathrm{E}-01 \quad 2.54000 \mathrm{E}-02 \quad 2.54000 \mathrm{E}-02$

15 2.65043E-02 3.71061E-01 2.54000E-02 2.54000E-02

$16 \quad 2.65043 \mathrm{E}-02 \quad 3.97565 \mathrm{E}-01 \quad 2.54000 \mathrm{E}-02 \quad 2.54000 \mathrm{E}-02$

17 2.65043E-02 4.24070E-01 2.54000E-02 2.54000E-02

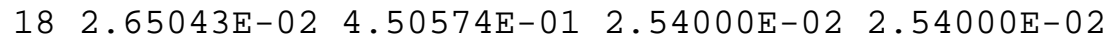

19 2.65043E-02 4.77078E-01 2.54000E-02 2.54000E-02

$202.65043 \mathrm{E}-02$ 5. $03583 \mathrm{E}-01 \quad 2.54000 \mathrm{E}-02 \quad 2.54000 \mathrm{E}-02$

21 2.65043E-@2 5.30087E-01 2.54000E-@2 2.54000E-@2

22 2.65043E-@2 5.56591E-01 2.54000E-๑2 2.54000E-02

23 2.65043E-02 5.83096E-01 2.54000E-02 2.54000E-02

24 1.32522E-@2 6.09600E-01 2.54000E-๑2 3.81000E-๑2

ORIGINAL FUEL MESH CENTERS (ZORIG)

OPTIMIZED FUEL MESH CENTERS (ZREV)

$\begin{array}{rr}1 & 1.2700 \odot \mathrm{E}-02 \\ 2 & 3.810 \odot \odot \mathrm{E}-\odot 2 \\ 3 & 6.3500 \odot \mathrm{E}-02 \\ 4 & 8.890 \odot \odot \mathrm{E}-\odot 2 \\ 5 & 1.1430 \odot \mathrm{E}-01 \\ 6 & 1.3970 \odot \mathrm{E}-01 \\ 7 & 1.6510 \odot \mathrm{E}-01 \\ 8 & 1.9050 \odot \mathrm{E}-01 \\ 9 & 2.1590 \odot \mathrm{E}-01 \\ 10 & 2.4130 \odot \mathrm{E}-01 \\ 11 & 2.6670 \odot \mathrm{E}-01 \\ 12 & 2.9210 \odot \mathrm{E}-01\end{array}$

$6.62609 \mathrm{E}-03$

$2.65043 \mathrm{E}-02$

$5.30087 \mathrm{E}-02$

7. $95130 \mathrm{E}-02$

1. $06017 \mathrm{E}-01$

1. 32522E- -1

1. $59026 \mathrm{E}-01$

1. $85530 \mathrm{E}-01$

2. $12035 \mathrm{E}-01$

2. 38539E- 01

2. $65043 \mathrm{E}-01$

2. $91548 \mathrm{E}-01$ 


\begin{tabular}{|c|c|}
\hline $3.17500 \mathrm{E}-01$ & $3.18052 \mathrm{E}-01$ \\
\hline 3. $42900 \mathrm{E}-\odot 1$ & $3.44557 \mathrm{E}-\odot 1$ \\
\hline 3. 68300E- -1 & $3.71061 \mathrm{E}-01$ \\
\hline 3. $93700 \mathrm{E}-01$ & $3.97565 E-01$ \\
\hline 4. 19100E- 01 & $4.24070 E-01$ \\
\hline 4. 44500E- 01 & $4.50574 \mathrm{E}-01$ \\
\hline 4. 69900E- 01 & $4.77078 \mathrm{E}-01$ \\
\hline $4.95300 \mathrm{E}-01$ & $5.03583 E-01$ \\
\hline $5.20700 \mathrm{E}-\odot 1$ & $5.30087 \mathrm{E}-01$ \\
\hline $5.46100 \mathrm{E}-\odot 1$ & $5.56591 E-01$ \\
\hline $5.71500 \mathrm{E}-\odot 1$ & $5.83096 E-01$ \\
\hline $5.96900 \mathrm{E}-\odot 1$ & $6.02974 \mathrm{E}-01$ \\
\hline
\end{tabular}

THE MESH IS OPTIMAL

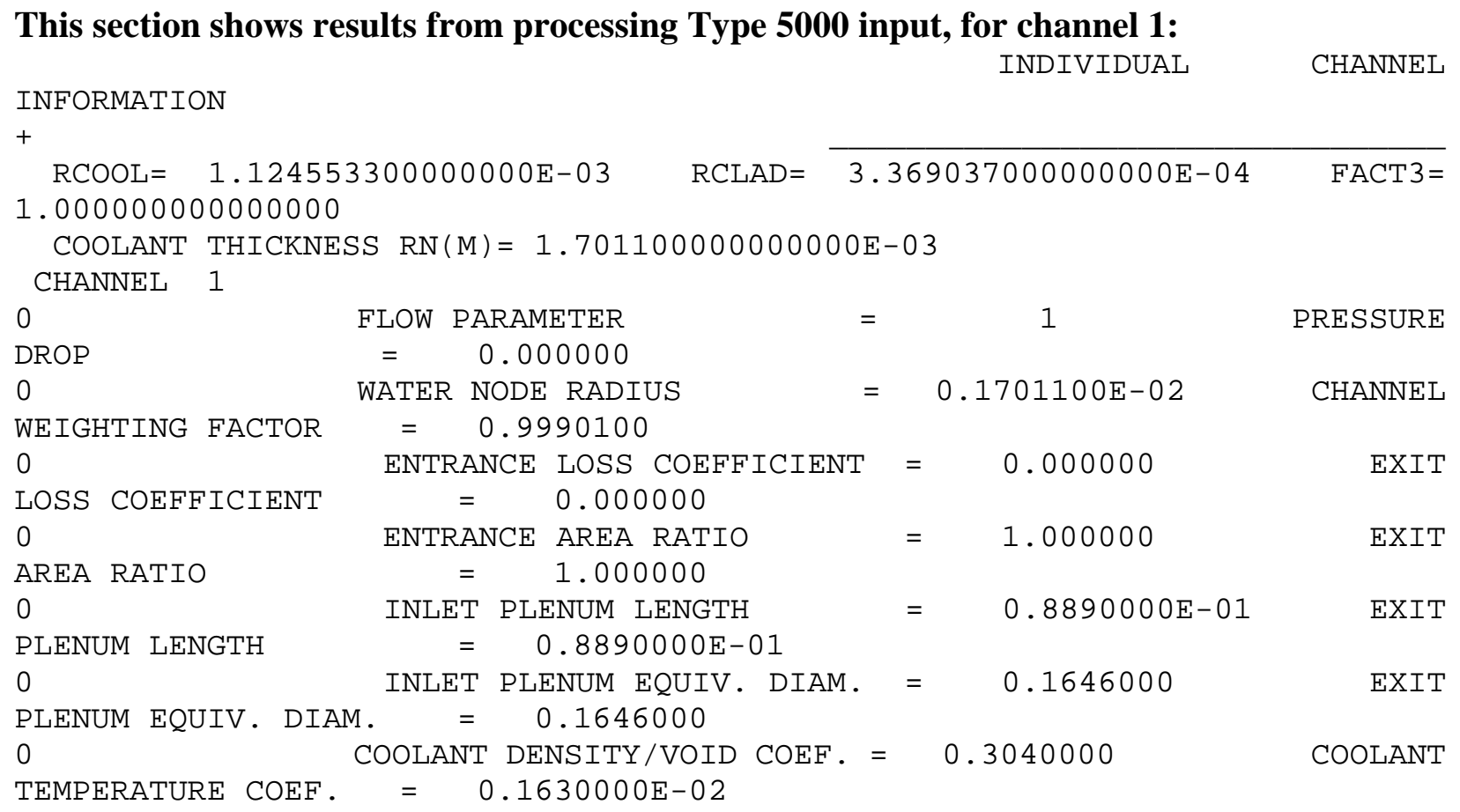

\begin{tabular}{|c|c|c|c|c|c|}
\hline RFW & RPW & RFLOW & ZQW & ZRS & ZRF \\
\hline$R C$ & FACT3 & & & & \\
\hline $\begin{array}{l}1 . \odot \odot \odot \odot \odot E+\odot ६ \\
2.65 \odot 43 E-\odot 4\end{array}$ & 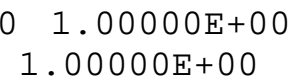 & 1. $\odot \odot \odot \odot \odot E+\odot \odot$ & $\odot . \odot \odot \odot \odot \odot E+\odot \odot$ & $5.76547 E-\odot 4$ & $2.39643 E-\odot 4$ \\
\hline
\end{tabular}

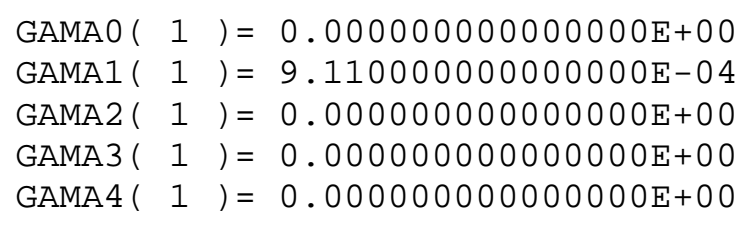


$\operatorname{DOPPNK}(1)=1.00000000000000 \odot$

AXIAL SOURCE DESCRIPTION FEED-BACK DISTR . $\odot$
$1.06900 \odot$

$1.00000 \odot \quad 0.897000 \odot$

1.000000

1. $00500 \odot$

1.000000

1.000000

1.000000

1.000000

1.000000

1.000000

1.000000

1.000000

1.000000

1.000000

1.000000

1.000000

1.000000

1.000000

1.000000

1.000000

1.000000

1.000000

1.000000

1.000000

1.000000

1.000000
COOLANT TEMP. FEEDBACK

DOPPLER

$1.00000 \odot$

1.000000

1. 000000

1.000000

1.000000

1.000000

$1.00000 \odot$

1. 000000

1.000000

1.000000

1. $00000 \odot$

1. $00000 \odot$

$1.00000 \odot$

1.000000

1.000000

1.000000

1.000000

1.000000

$1.00000 \odot$

1.000000

1.000000

1.000000

$1.00000 \odot$

1.000000

1.000000
1. $00000 \odot$

1.000000

1.000000

1.000000

1. 000000

1.000000

1.000000

1.000000

1.000000

1.000000

1. 000000

1.000000

1.000000

1.000000

1.000000

1.000000

1.000000

1. $00000 \odot$

1.000000

$1.00000 \odot$

1.000000

1.000000
1.000000 
1

PAGE 5

RCOOL $=1.181099900000000 \mathrm{E}-03 \quad \mathrm{RCLAD}=4.0640010000000000 \mathrm{E}-04 \quad$ FACT3=

1. 000000000000000

COOLANT THICKNESS RN $(M)=1.803400000000000 \mathrm{E}-\odot 3$

CHANNEL 2

$\odot$

DROP

$\odot$

WEIGHTING FACTOR

$\odot$

LOSS COEFFICIENT

$\odot$

AREA RATIO

○

PLENUM LENGTH

$\odot$

PLENUM EQUIV. DIAM.

$\odot$

TEMPERATURE COEF.
FLOW PARAMETER

$=\quad \odot .000 \odot \odot \odot$

WATER NODE RADIUS

$=0.3300000 \mathrm{E}-03$

ENTRANCE LOSS COEFFICIENT = $=0.000000$

ENTRANCE AREA RATIO

$=1.000000$

INLET PLENUM LENGTH

$=0.8890000 \mathrm{E}-01$

INLET PLENUM EQUIV. DIAM. $=0.1646000$ $=0.1646000$

COOLANT DENSITY/VOID COEF. $=0.3040000$
$=1$

$=\odot .1803400 \mathrm{E}-\odot 2$

$\odot .000000$

1.000000

$\odot .8890000 \mathrm{E}-01$

COOLANT
PRESSURE

CHANNEL

EXIT

EXIT

EXIT

EXIT

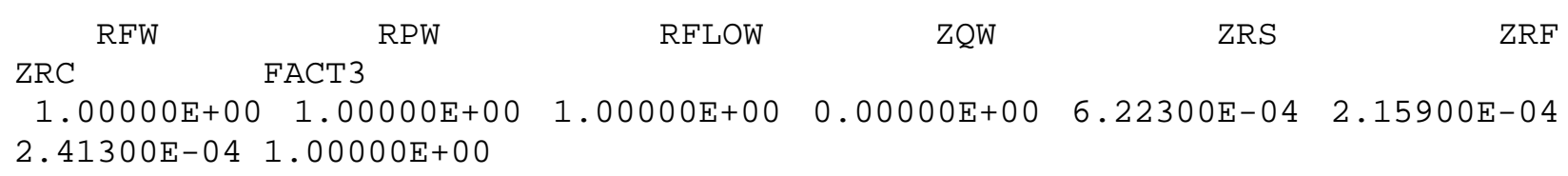

$\operatorname{GAMA0}(2)=0.0000000000000000 \mathrm{E}+\odot \odot$

GAMA1 ( 2 ) $=9.110000000000000 \mathrm{E}-04$

GAMA2 ( 2 ) $=0.000000000000000 \mathrm{E}+\odot \odot$

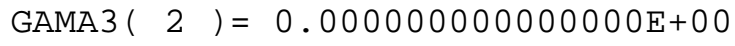

GAMA4( 2 ) = $0.000000000000000 \mathrm{E}+00$

$\operatorname{DOPPNK}(2)=1.000000000000000$

AXIAL SOURCE DESCRIPTION

COOLANT DENSITY FEEDBACK

DOPPLER FEED-BACK DISTR.

COOLANT TEMP. FEEDBACK

$\odot$

$\begin{array}{llll}0.000000 & 2.420000 & 0.000000 & 0.000000 \\ 0.000000 & 2.326000 & 0.000000 & 0.000000 \\ 0.000000 & 2.538000 & 0.000000 & 0.000000 \\ 0.000000 & 2.821000 & 0.000000 & 0.000000 \\ 0.000000 & 3.048000 & 0.000000 & 0.00000 \odot \\ 0.000000 & 3.183000 & 0.000000 & 0.000000\end{array}$




\begin{tabular}{|c|c|c|c|}
\hline & 3.367000 & & $\odot . ๑ \odot \odot \odot \odot \odot$ \\
\hline 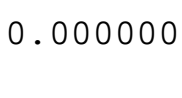 & $3.4450 \odot \odot$ & $\odot . ๑ \odot \odot \odot \odot \odot ~$ & \\
\hline 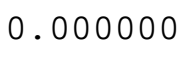 & 3.508000 & $\odot . ๑ \odot \odot \odot \odot \odot$ & \\
\hline$\odot . \odot \odot \odot \odot \odot \odot ~$ & 3.461000 & $\odot . ๑ \odot \odot \odot \odot \odot ~$ & ๑.०००००० \\
\hline 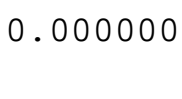 & $3.3980 \odot \odot$ & 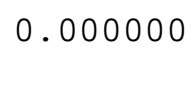 & $\odot .0 \odot \odot \odot \odot \odot$ \\
\hline$\odot . ๑ \odot \odot \odot \odot \odot$ & 3.241000 & $\odot . ๑ \odot \odot \odot \odot \odot$ & $\odot .0000 \odot \odot$ \\
\hline ๑. ๑००००० & 2.958000 & $\odot . ๑ \odot \odot \odot \odot \odot$ & ๑. . $00000 \odot$ \\
\hline ๑. $\odot \odot \odot ० ० \odot$ & 2.451000 & $\odot . \diamond \odot \odot \odot \odot \odot$ & $\odot .00000 \odot$ \\
\hline 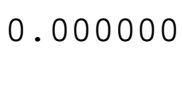 & $1.99000 \odot$ & $\odot . ๑ \odot \odot \odot \odot \odot ~$ & 0.000000 \\
\hline ๑. ๑๑०००० & 1.758000 & $\odot . \diamond \odot \odot \odot \odot \odot$ & $\odot .000000$ \\
\hline$\odot . ๑ \odot \odot \odot \odot \odot ~$ & 1.537000 & $\odot . \odot \odot \odot \odot \odot \odot$ & $\odot .00000 \odot$ \\
\hline$\odot . ๑ \odot \odot \odot \odot \odot$ & 1.299000 & $\odot . \diamond \odot \odot \odot \odot \odot$ & $\odot . \odot \odot \odot \odot \odot \odot$ \\
\hline 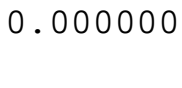 & 1.000000 & $\odot . \odot \odot \odot \odot \odot \odot$ & 0.000000 \\
\hline$\odot . ๑ \odot \odot \odot \odot \odot ~$ & $\odot .7270000$ & $\odot . ๑ \odot \odot \odot \odot \odot$ & $\odot .0 \odot \odot \odot \odot \odot$ \\
\hline ๑.०००००० & $\odot .5990000$ & ๑.๑००००० & 0.000000 \\
\hline ๑.๑००००० & ๑. 4940000 & ๑. 000000 & $\odot .00 \odot \odot \odot \odot$ \\
\hline ๑.๑९९७०९ & $\odot .4260000$ & ๑.๑९०००९ & 0.000000 \\
\hline ๑. 000000 & $\odot .4170000$ & $\begin{array}{l}\odot .00 \odot \odot ० \odot \\
\odot . \odot \odot \odot \odot \odot \odot ~\end{array}$ & 0.000000 \\
\hline
\end{tabular}

1

PAGE 6

RCOOL $=1.0794780000000000 \mathrm{E}-03 \quad \mathrm{RCLAD}=4.3002200000000000 \mathrm{E}-04 \quad \mathrm{FACT} 3=$

1. 0000000000000000

COOLANT THICKNESS RN $(M)=1.725400000000000 \mathrm{E}-03$ CHANNEL 3

$\odot$

DROP

$\odot$ WEIGHTING FACTOR $\odot$ LOSS COEFFICIENT $\odot$ AREA RATIO ○

PLENUM LENGTH
FLOW PARAMETER $=\quad 0.000000$

WATER NODE RADIUS $=0.3300000 \mathrm{E}-03$

ENTRANCE LOSS COEFFICIENT $=0.00000 \odot$ $=\quad 0.000000$

ENTRANCE AREA RATIO $=1.000000$

INLET PLENUM LENGTH $=0.8890000 \mathrm{E}-01$

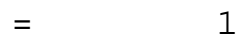

$=0.1725400 \mathrm{E}-\odot 2$

$=\quad 1.000000$

$=\quad 0.8890000 \mathrm{E}-01$
PRESSURE

CHANNEL

EXIT

EXIT

EXIT 


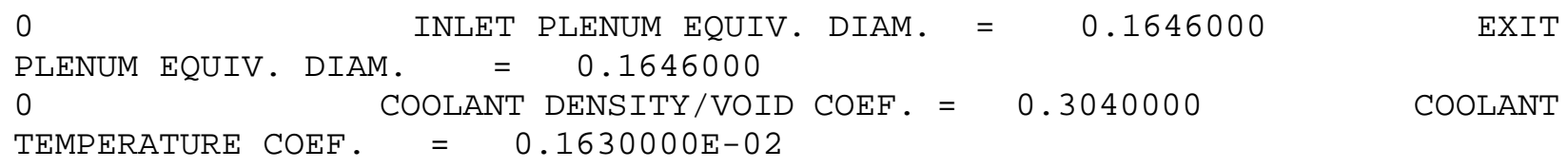

\begin{tabular}{|c|c|c|c|c|c|}
\hline RFW & RPW & RFLOW & ZQW & ZRS & ZRF \\
\hline ZRC & FACT3 & & & & \\
\hline $\begin{array}{l}1.00000 \mathrm{E}+\odot \odot \\
2.41300 \mathrm{E}-\odot 4\end{array}$ & 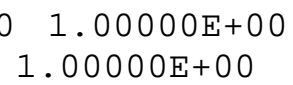 & 1. $\odot \odot \odot \odot \odot E+\odot \odot$ & $\odot . \odot \odot \odot \odot \odot E+\odot \odot$ & $6.45922 E-04$ & $2.1590 \odot E-\odot 4$ \\
\hline
\end{tabular}

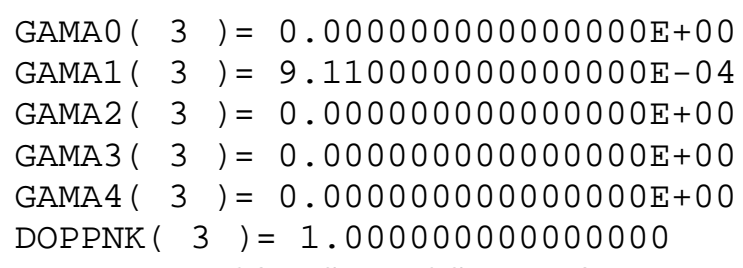

AXIAL SOURCE DESCRIPTION

FEED-BACK DISTR. COOLANT TEMP. FEEDBACK

DOPPLER $\odot$
$\odot .000000$
1.921000
$\odot .00000 \odot$
$\odot .000000$
$\odot .000000$
1.852000
$\odot . \odot \odot \odot \odot \odot \odot$
$\odot . \odot \odot \odot \odot \odot \odot$
2. $02400 \odot$
$\odot .000000$
$\odot . \odot \odot \odot \odot \odot \odot$
0.000000
$2.21600 \odot$
$\odot .0000 \odot \odot$
2.336000
0.000000
2.496000
0.000000
0.000000
0.000000
$\odot .00000 \odot$
$\odot .000000$
2.549000
2.642000
๑ . 000000
2.610000
0.000000
2.640000
0.000000
๑. 000000
0.000000
2. 601000
$\odot .00000 \odot$
$\odot .000000$
0.000000
2.542000
$\odot .000000$
2.501000
$\odot .00000 \odot$
$\odot .000000$
$\odot .000000$
0.000000
2.364000
$\odot .000000$
$\odot .00000 \odot$
0.000000
$2.36400 \odot$
0.000000
0.000000
$\odot .00000 \odot$
$\odot .00000 \odot$
0.000000
$\odot .000000$
$\odot .00000 \odot$ 
$\odot .000000$

$\odot .000000$

1.940000

$\odot . \odot \odot \odot \odot \odot \odot$

0.000000

1.776000

0.000000

$\odot .000000$

0.000000

1.446000

$\odot .000 \odot \odot \odot$

$\odot . \odot \odot \odot \odot \odot \odot$

$\odot .00000 \odot$

$\odot .9520000$

$\odot . \odot \odot \odot \odot \odot \odot$

$\odot .00000 \odot$

$\odot .000000$

$\odot .537000 \odot$

$\odot .000000$

$\odot .00000 \odot$

$\odot .000000$

0.4250000

0.000000

$\odot .000000$

0.000000

๑. 33900000

$\odot . \odot \odot \odot \odot \odot \odot$

$\odot .00000 \odot$

$\odot .000000$

$\odot .2990000$

$\odot . \odot \odot \odot \odot \odot \odot$

0.000000

๑. 000000

$\odot .302000 \odot$

$\odot . \odot \odot \odot \odot \odot \odot$

$\odot .000000$

$\odot .000000$

$\odot .00000 \odot$

$\odot .00000 \odot$

1

PAGE 7

$\mathrm{RCOOL}=1.126898000000000 \mathrm{E}-03 \quad \mathrm{RCLAD}=4.2240200000000000 \mathrm{E}-04 \quad \mathrm{FACT} 3=$

1. 0000000000000000

COOLANT THICKNESS RN $(M)=1.765200000000000 \mathrm{E}-03$ CHANNEL 4

$\odot$

DROP

$\odot$

WEIGHTING FACTOR

$\odot$

LOSS COEFFICIENT

$\odot$

AREA RATIO

$\odot$

PLENUM LENGTH

$\odot$

PLENUM EQUIV. DIAM

$\odot$

TEMPERATURE COEF.
FLOW PARAMETER

$=\quad 0.00000 \odot$

WATER NODE RADIUS

$=0.3300000 \mathrm{E}-03$

ENTRANCE LOSS COEFFICIENT $=0.000000$ $=\quad 0.00000 \odot$

ENTRANCE AREA RATIO $=1.000000$

INLET PLENUM LENGTH $=\quad 0.8890000 \mathrm{E}-01$

INLET PLENUM EQUIV. DIAM. = 0.1646000 $=0.1646000$

COOLANT DENSITY/VOID COEF. $=0.3040000$
$=1$

$=\quad 0.1765200 \mathrm{E}-\odot 2$

$=\quad 1.000000$

$=\quad 0.8890000 \mathrm{E}-01$
PRESSURE

CHANNEL

EXIT

EXIT

EXIT

EXIT

COOLANT

ZRC RFW RFLOW ZQW ZRS ZRF

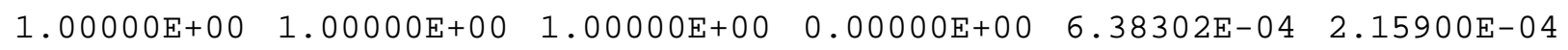
2. $41300 \mathrm{E}-\odot 4$ 1. $.0000 \odot \mathrm{E}+\odot \odot$

$\operatorname{GAMA} \odot(4)=0.000000000000000 \mathrm{E}+0 \odot$

GAMA1 $(4)=9.110000000000000 \mathrm{E}-\odot 4$ 


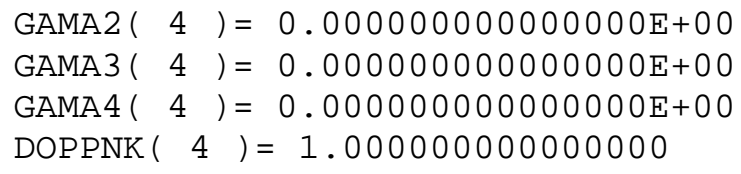

๑. $00000 \odot$

$\odot .00000 \odot$

$\odot .00000 \odot$

0.000000

$\odot .000000$

0.000000

$\odot .000000$

$\odot .000000$

๑. 000000

0.000000

$\odot .000000$

$\odot .00000 \odot$

$\odot .000000$

๑. 000000

$\odot .00000 \odot$

0.000000

0.000000

$\odot .000000$

๑. 000000

๑. 000000

๑. 000000

๑. 000000

$\odot .000000$

$\odot .00000 \odot$

0.000000

0.000000 
This section shows development of the optimal axial mesh.

F500X: A NEW MESH WILL BE DEFINED

NEW INTERPOLATED PFQ=

$N$ OLD Zmid OLD PFQ NEW Zmid NEW PFQ

1 1.2700९E-02 3.75558E+@3 6.62609E-@3 3.95859E+@3

$23.81000 \mathrm{E}-02$ 3.15132E+@3 2.65043E- 02 3.32780E+@3

$36.35000 \mathrm{E}-02$ 3.53074E+@3 5.30087E- 02 3.30603E+@3

4 8.8900९E-@2 3.94178E+@3 7.95130E-@2 3.81122E+@3

5 1.14300E- 01 4.25797E+@3 1.06017E- 01 4.15732E+@3

6 1.39700E-@1 4.54956E+@3 1.32522E-@1 4.47393E+@3

7 1.65100E-@1 4.76035E+@3 1.59026E-@1 4.71449E+@3

8 1.90500E-01 4.92547E+03 1.85530E-01 4.90062E+@3

9 2.15900E-01 4.98519E+03 2.12035E-01 4.97997E+03

$102.41300 \mathrm{E}-01$ 4.99925E+03 2.38539E-01 5.00144E+०3

11 2.66700E-01 4.92196E+-03 2.65043E-01 4.92946E+03

12 2.92100E-01 4.77089E+03 2.91548E-01 4.77501E+03

13 3.17500E-01 4.51794E+03 3.18052E-01 4.51065E+@3

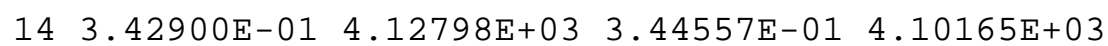

$153.68300 \mathrm{E}-01 \quad 3.74504 \mathrm{E}+03 \quad 3.71061 \mathrm{E}-01 \quad 3.70571 \mathrm{E}+03$

$163.93700 \mathrm{E}-01 \quad 3.40427 \mathrm{E}+03 \quad 3.97565 \mathrm{E}-01 \quad 3.35770 \mathrm{E}+\odot 3$

17 4. 19100E-01 3.10213E+-3 4.24070E-01 3.03761E+०3

18 4.44500E-01 2.75082E+03 4.50574E-01 2.66376E+-3

19 4.69900E-01 2.38193E+03 4.77078E-01 2.27317E+03

20 4.95300E-01 2.00954E+03 5.03583E-01 1.90717E+03

21 5.20700E-01 1.72146E+03 5.30087E-01 1.62294E+-3

22 5.46100E-01 1.44391E+03 5.56591E-01 1.31982E+03

23 5.71500E-01 1.21205E+०3 5.83096E-01 1.24058E+03

$245.96900 \mathrm{E}-01 \quad 1.35609 \mathrm{E}+\odot 3 \quad 6.02974 \mathrm{E}-01 \quad 1.41245 \mathrm{E}+\odot 3$ NEW INTERPOLATED PFQ=

$N$ OLD Zmid OLD PFQ NEW Zmid NEW PFQ

1 1.2700९E-@2 8.50188E+@3 6.62609E-@3 8.64137E+@3

$23.81000 \mathrm{E}-02$ 8.17164E+@3 2.65043E-02 8.21962E+@3

$36.35000 \mathrm{E}-02$ 8.91644E+03 5.30087E-02 8.51631E+03

4 8.89000E-02 9.91066E+03 7.95130E-02 9.55212E+@3

5 1.14300E-01 1.07082E+@4 1.06017E-01 1.04920E+@4

6 1.39700E-01 1.11824E+@4 1.32522E-01 1.10393E+-04

7 1.65100E- 01 1.18289E+@4 1.59026E- 01 1.16934E+@4

8 1.90500E-@1 1.21029E+@4 1.85530E-01 1.20599E+@4

9 2.15900E-01 1.23242E+@4 2.12035E-01 $1.23113 \mathrm{E}+04$

$102.41300 \mathrm{E}-01 \quad 1.21591 \mathrm{E}+04 \quad 2.38539 \mathrm{E}-01 \quad 1.21832 \mathrm{E}+04$

$112.66700 \mathrm{E}-01$ 1.19378E+०4 2.65043E-01 $1.19595 \mathrm{E}+04$

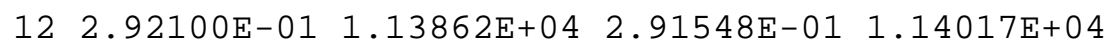

13 3.17500E-01 1.03920E+-4 3.18052E-01 1.03607E+-4

$143.42900 \mathrm{E}-01$ 8.61079E+03 3.44557E-01 8.48745E+०3

15 3.68300E-01 6.99122E+-3 3.71061E-01 6.87023E+०3

16 3.93700E-01 6.17616E+03 3.97565E-01 6.06685E+03

17 4.19100E-01 5.39975E+03 4.24070E-01 5.24402E+03

18 4.44500E-01 4.56361E+@3 4.50574E-01 4.32977E+०3

19 4.69900E-01 3.51317E+०3 4.77078E-01 3.20653E+०3 
$20 \quad 4.95300 \mathrm{E}-01 \quad 2.55408 \mathrm{E}+03 \quad 5.03583 \mathrm{E}-01 \quad 2.36479 \mathrm{E}+03$

21 5.20700E-01 2.10439E+03 5.30087E-01 1.96702E+03

22 5.46100E-01 1.73551E+03 5.56591E-01 1.61133E+03

$235.71500 \mathrm{E}-01$ 1.49661E+०3 5.83096E-01 1.46481E+@3

24 5.96900E-01 1.46499E+03 6.02974E-01 1.46765E+-3 NEW INTERPOLATED PFQ=

N OLD Zmid OLD PFQ NEW Zmid NEW PFQ

1 1.27000E-@2 6.74881E+03 6.62609E-@3 6.85539E+@3

$23.81000 \mathrm{E}-02$ 6.50640E+03 2.65043E- 02 6.53450E+@3

$36.35000 \mathrm{E}-02$ 7.11066E+@3 5.30087E-02 6.79328E+03

4 8.89000E-02 7.78519E+03 7.95130E-02 7.57221E+@3

5 1.14300E-01 8.20678E+03 1.06017E-01 8.05943E+@3

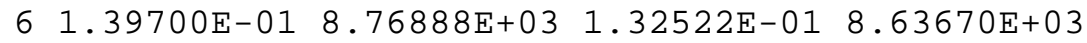

7 1.65100E- 01 8.95508E+@3 1.59026E-01 8.90699E+@3

8 1.90500E-01 9.28181E+03 1.85530E-01 9.24419E+03

9 2.15900E-01 9.16938E+03 2.12035E-01 9.18315E+@3

$102.41300 \mathrm{E}-01 \quad 9.27478 \mathrm{E}+03 \quad 2.38539 \mathrm{E}-01 \quad 9.26689 \mathrm{E}+03$

$112.66700 \mathrm{E}-01 \quad 9.13777 \mathrm{E}+03 \quad 2.65043 \mathrm{E}-01 \quad 9.15307 \mathrm{E}+03$

12 2.92100E-๑1 8.93049E+०3 2.91548E-01 8.93347E+@3

13 3.17500E-01 8.78645E+03 3.18052E-01 8.78026E+03

14 3. 42900E- 01 8.30514E+०3 3.44557E- 01 8.26404E+@3

15 3.68300E-01 7.59197E+03 3.71061E-01 7.50345E+03

16 3.93700E-01 6.81556E+-03 3.97565E-01 6.72650E+-03

17 4.19100E-01 6.23940E+03 4.24070E-01 6.07424E+03

18 4.44500E-01 5.08005E+03 4.50574E-01 4.69557E+03

19 4.69900E-01 3.34454E+03 4.77078E-01 2.85098E+03

20 4.95300E- 01 1.88657E+@3 5.03583E-01 $1.67463 \mathrm{E}+03$

$215.20700 \mathrm{E}-01$ 1.49310E+03 5.30087E-01 1.38785E+03

22 5. 46100E-@1 1.19097E+@3 5.56591E-01 1.10552E+@3

23 5.71500E-01 1.05044E+03 5.83096E-01 1.04542E+03

24 5.96900E-01 1.06098E+03 6.02974E-01 1.06929E+०3 NEW INTERPOLATED PFQ=

$N$ OLD Zmid OLD PFQ NEW Zmid NEW PFQ

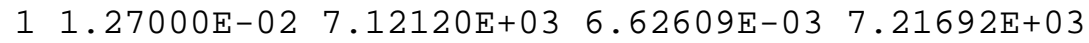

2 3.81000E-02 6.94203E+03 2.65043E-02 6.93402E+03

$36.35000 \mathrm{E}-02$ 7.67277E+@3 5.30087E-02 7.30144E+@3

4 8.8900९E-@2 8.46324E+@3 7.95130E-@2 8.20370E+@3

5 1.14300E-01 9.02886E+०3 1.06017E-01 8.84345E+०3

6 1.39700E-@1 9.67880E+@3 1.32522E-01 9.50285E+@3

7 1.65100E-@1 1.01355E+@4 1.59026E-@1 1.00405E+@4

8 1.90500E-01 1.04728E+04 1.85530E-01 1.04221E+@4

9 2.15900E-01 1.06063E+04 2.12035E-01 1.05916E+04

$102.41300 \mathrm{E}-01$ 1.06976E+०4 2.38539E-01 $1.06916 \mathrm{E}+\odot 4$

$112.66700 \mathrm{E}-01$ 1.06730E+०4 2.65043E-01 1.06786E+०4

12 2.92100E-01 1.05044E+@4 2.91548E-01 1.05102E+०4

13 3.17500E-01 1.01215E+-4 3.18052E-01 1.01109E+@4

$143.42900 \mathrm{E}-01 \quad 9.52773 \mathrm{E}+\odot 3 \quad 3.44557 \mathrm{E}-01 \quad 9.47970 \mathrm{E}+\odot 3$

15 3.68300E-01 8.70916E+-3 3.71061E-01 8.61744E+@3

$163.93700 \mathrm{E}-01$ 7.87654E+@3 3.97565E-@1 7.74846E+@3

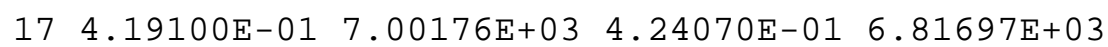

18 4.44500E-01 5.80728E+@3 4.50574E-01 5.37245E+@3

19 4.69900E-01 3.76964E+03 4.77078E-01 3.20758E+03

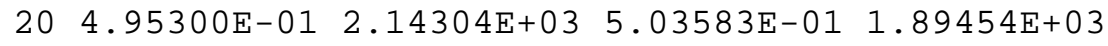


21 5.20700E-01 1.66173E+03 5.30087E-01 1.55514E+03

22 5.46100E-01 1.35609E+03 5.56591E-01 1.23781E+03

23 5.71500E-01 1.13124E+03 5.83096E-01 1.12222E+03

24 5.96900E-01 1.16286E+03 6.02974E-01 1.18423E+03

REVISED MESH REACTIVITY FEEDBACK WEIGHTING FACTORS

\begin{tabular}{|c|c|c|c|}
\hline & DENSITY & DOPPLER & TEMPERATURE \\
\hline & VOIDVC & DOPPLR & TEMPC \\
\hline 1 & 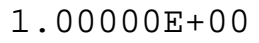 & 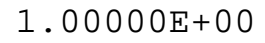 & $1.000 \odot \odot \mathrm{E}+\odot \odot$ \\
\hline 2 & 1. $\odot \odot \odot \odot \odot E+\odot \odot$ & 1. $\odot \odot \odot \odot \odot E+\odot \odot$ & 1. $\odot \odot \odot \odot \odot E+\odot \odot$ \\
\hline 3 & 1. $\odot \odot \odot \odot \odot E+\odot \odot$ & 1. $\odot \odot \odot \odot \odot E+\odot \odot$ & 1. $\odot \odot \odot \odot \odot E+\odot \odot$ \\
\hline 4 & 1. $\odot \odot \odot \odot \odot E+\odot \odot$ & 1. $\odot \odot \odot \odot \odot E+\odot \odot$ & 1. $\odot \odot \odot \odot \odot E+\odot \odot$ \\
\hline 5 & 1. $\odot \odot \odot \odot \odot E+\odot \odot$ & 1. $\odot \odot \odot \odot \odot E+\odot \odot$ & 1. $\odot \odot \odot \odot \odot E+\odot \odot$ \\
\hline 6 & 1. $\odot \odot \odot \odot \odot E+\odot \odot$ & 1. $\odot \odot \odot \odot \odot E+\odot \odot$ & 1. $\odot \odot \odot \odot \odot E+\odot \odot$ \\
\hline 7 & 1. $. \odot \odot \odot \odot E+\odot \odot$ & 1. $00 \odot \odot \odot E+\odot \odot$ & 1. $00 \odot \odot \odot E+\odot \odot$ \\
\hline 8 & 1. $\odot \odot \odot \odot \odot E+\odot \odot$ & 1. $00 \odot \odot \odot E+\odot \odot$ & 1. $00 \odot \odot \odot E+\odot \odot$ \\
\hline 9 & 1. $.00 \odot \odot E+\odot \odot$ & 1. $.00 \odot \odot E+\odot \odot$ & $1.00000 \mathrm{E}+\odot \odot$ \\
\hline 10 & 1. $.000 \odot \odot E+\odot \odot$ & 1. $.0 \odot \odot \odot E+\odot \odot$ & 1. $00000 \mathrm{E}+00$ \\
\hline 11 & 1. $\odot \odot \odot \odot \odot E+\odot \odot$ & 1. $\odot \odot \odot \odot \odot E+\odot \odot$ & 1. $\odot \odot \odot \odot \odot E+\odot \odot$ \\
\hline 12 & 1. $00 \odot \odot \odot E+\odot \odot$ & 1. $00 \odot \odot \odot E+\odot \odot$ & 1. $000 \odot \odot \mathrm{E}+\Theta \odot$ \\
\hline 13 & 1. $.0 \odot \odot \odot E+\odot \odot$ & 1. $00 \odot \odot \odot E+\odot \odot$ & 1. $0 \odot \odot \odot \odot E+\odot \odot$ \\
\hline 14 & 1. $\odot \odot \odot \odot \odot E+\odot \odot$ & 1. $000 \odot \odot E+\odot \odot$ & 1. $000 \odot \odot \mathrm{E}+\Theta \odot$ \\
\hline 15 & 1. $\odot \odot \odot \odot \odot E+\odot \odot$ & 1. $\odot \odot \odot \odot \odot E+\odot \odot ~$ & 1. $\odot \odot \odot \odot \odot E+\odot \odot$ \\
\hline 16 & 1. $0000 \odot E+\odot \odot$ & 1. $\odot \odot \odot \odot \odot E+\odot \odot$ & 1. $000 \odot \odot E+\odot \odot$ \\
\hline 17 & 1. $.0 \odot \odot \odot E+\odot \odot$ & 1. $\odot \odot \odot \odot \odot E+\odot \odot$ & $1.000 \odot \odot E+\odot \odot$ \\
\hline 18 & 1. $.0 \odot \odot \odot E+\odot \odot$ & 1. $00 \odot \odot \odot E+\odot \odot$ & 1. $00 \odot \odot \odot E+\odot \odot$ \\
\hline 19 & 1. $00 \odot \odot \odot E+\odot \odot$ & 1. $00 \odot \odot \odot E+\odot \odot$ & 1. $000 \odot \odot \mathrm{E}+\Theta \odot$ \\
\hline 20 & 1. $00 \odot \odot \odot E+\odot \odot$ & 1. $00 \odot \odot \odot E+\odot \odot$ & 1. $. \odot \odot \odot \odot E+\odot \odot$ \\
\hline 21 & 1. $00 \odot \odot \odot E+\odot \odot$ & 1. $00 \odot \odot \odot E+\odot \odot$ & 1. $000 \odot \odot \mathrm{E}+\Theta \odot$ \\
\hline 22 & 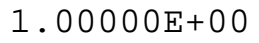 & 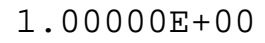 & 1. $000 \odot \odot \mathrm{E}+\odot \odot$ \\
\hline 23 & 1. $\odot \odot \odot \odot ० E+\odot \odot$ & 1. $00 \odot \odot \odot E+\odot \odot$ & $1.000 \odot \odot E+\odot \odot$ \\
\hline 24 & $\odot . \odot \odot \odot \odot \odot Е+\odot \odot$ & 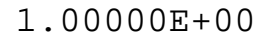 & $\odot . \odot \odot \odot \odot \odot Е+\odot \odot$ \\
\hline 1 & $\odot . \odot \odot \odot \odot \odot E+\odot \odot$ & $\odot . \odot \odot \odot \odot \odot E+\odot \odot$ & $\odot . \odot \odot \odot \odot \odot E+\odot \odot$ \\
\hline 2 & $\odot . \odot \odot \odot \odot \odot E+\odot \odot$ & $\odot . \odot \odot \odot \odot \odot E+\odot \odot$ & $\odot . \odot \odot \odot \odot \odot E+\odot \odot$ \\
\hline 3 & $\odot . \odot \odot \odot \odot \odot E+\odot \odot$ & $\odot .00 \odot \odot \odot E+\odot \odot$ & $\odot .0 \odot \odot \odot \odot E+\odot \odot$ \\
\hline 4 & $\odot . \odot \odot \odot \odot \odot E+\odot \odot$ & $\odot . \odot ० \odot \odot \odot E+\odot \odot$ & $\odot .0 \odot \odot \odot \odot E+\odot \odot$ \\
\hline 5 & $\odot . \odot \odot \odot \odot \odot Е+\odot \odot$ & $\odot . \odot \odot \odot \odot \odot Е+\odot \odot$ & $\odot . \odot \odot \odot \odot \odot E+\odot \odot$ \\
\hline 6 & $\odot . \odot \odot \odot \odot \odot Е+\odot \odot$ & $\odot . \odot \odot \odot \odot \odot Е+\odot \odot$ & $\odot . \odot \odot \odot \odot \odot Е+\odot \odot$ \\
\hline 7 & $\odot . \odot \odot \odot \odot \odot Е+\odot \odot ~$ & $\odot . \odot ० \odot \odot \odot Е+\odot \odot$ & $\odot . \odot \odot \odot \odot \odot Е+\odot \odot$ \\
\hline 8 & $\odot . \odot \odot \odot \odot \odot Е+\odot \odot$ & $\odot . \odot \odot \odot \odot \odot Е+\odot \odot$ & $\odot . \odot \odot \odot \odot \odot Е+\odot \odot$ \\
\hline 9 & $\odot . \odot \odot \odot \odot \odot E+\odot \odot$ & $\odot . \odot \odot \odot \odot \odot E+\odot \odot$ & $\odot . \odot \odot \odot \odot \odot E+\odot \odot$ \\
\hline 10 & $\odot . \odot \odot \odot \odot \odot E+\odot \odot$ & $\odot . \odot ० \odot \odot \odot E+\odot \odot$ & $\odot . \odot \odot \odot \odot \odot E+\odot \odot$ \\
\hline 11 & $\odot . \odot \odot \odot \odot \odot E+\odot \odot$ & $\odot . \odot \odot \odot \odot \odot E+\odot \odot$ & $\odot . \odot \odot \odot \odot \odot E+\odot \odot$ \\
\hline 12 & $\odot . \odot \odot \odot \odot \odot E+\odot \odot$ & $\odot . \odot \odot \odot \odot \odot E+\odot \odot$ & $\odot . \odot \odot \odot \odot \odot E+\odot \odot$ \\
\hline 13 & $\odot . \odot \odot \odot \odot \odot E+\odot \odot$ & $\odot . \odot \odot \odot \odot \odot E+\odot \odot$ & $\odot . \odot \odot \odot \odot \odot E+\odot \odot$ \\
\hline 14 & $\odot . \odot \odot \odot \odot \odot Е+\odot \odot$ & $\odot . \odot \odot \odot \odot \odot Е+\odot \odot$ & $\odot . \odot \odot \odot \odot \odot Е+\odot \odot$ \\
\hline 15 & $\odot . \odot \odot \odot \odot \odot E+\odot \odot$ & $\odot . \odot \odot \odot \odot \odot E+\odot \odot$ & $\odot . \odot \odot \odot \odot \odot E+\odot \odot$ \\
\hline 16 & $\odot . \odot \odot \odot \odot \odot E+\odot \odot$ & $\odot . \odot \odot \odot \odot \odot E+\odot \odot$ & $\odot . \odot \odot \odot \odot \odot E+\odot \odot$ \\
\hline 17 & $\odot . \odot \odot \odot \odot \odot E+\odot \odot$ & $\odot . \odot ० \odot \odot \odot E+\odot \odot$ & $\odot . \odot \odot \odot \odot \odot E+\odot \odot$ \\
\hline 18 & $\odot . \odot \odot \odot \odot \odot E+\odot \odot$ & $\odot . \odot ० \odot \odot \odot E+\odot \odot$ & $\odot . \odot \odot \odot \odot \odot E+\odot \odot$ \\
\hline 19 & $\odot . \odot \odot \odot \odot \odot E+\odot \odot$ & $\odot . \odot ० \odot \odot \odot E+\odot \odot$ & $\odot .0 \odot \odot \odot \odot E+\odot \odot$ \\
\hline 20 & $\odot . \odot \odot \odot \odot \odot E+\odot \odot$ & $\odot . \odot \odot \odot \odot \odot Е+\odot \odot$ & $\odot . \odot \odot \odot \odot \odot E+\odot \odot$ \\
\hline 21 & $\odot . \odot \odot \odot \odot \odot Е+\odot \odot$ & $\odot . \odot \odot \odot \odot \odot Е+\odot \odot$ & $\odot . \odot \odot \odot \odot \odot Е+\odot \odot$ \\
\hline 22 & $\odot . \odot \odot \odot \odot \odot Е+\odot \odot$ & $\odot . \odot \odot \odot \odot \odot Е+\odot \odot ~$ & $\odot . \odot \odot \odot \odot \odot Е+\odot \odot$ \\
\hline
\end{tabular}




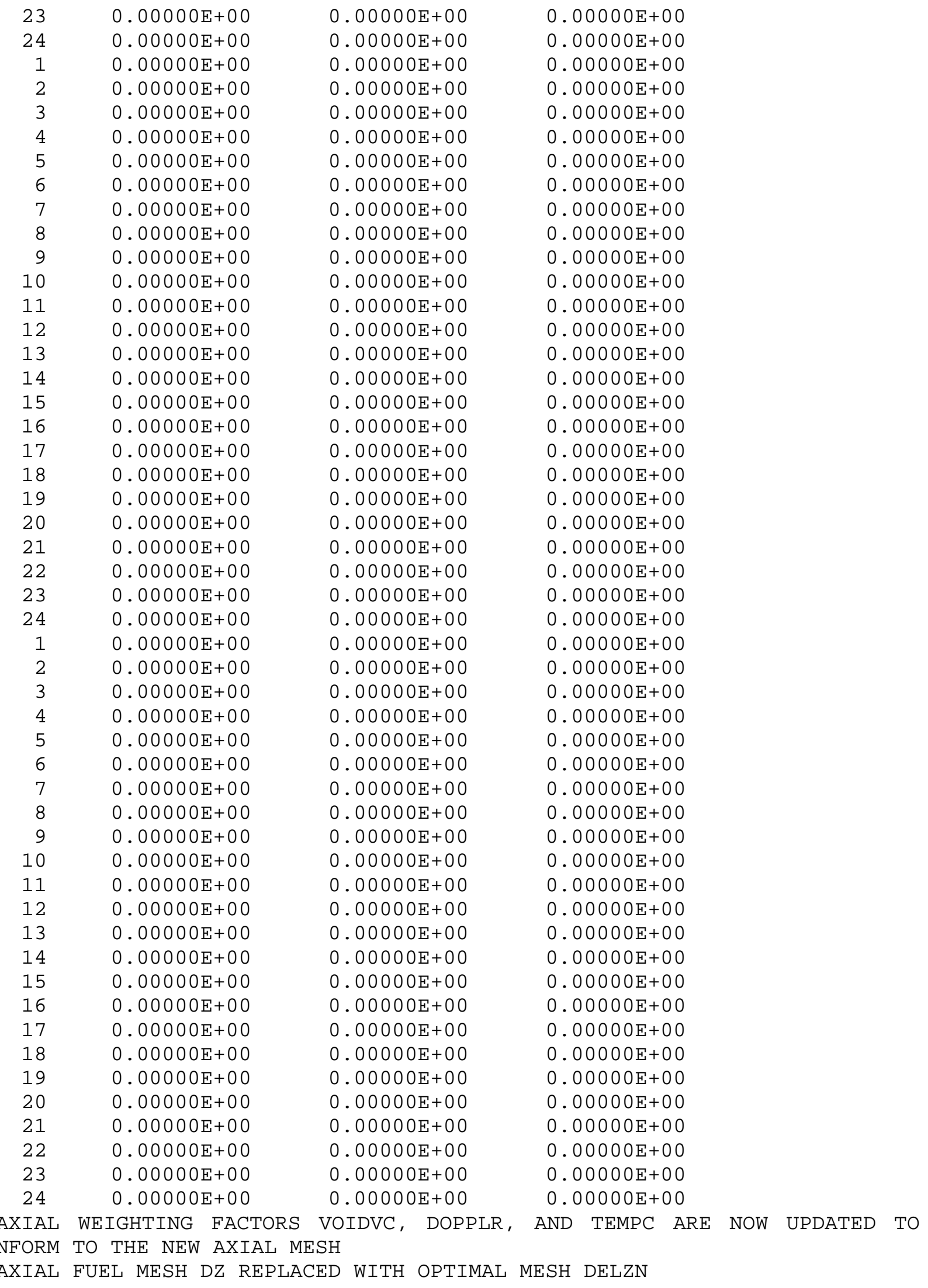


AVG. FUEL MEAT POWER DENSITY $=3513.174565137049 \mathrm{MW} / \mathrm{m} \wedge 3$

AVG. POWER DENSITY FOR EACH CHANNEL $(\mathrm{MW} / \mathrm{m} \wedge 3)$

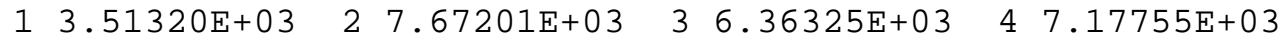

(POWER DENSITY/CORE AVG. POWER DENSITY) FOR EACH CHANNEL

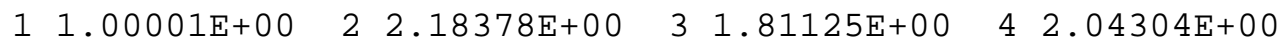

$\mathrm{PF}=2.42462 \mathrm{E}+07 \quad \mathrm{POWER}=1.40000 \mathrm{E}+01$

PFQ EDIT OF CHANNELS SI $\mathrm{MW} / \mathrm{m}^{\wedge} 3 ; \mathrm{P}=1.40000 \mathrm{E}+01 \mathrm{MW}$

CHANNEL -> 1 2 3 4

$13.9586 \mathrm{E}+03 \quad 8.6414 \mathrm{E}+03 \quad 6.8554 \mathrm{E}+03 \quad 7.2169 \mathrm{E}+03$

$23.3278 \mathrm{E}+03$ 8.2196E+@3 6.5345E+@3 $6.9340 \mathrm{E}+03$

3 3.3060E+@3 8.5163E+03 6.7933E+03 7.3014E+@3

$4 \quad 3.8112 \mathrm{E}+03$ 9.5521E+03 7.5722E+03 8.2037E+03

$5 \quad 4.1573 \mathrm{E}+03$ 1.0492E+@4 8.0594E+@3 8.8435E+03

$6 \quad 4.4739 \mathrm{E}+03$ 1.1039E+०4 8.6367E+०3 $9.5028 \mathrm{E}+03$

$7 \quad 4.7145 \mathrm{E}+03$ 1.1693E+@4 8.9070E+@3 $1.0040 \mathrm{E}+\odot 4$

$8 \quad 4.9006 \mathrm{E}+03 \quad 1.2060 \mathrm{E}+04 \quad 9.2442 \mathrm{E}+03 \quad 1.0422 \mathrm{E}+04$

$94.9800 \mathrm{E}+03 \quad 1.2311 \mathrm{E}+04 \quad 9.1831 \mathrm{E}+03 \quad 1.0592 \mathrm{E}+\odot 4$

$105.0014 \mathrm{E}+03 \quad 1.2183 \mathrm{E}+04 \quad 9.2669 \mathrm{E}+03 \quad 1.0692 \mathrm{E}+04$

$114.9295 \mathrm{E}+03$ 1.1959E+०4 9.1531E+03 $1.0679 \mathrm{E}+04$

$124.7750 \mathrm{E}+03 \quad 1.1402 \mathrm{E}+\odot 4 \quad 8.9335 \mathrm{E}+03 \quad 1.0510 \mathrm{E}+04$

13 4.5107E+03 1.0361E+-04 8.7803E+03 1.0111E+04

14 4.1016E+03 8.4874E+03 8.2640E+03 9.4797E+03

$153.7057 \mathrm{E}+03 \quad 6.8702 \mathrm{E}+03 \quad 7.5034 \mathrm{E}+03 \quad 8.6174 \mathrm{E}+03$

$163.3577 \mathrm{E}+03 \quad 6.0669 \mathrm{E}+03 \quad 6.7265 \mathrm{E}+03 \quad 7.7485 \mathrm{E}+03$

$173.0376 \mathrm{E}+03 \quad 5.2440 \mathrm{E}+03 \quad 6.0742 \mathrm{E}+03 \quad 6.8170 \mathrm{E}+03$

$182.6638 \mathrm{E}+03 \quad 4.3298 \mathrm{E}+03 \quad 4.6956 \mathrm{E}+03 \quad 5.3724 \mathrm{E}+03$

$192.2732 \mathrm{E}+03 \quad 3.2065 \mathrm{E}+03 \quad 2.8510 \mathrm{E}+03 \quad 3.2076 \mathrm{E}+03$

$2 \odot 1.9072 \mathrm{E}+03 \quad 2.3648 \mathrm{E}+03 \quad 1.6746 \mathrm{E}+03 \quad 1.8945 \mathrm{E}+03$

$211.6229 \mathrm{E}+03 \quad 1.9670 \mathrm{E}+03 \quad 1.3878 \mathrm{E}+03 \quad 1.5551 \mathrm{E}+03$

$221.3198 \mathrm{E}+03$ 1.6113E+03 $1.1055 \mathrm{E}+03 \quad 1.2378 \mathrm{E}+03$

$231.2406 \mathrm{E}+03$ 1.4648E+03 $1.0454 \mathrm{E}+03 \quad 1.1222 \mathrm{E}+03$

24 1.4124E+O3 1.4677E+०3 1.0693E+03 1.1842E+03

PFQ EDIT OF CHANNELS (EACH CHANNEL NORMALIZED TO 1.)

CHANNEL ->

1

$2 \quad 3 \quad 4$

$3.5132 \mathrm{E}+03 \quad 7.6720 \mathrm{E}+03 \quad 6.3632 \mathrm{E}+03 \quad 7.1776 \mathrm{E}+03$

$11.1268 \mathrm{E}+\odot \odot \quad 1.1263 \mathrm{E}+\odot \odot \quad 1.0773 \mathrm{E}+\odot \odot \quad 1.0055 \mathrm{E}+0 \odot$

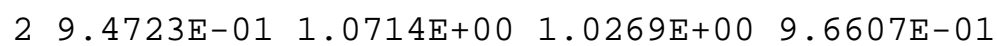

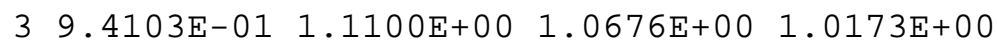

$41.0848 \mathrm{E}+\odot \odot 1.2451 \mathrm{E}+\odot \odot \quad 1.1900 \mathrm{E}+\odot \odot \quad 1.1430 \mathrm{E}+\odot \odot$

$51.1833 \mathrm{E}+0 \odot \quad 1.3676 \mathrm{E}+0 \odot \quad 1.2666 \mathrm{E}+\odot \odot \quad 1.2321 \mathrm{E}+0 \odot$

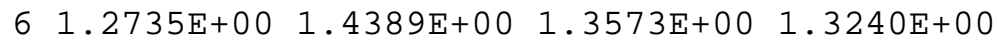

$71.3419 \mathrm{E}+\odot \odot \quad 1.5242 \mathrm{E}+\odot \odot \quad 1.3998 \mathrm{E}+\odot \odot \quad 1.3989 \mathrm{E}+\Theta \odot$

$81.3949 \mathrm{E}+\odot \odot \quad 1.5719 \mathrm{E}+\odot \odot \quad 1.4527 \mathrm{E}+\odot \odot \quad 1.452 \odot \mathrm{E}+\odot \odot$

$91.4175 \mathrm{E}+\odot \odot \quad 1.6047 \mathrm{E}+\odot \odot \quad 1.4432 \mathrm{E}+\odot \odot \quad 1.4757 \mathrm{E}+\odot \odot$

$101.4236 \mathrm{E}+0 \odot \quad 1.5880 \mathrm{E}+00 \quad 1.4563 \mathrm{E}+00 \quad 1.4896 \mathrm{E}+0 \odot$

$111.4031 \mathrm{E}+\odot \odot \quad 1.5588 \mathrm{E}+\odot \odot \quad 1.4384 \mathrm{E}+\odot \odot \quad 1.4878 \mathrm{E}+0 \odot$

$121.3592 \mathrm{E}+\odot \odot \quad 1.4861 \mathrm{E}+\odot \odot \quad 1.4039 \mathrm{E}+\odot \odot \quad 1.4643 \mathrm{E}+0 \odot$

$131.2839 \mathrm{E}+\odot \odot \quad 1.3504 \mathrm{E}+\odot \odot \quad 1.3798 \mathrm{E}+\odot \odot \quad 1.4087 \mathrm{E}+\odot \odot$

$141.1675 \mathrm{E}+0 \odot \quad 1.1063 \mathrm{E}+\odot \odot \quad 1.2987 \mathrm{E}+\odot \odot \quad 1.3207 \mathrm{E}+0 \odot$

$151.0548 \mathrm{E}+0 \odot \quad 8.9549 \mathrm{E}-01 \quad 1.1792 \mathrm{E}+\odot \odot \quad 1.2006 \mathrm{E}+\odot \odot$

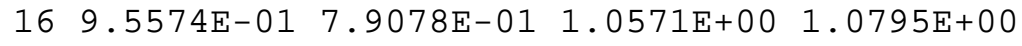


17 8.6463E-01 6.8353E-01 9.5458E-01 9.4976E-01

18 7.5821E-01 5.6436E-01 7.3792E-01 7.4851E-01

19 6.4704E-01 4.1795E-01 4.4804E-01 4.4689E-01

$205.4286 \mathrm{E}-01$ 3.0824E-01 2.6317E-01 2.6395E-01

21 4.6196E-01 2.5639E-01 2.1810E-01 2.1667E-01

22 3.7567E-01 2.1003E-01 1.7374E-01 1.7246E-01

23 3.5312E-01 1.9093E-01 1.6429E-01 1.5635E-01

24 4.0204E-01 1.9130E-01 1.6804E-01 1.6499E-01

$M \quad \operatorname{ZRN}(\mathrm{m}) \quad \mathrm{ZRS}(\mathrm{m}) \quad \mathrm{BM}=$

1 1.70110E-03 5.76547E-04 9.99010E-01

2 1.80340E-03 6.22300E-04 3.30000E-04

3 1.72540E-03 6.45922E-04 3.30000E- 04

4 1.76520E-03 6.38302E-04 3.3000०E- 4

RELATIVE PLATE WIDTHS=

1. $00000 \mathrm{E}+00$ 1.00000E+00 1.00000E+00 1.00000E+00

(VOLPOW)CHANNEL FLOW AREAS $\left(\mathrm{m}^{\wedge} 2\right)$ AND AREA FRACTIONS

CHANNEL AREA FRACTION REL. WIDTH THICK.

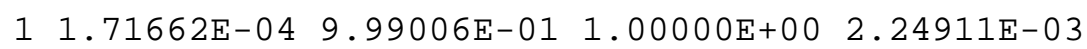

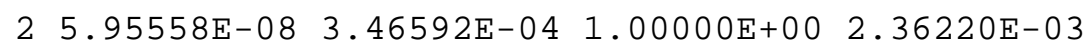

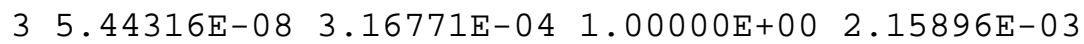

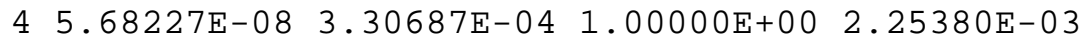

\section{This section lists delayed neutron data}

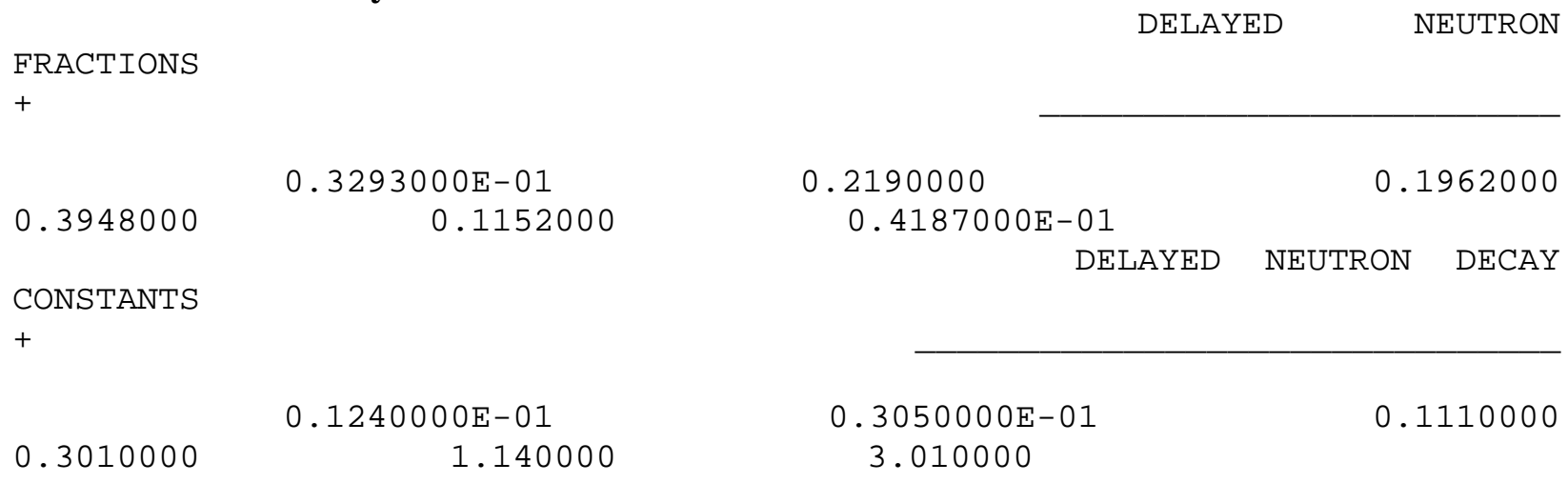

This section lists card type 22000 data

CARD 22000 (STEADY-STATE CONVERGENCE) VALUES ARE: TIMSS $=1.00000 \mathrm{E}+02$ DTSS $=$ $1.00000 \mathrm{E}-03$

This section lists input Tables 9, 10, 11, 12, 14, 16, 17, 18

$\odot$

$+$

TABLE

\#9 REACTIVITY TIME \#10 MASS FLOW TIME \#11 Y OF

CLAD TEMPERATURE \#12 DEL-P TIME 







\begin{tabular}{|c|c|c|c|c|c|}
\hline$\odot . \odot \odot \odot \odot \odot \odot \odot E+\odot \odot$ & $\odot .0 \odot \odot ० \odot \odot \odot E+\odot \odot$ & $\odot . \odot \odot \odot \odot E+\odot \odot$ & $\odot$ & $\odot . \odot \odot \odot \odot E+\odot \odot$ & $\odot \odot \odot E+\odot \odot$ \\
\hline$\odot \odot \odot \odot \odot \odot \odot E+\odot \odot \quad-1$ & $312 \odot \odot \odot \odot E+\odot 1$ & 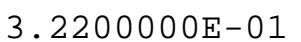 & & & \\
\hline$\odot . \odot \odot \odot \odot \odot \odot \odot E+\odot \odot$ & $\odot . \odot \odot \odot \odot \odot \odot \odot E+\odot \odot$ & $\odot . \odot \odot \odot \odot E+\odot \odot$ & $\Theta$ & $\odot . \odot \odot \odot \odot E+\odot \odot$ & $\odot . \odot \odot \odot \odot \odot \odot \odot Е+\odot \odot$ \\
\hline$. \odot \odot \odot \odot \odot \odot \odot E+\odot \odot \quad-1$ & $1.45260 \odot \odot E+\odot 1$ & ๑๑९Е - ๑1 & & & \\
\hline$\odot .0000000 \mathrm{E}+\odot \odot$ & $\odot .0 \odot \odot \odot \odot \odot \odot E+\odot \odot$ & 0. & $\Theta$ & $\odot . \odot \odot \odot \odot E+\odot \odot$ & $\odot . \odot \odot \odot \odot \odot \odot \odot Е+\odot \odot$ \\
\hline $.0 \odot \odot \odot \odot \odot \odot E+\odot \odot \quad-1$ & $1.5802000 \mathrm{E}+01$ & 3.89 & & & \\
\hline$\odot . \odot \odot \odot \odot \odot \odot \odot E+\odot \odot$ & $\odot . \odot \odot \odot \odot \odot \odot \odot E+\odot \odot$ & $\odot$. & $\odot$ & $\odot . \odot \odot \odot \odot E+\odot \odot$ & $\odot . \odot \odot \odot \odot \odot \odot \odot E+\odot \odot$ \\
\hline $.0000000 E+\odot \odot \quad-1$ & $1.6834000 E+01$ & 4.23 & & & \\
\hline$\odot \odot \odot \odot \odot E+\odot \odot$ & $\odot \odot \odot \odot \odot \odot E+\odot \odot$ & $E+\odot \odot$ & $\odot$ & $\odot . \odot \odot \odot \odot E+\odot \odot$ & $\odot . \odot \odot \odot \odot \odot \odot \odot Е+\odot \odot$ \\
\hline $0 \odot E+\odot \odot \quad-1$ & $1.7492000 \mathrm{E}+\odot 1$ & $4.56 €$ & & & \\
\hline$\odot . \odot \odot \odot \odot \odot \odot \odot E+\odot \odot$ & $\odot . \odot \odot \odot \odot \odot \odot \odot E+\odot \odot$ & $\odot \odot$ & $\odot$ & $\odot \odot \odot E+\odot \odot$ & $\odot . \odot \odot \odot \odot \odot \odot \odot E+\odot \odot$ \\
\hline 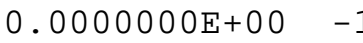 & $1.8056000 \mathrm{E}+01$ & 4.900 & & & \\
\hline$\odot . \odot \odot \odot \odot \odot \odot \odot E+\odot \odot$ & $\odot . \odot \odot \odot \odot \odot \odot \odot E+\odot \odot$ & $\odot E+\odot \odot$ & $\odot$ & $\odot . \odot \odot \odot \odot E+\odot \odot$ & 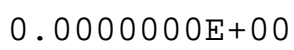 \\
\hline $0000000 E+0 \odot \quad-1$ & $1.8321000 \mathrm{E}+01$ & 5.24000 & & & \\
\hline$\odot . \odot \odot \odot \odot \odot \odot \odot E+\odot \odot$ & ) $\quad . \odot \odot \odot \odot \odot \odot \odot E+\odot \odot$ & 0.00 & $\Theta$ & $\odot . \odot \odot \odot \odot E+\odot \odot$ & $\odot . \odot \odot \odot \odot \odot \odot \odot E+\odot \odot$ \\
\hline 0000 & & $5.57 \odot$ & & & \\
\hline$\odot \odot E+\odot \odot$ & $\odot \odot \odot \odot E+\odot \odot$ & $+\odot \odot$ & & $\odot . \odot \odot \odot \odot E+\odot \odot$ & $\odot . \odot \odot \odot \odot \odot \odot \odot E+\odot \odot$ \\
\hline$. \odot \odot \odot \odot \odot \odot \odot E+\odot \odot \quad-1$ & 1.85120 & $E-01$ & & & \\
\hline
\end{tabular}

This section lists processed power density information

AVG. FUEL MEAT POWER DENSITY $=3513.174565137049 \mathrm{MW} / \mathrm{m} \wedge 3$ AVG. POWER DENSITY FOR EACH CHANNEL $(\mathrm{MW} / \mathrm{m} \wedge 3)$

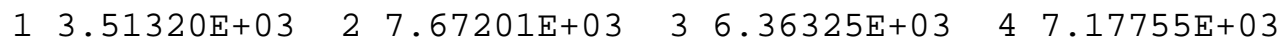
(POWER DENSITY/CORE AVG. POWER DENSITY) FOR EACH CHANNEL

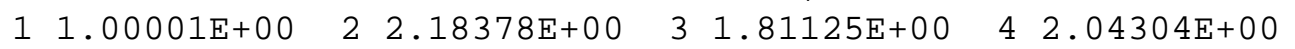
$\mathrm{PF}=2.42462 \mathrm{E}+07$ POWER $=1.40000 \mathrm{E}+01$

PFQ EDIT OF CHANNELS SI $\mathrm{MW} / \mathrm{m}^{\wedge} 3 ; \mathrm{P}=1.40000 \mathrm{E}+01 \mathrm{MW}$ CHANNEL ->

\begin{tabular}{|c|c|c|c|c|}
\hline & $\perp$ & 2 & & \\
\hline 1 & & & $+\odot 3$ & 7.2169 \\
\hline 2 & & & & \\
\hline 3 & & & & \\
\hline 4 & & +03 & & \\
\hline 5 & ○3 & $+\odot 4$ & & \\
\hline 6 & & $+\odot 4$ & & \\
\hline 7 & & $E+04$ & +03 & $E+C$ \\
\hline 8 & & $E+\odot 4$ & +03 & $2 \mathrm{E}+0$ \\
\hline 9 & 3 & $\mathrm{LE}+\odot 4$ & +03 & $92 \mathrm{E}+0$ \\
\hline & & $3 \mathrm{E}+\odot 4$ & $=+03$ & $92 \mathrm{E}+\odot<$ \\
\hline & +03 & $\mathrm{E}+04$ & E+03 & $79 E+\odot 4$ \\
\hline 2 & 93 & $E+\odot 4$ & $=+03$ & $\ominus \mathrm{E}+\mathrm{OL}$ \\
\hline 3 & & $E+\odot 4$ & +03 & $\mathrm{LE}+\odot \angle$ \\
\hline & & +03 & & $E+03$ \\
\hline & & +03 & & $=+63$ \\
\hline & & & & \\
\hline 7 & & $+\odot 3$ & & $E+Q 3$ \\
\hline 18 & & & & \\
\hline 19 & & & & $E+0$ \\
\hline 20 & & & & $5 \mathrm{~F}+0$ \\
\hline 21 & & & & \\
\hline 22 & & & & \\
\hline 23 & & & & \\
\hline & & & & \\
\hline
\end{tabular}


PFQ EDIT OF CHANNELS (EACH CHANNEL NORMALIZED TO 1.)

CHANNEL ->

1

2

3

4

$3.5132 \mathrm{E}+03 \quad 7.6720 \mathrm{E}+03 \quad 6.3632 \mathrm{E}+03 \quad 7.1776 \mathrm{E}+03$

$11.1268 \mathrm{E}+\odot \odot \quad 1.1263 \mathrm{E}+\odot \odot \quad 1.0773 \mathrm{E}+\odot \odot \quad 1.0055 \mathrm{E}+0 \odot$

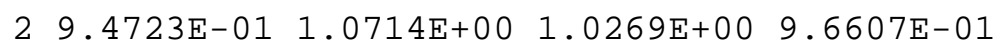

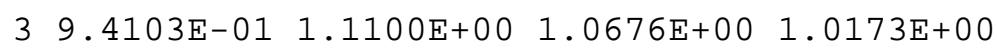

4 1. $0848 \mathrm{E}+\odot \odot \quad 1.2451 \mathrm{E}+0 \odot \quad 1.1900 \mathrm{E}+\odot \odot \quad 1.1430 \mathrm{E}+\odot \odot$

$51.1833 \mathrm{E}+\odot \odot \quad 1.3676 \mathrm{E}+\odot \odot \quad 1.2666 \mathrm{E}+\odot \odot \quad 1.2321 \mathrm{E}+00$

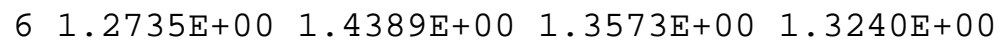

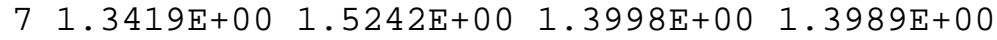

$81.3949 \mathrm{E}+\odot \odot \quad 1.5719 \mathrm{E}+\odot \odot \quad 1.4527 \mathrm{E}+\odot \odot \quad 1.4520 \mathrm{E}+\odot \odot$

$91.4175 \mathrm{E}+\odot \odot \quad 1.6047 \mathrm{E}+\odot \odot \quad 1.4432 \mathrm{E}+\odot \odot \quad 1.4757 \mathrm{E}+\odot \odot$

$101.4236 \mathrm{E}+\odot \odot \quad 1.5880 \mathrm{E}+\odot \odot \quad 1.4563 \mathrm{E}+\odot \odot \quad 1.4896 \mathrm{E}+\odot \odot$

$111.4031 \mathrm{E}+\odot \odot \quad 1.5588 \mathrm{E}+\odot \odot \quad 1.4384 \mathrm{E}+\odot \odot \quad 1.4878 \mathrm{E}+0 \odot$

$121.3592 \mathrm{E}+\odot \odot \quad 1.4861 \mathrm{E}+\odot \odot \quad 1.4039 \mathrm{E}+\odot \odot \quad 1.4643 \mathrm{E}+\odot \odot$

$131.2839 \mathrm{E}+0 \odot \quad 1.3504 \mathrm{E}+0 \odot \quad 1.3798 \mathrm{E}+\odot \odot \quad 1.4087 \mathrm{E}+0 \odot$

$141.1675 \mathrm{E}+\odot \odot \quad 1.1063 \mathrm{E}+\odot \odot \quad 1.2987 \mathrm{E}+\odot \odot \quad 1.3207 \mathrm{E}+\odot \odot$

$151.0548 \mathrm{E}+\odot \odot \quad 8.9549 \mathrm{E}-01 \quad 1.1792 \mathrm{E}+\odot \odot \quad 1.2006 \mathrm{E}+\odot \odot$

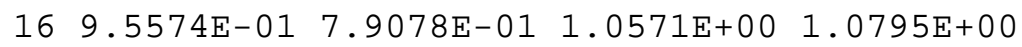

17 8.6463E-01 6.8353E-01 9.5458E-01 9.4976E-01

18 7.5821E-01 5.6436E-01 7.3792E-01 7.4851E-01

19 6.4704E-01 4.1795E-01 4.4804E-01 4.4689E-01

20 5.4286E-01 3.0824E-01 2.6317E-01 2.6395E-01

21 4.6196E-01 2.5639E-01 2.1810E-01 2.1667E-01

22 3.7567E-01 2.1003E-01 1.7374E-01 1.7246E-01

23 3.5312E-01 1.9093E-01 1.6429E-01 1.5635E-01

24 4.0204E-01 1.9130E-01 1.6804E-01 1.6499E-01

$M \quad \operatorname{ZRN}(\mathrm{m}) \quad \mathrm{ZRS}(\mathrm{m}) \quad \mathrm{BM}=$

1 1.70110E-03 5.76547E-04 9.99010E-01

$21.80340 \mathrm{E}-03 \quad 6.22300 \mathrm{E}-04 \quad 3.30000 \mathrm{E}-04$

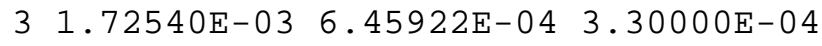

4 1.76520E-03 6.38302E-04 3.30000E-04

RELATIVE PLATE WIDTHS=

1. $.0000 \odot \mathrm{E}+\odot \odot \quad 1.00000 \mathrm{E}+\odot \odot \quad 1.00000 \mathrm{E}+\odot \odot \quad 1.00000 \mathrm{E}+\odot \odot$

(VOLPOW)CHANNEL FLOW AREAS $\left(\mathrm{m}^{\wedge} 2\right)$ AND AREA FRACTIONS

CHANNEL AREA FRACTION REL. WIDTH THICK.

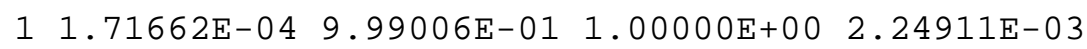

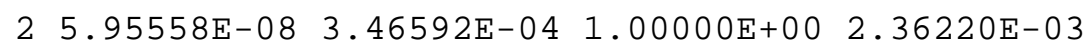

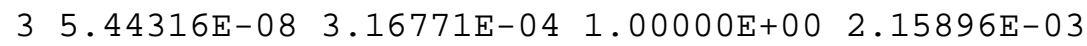

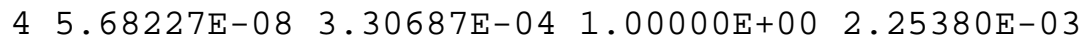

This section lists decay heat initial conditions

DECAY HEAT PARAMETERS :

OPTION FLAG IDKOPT $=0$

PREVIOUS OPERATION TIME $=0.56160 \mathrm{E}+06$ SEC

PREVIOUS OPERATION POWER $=0.14450 E+02 \mathrm{MW}$

ENERGY RELEASE/FISSION $=200.000 \mathrm{MeV}$

This section lists special output from using IGEOM=2 for each channel 
9890 CALC. OF DHP AND DE AND RH (SI)

$\mathrm{DE}(\mathrm{I})$

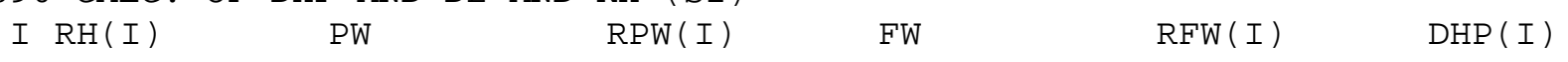

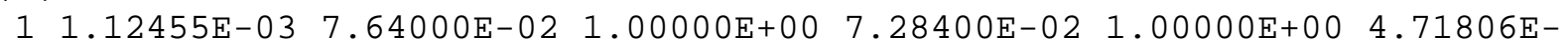
03 4.36958E-03

FINAL VALUE FOR DE $(\mathrm{I})(\mathrm{m})=4.369579049738374 \mathrm{E}-03$

9890 CALC. OF DHP AND DE AND RH (SI)

$\mathrm{DE}(\mathrm{I})$

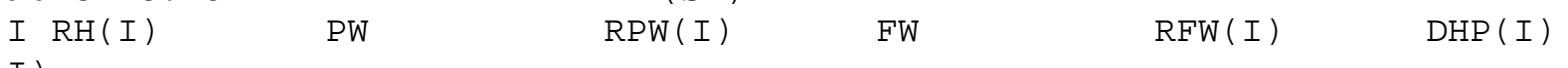

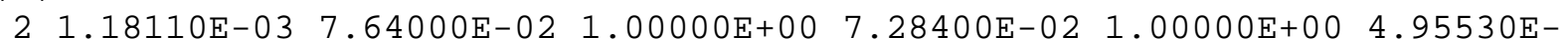
03 4.58271E-03

FINAL VALUE FOR DE $(\mathrm{I})(\mathrm{m})=4.582707572370268 \mathrm{E}-03$

9890 CALC. OF DHP AND DE AND RH (SI)

$\mathrm{DE}(\mathrm{I})$

$\begin{array}{llllll}\mathrm{I} R H(I) & \mathrm{PW} & \mathrm{RPW}(\mathrm{I}) & \mathrm{FW} & \mathrm{RFW}(\mathrm{I}) & \mathrm{DHP}(\mathrm{I})\end{array}$

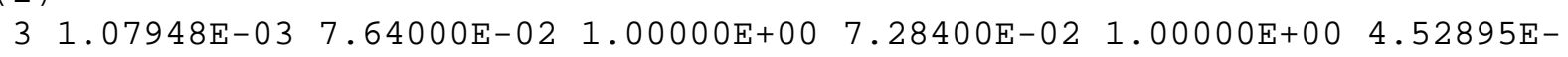
○3 4.19925E- 03

FINAL VALUE FOR DE $(\mathrm{I})(\mathrm{m})=4.199247209955285 \mathrm{E}-03$

9890 CALC. OF DHP AND DE AND RH (SI)

$\begin{array}{llllll}\mathrm{I} R H(I) & \mathrm{RW} & \mathrm{RPW}(\mathrm{I}) & \mathrm{FW} & \mathrm{RFW}(\mathrm{I}) & \mathrm{DHP}(\mathrm{I})\end{array}$

$\mathrm{DE}(\mathrm{I})$

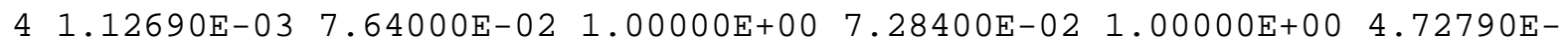

03 4.37843E- 03

FINAL VALUE FOR DE $(\mathrm{I})(\mathrm{m})=4.378428585951529 \mathrm{E}-03$

INLK2 SETTING UP ARRAYS RADIUS AND ICOMP

ICLASS from MRCLAS $=1$

ICLASS from MRCLAS $=1$

NR frOm MRCHAN $=12$

SELECTED RADIUS=

$9.5857400 \odot \odot \odot \odot \odot \odot \odot 2 \mathrm{E}-\odot 5 \quad 1.43786100 \odot \odot \odot \odot \odot \odot \odot \mathrm{E}-\odot 4 \quad 1.9171480 \odot \odot \odot \odot \odot \odot \odot \odot \odot \mathrm{E}-\odot 4$

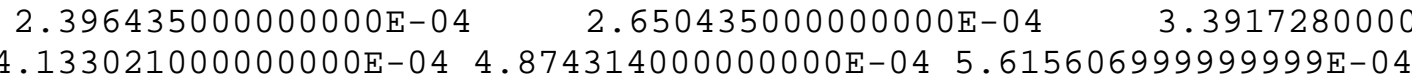

$5.765467000000000 \mathrm{E}-04$

FUEL ENDS AT 6

FINDRS: PIN/PLATE SURFACE RADIUS $=5.76547 \mathrm{E}-04 \mathrm{~m}$

CLAD IS COMPOSITION 4

CLAD BEGINS AT 8

INLK2 SETTING UP ARRAYS RADIUS AND ICOMP

ICLASS from MRCLAS $=2$

ICLASS from MRCLAS $=2$

NR from MRCHAN= 12

SELECTED RADIUS $=\quad 0.0000000000000000 \mathrm{E}+00 \quad 4.31800000000000000 \mathrm{E}-05$

$8.636000000000001 E-051.295400000000000 E-04 \quad 1.727200000000000 E-04$

$2.159000000000000 \mathrm{E}-\odot 4 \quad 2.41300000000000000 \mathrm{E}-04 \quad 3.36550000000000000 \mathrm{E}-\odot 4$

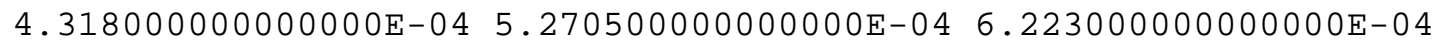

$6.223001000000000 \mathrm{E}-04$

FUEL ENDS AT 6

FINDRS: PIN/PLATE SURFACE RADIUS $=6.22300 \mathrm{E}-04 \mathrm{~m}$

CLAD IS COMPOSITION 4

CLAD BEGINS AT 8

INLK2 SETTING UP ARRAYS RADIUS AND ICOMP

ICLASS from MRCLAS $=3$

ICLASS from MRCLAS $=3$ 
NR from MRCHAN= 12

SELECTED RADIUS $=\quad 0.0000000000000000 \mathrm{E}+00 \quad 4.3180000000000000 \mathrm{E}-05$

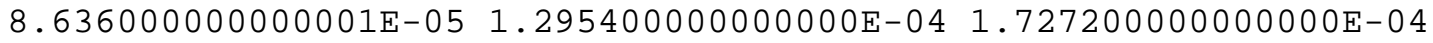

$2.159000000000000 \mathrm{E}-\odot 4 \quad 2.41300000000000000 \mathrm{E}-\odot 4 \quad 3.365500000000000 \mathrm{E}-\odot 4$

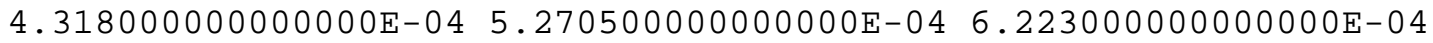

$6.459219999999999 \mathrm{E}-04$

FUEL ENDS AT 6

FINDRS: PIN/PLATE SURFACE RADIUS $=6.45922 \mathrm{E}-\odot 4 \mathrm{~m}$

CLAD IS COMPOSITION 4

CLAD BEGINS AT 8

INLK2 SETTING UP ARRAYS RADIUS AND ICOMP

ICLASS from MRCLAS $=4$

ICLASS from MRCLAS $=4$

NR from MRCHAN= 12

SELECTED RADIUS $=\quad 0.0000000000000 \odot \odot \mathrm{E}+0 \odot \quad 4.3180000000000000 \mathrm{E}-05$

$8.636000000000001 E-05 \quad 1.2954000000000000 E-04 \quad 1.727200000000000 E-04$

$\begin{array}{lll}2.159000000000000 \mathrm{E}-\odot 4 & 2.4130000000000000 \mathrm{E}-\odot 4 & 3.365500000000000 \mathrm{E}-\odot 4\end{array}$

$4.318000000000000 \mathrm{E}-04 \quad 5.270500000000000 \mathrm{E}-04 \quad 6.223000000000000 \mathrm{E}-04$

$6.383020000000000 \mathrm{E}-\odot 4$

FUEL ENDS AT 6

FINDRS: PIN/PLATE SURFACE RADIUS $=6.38302 \mathrm{E}-04 \mathrm{~m}$

CLAD IS COMPOSITION 4

CLAD BEGINS AT 8

\title{
This section lists coolant properties at the specified pressure
}

\author{
ENTERED SUBROUTINE WATER; IFLUID $=\odot \quad I C P=\odot \quad$ PAVPA $=434200.0000000000$ \\ LIGHT WATER PROPERTIES \\ subscript _l denotes liquid; _ $v$ denotes vapor

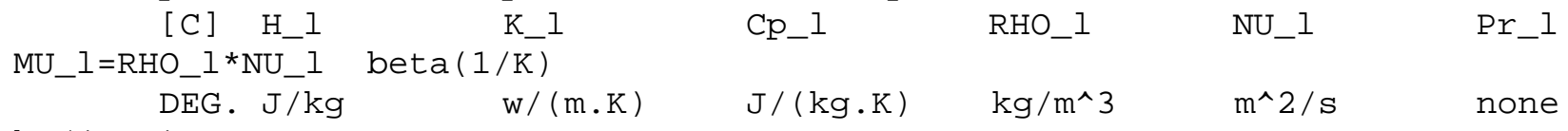 \\ $\mathrm{Pa} \cdot \mathrm{S}$ \\ $\begin{array}{lllllll}1 & 8.00 \odot & 3.39778 \mathrm{E}+04 & 5.88064 \mathrm{E}-01 & 4.15871 \mathrm{E}+03 & 9.99470 \mathrm{E}+02 & 1.36942 \mathrm{E}-06\end{array}$ \\ $9.67922 \mathrm{E}+00$ 1.36869E- $03 \quad 7.2851 \mathrm{E}-05$ \\ $2 \quad 16.00 \odot \quad 6.72405 \mathrm{E}+04 \quad 6.01141 \mathrm{E}-01 \quad 4.15871 \mathrm{E}+03 \quad 9.98603 \mathrm{E}+\odot 2 \quad 1.12026 \mathrm{E}-\odot 6$ \\ 7.73916E+@९ 1.11870E-๑3 1.4398E-04

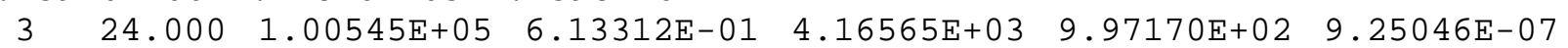 \\ 6. 26519E+๑९ 9.22429E-๑4 2.1465E- 04 \\ $4 \quad 32.000 \quad 1.33884 \mathrm{E}+05 \quad 6.24588 \mathrm{E}-01 \quad 4.16912 \mathrm{E}+03 \quad 9.95180 \mathrm{E}+02 \quad 7.73723 \mathrm{E}-07$ \\ $5.13970 \mathrm{E}+00 \quad 7.69994 \mathrm{E}-042.8452 \mathrm{E}-04$ \\ $5 \quad 40.000 \quad 1.67265 \mathrm{E}+05 \quad 6.34982 \mathrm{E}-01 \quad 4.17259 \mathrm{E}+03 \quad 9.92643 \mathrm{E}+02 \quad 6.57312 \mathrm{E}-07$ \\ $4.28755 \mathrm{E}+\Theta \odot \quad 6.52476 \mathrm{E}-\odot 4 \quad 3.5325 \mathrm{E}-\odot 4$ \\ $\begin{array}{lllllll}6 & 48.00 \odot \quad 2.00687 \mathrm{E}+05 & 6.44509 \mathrm{E}-01 & 4.17953 \mathrm{E}+03 & 9.89574 \mathrm{E}+02 & 5.67999 \mathrm{E}-07\end{array}$ \\ 3. $64498 \mathrm{E}+0 \odot 5.62077 \mathrm{E}-04 \quad 4.2043 \mathrm{E}-04$ \\ $\begin{array}{llllll}7 & 56.00 \odot & 2.34165 \mathrm{E}+05 & 6.53182 \mathrm{E}-01 & 4.18648 \mathrm{E}+\odot 3 \quad 9.85991 \mathrm{E}+02 \quad 4.99047 \mathrm{E}-07\end{array}$ \\ $3.15376 \mathrm{E}+0 \odot \quad 4.92055 \mathrm{E}-04 \quad 4.8564 \mathrm{E}-04$ \\ $\begin{array}{lllllll}8 & 64.00 \odot & 2.67685 \mathrm{E}+05 & 6.61012 \mathrm{E}-01 & 4.19342 \mathrm{E}+03 & 9.81917 \mathrm{E}+02 & 4.44872 \mathrm{E}-07\end{array}$ \\ $2.77121 \mathrm{E}+\odot \odot \quad 4.36827 \mathrm{E}-\odot 4 \quad 5.4864 \mathrm{E}-04$
}


$9 \quad 72.000 \quad 3.01260 \mathrm{E}+05 \quad 6.68013 \mathrm{E}-01$ $2.45943 \mathrm{E}+\odot \odot \quad 3.91140 \mathrm{E}-\odot 4 \quad 6.0880 \mathrm{E}-\odot 4$

$10 \quad 80.000 \quad 3.34897 \mathrm{E}+05 \quad 6.74199 \mathrm{E}-01$ $2.22147 \mathrm{E}+0 \odot \quad 3.55978 \mathrm{E}-04 \quad 6.6574 \mathrm{E}-04$

$11 \quad 88.00 \odot \quad 3.68591 \mathrm{E}+05 \quad 6.79580 \mathrm{E}-01$ $2.02906 \mathrm{E}+\odot \odot \quad 3.27201 \mathrm{E}-04 \quad 7.1881 \mathrm{E}-04$

$12 \quad 96.00 \odot \quad 4.02353 \mathrm{E}+05 \quad 6.84170 \mathrm{E}-01$ $1.86463 \mathrm{E}+\odot \odot \quad 3.01971 \mathrm{E}-\odot 4 \quad 7.6769 \mathrm{E}-\odot 4$

$13 \quad 104.000 \quad 4.36192 \mathrm{E}+05 \quad 6.87981 \mathrm{E}-01$

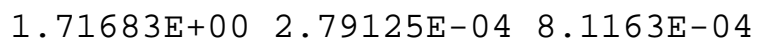
$14 \quad 112.000 \quad 4.70107 \mathrm{E}+05 \quad 6.91024 \mathrm{E}-01$ $1.58769 \mathrm{E}+00 \quad 2.58635 \mathrm{E}-04 \quad 8.4995 \mathrm{E}-04$

$15 \quad 120.00 \odot \quad 5.04113 \mathrm{E}+05 \quad 6.93312 \mathrm{E}-01$

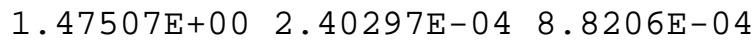

$16 \quad 128.00 \odot \quad 5.38209 \mathrm{E}+05 \quad 6.94854 \mathrm{E}-01$

$1.37488 \mathrm{E}+0 \odot \quad 2.23926 \mathrm{E}-04 \quad 9.0686 \mathrm{E}-04$

$17 \quad 136.000 \quad 5.72409 \mathrm{E}+05 \quad 6.95663 \mathrm{E}-01$

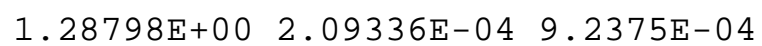

$18 \quad 144.000 \quad 6.06727 \mathrm{E}+05 \quad 6.95748 \mathrm{E}-01$

$1.21188 \mathrm{E}+0 \odot$ 1.96355E- 04 9.3058E-04

$19 \quad 146.608 \quad 6.17939 \mathrm{E}+05 \quad 6.95620 \mathrm{E}-01$ $1.18892 \mathrm{E}+\odot \odot \quad 1.92444 \mathrm{E}-\odot 4 \quad 9.3058 \mathrm{E}-\odot 4$

\begin{tabular}{|c|c|c|c|c|c|}
\hline [C] H_V & K_V & Cp_v & RHO_V & NU_v & Pr_v \\
\hline MU_V=RHO_V*NU_v & & & & & \\
\hline DEG. J/kg & $\mathrm{w} /(\mathrm{m} \cdot \mathrm{K})$ & $\mathrm{J} /(\mathrm{kg} \cdot \mathrm{K})$ & $\mathrm{kg} / \mathrm{m}^{\wedge} 3$ & $m^{\wedge} 2 / s$ & none \\
\hline
\end{tabular}

$\mathrm{kg} /(\mathrm{m} . \mathrm{s})$ DEG. J/kg

Pa.S

TSAT $=146.608$

$1 \quad 146.608 \quad 2.73920 \mathrm{E}+06$

1. $06204 \mathrm{E}+00$ 1.37755E- 05

$2 \quad 158.000 \quad 2.76513 E+06$

1. $06740 \mathrm{E}+0 \odot$ 1.42616E- 05

$3 \quad 169.000 \quad 2.79000 \mathrm{E}+06$

1. $06615 \mathrm{E}+0 \odot$ 1.47295E- 05

$4 \quad 180.000 \quad 2.81470 \mathrm{E}+06$

1. $06241 \mathrm{E}+0 \odot$ 1.51963E- 05

$5 \quad 191.000 \quad 2.83924 \mathrm{E}+06$

$1.05785 \mathrm{E}+\odot \odot$ 1.56621E- $\odot 5$

$6 \quad 202.000 \quad 2.86361 \mathrm{E}+06$

1. $05037 \mathrm{E}+00$ 1.61269E- 05

$7 \quad 213.000 \quad 2.88783 E+06$

$1.04313 \mathrm{E}+0 \odot 1.65907 \mathrm{E}-05$

$8 \quad 224.000 \quad 2.91189 \mathrm{E}+06$

$1.03437 \mathrm{E}+001.70538 \mathrm{E}-05$

$9 \quad 235.000 \quad 2.93580 \mathrm{E}+06$

$1.02498 \mathrm{E}+0 \odot$ 1.75161E- 05

$10 \quad 246.000 \quad 2.95956 \mathrm{E}+06$

$1.01578 \mathrm{E}+0 \odot 1.79777 \mathrm{E}-05$

$11257.000 \quad 2.98317 \mathrm{E}+06$

$1.00620 \mathrm{E}+00$ 1.84387E- 05

$12 \quad 268.000 \quad 3.00665 \mathrm{E}+06$

9.95662E-01 1.88991E-05
4. 20036E+@3 9.77378E+@2 4.00194E- 07

4. 20731E+03 9.72403E+02 3.66081E-07

4. 21425E+@3 9.67028E+@2 3.38358E- 07

4. 22466E+@3 9.61289E+@2 3.14131E- 07

4. 23161E+@3 9.55229E+@2 2.92208E- 07

4. 24202E+@3 9.48895E+०2 2.72564E-๑7

4.25591E+@3 9.42336E+@2 2.55001E-07

4.26632E+@3 9.35609E+@2 2.39337E- 07

4. 28020E+@3 9.28773E+@2 2.25390E- 07

4. 29409E+@3 9.21894E+@2 2.12991E-๑7

4.29756E+@3 9.19653E+@2 2. $29257 \mathrm{E}-07$$$
\mathrm{W} /(\mathrm{m} \cdot \mathrm{K}) \quad \mathrm{J} /(\mathrm{kg} \cdot \mathrm{K}) \quad \mathrm{kg} / \mathrm{m}^{\wedge} 3 \quad \mathrm{~m}^{\wedge} 2 / \mathrm{s}
$$

$2.33041 \mathrm{E}+00$

$2.25797 \mathrm{E}+\odot \odot$

$3.03134 \mathrm{E}-02$

$3.11075 \mathrm{E}-02$

$3.19814 \mathrm{E}-02$

$3.29131 E-02$

$3.38893 E-\odot 2$

$3.49013 E-02$

$3.59435 \mathrm{E}-02$

$3.70117 \mathrm{E}-02$

$3.81035 \mathrm{E}-02$

3. $92166 \mathrm{E}-02$

4. 03497E-02
$2.15292 \mathrm{E}+03$

$2.14005 E+03$

$2.12574 \mathrm{E}+\Theta 3$

$2.19261 \mathrm{E}+\odot \odot$

$2.13134 \mathrm{E}+00$

$2 . \odot 7378 E+\odot \odot$

$7.55244 E-06$

$2 . \odot 1958 \mathrm{E}+\odot \odot$

7. $98524 \mathrm{E}-06$

$1.96848 \mathrm{E}+\Theta \odot$

$8.42820 E-06$

$2.18010 \mathrm{E}+03$

$1.92020 \mathrm{E}+0 \odot$

8. 88127E-๑6

$1.87451 \mathrm{E}+\odot \odot$

$9.34439 E-06$

$1.83121 \mathrm{E}+\odot \odot$

$9.81739 E-06$

$1.79012 \mathrm{E}+0 \odot \quad 1.03003 \mathrm{E}-05$

$1.75106 \mathrm{E}+\odot \odot$

1. $07929 E-05$ 
$13 \quad 279.000 \quad 3.02997 \mathrm{E}+06$ $9.86244 \mathrm{E}-01$ 1.93590E- 05

$14 \quad 290.000 \quad 3.05317 \mathrm{E}+06$ $9.75326 \mathrm{E}-01$ 1.98183E- 05

$15 \quad 301.000 \quad 3.07622 \mathrm{E}+06$ $9.65619 \mathrm{E}-01$ 2.02772E-05

$16 \quad 312.000 \quad 3.09914 \mathrm{E}+06$ $9.56002 \mathrm{E}-01$ 2.07396E- 05

$17 \quad 323.000 \quad 3.12193 \mathrm{E}+06$ $9.45872 \mathrm{E}-01$ 2.12063E- 05

$18 \quad 334.000 \quad 3.14459 \mathrm{E}+06$ $9.37089 \mathrm{E}-01$ 2.16747E-05

$19345.000 \quad 3.16713 \mathrm{E}+06$ $9.27594 \mathrm{E}-01$ 2.21424E-05

$20 \quad 356.000 \quad 3.18954 \mathrm{E}+06$ $9.17311 \mathrm{E}-01$ 2.26065E-05

$21367.000 \quad 3.21182 \mathrm{E}+06$ 9. 08107E-01 2.30647E- 05

END OF SUBROUTINE WATER

FUEL VOLUME IS BASED ON 2. ${ }^{\star} \mathrm{ZRF}(\mathrm{J}){ }^{*}\left(\mathrm{FW}^{\star} \mathrm{ZRFW}(\mathrm{J})\right){ }^{\star} A L$

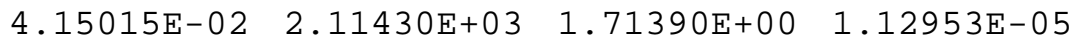

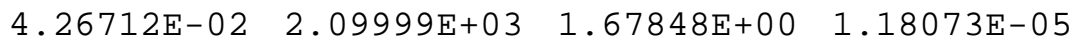

4.38578E-๑2 2. $28855 E+\odot 3 \quad 1.64470 E+\odot \odot \quad 1.23289 E-\odot 5$

4.50609E-๑2 2. $07710 E+\odot 3 \quad 1.61242 E+\odot \odot \quad 1.28624 E-\odot 5$

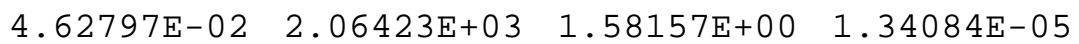

4.75137E-๑2 2. $05421 E+\odot 3 \quad 1.55204 E+\odot \odot \quad 1.39653 E-\odot 5$

4.87625E-๑2 2. $44277 \mathrm{E}+\odot 3 \quad 1.52376 \mathrm{E}+\odot \odot \quad 1.45314 \mathrm{E}-\odot 5$

$5.00255 \mathrm{E}-\odot 2 \quad 2.02990 \mathrm{E}+\odot 3 \quad 1.49663 \mathrm{E}+\odot \odot \quad 1.51050 \mathrm{E}-\odot 5$

$5.13024 \mathrm{E}-\odot 2 \quad 2.01988 \mathrm{E}+03 \quad 1.47059 \mathrm{E}+\odot \odot \quad 1.56840 \mathrm{E}-\odot 5$

Note: The quantity beta (expansion coefficient at constant pressure) for liquid water is defined as $(1 / \rho) d(\rho) / d T)$ at constant pressure.

\section{This section provides power-related derived parameters for IGEOM=2}

FUEL VOLUME BY CHANNEL=

$2.128186278950400 \mathrm{E}-05$

$1.917332939520000 \mathrm{E}-05$

$1.917332939520000 \mathrm{E}-05$

1.917332939520000E- 05

CALCULATING CHANNEL FACTOR BMS

$M M=1 \quad B M(M M)=0.9990100000000000 \quad Z R F(M M)=2.396430000000000 E-04$

$M M=2 \quad B M(M M)=3.3000000000000000 \mathrm{E}-04 \quad Z R F(M M)=2.15900000000000000 \mathrm{E}-04$

$M M=3 \quad \mathrm{BM}(\mathrm{MM})=3.3000000000000000 \mathrm{E}-04 \quad \mathrm{ZRF}(\mathrm{MM})=2.15900000000000000 \mathrm{E}-04$

$M M=4 \quad B M(M M)=3.300000000000000 E-04 \quad Z R F(M M)=2.1590000000000000-04$

DENOM= 1272.030413298605

BMS $=0.9989012471366945 \quad 3.662509544351689 \mathrm{E}-04 \quad 3.662509544351689 \mathrm{E}-04$

3. $662509544351689 \mathrm{E}-04$

CHECK OF TOTAL POWER: SUMPX $=2.591262335542046 \mathrm{E}-06$

CHECK OF CHANNEL POWERS: $2.586104283412417 \mathrm{E}-06 \quad 1.865506590543781 \mathrm{E}-09$

1.547270177875759E-๑9 1.745275361209685E- 09

IGEOM $=2$ : EXPECTED POWER FRACTIONS EXPECW ARE : 0.9980094442546860

$7.199219333975886 E-04 \quad 5.971105884005748 E-04 \quad 6.735232235159257 E-04$

$\operatorname{PBAR}(M)=\quad 3513.198643898371 \quad 7672.013460327878 \quad 6363.246150723338$

7177.554949980793

ZCVOL $(M)=1.046335384301482 E-04 \quad 4.029338100469616 E-08 \quad 3.682653629907800 E-$

$083.844427593925806 \mathrm{E}-08$

EXPECTED DIRECT HEAT FRACTIONS TO COOLANT:

$\odot .0000 \odot \mathrm{E}+\odot \odot \quad 0.00000 \mathrm{E}+\odot \odot \quad \odot .00000 \mathrm{E}+\odot \odot \quad \odot .00000 \mathrm{E}+\odot \odot$

EXPECTED CONDUCTION HEAT FRACTIONS

9.98009E-01 7.19922E-๑4 5.97111E-04 6.73523E-04

EXPECTED TOTAL HEAT FRACTIONS

9.98009E-@1 7.19922E-04 5.97111E-@4 6.73523E-@4

F500Y: EXPECW= 
9.98009E-01 7.19922E-๑4 5.97111E-@4 6.73523E-๑4

PFSI $=3.984999817239044 \mathrm{E}-03$

CONSISTENCY CHECK: POWER FACTOR= 1.001009412098161

$3.51320 \mathrm{E}+03 \quad 2.12585 \mathrm{E}-05$

7.67201E+03 7.02225E- 09

$6.36325 \mathrm{E}+03 \quad 7.02225 \mathrm{E}-09$

$7.17755 \mathrm{E}+03 \quad 7.02225 \mathrm{E}-09$

SUBROUTINE CHECK: INORM $=\odot \quad$ IGEOM $=2 \quad \mathrm{NW}=11640$

CHECK: $M, C O N, B M(M)=11.0000000000000000 .9990100000000000$

CHECK: $M, C O N, B M(M)=21.00000000000000003 .300000000000000 E-04$

CHECK: $M, C O N, B M(M)=31.0000000000000003 .300000000000000 E-04$

CHECK: $M, C O N, B M(M)=41.0000000000000003 .3000000000000000 \mathrm{E}-04$

NORMALIZATION SCALE FACTOR (IF USED) $=0.9989916057871567$

CHECK OF POWER NORMALIZATION

WARNING: THE REACTOR IS OVER-SPECIFIED. RENORMALIZATION MAY CORRECT IT.

CHANNEL POWER ALLOCATION WILL BE RENORMALIZED BY A FACTOR OF

0.9989916057871567

CHANNEL JJJ= 1

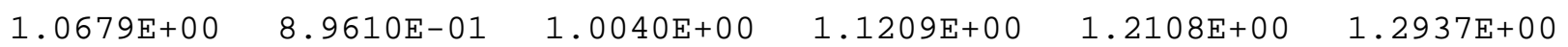

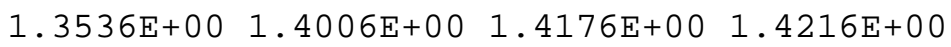

$1.3996 \mathrm{E}+\odot \odot 1.3566 \mathrm{E}+\odot \odot \quad 1.2847 \mathrm{E}+\odot \odot \quad 1.1738 \mathrm{E}+\odot \odot \quad 1.0649 \mathrm{E}+\odot \odot \quad 9.6802 \mathrm{E}-01 \quad 8.8211 \mathrm{E}-$

01 7.8221E-01 6.7732E-01 5.7142E-01

4.8951E-01 4.1059E-01 3.4465E-01 3.8561E-01

CHANNEL JJJ $=2$

$2.4176 \mathrm{E}+\odot \odot \quad 2.3237 \mathrm{E}+0 \odot \quad 2.5354 \mathrm{E}+00 \quad 2.8182 \mathrm{E}+\odot \odot \quad 3.0449 \mathrm{E}+\odot \odot \quad 3.1798 \mathrm{E}+\odot \odot$

$3.3636 \mathrm{E}+0 \odot \quad 3.4415 \mathrm{E}+0 \odot \quad 3.5045 \mathrm{E}+0 \odot \quad 3.4575 \mathrm{E}+0 \odot$

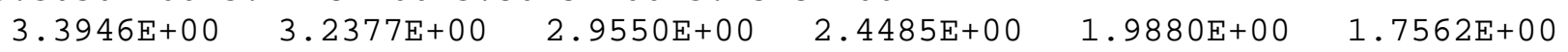

$1.5355 \mathrm{E}+00$ 1.2977E+०९ 9.9899E-01 7.2627E-01

5.9840E-01 4.9350E-01 4.2557E-01 4.1658E-01

CHANNEL JJJ $=3$
$1.9191 \mathrm{E}+00$
$1.8501 \mathrm{E}+\odot \odot$
$2.0220 \mathrm{E}+\odot \odot$
2. $2138 \mathrm{E}+00$
$2.3336 \mathrm{E}+0 \odot$
$2.4935 \mathrm{E}+\odot \odot$
$2.5464 \mathrm{E}+0 \odot \quad 2.6393 \mathrm{E}+0 \odot \quad 2.6074 \mathrm{E}+00 \quad 2.6373 \mathrm{E}+0 \odot$
$2.5984 \mathrm{E}+0 \odot \quad 2.5394 \mathrm{E}+0 \odot \quad 2.4985 \mathrm{E}+\odot \odot \quad 2.3616 \mathrm{E}+\odot \odot$

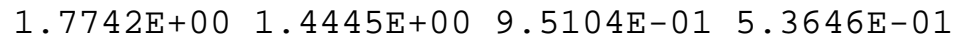
4. 2457E-01 3.3866E-01 2.9870E-01 3.0170E-01
CHANNEL JJJ $=4$
$2.0250 \mathrm{E}+\odot \odot \quad 1.9740 \mathrm{E}+\odot \odot \quad 2.1818 \mathrm{E}+\odot \odot \quad 2.4066 \mathrm{E}+\odot \odot$
$2.8821 \mathrm{E}+\odot \odot \quad 2.9780 \mathrm{E}+\odot \odot \quad 3.0160 \mathrm{E}+0 \odot \quad 3.0419 \mathrm{E}+\odot \odot$

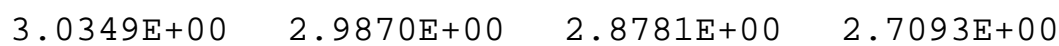

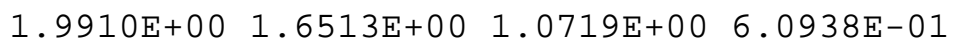
$\begin{array}{ll}2.5674 \mathrm{E}+\odot \odot & 2.7522 \mathrm{E}+\odot \odot \\ 2.4765 \mathrm{E}+\odot \odot & 2.2397 \mathrm{E}+\odot \odot\end{array}$
$2.1588 \mathrm{E}+\odot \odot \quad 1.9380 \mathrm{E}+\odot \odot$
$2.7522 \mathrm{E}+\odot \odot$
$2.2397 \mathrm{E}+\odot \odot$

4.7252E-01 3.8561E-01 3.2168E-01 3.3067E-01

This section notes the revised inlet coolant density to be consistent with coolant properties, and then sets up the steady-state solution

RHOREF SET TO $982.56 \mathrm{KG} / \mathrm{M}^{*}$ *3 CORRESPONDING TO THE INLET COOLANT DENSITY.

THIS PROBLEM BEGINS WITH DOWNFLOW

THIS PROBLEM BEGINS WITH DOWNFLOW

TRANSO: THE DTSS STEP SIZE IS LIMITING AND WILL BE SELECTED; $d t=$ $1.000000000000000 \mathrm{E}-03 \mathrm{Sec}$ 
RACTIV: AFTER 20; AKIN3 $=0$; ATEMP $=1.388888888888889 \mathrm{E}-\Theta 7$ AKIN1 $=$

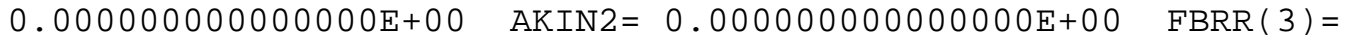

$\odot .000000000000000 \mathrm{E}+0 \odot$

RACTIV: AFTER 20; AKIN3 $=0$; ATEMP $=0.00000000 \odot \odot \odot \odot \odot \odot \odot E+\odot \odot$ AKIN1 $0.000000000000000 \mathrm{E}+00 \quad$ AKIN2 $=0.000000000000000000 \mathrm{E}+00 \quad \mathrm{FBRR}(3)=$

$0.000000000000000 \mathrm{E}+\odot \odot$

STEADY-STATE SOLUTION

DEFAULT DURATION AND TIME STEP SIZE

NULL TRANSIENT DURATION $1.00000 \mathrm{E}+02$ SEC

TIME STEP SIZE $1.00000 \mathrm{-}-03$ SEC

CHANNEL NUMBER 1

OUTLET ENTHALPY RATE OF CHANGE (dH/dt): $3.37604 \mathrm{E}-05$ (KJ/KG-SEC) OUTLET MASS FLUX RATE OF CHANGE (dG/dt): $\odot .00000 \mathrm{~d}+\odot \odot\left(\mathrm{KG} / \mathrm{SEC} * * 2-\mathrm{M}^{*} * 2\right)$ MAXIMUM FUEL TEMPERATURE RATE OF CHANGE (dT/dt): $0.00000 \mathrm{~d}+\odot \odot$ (C/SEC)

CONVERGENCE OF ENTHALPY: $2.35275 E-10$

CONVERGENCE OF MASS FLUX: $\odot .00000 \mathrm{E}+0 \odot$

CONVERGENCE OF FUEL TEMP: $\odot .0000 \odot E+\odot \odot$

CHANNEL NUMBER 2

OUTLET ENTHALPY RATE OF CHANGE (dH/dt): $1.49010 \mathrm{~d}+02$ (KJ/KG-SEC) OUTLET MASS FLUX RATE OF CHANGE (dG/dt): $0.00000 \mathrm{~d}+0 \odot\left(\mathrm{KG} / \mathrm{SEC} * \star 2-\mathrm{M}^{* *} 2\right)$ MAXIMUM FUEL TEMPERATURE RATE OF CHANGE (dT/dt): 5.82026E-02 (C/SEC)

CONVERGENCE OF ENTHALPY: $8.74485 E-04$

CONVERGENCE OF MASS FLUX: $\odot .00000 \mathrm{E}+0 \odot$

CONVERGENCE OF FUEL TEMP: 1.69467E-๑7

CHANNEL NUMBER 3

OUTLET ENTHALPY RATE OF CHANGE (dH/dt): $5.39003 \mathrm{~d}-05$ (KJ/KG-SEC) OUTLET MASS FLUX RATE OF CHANGE (dG/dt): $0.00000 \mathrm{~d}+0 \odot\left(\mathrm{KG} / \mathrm{SEC} * * 2-\mathrm{M}^{* *} 2\right)$ MAXIMUM FUEL TEMPERATURE RATE OF CHANGE (dT/dt): 2.84217E-11 (C/SEC)

CONVERGENCE OF ENTHALPY: $3.26511 \mathrm{E}-10$

CONVERGENCE OF MASS FLUX: $\odot .00 \odot \odot \odot E+\odot \odot$

CONVERGENCE OF FUEL TEMP: $8.13115 \mathrm{E}-17$

CHANNEL NUMBER 4

OUTLET ENTHALPY RATE OF CHANGE (dH/dt): 9.06293E-05 (KJ/KG-SEC) OUTLET MASS FLUX RATE OF CHANGE (dG/dt): $0.00000 \mathrm{~d}+0 \odot\left(\mathrm{KG} / \mathrm{SEC} * \star 2-\mathrm{M}^{*} * 2\right)$ MAXIMUM FUEL TEMPERATURE RATE OF CHANGE (dT/dt): 5.68434E-11 (C/SEC)

CONVERGENCE OF ENTHALPY: $5.35414 \mathrm{E}-10$

CONVERGENCE OF MASS FLUX: $\odot .00000 \mathrm{E}+0 \odot$

CONVERGENCE OF FUEL TEMP: $1.59429 \mathrm{E}-16$ 


\begin{abstract}
REACTIVITY OFFSET CONVERGENCE CRITERIA
MODERATOR EXPANSION \& VOID: $-7.24421 E-14$

COOLANT TEMPERATURE: $-6.21725 E-15$

FUEL TEMPERATURE (DOPPLER): $0.00000 \mathrm{E}+\odot \odot$

PARET TRANSIENT SOLUTION TIME $=0.000000000000000 \mathrm{E}+\odot \odot$

PARET FINDS REACTIVITY TO BEGIN TRANSIENT SOLUTION $=0.000000000000000 \mathrm{E}+00$

ALPHA $A=-711627.9069767442$
\end{abstract}

This section begins the transient solution and lists key conditions at initialization time zero. TRANSIENT SOLUTION

PARET DO 9500 LOOP STARTING WITH ITRANS $=1$

PARET: INTERVAL ITRANS $=1$ TSTART $=0.0000000000000000 \mathrm{E}+00 \quad$ TIME TT $(4)=$

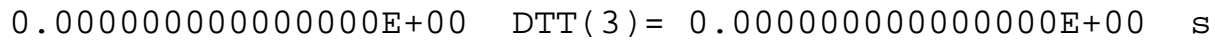

PARET: TEND FROM TBL9 IS 0.10000000000000000 SEC

PROCESSING TABLE 9 TIME INTERVAL 1 FROM TIME $=0.0000000000 \mathrm{E}+00$ TO TIME= 1. $0000000000 \mathrm{E}-01$

@@@@@@@@@@@@@@@@@@@@@@@@@@@@@@@@@@@@@@@@@@@@@@@@@@@@@@@@@@@@@@@@@@@@@@@@@@ @@@@@@@@@@@@@@@@@@@@@@@@@@@@@@@@@@@@@@@@@@@@@@

TRANSS TIME ZERO SET MAJOR= 1

1

PAGE 9

OPRESSURE DROP (KPa)

FRICTION -5.3389E+01 ELEVATION 7.9135E+0๑ SPATIAL ACCELERATION 4.2892E○1 TRANSIENT ACCEL. $\quad 0.0000 \mathrm{E}+0 \odot$ TOTAL $-4.5046 \mathrm{E}+\odot 4$

INTERNAL PRESSURES (KPa)

INLET PRESSURE $=\quad 434.20 \mathrm{KPa}$

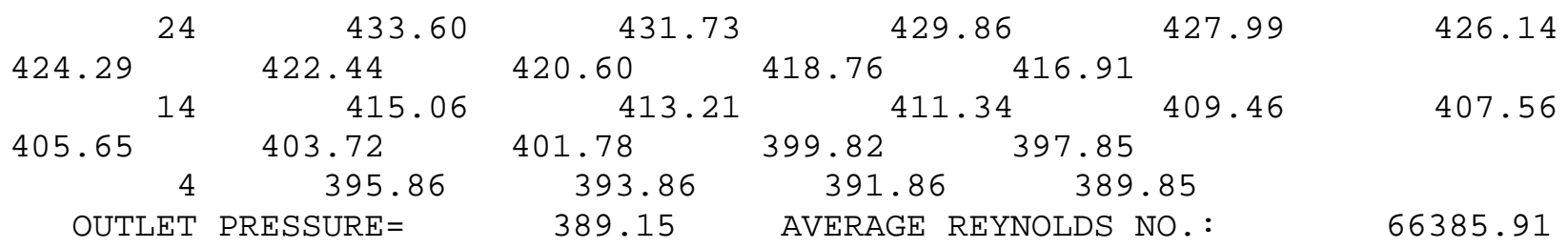

OPRESSURE DROP (KPa)

FRICTION -4.8082E+01 ELEVATION 7.8831E+@० SPATIAL ACCELERATION 8.7337E01 TRANSIENT ACCEL. $0.00 \odot \odot E+\odot \odot$ TOTAL $-3.9325 \mathrm{E}+\odot 4$

INTERNAL PRESSURES (KPa)

\begin{tabular}{|c|c|c|c|c|c|}
\hline \multicolumn{2}{|r|}{ PRESSURE= } & \multirow{2}{*}{$\begin{array}{r}434.20 \mathrm{KPa} \\
432.17\end{array}$} & & \multirow[b]{2}{*}{428.99} & \multirow[b]{2}{*}{427.43} \\
\hline 24 & $\quad 433.76$ & & 430.57 & & \\
\hline 425.88 & 424.35 & 422.82 & $421.30 \quad 419.77$ & & \\
\hline 14 & 418.24 & 416.69 & 415.11 & 413.48 & 411.81 \\
\hline 10.09 & 408.35 & 406.58 & $404.78 \quad 402.95$ & & \\
\hline 4 & 401.09 & 399.23 & $397.36 \quad 395$ & 48 & \\
\hline OUTLET & PRESSURE= & 394.87 & AVERAGE REYNOLDS & VO.: & 74106.43 \\
\hline
\end{tabular}


OPRESSURE DROP (KPa)

FRICTION -5.4292E+01 ELEVATION 7.8882E+00 SPATIAL ACCELERATION 7.8007E01 TRANSIENT ACCEL. $\quad 0.0000 \mathrm{E}+0 \odot$ TOTAL $-4.5623 \mathrm{E}+\odot 4$

INTERNAL PRESSURES (KPa)

\begin{tabular}{|c|c|c|c|c|c|}
\hline INLET & PRESSURE= & $434.20 \mathrm{KPa}$ & & & \\
\hline 24 & 433.58 & 431.72 & 429.86 & 428.01 & 426.17 \\
\hline 4.35 & 422.53 & 420.71 & $418.90 \quad 417.08$ & & \\
\hline 14 & 415.25 & 413.42 & 411.57 & 409.71 & 407.82 \\
\hline 5.90 & $\begin{array}{l}403.95 \\
395.74\end{array}$ & $\begin{array}{l}401.97 \\
393.62\end{array}$ & $\begin{array}{rr}399.93 & 397.85 \\
391.49 & 389\end{array}$ & .36 & \\
\hline OUTLET & PRESSURE= & 388.58 & AVERAGE REYNOLDS & NO.: & 67330.22 \\
\hline
\end{tabular}

OPRESSURE DROP (KPa)

FRICTION -5.1087E+01 ELEVATION 7.8822E+0๑ SPATIAL ACCELERATION 8.5374E01 TRANSIENT ACCEL. $\quad 0.0000 \mathrm{E}+\odot \odot$ TOTAL $-4.2351 \mathrm{E}+04$

INTERNAL PRESSURES (KPa)

\section{INLET PRESSURE $=\quad 434.20 \mathrm{KPa}$}

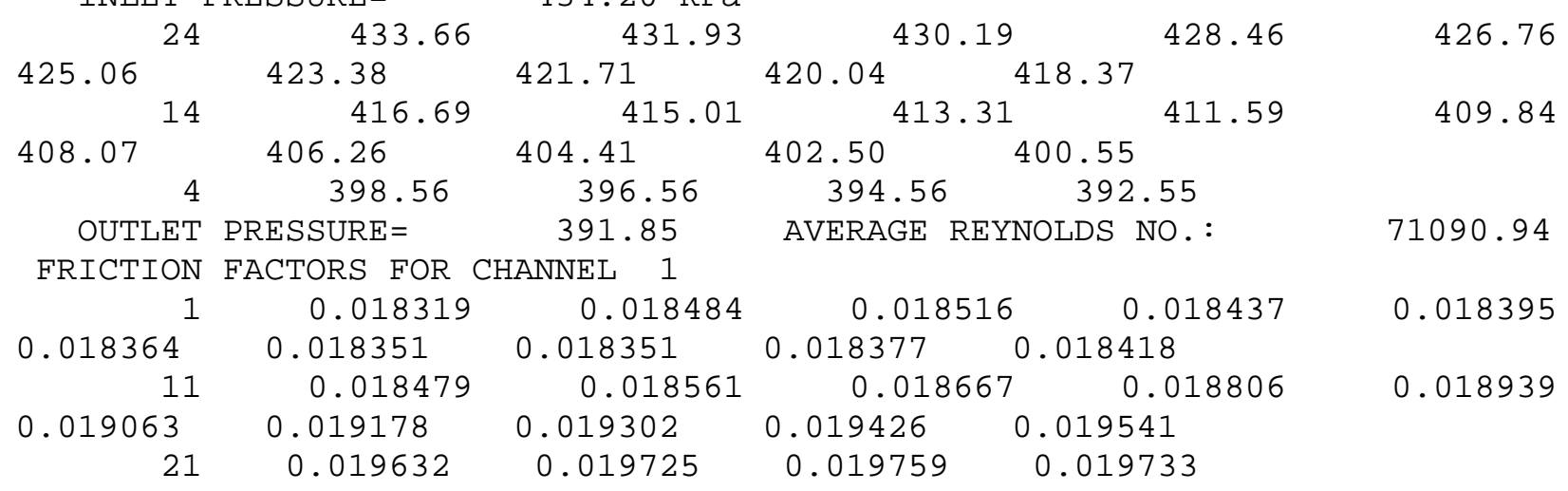

FRICTION FACTORS FOR CHANNEL 2
$\odot .018364$
$1 \quad 0.018319$
0.018484
$0.018516 \quad 0.018437$
0.018395
$\odot .018351$
0.018351
0.018377
0.018418
0.018561
$0.018667 \quad 0.018806$
$\odot .018939$
$\odot .019063$
0.019178
0.019302
0.019426
0.019541
0.019632
0.019725
0.019759
$\odot .019733$

FRICTION FACTORS FOR CHANNEL 3
0.018364
$1 \quad 0.018319$
0.018484
$0.018516 \quad 0.018437$
$\odot .018395$
$\odot .018351$
0.018351
$\begin{array}{ll}0.018377 & 0.018418\end{array}$
$\odot .018561$
๑. 019063
0.018479
$\odot .019302$
$\odot .019178$
$\odot .018667$
0.018806
๑. 018939
0.019426
0.019541
$\odot .019759 \quad 0.019733$

$21 \quad 0.019632 \quad 0.019725$

$\begin{array}{rr}\text { FRICTION } & \text { FACTORS FOR } \\ 1 & 0.018319\end{array}$

0.018484

$\begin{array}{ccccc}1 & 0.018319 & 0.018484 & 0.018516 & 0.018437 \\ 0.018364 & 0.018351 & 0.018351 & 0.018377 & 0.018418 \\ 11 & 0.018479 & 0.018561 & 0.018667 & 0.018806 \\ 0.019063 & 0.019178 & 0.019302 & 0.019426 & 0.019541 \\ 21 & 0.019632 & 0.019725 & 0.019759 & 0.019733\end{array}$

Reynolds Numbers FOR CHANNEL 1

$1 \quad 74665.66$

71394.87

74012.89

69732.84

73463.31

72862.80

$68829.99 \quad 67924.17$
72169.41 


\begin{tabular}{|c|c|c|c|c|c|}
\hline 11 & 67036.79 & 66147.25 & 65279.12 & $2 \quad 64492.91$ & 63788.48 \\
\hline 63069.23 & 62432.86 & 61868.91 & 61393.90 & 60996.17 & \\
\hline 21 & 60665.64 & 60381.90 & 60161.44 & 59924.76 & \\
\hline Reynolds & Numbers FOR & CHANNEL 2 & & & \\
\hline 1 & 91274.38 & 89906.86 & 88596.38 & 87196.96 & 85606.81 \\
\hline 83940.43 & 82175.69 & 80306.77 & 78438.42 & 76459.67 & \\
\hline 11 & 74547.43 & 72668.98 & 70861.88 & $3 \quad 69271.68$ & 68029.85 \\
\hline 67012.04 & 65959.48 & 65106.64 & 64427.11 & 63972.86 & \\
\hline 21 & 63613.10 & 63303.48 & 63060.49 & 62816.93 & \\
\hline Reynolds & Numbers FOR & CHANNEL 3 & & & \\
\hline 1 & 81219.46 & 80155.82 & 79139.26 & $6 \quad 78023.27$ & 76797.28 \\
\hline 75506.97 & 74125.20 & 72721.18 & 71239.86 & 69816.70 & \\
\hline 11 & 68308.20 & 66887.31 & 65425.33 & $3 \quad 64041.51$ & 62706.26 \\
\hline 61550.33 & 60408.42 & 59390.06 & 58725.00 & 58370.87 & \\
\hline 21 & 58139.32 & 57907.99 & 57752.74 & 57567.04 & \\
\hline Reynolds & Numbers FOR & CHANNEL 4 & & & \\
\hline 1 & 86665.62 & 85525.30 & 84412.69 & $9 \quad 83208.28$ & 81844.03 \\
\hline 80444.43 & 78898.04 & 77323.51 & 75663.05 & 73992.12 & \\
\hline 11 & 72317.98 & 70595.48 & 68927.78 & $3 \quad 67326.84$ & 65819.16 \\
\hline 89 & 63203.92 & 62077.67 & 61288.38 & 60914.65 & \\
\hline 21 & 60636.67 & 60388.92 & $6 \odot 2 \odot 9 . \odot 7$ & 60017.98 & \\
\hline
\end{tabular}

The next lines show the power in the coolant, called GAIN, which should be very close to the supplied power. It is a consistency check.

POINT KINETICS SOLUTION POWER SUMMED OVER CHANNELS $=1.40000 E+01$ MW AT TIME $=\quad 0.000000$

CHANNEL FLOW AREAS AND AREA FRACTIONS

CHANNEL AREA*BMS FRACTION GAIN(MW) BMS BM

1 1.71643E-04 9.99006E-01 1.39901E+01 9.98901E-01 9.99010E-01

2 6.60981E-08 3.46592E-04 1.01231E-02 3.66251E-04 3.30000E-04

3 6.04110E-08 3.16771E-04 8.39633E-03 3.66251E-04 3.3000९E-04

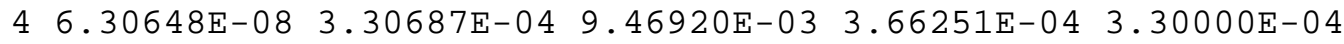

COOLANT FLOW, kg/s, BY CHANNEL (CORE refers to the whole reactor)

CHANNEL OUT IN CORE OUT CORE IN

$1-1.04783 \mathrm{E}+\odot \odot-1.04838 \mathrm{E}+\odot \odot-1.96010 \mathrm{E}+\odot 2-1.96113 \mathrm{E}+\odot 2$

$2-1.09998 \mathrm{E}+0 \odot-1.10110 \mathrm{E}+00-7.54448 \mathrm{E}-02-7.55214 \mathrm{E}-02$

$3-1.00545 E+0 \odot-1.00636 E+\odot \odot-6.89610 E-02-6.90235 E-02$

$4-1.04952 \mathrm{E}+0 \odot-1.05057 \mathrm{E}+\odot \odot-7.19839 \mathrm{E}-02-7.20556 \mathrm{E}-\odot 2$

$\operatorname{FLOW}(\mathrm{kg} / \mathrm{s})$

$-1.96226 \mathrm{E}+02-1.96330 \mathrm{E}+\odot 2 \quad$ TOTAL CORE

COOLANT POWER GAIN (IF IN STEADY STATE) $=\quad 1.40181 \mathrm{E}+01 \mathrm{MW}$

This is a typical MINOR EDIT (at time $0.170 \mathrm{sec}$ )

$\odot * * *$ STEP NO. $17000 \quad$ SUMMARY NO. 17

TIME $=0.17000000, \quad$ POWER $=9.30854163 \mathrm{E}+00, \quad$ ENERGY $=2.386$, REACTIVITY $=$ $-0.653, \quad$ MFLOW $($ OUT $)=-6.101 \mathrm{E}+03, \quad$ PERIOD $=-5.3452 \mathrm{E}-02$

$\mathrm{DKPOW}=9.200152 \mathrm{E}-01$

MIN. BR $=3.04$ ETA $=159.94 \quad$ MAX. TEMPS $:$ COOLANT $=95.670 \quad$ EDIT ( $11)=154.773 \quad$ FUEL $=174.586 \quad$ BOIL $=0 / \Theta / \odot / \odot$

MAXIMA THUS FAR: $0.17649 \mathrm{E}+02 \mathrm{MW}$ at $0.12437 \mathrm{E}+0 \odot \mathrm{s} 0.17808 \mathrm{E}+01$ MWs at $0.12437 \mathrm{E}+\Theta \odot \mathrm{S}$ 
Tmax (C) THUS FAR: COOL $=9.5670 \mathrm{E}+01$ at $1.7000 \mathrm{E}-01 \mathrm{~s} ; \operatorname{EDIT}(11)=1.6144 \mathrm{E}+02$ at 1.4001E-01 s; FUEL=1.8806E+02 at $1.3001 \mathrm{E}-01 \mathrm{~s}$

HOTTEST EXIT COOLANT T IS IN CHANNEL 2 ; $\operatorname{Tmax}($ exit $)=95.67 \mathrm{C}$ at $\mathrm{t}=$ $0.170 \mathrm{~s}$; Thus Far: $95.70 \mathrm{C}$ at $0.165 \mathrm{~s}$

1

PAGE 133

OPRESSURE DROP (KPa)

FRICTION -5.3467E+01 ELEVATION 7.9123E+0๑ SPATIAL ACCELERATION 3.9467E01 TRANSIENT ACCEL. -2.4240E-01 TOTAL -4.5402E+@4

INTERNAL PRESSURES (KPa)

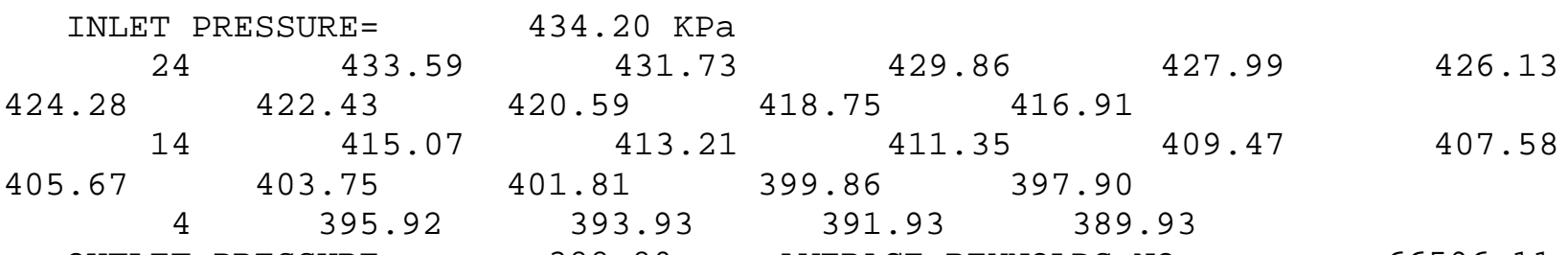

OUTLET PRESSURE=

388.80

AVERAGE REYNOLDS NO.: ... CHANNEL $2 . .$.

OPRESSURE DROP (KPa)

FRICTION -4.8295E+01 ELEVATION 7.8806E+00 SPATIAL ACCELERATION 7.8566E01 TRANSIENT ACCEL. - 4.8473E-01 TOTAL -4.0114E+@4

INTERNAL PRESSURES (KPa)

\begin{tabular}{|c|c|c|c|c|c|}
\hline INLET & PRESSURE= & $434.20 \mathrm{KPa}$ & & & \\
\hline 24 & 433.76 & 432.16 & 430.55 & 428.96 & 427.40 \\
\hline 5.85 & 424.32 & 422.79 & $421.27 \quad 419.75$ & & \\
\hline 14 & 418.22 & 416.67 & 415.10 & 413.48 & 411.81 \\
\hline .10 & $\begin{array}{l}408.37 \\
401.16\end{array}$ & $\begin{array}{l}406.61 \\
399.31\end{array}$ & $\begin{array}{rr}404.82 & 403.00 \\
397.45 & 395\end{array}$ & & \\
\hline OUTLET & PRESSURE $=$ & 394.09 & AVERAGE REYNOLDS & NO.: & 74539.09 \\
\hline
\end{tabular}

OPRESSURE DROP (KPa)

FRICTION -5.4390E+01 ELEVATION 7.8864E+@० SPATIAL ACCELERATION 7.3647E01 TRANSIENT ACCEL. - -3.9815E-01 TOTAL -4.6166E+@4

INTERNAL PRESSURES (KPa)

\begin{tabular}{|c|c|c|c|c|c|}
\hline \multicolumn{2}{|c|}{ INLET PRESSURE= } & $434.20 \mathrm{KPa}$ & & \multirow[b]{2}{*}{428.00} & \multirow[b]{2}{*}{426.16} \\
\hline 24 & 433.58 & 431.71 & 429.85 & & \\
\hline 424.33 & 422.51 & 420.70 & $418.88 \quad 417.06$ & & \\
\hline 14 & 415.23 & 413.41 & 411.56 & 409.71 & 407.83 \\
\hline 05.93 & 403.99 & 402.03 & $400.01 \quad 397.94$ & & \\
\hline 4 & 395.85 & 393.75 & 391.64 & 53 & \\
\hline OUTLET & PRESSURE= & 388.03 & AVERAGE REYNOLDS & NO.: & 67605.21 \\
\hline
\end{tabular}

OPRESSURE DROP (KPa)

FRICTION -5.1219E+01 ELEVATION 7.8802E+@० SPATIAL ACCELERATION 7.9677E01 TRANSIENT ACCEL. $-2.5585 \mathrm{E}-01$ TOTAL $-4.2798 \mathrm{E}+\odot 4$

INTERNAL PRESSURES (KPa) 
INLET PRESSURE=

\begin{tabular}{|c|c|c|}
\hline \multirow{2}{*}{\multicolumn{2}{|c|}{$24 \quad 433.66$}} & \\
\hline & & 431.92 \\
\hline 425.04 & 423.35 & 421.67 \\
\hline 14 & 416.65 & 414.96 \\
\hline 408.03 & 406.23 & 404.38 \\
\hline 4 & 398.55 & 396.56 \\
\hline OUTLET & PRESSURE= & 391.40 \\
\hline
\end{tabular}

FRICTION FACTORS FOR CHANNEL 1

\begin{tabular}{|c|c|c|c|c|c|}
\hline 1 & 0.018329 & 0.018489 & 0.018520 & 0.018445 & 0.018406 \\
\hline ๑. 018376 & $\odot .018366$ & $\odot .018367$ & ๑. 018394 & ๑.018435 & \\
\hline 11 & ๑. 018498 & 0.018578 & 0.018686 & $\quad 0.018822$ & ๑.018953 \\
\hline ๑. 019076 & $\begin{array}{c}\odot .019190 \\
0.019638\end{array}$ & $\begin{array}{c}\odot .019313 \\
\odot .019730\end{array}$ & $\begin{array}{c}\odot .019436 \\
0.019764\end{array}$ & $\odot .019548$ & \\
\hline
\end{tabular}

FRICTION FACTORS FOR CHANNEL 2

\begin{tabular}{|c|c|c|c|c|c|}
\hline 1 & 0.018329 & ๑. 018489 & 0.018520 & 0.018445 & 0.018406 \\
\hline$\odot .018376$ & $\odot .018366$ & ๑.018367 & 0.018394 & $\odot .018435$ & \\
\hline 11 & ๑. 018498 & 0.018578 & 0.018686 & ๑.018822 & ๑.018953 \\
\hline $\begin{array}{r}\odot .019076 \\
21\end{array}$ & $\begin{array}{c}\odot .019190 \\
\odot .019638\end{array}$ & $\begin{array}{l}\odot .019313 \\
\odot .019730\end{array}$ & $\begin{array}{l}\odot .019436 \\
0.019764\end{array}$ & $\begin{array}{l}\odot .019548 \\
\odot .019739\end{array}$ & \\
\hline
\end{tabular}

FRICTION FACTORS FOR CHANNEL 3
$\odot .018376$
$1 \quad 0.018329$
0.018489
0.018520
0.018445
๑. 018406
$\odot .018366$
0.018367
0.018394
0.018435
$\odot .018578$
$\odot .018686$
$\odot .019313$
0.019436
0.019548
$\odot .019190$
$\odot .019730$
$\odot .019764$
0.019739
0.018953
0.018953

FRICTION FACTORS FOR CHANNEL 4
$\odot .018376$
0.018329
0.018489
0.018367
$\odot .018578$
$\odot .019076$
0.018498
0.019313
0.019730
0.019190
0.019638
$\begin{array}{cc}0.018394 & 0.018435 \\ 0.018686 & 0.018822\end{array}$
$0.019436 \quad 0.019548$
$0.018520 \quad 0.018445$
$0.019764 \quad 0.019739$

Reynolds Numbers FOR CHANNEL 1

$\begin{array}{ccc}1 & 75068.83 & 74437.84 \\ 71771.74 & 70911.58 & 70042.70 \\ 11 & 67255.07 & 66363.38 \\ 63184.84 & 62513.86 & 61942.04 \\ 21 & 60706.57 & 60420.54\end{array}$

$\odot .018406$

$\odot .018953$

Reynolds Numbers FOR CHANNEL 2

\begin{tabular}{|c|c|c|c|c|}
\hline 1 & 92283.32 & 90902.49 & 89588.71 & 88095.4 \\
\hline 84688.46 & 82870.53 & 80896.41 & 78953.28 & 76864.20 \\
\hline 11 & 74947.60 & 72943.82 & 71152.22 & 2. $\quad 69465.9$ \\
\hline 67141.59 & 66169.25 & 65209.09 & 64608.23 & 64080.72 \\
\hline
\end{tabular}

Reynolds Numbers FOR CHANNEL 3

$\begin{array}{cccccc}1 & 81846.23 & 80774.87 & 79764.52 & 78608.41 & 77361.08 \\ 76050.46 & 74623.43 & 73194.63 & 71633.63 & 70201.98 & \\ 11 & 68569.68 & 67168.26 & 65556.74 & 64210.94 & 62753.35 \\ 61654.72 & 60403.95 & 59450.38 & 58736.45 & 58454.69 & \\ 21 & 58152.98 & 57967.02 & 57769.86 & 57616.71 & \end{array}$

Reynolds Numbers FOR CHANNEL 4

$\begin{array}{ccccc}1 & 87416.02 & 86278.01 & 85176.69 & 83914.97 \\ 81086.92 & 79504.43 & 77875.40 & 76133.82 & 74423.91\end{array}$

\section{$\begin{array}{lll}73895.82 & 73255.37 & 72550.54\end{array}$}

$69123.25 \quad 68189.67$

$\begin{array}{lll}65445.85 & 64648.22 & 63920.42 \\ 61446.25 & 61047.63\end{array}$

86461.29

68294.15

82546.75 
$\begin{array}{cccccc}11 & 72643.75 & 70880.29 & 69120.44 & 67480.93 & 65902.62 \\ 64562.75 & 63226.29 & 62121.22 & 61313.52 & 61001.64 & \\ 21 & 60652.93 & 60457.74 & 60226.09 & 60083.20 & \end{array}$ FLOW_FLAG $=F$

MIN.. BR $=3.04 \quad$ ETA $=159.95 \quad$ MAX. TEMPS $:$ COOLANT $=95.670 \quad$ EDIT ( $11)=154.770 \quad$ FUEL $=174.580 \quad$ BOIL $=0 / 0 / 0 / 0$

MAXIMA THUS FAR: $0.17649 \mathrm{E}+02 \mathrm{MW}$ at $0.12437 \mathrm{E}+0 \odot \mathrm{s} 0.17808 \mathrm{E}+01 \mathrm{MWs}$ at $\odot .12437 \mathrm{E}+\odot \odot \mathrm{S}$

$\operatorname{Tmax}(\mathrm{C})$ THUS FAR: $\mathrm{COOL} .=9.5670 \mathrm{E}+01$ at $1.7000 \mathrm{E}-01 \mathrm{~s} ; \operatorname{EDIT}(11)=1.6144 \mathrm{E}+02$ at $1.4001 \mathrm{E}-01 \mathrm{~s} ; \mathrm{FUEL}=1.8806 \mathrm{E}+02$ at $1.3001 \mathrm{E}-01 \mathrm{~s}$

HOTTEST EXIT COOLANT T IS IN CHANNEL 2 ; Tmax(exit) $=95.67 \mathrm{C}$ at $\mathrm{t}=$ $0.170 \mathrm{~s}$; Thus Far: $95.70 \mathrm{C}$ at $0.165 \mathrm{~s}$

TRANSS-1 HAS REACHED THE END OF A MAJOR INTERVAL 1

PAGE 134

OPRESSURE DROP (KPa)

FRICTION -5.3647E+01 ELEVATION 7.9129E+00 SPATIAL ACCELERATION 3.4798E01 TRANSIENT ACCEL. $\quad-5.3576 \mathrm{E}-02$ TOTAL $-4.5439 \mathrm{E}+04$

INTERNAL PRESSURES (KPa)

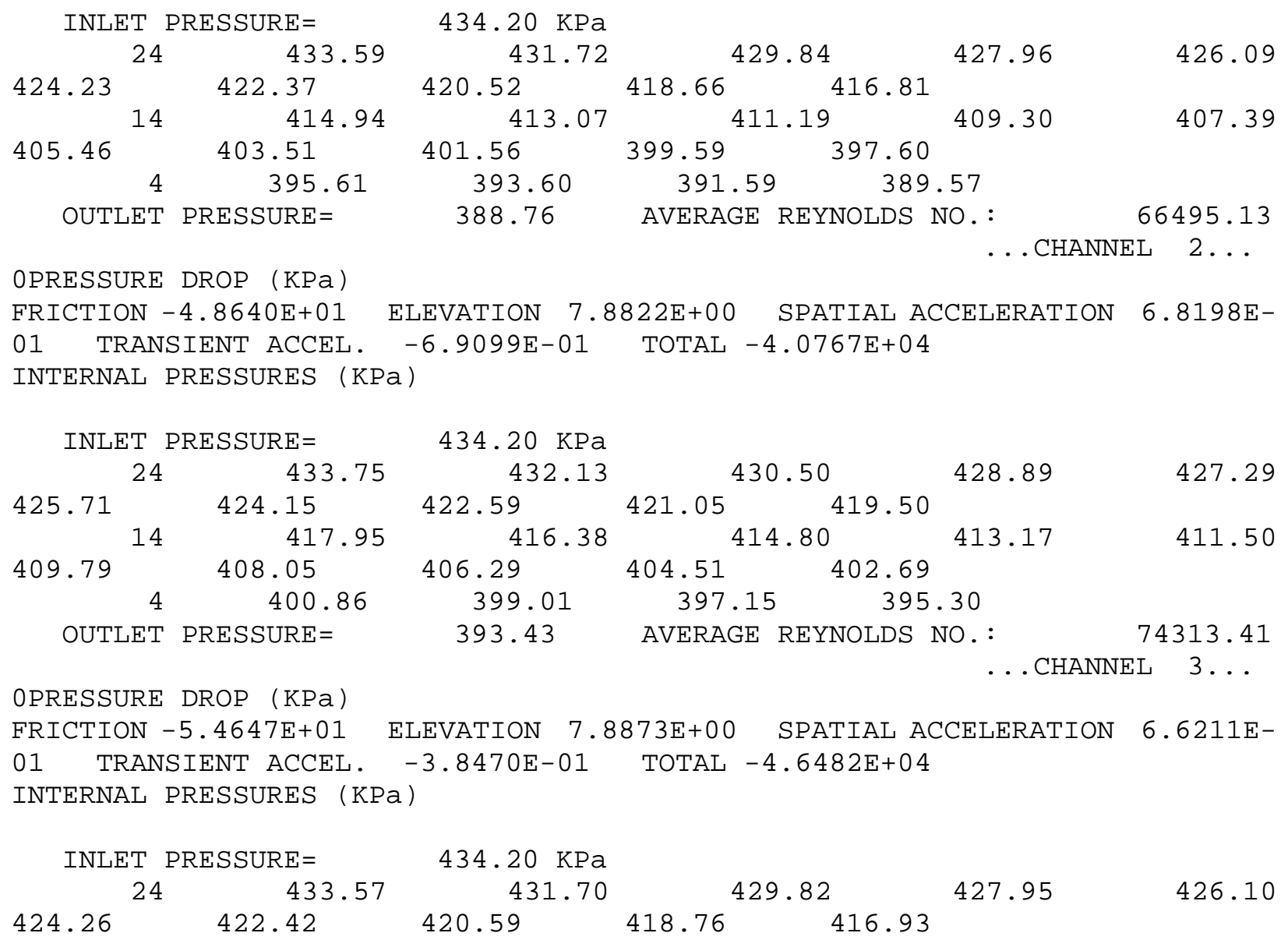




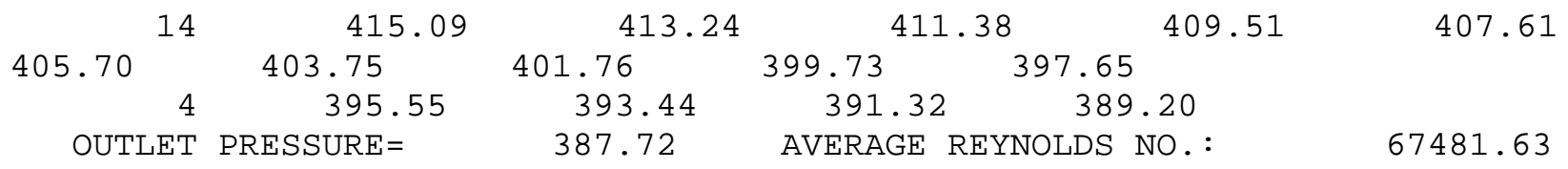
OPRESSURE DROP (KPa)

FRICTION -5.1513E+01 ELEVATION 7.8813E+@๑ SPATIAL ACCELERATION 7.0822E○1 TRANSIENT ACCEL. $-9.4793 \mathrm{E}-02$ TOTAL $-4.3018 \mathrm{E}+\odot 4$

INTERNAL PRESSURES (KPa)

INLET PRESSURE $=\quad 434.20 \mathrm{KPa}$

\begin{tabular}{|c|c|c|c|c|c|}
\hline \multirow{3}{*}{$424.93_{1}^{2}$} & 433.65 & 431.90 & 430.14 & 428.38 & 426.65 \\
\hline & 423.22 & 421.52 & 419.82 & 418.12 & \\
\hline & 416.41 & 414.69 & 412.97 & 411.22 & 409.45 \\
\hline \multirow[t]{2}{*}{407.66} & 405.83 & 403.96 & 402.04 & 400.08 & \\
\hline & 398.08 & 396.08 & 394.07 & 392.06 & \\
\hline OUTLET & PRESSURE= & 391.18 & AVERAGE REYI & NOLDS NO.: & 71261.59 \\
\hline FRICTION & FACTORS FOR & CHANNEL 1 & & & \\
\hline 1 & 0.018382 & ๑. 018535 & 0.018566 & 0.018498 & 0.018464 \\
\hline$\odot .018440$ & ๑. 018433 & 0.018437 & $\odot .018467$ & ๑. 018508 & \\
\hline 11 & ๑. 018570 & 0.018649 & 0.018753 & $3 \quad 0.018883$ & ๑ . 019010 \\
\hline ๑. . 019127 & ๑ . 019237 & $\odot .019353$ & $\odot .019470$ & ๑. 019576 & \\
\hline 21 & ๑. 019662 & ๑. 019748 & 0.019780 & $\odot .019757$ & \\
\hline
\end{tabular}

FRICTION FACTORS FOR CHANNEL 2

\begin{tabular}{|c|c|c|c|c|c|}
\hline 1 & ๑.018382 & ๑. 018535 & 0.018566 & ๑.018498 & 0.018464 \\
\hline ๑ . 018440 & $\odot .018433$ & 0.018437 & $\odot .018467$ & $\odot .018508$ & \\
\hline 11 & 0.018570 & 0.018649 & 0.018753 & $3 \quad 0.018883$ & 0.019010 \\
\hline$\odot .019127$ & ๑. 019237 & 0.019353 & ๑. 019470 & $\odot .019576$ & \\
\hline
\end{tabular}

FRICTION FACTORS FOR CHANNEL 3
0.018440
$1 \quad 0.018382$
0.018535
0.018566
0.018498
$\odot .018464$
$\odot .018433$
0.018437
0.018467
$\odot .018508$
$\odot .018649$
0.018753
0.018883
$\odot .019010$
$\odot .019127$
$\odot .019237$
0.019353
0.019470
0.019576
$21 \quad 0.019662 \quad 0.019748$
0.019780
0.019757

FRICTION FACTORS FOR CHANNEL 4
0.018440
0.018382
0.018535
$0.018566 \quad 0.018498$
$\odot .018464$
$\odot .018433$
0.018437
$0.018467 \quad 0.018508$
$\begin{array}{lll}0.018649 & 0.018753 & 0.018883\end{array}$
$\odot .019237$
0.019662
$\odot .019353$
0.019470
0.019576
0.019748
0.019780
$\odot .019757$
$\odot .019010$

Reynolds Numbers FOR CHANNEL 1

$\begin{array}{ccccc}1 & 74979.22 & 74331.28 & 73767.77 & 73113.44 \\ 71598.18 & 70735.72 & 69870.83 & 68943.85 & 68017.41 \\ 11 & 67097.94 & 66203.50 & 65307.49 & 64528.03 \\ 63085.29 & 62435.86 & 61886.06 & 61410.33 & 61027.95 \\ 21 & 60698.33 & 60430.64 & 60225.41 & 59996.38\end{array}$

Reynolds Numbers FOR CHANNEL 2

\begin{tabular}{|c|c|c|c|c|}
\hline 1 & 91975.18 & 90561.62 & 89185.11 & 87668.86 \\
\hline 84230.38 & 82391.29 & $8 \odot 427.34$ & 78537.07 & 76476.52 \\
\hline 11 & 74586.71 & 72630.57 & 70916.84 & $4 \quad 69272.39$ \\
\hline 67019.42 & 66090.56 & 65169.36 & 64603.14 & 64092.96 \\
\hline 21 & 63810.33 & 63448.16 & 63292.09 & 62994.24 \\
\hline
\end{tabular}




\begin{tabular}{rccccc} 
Reynolds & Numbers FOR CHANNEL 3 & & \\
1 & 81709.45 & 80627.32 & 79598.15 & 78423.18 & 77164.29 \\
75826.63 & 74385.35 & 72946.61 & 71378.11 & 69956.54 & \\
11 & 68323.16 & 66948.98 & 65362.16 & 64053.34 & 62630.26 \\
61571.61 & 60337.92 & 59433.79 & 58745.95 & 58471.81 & \\
21 & 58173.49 & 58005.20 & 57816.18 & 57669.66 & \\
Reynolds & Numbers FOR CHANNEL 4 & \multicolumn{4}{c}{ CH } \\
1 & 87257.69 & 86100.95 & 84961.45 & 83681.98 & 82279.48 \\
80801.69 & 79188.27 & 77558.51 & 75819.03 & 74098.17 & \\
11 & 72346.52 & 70595.34 & 68869.48 & 67291.74 & 65748.33 \\
64459.23 & 63146.75 & 62099.40 & 61327.74 & 61023.46 & \\
21 & 60683.37 & 60505.55 & 60284.95 & 60149.17 &
\end{tabular}

\begin{tabular}{|c|c|}
\hline \multicolumn{2}{|c|}{ This is a typical MAJOR EDIT (at time $0.16 \mathrm{sec}$ ) } \\
\hline TIME & STEP NUMBER \\
\hline Date $=3 / 15 / 2019$ & TIME $=10: 13: 10$ \\
\hline$\odot .160000$ & \\
\hline$\odot .000010$ & \\
\hline$\odot .372279319965$ & \\
\hline-0.36642 & \\
\hline$\odot .00015$ & \\
\hline 0.00000 & \\
\hline 0.00525 & \\
\hline$\odot .00 \odot 46$ & \\
\hline
\end{tabular}

ELAPSED REACTOR TIME (SECONDS) TIME STEP INCREMENT (SECONDS) REACTIVITY (\$)

EXTERNALLY

INSERTED DOPPLER

ROD

EXPANSION MODERATOR EXPANSION AND VOIDS MODERATOR TEMPERATURE 1 2 3 4 POWER (MW) 6.51938232250E- 03 POWER (MW) $7.35367197046 \mathrm{E}-03$ $1.08964825862 E+\Theta 1 \quad 7.86026310260 E-\odot 3$ DECAY POWER (MW) 5. 49938304093E- 04 $6.20314270929 E-\odot 4$ 1. $09182159036 \mathrm{E}+01$ $9.19165782526 \mathrm{E}-01 \quad 6.63047440161 \mathrm{E}-04$ DECAY POWER (MW) $9.20999082541 \mathrm{E}-01$ ENERGY GENERATED 1. 36449157588E- 03 $1.53910646118 \mathrm{E}-03$ $2.28060849328 \mathrm{E}+\odot \odot \quad 1.64513480835 \mathrm{E}-\odot 3$ ENERGY GENERATED (MJ) ENERGY IN FUEL (MJ) 1. 31671269271E-๑4 $1.35828590579 \mathrm{E}-\odot 4$ $2.28515722613 \mathrm{E}+\odot \odot$ ENERGY IN FUEL (MJ) COOLANT ENERGY (MJ) $1.12720140670 \mathrm{E}-07$ $1.28304169631 \mathrm{E}-07$ 3.19431100810E- $01 \quad 1.30570330198 \mathrm{E}-\odot 4$ COOLANT ENERGY (MJ) $6.12326753727 \mathrm{E}-01$ COOLANT ENERGY REMOVED (MJ) 4.27701675907E-03 $8.47555871835 \mathrm{E}-10 \quad 9.55929484873 \mathrm{E}-10$ 


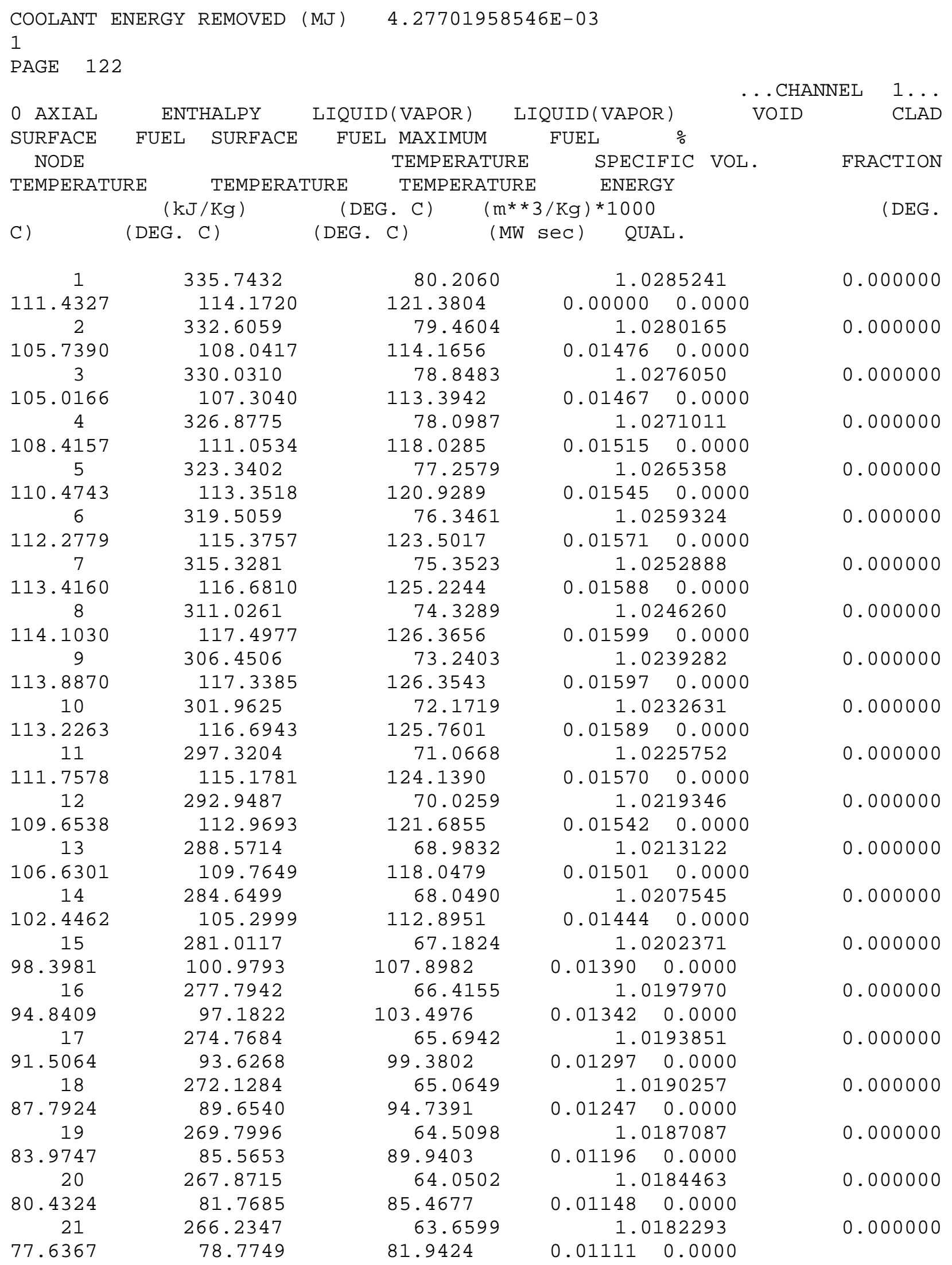




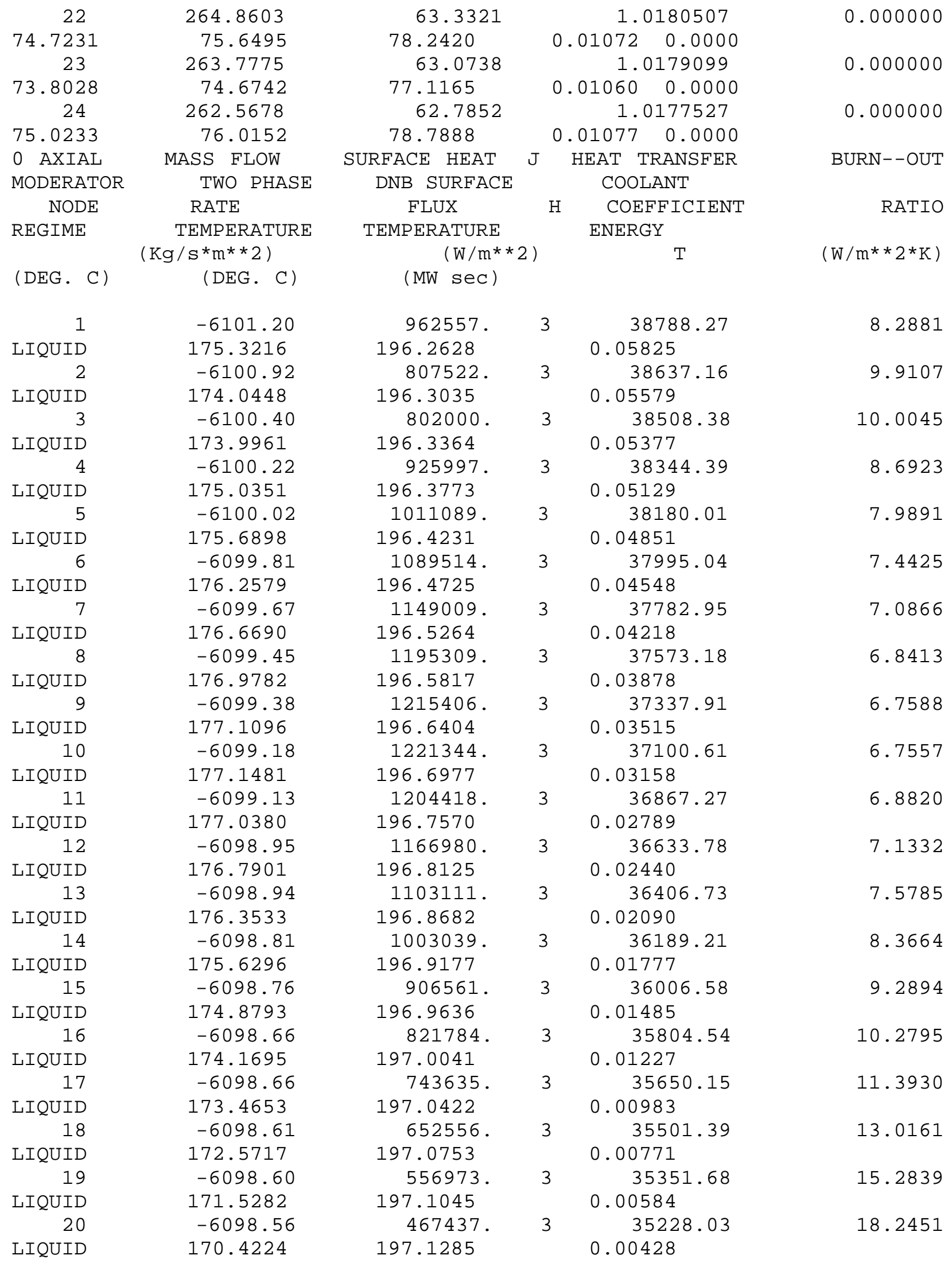




$\begin{array}{rccccc}21 & -6098.53 & 398036 . & 3 & 35144.42 & 21.4597 \\ \text { LIQUID } & 169.4514 & 197.1490 & & 0.00296 & \\ 22 & -6098.52 & 323798 . & 3 & 35064.47 & 26.4144 \\ \text { LIQUID } & 168.2622 & 197.1661 & & 0.00185 & \\ 23 & -6098.41 & 304539 . & 3 & 35001.84 & 28.1136 \\ \text { LIQUID } & 167.9210 & 197.1795 & & 0.00098 & \\ 24 & -6098.37 & 346725 . & 3 & 34921.47 & 24.7214 \\ \text { LIQUID } & 168.6493 & 197.1946 & & 0.00000 & \end{array}$

(channels 2-4 are deleted for brevity)

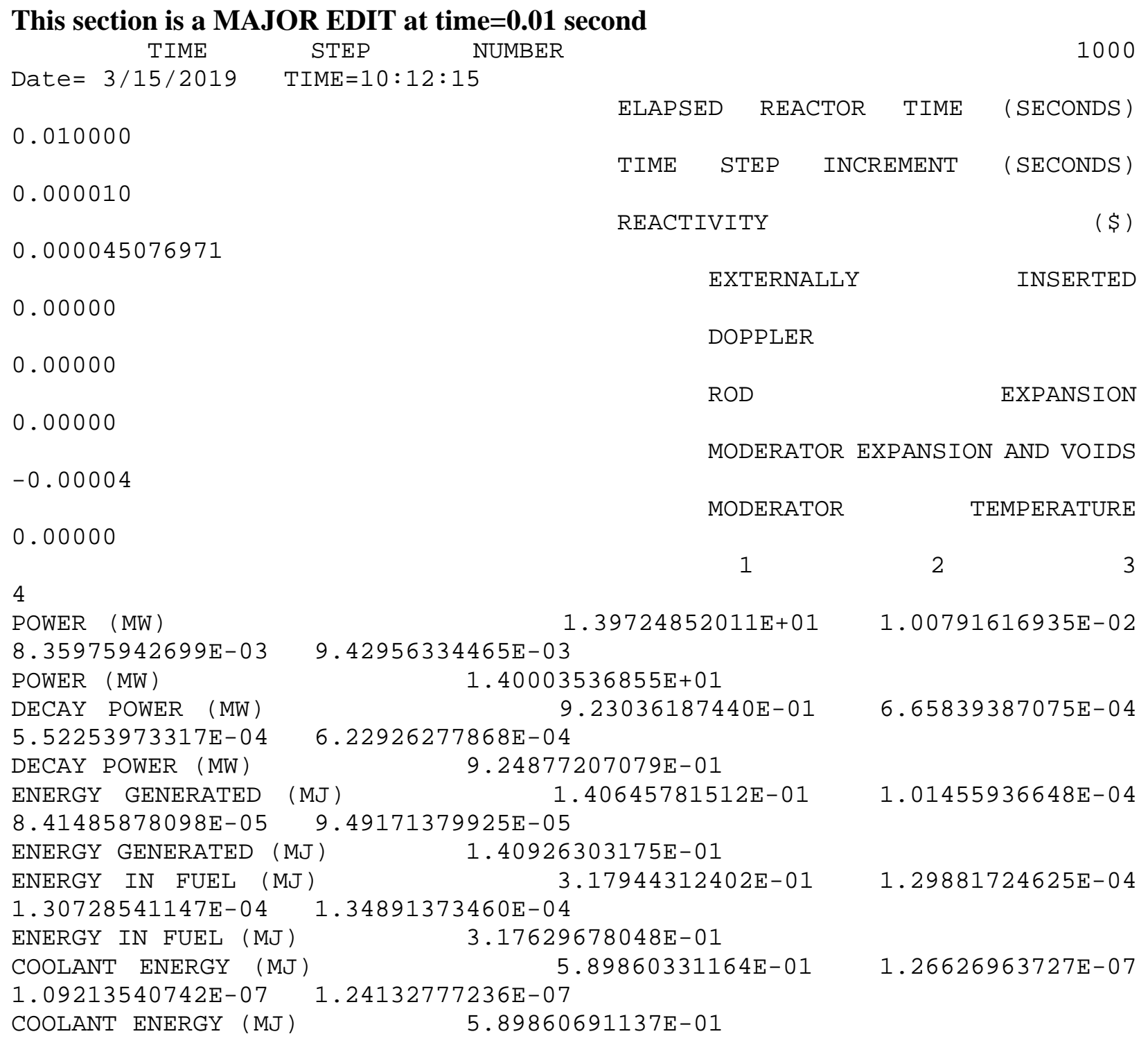


COOLANT ENERGY REMOVED (MJ) 6.98606814769E-05 $1.67032166103 \mathrm{E}-11$ $1.38541798505 \mathrm{E}-11 \quad 1.56250142139 \mathrm{E}-11$

(MW sec)

COOLANT ENERGY REMOVED (MJ) 6.98607276593E-05

1

PAGE 17

$\begin{array}{lccccc}\odot \text { AXIAL } & \text { ENTHALPY } & \text { LIQUID(VAPOR) } & \text { LIQUID(VAPOR) } & \text { VOCHANNEL } & 1 \ldots \\ \text { SURFACE } & \text { FUEL SURFACE } & \text { FUEL MAXIMUM } & \text { FUEL } & \% & \text { CLAD }\end{array}$ NODE TEMPERATURE SPECIFIC VOL.

TEMPERATURE TEMPERATURE TEMPERATURE ENERGY

C) (DEG.C) (DEG.C) (MW Sec) QUAL.

FRACTION
$(\mathrm{kJ} / \mathrm{Kg})$
(DEG.

(DEG .

\begin{tabular}{cc}
1 & 333.7451 \\
110.5382 & 113.4680 \\
2 & 330.5404 \\
104.9513 & 107.4169 \\
3 & 327.9353 \\
104.2070 & 106.6555 \\
4 & 324.8073 \\
107.5261 & 110.3477 \\
5 & 321.1880 \\
109.5139 & 112.5916 \\
6 & 317.5022 \\
111.2581 & 114.5681 \\
7 & 313.3339 \\
112.3472 & 115.8349 \\
8 & 309.1610 \\
113.0009 & 116.6260 \\
9 & 304.7096 \\
112.7796 & 116.4639 \\
10 & 300.3426 \\
112.1057 & 115.8062 \\
11 & 295.8805 \\
110.6709 & 114.3196 \\
12 & 291.5951 \\
108.5823 & 112.1176 \\
13 & 287.4235 \\
105.6328 & 108.9747 \\
14 & 283.5822 \\
101.5253 & 104.5670 \\
15 & 280.1573 \\
97.5676 & 100.3172 \\
16 & 277.0156 \\
94.0802 & 96.5737 \\
17 & 274.1887 \\
90.8261 & 93.0833 \\
18 & 271.6164 \\
87.1852 & 89.1662 \\
19 & 269.4469 \\
83.4605 & 85.1520 \\
& \\
\hline &
\end{tabular}

$$
\begin{gathered}
79.7312 \\
121.4616 \\
78.9694 \\
114.2124 \\
78.3502 \\
113.4133 \\
77.6066 \\
118.0842 \\
76.7462 \\
120.9961 \\
75.8694 \\
123.5767 \\
74.8779 \\
125.3049 \\
73.8852 \\
126.4542 \\
72.8258 \\
126.4529 \\
71.7862 \\
125.8484 \\
70.7240 \\
124.2438 \\
69.7035 \\
121.7675 \\
68.7098 \\
118.1432 \\
67.7947 \\
112.9727 \\
66.9788 \\
107.9705 \\
66.2299 \\
103.5578 \\
65.5560 \\
99.4432 \\
64.9429 \\
94.7854 \\
64.4257 \\
89.9844 \\
\end{gathered}
$$
1.0281986
$0.00000 \quad 0.0000$
1.0276864
$0.01470 \quad 0.0000$
1. 0272701
$0.01460 \quad 0.0000$
1.0267702

$0.01508 \quad 0.0000$

1.0261918

$0.01537 \quad 0.0000$

1.0256237

$0.01563 \quad 0.0000$

1.0249816

$0.01579 \quad 0.0000$

1. 0243387

$\odot .01590 \quad 0.000 \odot$

1.0236702

$0.01588 \quad 0.0000$

1.0230231

$0.01580 \quad 0.0000$

1.0223618

$0.01561 \quad 0.0000$

1. 0217421

$0.01533 \quad 0.0000$

1. 0211489

$0.01493 \quad 0.0000$

1.0206027

$0.01437 \quad 0.0000$

1.0201187

$0.01383 \quad 0.0000$

1. 0196910

0.013350 .0000

1. 0193062

$0.01291 \quad 0.0000$

1. 0189561

$0.01242 \quad 0.0000$

1. 0186607

$0.01191 \quad 0.0000$
0.000000

$\odot .000000$

$\odot .000000$

$\odot .000000$

0.000000

$\odot .000000$

$\odot .000000$

$\odot .000000$

$\odot .0000 \odot \odot$

0.000000

0.000000

$\odot .000000$

$\odot .000000$

0.000000

$\odot .000000$

0.000000

$\odot .000000$

$\odot .000000$

$\odot .00000 \odot$ 


\begin{tabular}{|c|c|c|c|c|c|}
\hline $2 \odot$ & 267.5850 & 63.9819 & & 1.0184073 & $\odot .0000 \odot \odot$ \\
\hline 79.9932 & 81.4134 & 85.4975 & & $01145 \quad 0.0000$ & \\
\hline 21 & 266.0569 & 63.6175 & & 1. 0182062 & $\odot . \odot \odot \odot \odot \odot \odot$ \\
\hline 77.2685 & 78.4777 & 81.9728 & & $01108 \quad 0.0000$ & \\
\hline 22 & 264.7167 & 63.2978 & & 1.0180320 & $\odot .0 \odot \odot \odot \odot \odot$ \\
\hline 74.4202 & 75.4042 & 78.2642 & & $01070 \quad 0.0000$ & \\
\hline 23 & 263.7388 & 63.0645 & & 1.0179049 & $\odot . \odot \odot \odot \odot \odot \odot$ \\
\hline 73.5232 & 74.4477 & 77.1402 & & $01058 \quad 0.000 \odot$ & \\
\hline 24 & 262.5678 & 62.7852 & & 1.0177527 & $\odot .0 \odot \odot \odot \odot \odot$ \\
\hline 74.7209 & 75.7736 & 78.8312 & & $01074 \quad 0.0000$ & \\
\hline$\odot$ AXIAL & MASS FLOW & SURFACE HEAT & J & HEAT TRANSFER & BURN - - OUT \\
\hline MODERATOR & TWO PHASE & DNB SURFACE & & COOLANT & \\
\hline NODE & RATE & FLUX & $\mathrm{H}$ & COEFFICIENT & RATIO \\
\hline REGIME & TEMPERATURE & TEMPERATURE & & ENERGY & \\
\hline$(D E G, C)$ & $\begin{array}{r}\left(\mathrm{Kg} / \mathrm{s}^{*} \mathrm{~m}^{* *} 2\right) \\
(\mathrm{DEG} \cdot \mathrm{C})\end{array}$ & 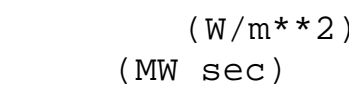 & & $\mathrm{T}$ & $(\mathrm{W} / \mathrm{m} * * 2 * \mathrm{~K})$ \\
\hline 1 & -6101.20 & 947808 & 3 & 38695.35 & 8.4342 \\
\hline LIQUID & 175.2067 & 196.2889 & & ๑.05669 & \\
\hline 2 & -6101.04 & 796745 & 3 & 38536.33 & 10.0659 \\
\hline LIQUID & 173.9492 & 196.3306 & & $\odot .05417$ & \\
\hline 3 & -6100.59 & 790616 & 3 & 38396.19 & 10.1703 \\
\hline LIQUID & 173.8946 & 196.3640 & & 0.05212 & \\
\hline 4 & -6100.43 & 912046 & 3 & 38249.16 & 8.8440 \\
\hline LIQUID & 174.9232 & 196.4046 & & $\odot .04966$ & \\
\hline 5 & -6100.37 & 995448 & 3 & 38085.06 & 8.1325 \\
\hline LIQUID & 175.5723 & 196.4515 & & 0.04681 & \\
\hline 6 & -6100.08 & 1070483 & 3 & 37881.42 & 7.5903 \\
\hline LIQUID & 176.1226 & 196.4989 & & $\odot .0439 \odot$ & \\
\hline 7 & -6100.00 & 1128466 & 3 & 37674.31 & 7.2303 \\
\hline LIQUID & 176.5286 & 196.5527 & & $\odot .04060$ & \\
\hline 8 & -6099.75 & 1173052 & 3 & 37474.56 & 6.9842 \\
\hline LIQUID & 176.8304 & 196.6061 & & 0.03730 & \\
\hline 9 & -6099.64 & 1192337 & 3 & 37246.23 & 6.9016 \\
\hline LIQUID & 176.9583 & 196.6632 & & 0.03377 & \\
\hline 10 & -6099.41 & 1197365 & 3 & 37019.11 & 6.9022 \\
\hline LIQUID & 176.9914 & 196.7188 & & 0.03029 & \\
\hline 11 & -6099.29 & 1180295 & 3 & 36785.83 & 7.0327 \\
\hline LIQUID & 176.8786 & 196.7756 & & $\odot .02674$ & \\
\hline 12 & -6099.11 & 1143054 & 3 & 36559.47 & 7.2923 \\
\hline LIQUID & 176.6283 & 196.8300 & & 0.02332 & \\
\hline 13 & $-6099.0 \odot$ & 1080165 & 3 & 36334.14 & 7.7482 \\
\hline LIQUID & 176.1915 & 196.8828 & & $\odot .01999$ & \\
\hline 14 & -6098.87 & 982418 & 3 & 36135.25 & 8.5509 \\
\hline LIQUID & 175.4736 & 196.9313 & & 0.01691 & \\
\hline 15 & -6098.71 & 887351. & 3 & 35956.21 & 9.4983 \\
\hline LIQUID & 174.7226 & 196.9743 & & 0.01417 & \\
\hline 16 & -6098.60 & 804048 & 3 & 35743.41 & 10.5141 \\
\hline LIQUID & 174.0139 & 197.0138 & & 0.01164 & \\
\hline 17 & -6098.49 & 727419 & 3 & 35613.83 & 11.6533 \\
\hline LIQUID & 173.3121 & 197.0492 & & $\odot .0 \odot 937$ & \\
\hline 18 & -6098.44 & 638000 & 3 & 35458.25 & 13.3194 \\
\hline LIQUID & 172.4202 & 197.0814 & & $\odot .00730$ & \\
\hline
\end{tabular}




$\begin{array}{rcclcc}19 & -6098.34 & 544393 . & 3 & 35329.86 & 15.6419 \\ \text { LIQUID } & 171.3810 & 197.1085 & & 0.00555 & \\ 20 & -6098.28 & 456791 . & 3 & 35221.98 & 18.6748 \\ \text { LIQUID } & 170.2805 & 197.1317 & & 0.00405 & \\ 21 & -6098.19 & 388651 . & 3 & 35132.47 & 21.9809 \\ \text { LIQUID } & 169.3105 & 197.1507 & & 0.00282 & \\ 22 & -6098.18 & 316092 . & 3 & 35054.63 & 27.0611 \\ \text { LIQUID } & 168.1273 & 197.1675 & & 0.00174 & \\ 23 & -6098.01 & 296757 . & 3 & 34986.21 & 28.8506 \\ \text { LIQUID } & 167.7784 & 197.1795 & & 0.00095 & \\ 24 & -6097.96 & 338142 . & 3 & 34919.63 & 25.3478 \\ \text { LIQUID } & 168.5065 & 197.1940 & & 0.00000 & \end{array}$

This section is the MAJOR EDIT and final edits at the end of the problem

TIME

Date $=3 / 15 / 2019$ TIME $=10: 24: 39$

2.200000

0.000100

17.564218776922

$-17.72800$

$-0.03555$

$\odot .0000 \odot$

$-\odot .11745$

$-\odot .01078$

4

POWER (MW)

$7.44243313206 \mathrm{E}-04$

POWER (MW)

DECAY POWER (MW)

4.75064512817E-04

DECAY POWER (MW)

ENERGY GENERATED

3. 44588871994E - 03

ENERGY GENERATED (MJ)

ENERGY IN FUEL (MJ)

7. 46142467979E- 05

ENERGY IN FUEL (MJ)

COOLANT ENERGY (MJ)

9.91928253681E- 09

1

8. 39484619982E - 04

$1.24392678648 \mathrm{E}+\odot \odot$

8. $97316335315 E-04$

$1.24640783075 \mathrm{E}+0 \odot$

$5.35858831289 \mathrm{E}-04$

$7.94021877408 \mathrm{E}-01 \quad 5.72773903528 \mathrm{E}-\odot 4$

$7.95605574655 \mathrm{E}-01$

MJ ) $\quad 5.75945152064 \mathrm{E}+\odot \odot \quad 4.15462548768 \mathrm{E}-\odot 3$

$3.88686136809 \mathrm{E}-03$

$5.77093889621 \mathrm{E}+\odot \odot$

$7.57689134179 \mathrm{E}-05$

$2.19727696819 \mathrm{E}-01 \quad 7.70138675241 \mathrm{E}-05$

$2.19510241440 \mathrm{E}-01$

$5.32840641560 \mathrm{E}-02 \quad 1.15211871095 \mathrm{E}-08$

COOLANT ENERGY (MJ) 5.32840968703E-02

COOLANT ENERGY REMOVED (MJ) 1.22864505371E-02 2.87128624719E-09

$2.47672536282 \mathrm{E}-09 \quad 2.76169328086 \mathrm{E}-09$

(MW sec) 
COOLANT ENERGY REMOVED (MJ) 1.22864586468 E- 02

1

PAGE 983

$\begin{array}{lccccc}\odot & & & & \\ \text { AXIAL } & \text { ENTHALPY } & \text { LIQUID(VAPOR) } & \text { LIQUID(VAPOR) } & \text { VOI } \\ \text { SURFACE } & \text { FUEL } & \text { SURFACE } & \text { FUEL MAXIMUM } & \text { FUEL } & \% \\ \quad \text { NODE } & & & \text { TEMPERATURE } & \text { SPECIFIC } & \text { VOL. } \\ \text { TEMPERATURE } & \text { TEMPERATURE } & \text { TEMPERATURE } & \text { ENERGY } & \end{array}$

...CHANNEL $1 \ldots$ VOID CLAD

C) (DEG.C $) \quad($ DEG,$C) \quad(M W$ sec $)$ QUAL.

FRACTION $(\mathrm{kJ} / \mathrm{Kg}) \quad(\mathrm{DEG} . \mathrm{C}) \quad\left(\mathrm{m}^{* *} 3 / \mathrm{Kg}\right) * 1000$ (DEG.

$1 \quad 268.9571$

67.2808

67.5450

66.7397

3

66.6665

4

66.9780

5

67.1620

6

67.3198

7

67.4134

8

67.4647

9

67.4307

10

67.3554

11

67.2070

12

67.0019

13

66.7144

14

66.3268

15

65. 9551

16

65.6274

17

65.3256

18

64.9901

19

64.6489

20

64.3336

21

64.0861
268.6667

66.9619

268.4253

66.8872

268.1401

67.2324

267.8191

67.4395

267.4796

67.6183

267.1093

67.7279

266.7313

67.7916

266.3323

67.7629

265.9418

67.6889

265.5406

67.5358

265.1612

67.3203

264.7848

67.0152

264.4465

66.6003

264.1359

66.2022

263.8603

65.8514

263.6044

65.5282

263.3795

65.1678

263.1833

64.8006

263.0198

64.4608

262.8816

64.1944

\author{
64.3090 \\ 68.3235 \\ 64.2397 \\ 67.6172 \\ 64.1822 \\ 67.5383 \\ 64.1142 \\ 67.9823
}

64.0377

68.2570

63.9568

68.4977

63.8685

68.6543

63.7783

68.7543

63.6832

68.7412

63.5900

68.6715

63.4943

68.5045

63.4038

68.2591

63.3141

67.9025

63.2333

67.4077

63.1593

66.9323

63.0935

66.5134

63.0325

66.1275

62.9788

65.6937

62.9321

65.2496

62.8930

64.8379

62.8601

64.5154

\subsection{0}

$0.00000 \quad 0.0000$

1.0185545

$0.00964 \quad 0.0000$

1. 0185217

$0.00963 \quad 0.0000$

1.0184828

$0.00967 \quad 0.0000$

1. 0184391

$\odot .00970 \quad 0.0000$

1.0183929

0.009720 .0000

1.0183429

$0.00974 \quad 0.0000$

1.0182938

$0.00974 \quad 0.0000$

1.0182420

$0.00974 \quad 0.0000$

1.0181912

$0.00973 \quad 0.0000$

1.0181391

$0.00971 \quad 0.0000$

1.0180898

$0.00969 \quad 0.0000$

1.0180409

$0.00965 \quad 0.0000$

1.0179969

$0.00960 \quad 0.0000$

1.0179565

$0.00955 \quad 0.0000$

1.0179207

$0.00951 \quad 0.0000$

1.0178875

$0.00947 \quad 0.0000$

1.0178582

$\odot .00942 \quad 0.000 \odot$

1.0178327

$0.00938 \quad 0.0000$

1.0178115

$0.00933 \quad 0.0000$

1.0177935

๑. $00930 \quad 0.0000$
0.000000

$\odot .000000$

$\odot .0000 \odot \odot$

$\odot .000000$

$\odot .000000$

$\odot .000000$

0.000000

$\odot .000000$

0.000000

0.000000

$\odot .0000 \odot \odot$

$\odot .000000$

$\odot .000000$

$\odot .000000$

$\odot .0000 \odot \odot$

$\odot .000000$

0.000000

$\odot .000000$

$\odot .000000$

$\odot .00000 \odot$

$\odot .000000$ 


\begin{tabular}{|c|c|c|c|c|c|}
\hline 22 & 262.7634 & 62.8319 & & 1.0177782 & $\odot . ๑ \odot \odot \odot \odot \odot$ \\
\hline 63.8290 & 63.9170 & 64.1782 & & $\odot \odot 927 \quad \odot . \odot \odot \odot \odot$ & \\
\hline 23 & 262.6727 & 62.8103 & & 1.0177664 & $\odot .0 \odot \odot \odot \odot \odot$ \\
\hline 63.7475 & 63.8303 & 64.0758 & & $00926 \quad 0.0000$ & \\
\hline 24 & 262.5678 & 62.7852 & & 1.0177527 & $\odot .0000 \odot \odot$ \\
\hline 63.8526 & 63.9469 & 64.2263 & & $00927 \quad 0.0000$ & \\
\hline$\odot$ AXIAL & MASS FLOW & SURFACE HEAT & J & HEAT TRANSFER & BURN - - OUT \\
\hline MODERATOR & TWO PHASE & DNB SURFACE & & COOLANT & \\
\hline NODE & RATE & FLUX & $\mathrm{H}$ & COEFFICIENT & RATIO \\
\hline REGIME & $\begin{array}{l}\text { TEMPERATURE } \\
\left(\mathrm{Kg} / \mathrm{s}^{*} \mathrm{~m} * 2\right)\end{array}$ & $\begin{array}{l}\text { TEMPERATURE } \\
\left(\mathrm{W} / \mathrm{m}^{*} * 2\right)\end{array}$ & & $\begin{array}{l}\text { ENERGY } \\
\qquad \mathrm{T}\end{array}$ & $(\mathrm{W} / \mathrm{m} * * 2 * \mathrm{~K})$ \\
\hline$(D E G \cdot C)$ & $(\mathrm{DEG}, \mathrm{C})$ & (MW sec) & & & \\
\hline 1 & -6101.20 & 84963 & 3 & 35314.61 & 100.3014 \\
\hline LIQUID & 161.9207 & 197.1186 & & 0.00516 & \\
\hline 2 & -6101.19 & 71447 & 3 & 35297.72 & 119.3100 \\
\hline LIQUID & 161.2487 & 197.1222 & & $\odot .0 \odot 492$ & \\
\hline 3 & -6101.16 & 70974 & 3 & 35283.63 & 120.1312 \\
\hline LIQUID & 161.2236 & 197.1252 & & 0.00473 & \\
\hline 4 & -6101.15 & 81787 & 3 & 35267.15 & 104.2781 \\
\hline LIQUID & 161.7703 & 197.1288 & & 0.00450 & \\
\hline 5 & -6101.15 & 89190 & 3 & 35248.65 & 95.6522 \\
\hline LIQUID & 162.1145 & 197.1328 & & $0.0 \odot 424$ & \\
\hline 6 & -6101.13 & 95959 & 3 & 35229.13 & 88.9330 \\
\hline LIQUID & 162.4111 & 197.1370 & & 0.00397 & \\
\hline 7 & -6101.12 & 101101 & 3 & 35207.80 & 84.4398 \\
\hline LIQUID & 162.6262 & 197.1416 & & $\odot .00367$ & \\
\hline 8 & -6101.11 & 105080 & 3 & 35185.44 & 81.2714 \\
\hline LIQUID & 162.7871 & 197.1464 & & 0.00336 & \\
\hline 9 & -6101.10 & 106767 & 3 & 35161.98 & 80.0176 \\
\hline LIQUID & 162.8540 & 197.1513 & & $\odot .00304$ & \\
\hline 10 & -6101.08 & 107189 & 3 & 35127.42 & 79.7323 \\
\hline LIQUID & 162.8706 & 197.1562 & & $\odot .0 \odot 273$ & \\
\hline 11 & -6101.07 & 105661 & 3 & 35115.65 & 80.9160 \\
\hline LIQUID & 162.8102 & 197.1612 & & $\odot .00240$ & \\
\hline 12 & -6101.05 & 102346 & 3 & 35093.55 & 83.5676 \\
\hline LIQUID & 162.6770 & 197.1659 & & 0.00210 & \\
\hline 13 & -6101.05 & 96674 & 3 & 35071.77 & 88.5026 \\
\hline LIQUID & 162.4415 & 197.1706 & & ๑.00179 & \\
\hline 14 & -6101.03 & 87885 & 3 & 35040.61 & 97.3846 \\
\hline LIQUID & 162.0554 & 197.1748 & & ๑.00152 & \\
\hline 15 & -6101.02 & 79396 & 3 & 35022.74 & 107.8283 \\
\hline LIQUID & 161.6543 & 197.1787 & & 0.00127 & \\
\hline 16 & -6101.01 & 71952 & 3 & 35018.51 & 119.0152 \\
\hline LIQUID & 161.2755 & 197.1821 & & 0.00104 & \\
\hline 17 & -6101.00 & 65091 & 3 & 35003.88 & 131.5914 \\
\hline LIQUID & 160.8997 & 197.1853 & & $\odot .00084$ & \\
\hline 18 & -6100.99 & 57060 & 3 & 34979.44 & 150.1447 \\
\hline LIQUID & 160.4205 & 197.1881 & & $\odot .00066$ & \\
\hline 19 & -6100.99 & 48695 & 3 & 34968.27 & 175.9687 \\
\hline LIQUID & 159.8649 & 197.1905 & & $\odot .0 \odot \odot 5 \odot$ & \\
\hline 20 & -6100.98 & 40860 & 3 & 34970.55 & 209.7458 \\
\hline LIQUID & 159.2760 & 197.1926 & & $\odot .00037$ & \\
\hline
\end{tabular}




$\begin{array}{rccccc}21 & -610 \odot .97 & 34768 . & 3 & 34962.70 & 246.5315 \\ \text { LIQUID } & 158.7572 & 197.1943 & & 0.00025 & \\ 22 & -6100.97 & 28272 . & 3 & 34956.00 & 303.2075 \\ \text { LIQUID } & 158.1236 & 197.1957 & & 0.00016 & \\ 23 & -6100.96 & 26572 . & 3 & 34950.83 & 322.6350 \\ \text { LIQUID } & 157.9401 & 197.1969 & & 0.00 \odot \odot 8 & \\ 24 & -6100.95 & 30250 . & 3 & 34933.32 & 283.4382 \\ \text { LIQUID } & 158.3270 & 197.1982 & & 0.000 \odot \odot & \end{array}$

TRANSS: problem is complete. RETURNING AT TIME T=2.200099999995056

This section contains edits that appear only at the end of the run

DUMP OF ARRAY; $\mathrm{NZ}=24 \mathrm{NCHN}=4$ SPECIFIC VOLUME, $\mathrm{m} \wedge 3 / \mathrm{kg}$

1 1.0186E-03 1.0186E-03 1.0185E-03 1.0185E-03 1.0184E-03 1.0184E-03

1.0183E-03 1.0183E-03 1.0182E-03 1.0182E-03

2 1.0181E-03 1.0181E-03 1.0180E-03 $\quad 1.0180 \mathrm{E}-03 \quad 1.0180 \mathrm{E}-03 \quad 1.0179 \mathrm{E}-03$

1.0179E-03 1.0179E-03 1.0178E-03 1.0178E-03

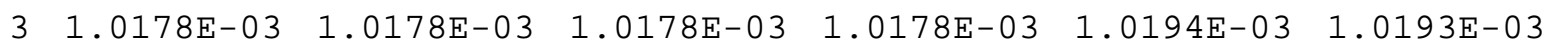

1.0192E-03 1.0191E-03 1.0190E-03 1.0189E-03

4 1.0188E-03 1.0187E-03 1.0186E-03 1.0185E-03 $1.0184 \mathrm{E}-03 \quad 1.0183 \mathrm{E}-03$

1.0182E-03 1.0181E-03 1.0180E-03 1.0180E-03

$5 \quad 1.0179 \mathrm{E}-03 \quad 1.0179 \mathrm{E}-03 \quad 1.0178 \mathrm{E}-03 \quad 1.0178 \mathrm{E}-03 \quad 1.0178 \mathrm{E}-03 \quad 1.0178 \mathrm{E}-03$

1.0178E-@3 1.0178E-03 1.0192E-03 1.0191E-03

$6 \quad 1.0191 \mathrm{E}-03 \quad 1.0190 \mathrm{E}-03 \quad 1.0189 \mathrm{E}-03 \quad 1.0188 \mathrm{E}-03 \quad 1.0187 \mathrm{E}-03 \quad 1.0187 \mathrm{E}-03$

1.0186E-03 1.0185E-03 1.0184E-03 1.0183E-03

$\begin{array}{lllllll}7 & 1.0182 \mathrm{E}-03 & 1.0181 \mathrm{E}-03 & 1.0180 \mathrm{E}-03 & 1.0180 \mathrm{E}-03 & 1.0179 \mathrm{E}-03 & 1.0179 \mathrm{E}-03\end{array}$

1.0178E-03 1.0178E-03 1.0178E-03 1.0178E-03

$\begin{array}{lllllll}8 & 1.0178 \mathrm{E}-03 & 1.0178 \mathrm{E}-03 & 1.0193 \mathrm{E}-03 & 1.0193 \mathrm{E}-03 & 1.0192 \mathrm{E}-03 & 1.0191 \mathrm{E}-03\end{array}$

1.0190E-03 1.0189E-03 1.0188E-03 1.0187E-03

9 1.0186E-03 1.0185E-03 1.0184E-03 1.0183E-03 $\quad 1.0182 \mathrm{E}-03 \quad 1.0181 \mathrm{E}-03$

1.0181E-03 1.0180E-03 1.0179E-03 1.0179E-03

10 1.0178E-03 1.0178E-03 1.0178E-03 1.0178E-03 1.0178E-03 1.0178E-03

DUMP OF ARRAY; $\mathrm{NZ}=24 \mathrm{NCHN}=4$ MASS FLOW RATE, $\mathrm{kg} / \mathrm{s} / \mathrm{m}^{\wedge} 2$

$1-6.1012 \mathrm{E}+03-6.1012 \mathrm{E}+03-6.1012 \mathrm{E}+03-6.1012 \mathrm{E}+03-6.1011 \mathrm{E}+03-6.1011 \mathrm{E}+03-$

$6.1011 \mathrm{E}+03-6.1011 \mathrm{E}+03-6.1011 \mathrm{E}+03-6.1011 \mathrm{E}+03$

$2-6.1011 \mathrm{E}+03-6.1011 \mathrm{E}+03-6.1010 \mathrm{E}+03-6.1010 \mathrm{E}+03-6.1010 \mathrm{E}+03-6.1010 \mathrm{E}+03-$

$6.1010 \mathrm{E}+03-6.1010 \mathrm{E}+03-6.1010 \mathrm{E}+03-6.1010 \mathrm{E}+03$

$3-6.1010 \mathrm{E}+03-6.1010 \mathrm{E}+03-6.1010 \mathrm{E}+03-6.1010 \mathrm{E}+03-6.1012 \mathrm{E}+03-6.1012 \mathrm{E}+03-$

$6.1011 \mathrm{E}+03-6.1011 \mathrm{E}+03-6.1011 \mathrm{E}+03-6.1011 \mathrm{E}+03$

$4-6.1010 \mathrm{E}+03-6.1010 \mathrm{E}+03-6.1010 \mathrm{E}+03-6.1010 \mathrm{E}+03-6.1009 \mathrm{E}+03-6.1009 \mathrm{E}+03-$

$6.1009 \mathrm{E}+03-6.1009 \mathrm{E}+03-6.1008 \mathrm{E}+03-6.1008 \mathrm{E}+03$

$5-6.1008 \mathrm{E}+03-6.1008 \mathrm{E}+03-6.1008 \mathrm{E}+03-6.1008 \mathrm{E}+03-6.1008 \mathrm{E}+03-6.1008 \mathrm{E}+03-$

$6.1007 \mathrm{E}+03-6.1008 \mathrm{E}+03-6.1012 \mathrm{E}+03-6.1012 \mathrm{E}+03$

$6-6.1011 \mathrm{E}+03-6.1011 \mathrm{E}+03-6.1011 \mathrm{E}+03-6.1011 \mathrm{E}+03-6.1011 \mathrm{E}+03-6.1010 \mathrm{E}+03-$

$6.1010 \mathrm{E}+03-6.1010 \mathrm{E}+03-6.1010 \mathrm{E}+03-6.1009 \mathrm{E}+03$

$7-6.1009 \mathrm{E}+03-6.1009 \mathrm{E}+03-6.1009 \mathrm{E}+03-6.1009 \mathrm{E}+03-6.1009 \mathrm{E}+03-6.1008 \mathrm{E}+03-$

$6.1008 \mathrm{E}+03-6.1008 \mathrm{E}+03-6.1008 \mathrm{E}+03-6.1008 \mathrm{E}+03$

$8-6.1008 \mathrm{E}+03-6.1008 \mathrm{E}+03-6.1012 \mathrm{E}+03-6.1012 \mathrm{E}+03-6.1011 \mathrm{E}+03-6.1011 \mathrm{E}+03-$

$6.1011 \mathrm{E}+03-6.1011 \mathrm{E}+03-6.1011 \mathrm{E}+03-6.1010 \mathrm{E}+03$

$9-6.1010 \mathrm{E}+03-6.1010 \mathrm{E}+03-6.1010 \mathrm{E}+03-6.1009 \mathrm{E}+03-6.1009 \mathrm{E}+03-6.1009 \mathrm{E}+03-$

$6.1009 \mathrm{E}+03-6.1008 \mathrm{E}+03-6.1008 \mathrm{E}+03-6.1008 \mathrm{E}+03$

$10-6.1008 \mathrm{E}+03-6.1008 \mathrm{E}+03-6.1008 \mathrm{E}+03-6.1008 \mathrm{E}+03-6.1008 \mathrm{E}+03-6.1008 \mathrm{E}+03$ 
VELOCITY EDIT OF CHANNELS $\mathrm{m} / \mathrm{s}$

CHANNEL ->

$123 \quad 3 \quad 4$

$1-6.215 \mathrm{E}+00-6.219 \mathrm{E}+0 \odot-6.218 \mathrm{E}+00-6.219 \mathrm{E}+0 \odot$

$2-6.214 \mathrm{E}+00-6.219 \mathrm{E}+0 \Theta-6.218 \mathrm{E}+00-6.219 \mathrm{E}+0 \odot$

$3-6.214 \mathrm{E}+0 \odot-6.218 \mathrm{E}+\odot \odot-6.218 \mathrm{E}+0 \odot-6.218 \mathrm{E}+\odot \odot$

$4-6.214 \mathrm{E}+00-6.218 \mathrm{E}+0 \odot-6.217 \mathrm{E}+0 \odot-6.218 \mathrm{E}+\odot \odot$

$5-6.214 \mathrm{E}+0 \odot-6.217 \mathrm{E}+\odot \odot-6.217 \mathrm{E}+0 \odot-6.217 \mathrm{E}+\odot \odot$

$6-6.213 \mathrm{E}+0 \odot-6.217 \mathrm{E}+0 \Theta-6.216 \mathrm{E}+00-6.217 \mathrm{E}+0 \odot$

$7-6.213 \mathrm{E}+0 \odot-6.216 \mathrm{E}+0 \odot-6.215 \mathrm{E}+00-6.216 \mathrm{E}+0 \odot$

$8-6.213 \mathrm{E}+0 \odot-6.215 \mathrm{E}+0 \odot-6.215 \mathrm{E}+00-6.215 \mathrm{E}+0 \odot$

$9-6.212 \mathrm{E}+0 \odot-6.214 \mathrm{E}+0 \odot-6.214 \mathrm{E}+0 \odot-6.215 \mathrm{E}+\odot \odot$

$10-6.212 \mathrm{E}+\odot \odot-6.214 \mathrm{E}+\odot \odot-6.214 \mathrm{E}+\odot \odot-6.214 \mathrm{E}+\odot \odot$

$11-6.212 \mathrm{E}+\odot \odot-6.213 \mathrm{E}+\odot \odot-6.213 \mathrm{E}+00-6.213 \mathrm{E}+0 \odot$

$12-6.211 \mathrm{E}+0 \odot-6.212 \mathrm{E}+0 \odot-6.212 \mathrm{E}+0 \odot-6.213 \mathrm{E}+\odot \odot$

$13-6.211 \mathrm{E}+\odot \odot-6.212 \mathrm{E}+\odot \odot-6.212 \mathrm{E}+0 \odot-6.212 \mathrm{E}+\odot \odot$

$14-6.211 \mathrm{E}+00-6.211 \mathrm{E}+00-6.211 \mathrm{E}+00-6.212 \mathrm{E}+00$

$15-6.211 \mathrm{E}+00-6.211 \mathrm{E}+0 \odot-6.211 \mathrm{E}+0 \odot-6.211 \mathrm{E}+0 \odot$

$16-6.210 \mathrm{E}+0 \odot-6.210 \mathrm{E}+\odot \odot-6.210 \mathrm{E}+0 \odot-6.211 \mathrm{E}+0 \odot$

$17-6.210 \mathrm{E}+00-6.210 \mathrm{E}+\odot \odot-6.210 \mathrm{E}+0 \odot-6.210 \mathrm{E}+\odot \odot$

$18-6.210 \mathrm{E}+00-6.210 \mathrm{E}+00-6.210 \mathrm{E}+00-6.210 \mathrm{E}+\odot \odot$

$19-6.210 \mathrm{E}+0 \odot-6.210 \mathrm{E}+\odot \odot-6.210 \mathrm{E}+\odot \odot-6.210 \mathrm{E}+\odot \odot$

$20-6.210 \mathrm{E}+0 \odot-6.209 \mathrm{E}+\odot \odot-6.209 \mathrm{E}+\odot \odot-6.209 \mathrm{E}+\odot \odot$

$21-6.210 \mathrm{E}+\odot \odot-6.209 \mathrm{E}+\odot \odot-6.209 \mathrm{E}+\odot \odot-6.209 \mathrm{E}+\odot \odot$

$22-6.209 \mathrm{E}+\odot \odot-6.209 \mathrm{E}+\odot \odot-6.209 \mathrm{E}+\odot \odot-6.209 \mathrm{E}+\odot \odot$

$23-6.209 \mathrm{E}+0 \odot-6.209 \mathrm{E}+0 \odot-6.209 \mathrm{E}+\odot \odot-6.209 \mathrm{E}+\odot \odot$

$24-6.209 \mathrm{E}+\odot \odot-6.209 \mathrm{E}+\odot \odot-6.209 \mathrm{E}+\odot \odot-6.209 \mathrm{E}+\odot \odot$

DENSITY EDIT OF CHANNELS $\mathrm{kg} / \mathrm{m} \wedge 3$

CHANNEL ->

1

1981.7453

2981.7834

3981.8151

$4 \quad 981.8525$

$\begin{array}{ll}5 & 981.8947\end{array}$

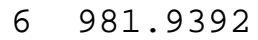

$\begin{array}{ll}7 & 981.9874\end{array}$

8982.0348

$9 \quad 982.0848$

$10 \quad 982.1337$

11982.1840

12982.2316

13982.2788

14982.3212

15982.3602

$\begin{array}{ll}16 & 982.3947\end{array}$

$17 \quad 982.4268$

$18 \quad 982.4550$

19982.4796

$20 \quad 982.5002$

$21 \quad 982.5175$

$22 \quad 982.5323$

$23 \quad 982.5437$

2
981.0110
981.0865
981.1583
981.2387
981.3288
981.4259
981.5258
981.6343
981.7408
981.8534
981.9579
982.0622
982.1529
982.2384
982.2976
982.3550
982.4009
982.4442
982.4746
982.4987
982.5150
982.5321
982.5425

\section{3}

981.1550

981.2207

981.2833

981.3538

981.4315

981.5115

981.6002

981.6857

981.7806

981.8653

981.9613

982.0413

982.1283

982.2050

982.2821

982.3450

982.4073

982.4582

982.4949

982.5116

982.5260

982.5375

982.5466
4

981.0416

981.1081

981.1720

981.2451

981.3258

981.4108

981.5036

981.5987

981.6984

981.7967

981.8982

981.9956

982.0893

982.1760

982.2583

982.3298

982.3965

982.4514

982.4924

982.5090

982.5260

982.5368

982.5481 
$\begin{array}{lllll}24 & 982.5569 & 982.5569 & 982.5569 & 982.5569\end{array}$

PFQ EDIT OF CHANNELS SI $M W / \mathrm{m}^{\wedge} 3 ; \mathrm{P}=1.24640 \mathrm{E}+\odot \odot \mathrm{MW}$

CHANNEL ->

$1 \quad 2 \quad 3 \quad 4$

$13.5207 \mathrm{E}+02 \quad 7.6855 \mathrm{E}+02 \quad 6.0971 \mathrm{E}+02 \quad 6.4186 \mathrm{E}+02$

$22.9597 \mathrm{E}+02 \quad 7.3104 \mathrm{E}+02 \quad 5.8117 \mathrm{E}+\Theta 2 \quad 6.1670 \mathrm{E}+02$

$32.9403 \mathrm{E}+02 \quad 7.5743 \mathrm{E}+02 \quad 6.0418 \mathrm{E}+02 \quad 6.4938 \mathrm{E}+02$

4 3.3896E+-2 8.4955E+@2 6.7346E+@2 7.2963E+@2

5 3.6975E+-2 9.3314E+02 7.1679E+-2 7.8652E+02

$63.9791 \mathrm{E}+02$ 9.8182E+02 7.6814E+02 8.4517E+02

7 4.1930E+02 1.0400E+03 7.9217E+02 8.9299E+@2

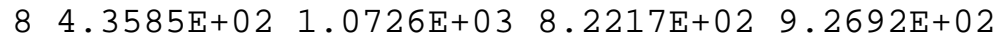

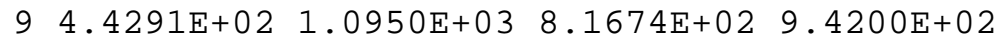

$10 \quad 4.4482 \mathrm{E}+02 \quad 1.0836 \mathrm{E}+03 \quad 8.2418 \mathrm{E}+02 \quad 9.5089 \mathrm{E}+02$

$114.3842 \mathrm{E}+02$ 1.0637E+03 8.1406E+02 9.4974E+02

$124.2468 \mathrm{E}+02$ 1. $1141 \mathrm{E}+03 \quad 7.9453 \mathrm{E}+02 \quad 9.3476 \mathrm{E}+02$

13 4.0117E+02 9.2146E+-02 7.8090E+02 8.9925E+02

$143.6479 \mathrm{E}+02 \quad 7.5486 \mathrm{E}+02 \quad 7.3499 \mathrm{E}+02 \quad 8.4311 \mathrm{E}+02$

$153.2958 \mathrm{E}+02 \quad 6.1103 \mathrm{E}+02 \quad 6.6735 \mathrm{E}+02 \quad 7.6642 \mathrm{E}+02$

$16 \quad 2.9863 \mathrm{E}+02 \quad 5.3958 \mathrm{E}+02 \quad 5.9824 \mathrm{E}+02 \quad 6.8914 \mathrm{E}+02$

$172.7016 \mathrm{E}+02 \quad 4.6640 \mathrm{E}+02 \quad 5.4023 \mathrm{E}+02 \quad 6.0629 \mathrm{E}+02$

$182.3691 \mathrm{E}+02 \quad 3.8508 \mathrm{E}+02 \quad 4.1762 \mathrm{E}+02 \quad 4.7782 \mathrm{E}+02$

$192.0217 \mathrm{E}+02 \quad 2.8518 \mathrm{E}+02 \quad 2.5356 \mathrm{E}+02 \quad 2.8528 \mathrm{E}+02$

$201.6962 \mathrm{E}+02 \quad 2.1032 \mathrm{E}+02 \quad 1.4894 \mathrm{E}+02 \quad 1.6850 \mathrm{E}+02$

21 1.4434E+-02 1.7494E+-02 1.2343E+-02 1.3831E+-02

$221.1738 \mathrm{E}+02 \quad 1.4331 \mathrm{E}+02 \quad 9.8324 \mathrm{E}+01 \quad 1.1009 \mathrm{E}+02$

$231.1034 \mathrm{E}+02 \quad 1.3028 \mathrm{E}+02 \quad 9.2978 \mathrm{E}+01 \quad 9.9809 \mathrm{E}+01$

$241.2562 \mathrm{E}+02$ 1.3053E+-02 9.5101E+01 1.0532E+02

This section edits the radial temperature profile (U) at each axial node, for each channel

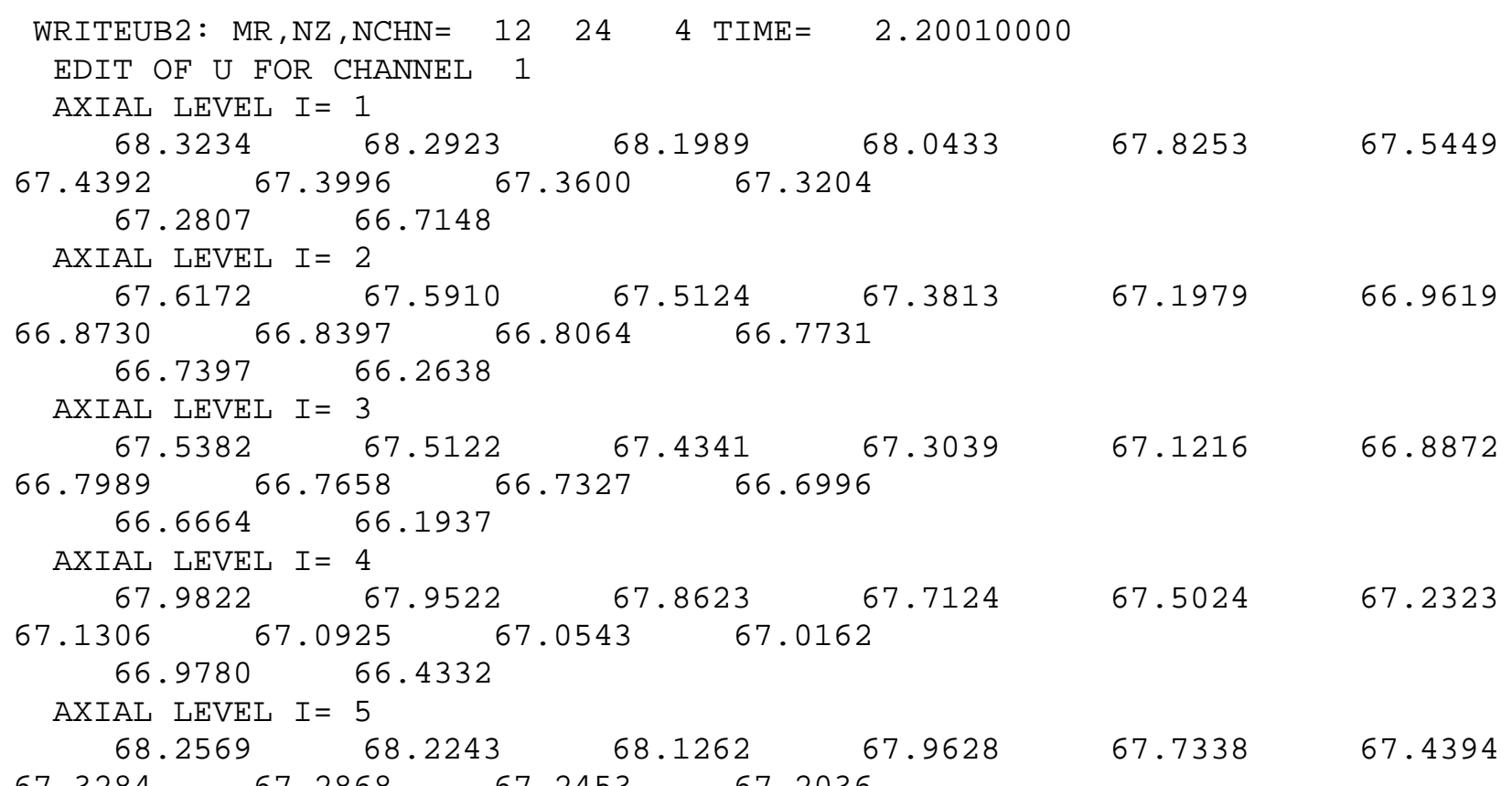




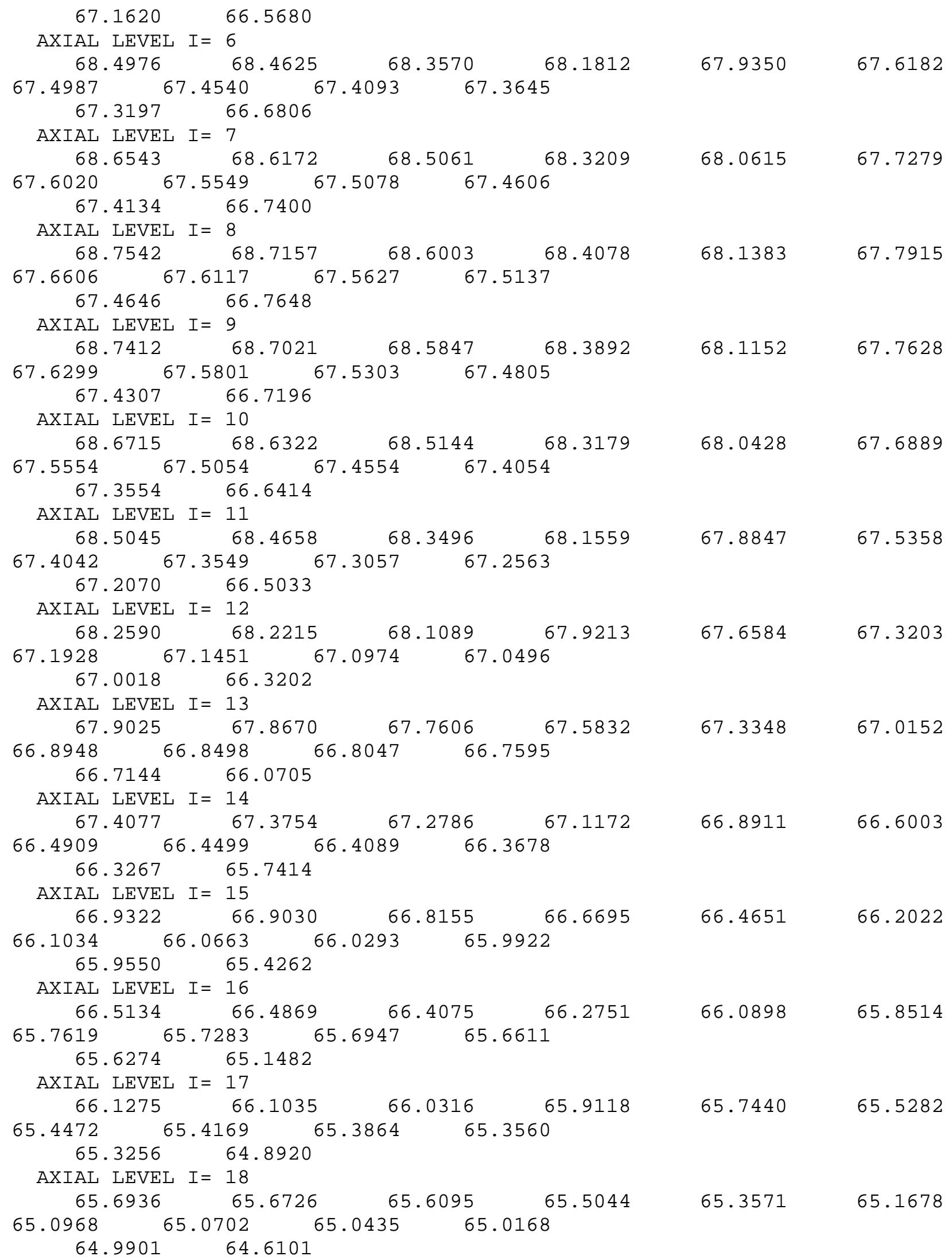




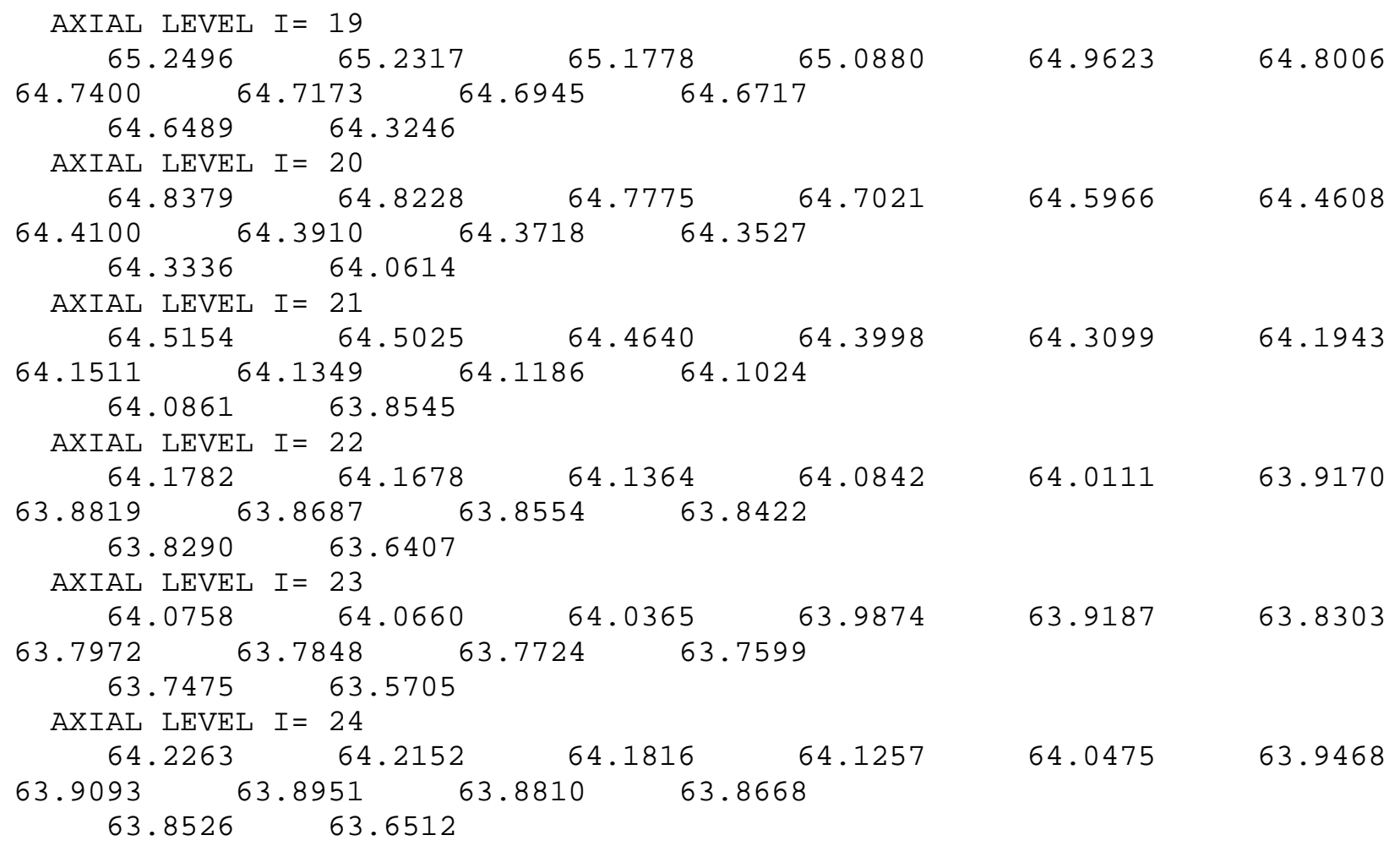

This section show volume-weighted average temperature in each material composition TIME $=2.2001$ SYSTEM AVG. TEMPERATURES(C) FOR EACH COMPOSITION $\begin{array}{llll}66.78 & 66.27 & 65.83 & 66.16\end{array}$

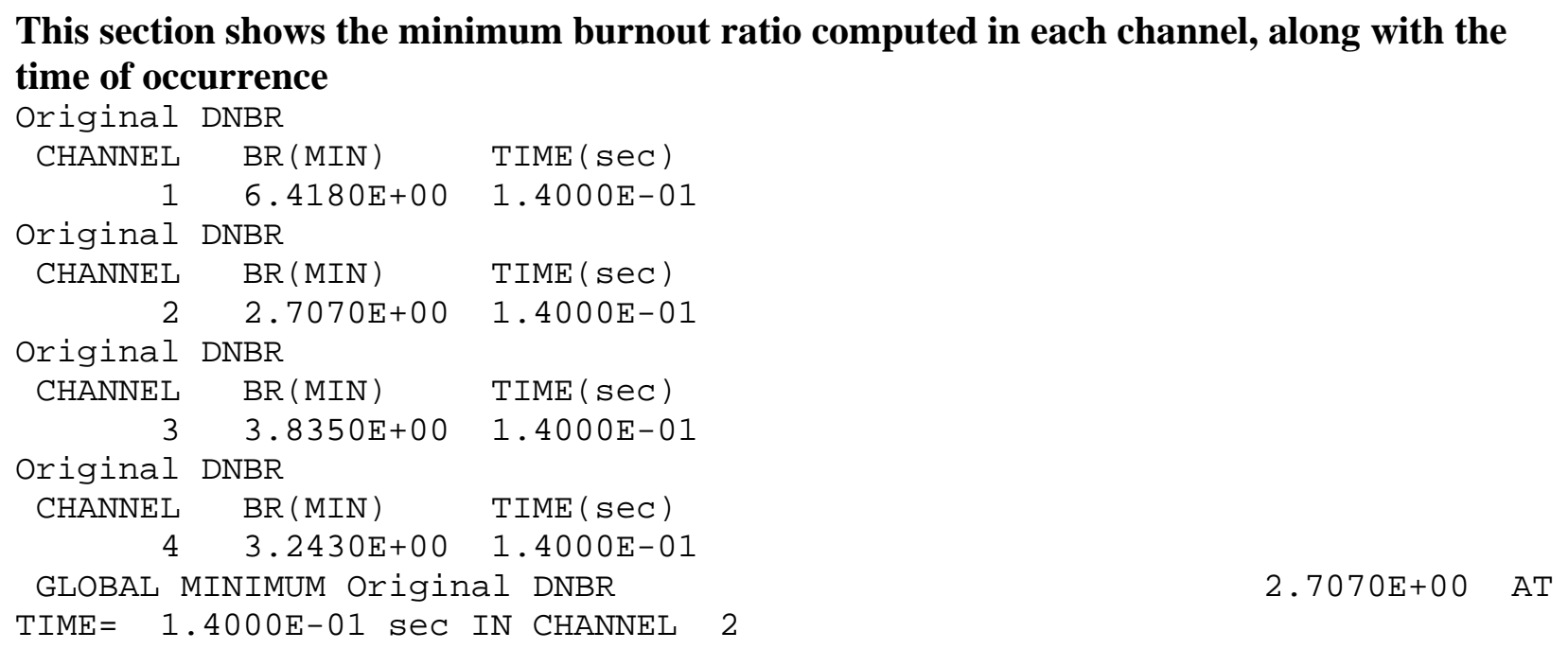


This section ends the output with information about how the shortened channel-dependent output files are created

ENTERED SHORTSU WITH NSU $=10 \quad \mathrm{NCHN}=4$ SUTOL $=0.5000000000000000$

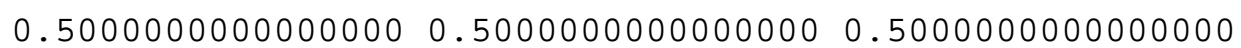

SUMMARY file lines processed $=205$ lines saved $=57$ on SUMMARY. short

This section ends the run

PARET/ANL Version $=$ V7.6

3/15/2019 TIME $=10: 24: 39$

Version Date=Thu Mar 14 12:07:1 Date=

EXECUTION TIME $=18.626$ MINUTES

\subsection{Channel Output}

The PARET/ANL code writes a text (ASCII) summary file for each coolant channel (up to 120 available as NCHN cannot exceed 120). The files are called OUTPUT.ch01 through OUTPUT.chnn, where $\mathrm{nn}=\mathrm{NCHN}$. Also written are shortened text files, with the data "thinned". See discussion in Section 6. These files contain a record for each time step as follows:

$\begin{array}{lll}\text { TIME } & = & \text { Time, sec } \\ \text { POWER } & = & \text { Power, } \mathrm{MW} \\ \text { ENRGYR } & = & \text { Energy, MWs } \\ \text { REAC } & = & \text { Net reactivity, } \$ \\ \text { AMFR I } & = & \text { Mass flow rate, } \mathrm{kg} / \mathrm{s} / \mathrm{m}^{2} \text { or } \mathrm{lb}_{\mathrm{m}} / \mathrm{hr} \mathrm{ft}^{2} \\ \text { BRM } & = & \text { Min. critical heat flux ratio } \\ \text { TCOOL } & = & \text { Max. coolant temperature, } \mathrm{C} \text { or }{ }^{\circ} \mathrm{F} \\ \text { TCLAD } & = & \text { Max. clad surface temperature, } \mathrm{C} \text { or }{ }^{\circ} \mathrm{F} \\ \text { TCNTR } & = & \text { Max. fuel center line temperature, } \mathrm{C} \text { or }{ }^{\circ} \mathrm{F} \\ \text { TCOUT } & = & \text { Coolant outlet temperature, } \mathrm{C} \text { or }{ }^{\circ} \mathrm{F} \\ \text { PERIOD } & = & \text { Reactor period, sec }\end{array}$

This data is edited in FORMAT(1P,3E12.5,2E12.4,E10.3,5E11.4)

\subsection{Summary}

The PARET/ANL code writes a binary SUMMARY file to facilitate post-processing of the large amount of data that is often generated. This file contains a record for each time step, written in the following format:

TIME, POWER, REAC, (AMFR(I), I=1, NCHN), (BRM $\quad(1), \quad I=1, \quad$ NCHN), (TCOOL (I), I=1, NCHN), (TCLAD(I),I=1,NCHN),

(TCNTR(I),I=1,NCHN),(TCOUT(I),I=1,NCHN)

where

TIME = Time at each step, sec 
POWER = Power at each step, MW

REAC = Net reactivity at each step, $\$$

and for each of the NCHN channels:

AMFR $=\quad$ Mass flow rate at each step, $\mathrm{lb}_{\mathrm{m}} / \mathrm{hr} \mathrm{ft}^{2}$

BRM = Min. critical heat flux ratio

TCOOL $=$ Max. coolant temperature, $\mathrm{C}$ or ${ }^{\circ} \mathrm{F}$

TCLAD $=$ Max. clad surface temperature, $\mathrm{C}$ or ${ }^{\circ} \mathrm{F}$

TCNTR $=\quad$ Max. fuel center line temperature, $\mathrm{C}$ or ${ }^{\circ} \mathrm{F}$

TCOUT $=$ Coolant outlet temperature, $\mathrm{C}$ or ${ }^{\circ} \mathrm{F}$

An edit of this file provides a summary of the PARET/ANL results.

\subsection{Short Output}

This information is the same as in Section 8.3, but the changes from line to line are processed by a filter to reduce the number of lines retained. See Card Type 1116. 


\section{References}

[1] C. F. Obenchain, "PARET - A program for the analysis of reactor transients," Philips Petroleum Company, 1969.

[2] W. Woodruff, "A Kinetics and Thermal-hydraulics Capability for the Analysis of Research Reactors," Nuclear Technology, no. 64, February 1984.

[3] W. L. Woodruff, "The PARET Code and the Analysis of the SPERT I Transients," ANL/RERTR/TM-4, 1982.

[4] W. Woodruff, "Additional Capabilities and Benchmarking with the SPERT Transients for Heavy Water Applications of the PARET Code," in Int. Mtg. on Reduced Enrichment for Research and Test Reactors, Berlin, Germany, 1989.

[5] E. R. Cohen, "Some Topics in Reactor Kinetics," in Second United Nations International Conference on the Peaceful Uses of Atomic Energy Held in Geneva 1 September - 13 September 1958, Geneva, 1958.

[6] A. Schwartz, "Generalized Reactor Kinetics Code - AIREK II," NAA-SR-Memo-4980, 1960.

[7] R. W. Garner, "An Analysis of Nonboiling Reactivity Feedback MEchanisms in Pressurized Power Excursions in the Spert III Reactor," IDO-16819, 1963.

[8] R. K. McCardell, H. D. O. and J. E. Houghtaling, "Reactivity Accident Test Results and Analyses for the Spert III E-Core - A small Oxide-Fueled, Pressurized-Water Reactor," IDO-17281, 1969.

[9] L. Bernath, "A Theory of Local-Boiling Burnout and Its Applicationto Existing Data," Chem. Eng. Prog. Sym. Series, vol. 56, no. 30, pp. 95-116, 1960.

[10] H. e. a. Johnson, "Reactor Heat Transients Project 1962 Annual Report - Transient Boiling Heat Transfer and Void Volume Production in Channel Flow," SAN-1007, 1963.

[11] R. J. Wagner, "HEAT 1 - A One Dimensional Time Dependent or Steady State Heat Conduction Code for the IBM-650," IDO-16867, 1963.

[12] W. H. McAdams, Heat Transmission, 3rd ed., New-York: McGraw-Hill Book Co., 1954.

[13] J. Meyer and J. J. Williams, "A Momentum Integral Model for the Treatment of Transient Fluid Flow," Westinghous Electric Corp., Bettis Technical Review - Reactor Technology, WAPD-BT$25,1962$.

[14] W. H. Jens and P. A. Lottes, "Analysis of Heat Transfer, Burnout, Pressure Drop and Density Data for High-Pressure Water," ANL-4627, 1951.

[15] J. B. McDonough, W. Milich and E. King, "An Experimental Study of Partial Film Boiling Region with Water at Elevated Pressures in a Round Vertical Tube," in Fourth National Heat Transfer Conference A.I.C.H.E. - A.S.M.E., Buffalo, New-York, 1960.

[16] J. A. Redfield, "A FORTRAN Code (MO 438) for Super-Prompt-Critical Excursion Analysis," WAPD-V (PK)-23, 1963. 
[17] L. Tong, H. Currin and A. G. Thorp, "New DNB (Burnout) Correlations," WCAP-1997 (Rev.2), 1963.

[18] J. A. Redfield, "CHIC-KIN - A FORTRAN Program for Intermediate and Fast Transients in a Water Moderated Reactor," WAPD-TM-479, 1965.

[19] A. Bergles and W. M. Rohsenow, "The Determination of Forced-Convection Surface Boiling Heat Transfer," Journal of Heat Transfer, vol. 86, no. 3, pp. 365-372, 1964.

[20] J. Meyer, "Hydrodynamic Models for the Treatment of Reactor Thermal Transients," Nuclear Science and Engineering, vol. 10, p. 269, 1961.

[21] N. Zuber, F. W. Staub and G. Bijwaard, "Vapor Void Fraction in Subcooled Boiling and in Staturated Boiling Systems," in Proceedings of the Third International Heat Transfer Conference, Chicago, IL, 1966.

[22] N. C. Sher, "Review of Martinelli-Nelson Pressure Drop Correlation," WAPD-TH-219, July 1956.

[23] R. Martinelli and D. Nelson, "Prediction of Pressure Drop During Forced-Circulation Boiling of Water," ASME Trans., vol. 70, pp. 695-702, 1948.

[24] B. W. LeTourneau and M. Troy, "Heating, Local Boiling, and Two-Phase Pressure Drop for Vertical Upflow of Water at Pressures Below 1850 Psia; Test Data and Correlations," WAPD$\mathrm{TH}=410$, November 1959.

[25] R. P. Morgan, "A Review and Discussion of Literature Converning Transient Heat Transfer and Steam Formation," IDO-17226, 1967.

[26] P. Lax and B. Wendroff, "Systems of Conservation Laws," Comm. on Pure and Appl. Math., no. 13, pp. 217-237, 1960.

[27] F. Dittus and L. Boelter, "Heat Transfer in Automobile Radiators of the Tubular Type," International Communication in Heat and Mass Transfer, vol. 12, pp. 3-22, 1985.

[28] E. Sieder and G. Tate, "Heat Transfer and Pressure Drop of Liquids in Tubes," Industrial \& Engineering Chemistry, vol. 28, no. 12, pp. 1429-1435, 1936.

[29] B. Petukhov and V. Popov, "Theoretical Calculation of Heat Exchange in Turbulent Flow in Tubes of an Incompressible Fluid with Variable Physical Properties"," High Temp., vol. 1, no. 1, pp. 69-83, 1963.

[30] A. Colburn, "A Method of Correlating Forced Convection Heat Transfer Data and a Comparison with Fluid Friction," Transaction AIChE, vol. 29, no. 174, 1933.

[31] S. Shuangkai, "MNSR Thermal Hydraulics," China Institute of Atomic Energy, 1993.

[32] The RELAP5-3D Code Development Team, "Athena Code Manual, Vol1, Code Structure, System Models, and Solution Methods," INEEL-EXT-98-00834, 2003.

[33] s. Mirshak, W. Durant and R. Towell, "Heat flux at burnout," AEC Report DP-355, 1959.

[34] W. H. McAdams, W. Kennel, C. Minden and C. P. P. D. J. Rudolph, "Heat Transfer at High Rates to Water with Surface Boiling," Industrial Engineering Chemistry, no. 41, pp. 1945-1953, September 1949. 
[35] M. Siman-Tov, W. R. Gambill, W. R. Nelson and A. E. Y. G. Ruggles, "Thermal-Hydraulic correlations for the advanced neutron source reactor fuel element design and analysis," in Proc. of Symposium on Nuclear Reactor Thermal-Hydraulics-II, ASME Winter Annual Meeting, Atlanta, GA, 1991.

[36] X-5 Monte Carlo Team, "MCNP - A General Monte Carlo N-Particle Transport Code, Version 5," Los Alamos National Laboratory, 2003.

[37] P. J. Roache, in Computational Fluid Dynamics, Albuquerque, NM, Hermosa Publishers, 1972, pp. Section III-A-4.

[38] R. J. Wagner, "IREKIN -- Program for the Numerical Solution of the Reactor Kinetics Equations," IDO-17114, 1966.

[39] S. Churchill and H. Chu, "Correlating Equations for Laminar and Turbulent Free Convection From a Vertical Plate," Int. Journal of Heat and Mass Transfer, no. 18, pp. 1323-1329, 1975.

[40] J. Matos, E. M. Pennington, K. Freese and W. Woodruff, "Safety-Related Benchmark Calculations for MTR-Type Reactors with HEU, MEU and LEU fuels," International Atomic Energy Agency, IAEA-TECDOC-643, Vienna, Austria, 1992.

[41] IAEA, "Research reactor core conversion guidebook Volume 3: Analytical verification," IAEATECDOC-643, Vienna, 1992.

[42] C. Groenveld, J. Q. Shan, A. Z. Vasic, L. Leung, A. Durmayaz, J. Yang, S. Cheng and A. Tanase, "The 2006 CHF Look-up table," Nuclear Engineering and Design, vol. 163, no. 1, 1996. 


\section{Acknowledgements}

Sample problems were created by many individuals. Selected problems became important test cases, which were run and compared with solutions from other calculations. Able assistance from John Stillman, Ed Morris, and Benoit Dionne is greatly appreciated. Abel Marin-Lafleche assisted with updating the format of the equations.

This work was sponsored by the U.S. Department of Energy, Office of Material Management and Minimization in the U.S. National Nuclear Security Administration Office of Defense Nuclear Nonproliferation under Contract DE-AC02-06CH11357. 


\section{Appendix I Units, Constants and Conversion Factors}

In PARET/ANL, the user has the option to specify quantity values in either one of the United States Customary unit system or the international system (SI) of units. Table 11.1lists the quantities used in PARET/ANL in both system of units and conversion factors to apply to convert from one system to the other. Table 11.2 lists the constants defined and used by PARET.

Table 11.1 Conversion table between United States Customary units and SI units

\begin{tabular}{|c|c|c|c|c|}
\hline Quantity & $\begin{array}{l}\text { United States } \\
\text { Customary } \\
\text { Unit }\end{array}$ & SI Unit & Conversion factors & Code Symbol \\
\hline Conductivity & $\mathrm{Btu} /\left(\mathrm{hr} \cdot \mathrm{ft} \cdot{ }^{\circ} \mathrm{F}\right)$ & $\mathrm{W} /(\mathrm{m} \cdot \mathrm{K})$ & $1 \mathrm{Btu} /\left(\mathrm{hr} \cdot \mathrm{ft}^{\circ}{ }^{\circ} \mathrm{F}\right)=1.730735 \mathrm{~W} /(\mathrm{m} \cdot \mathrm{K})$ & CON_K \\
\hline Density & $\mathrm{lb} / \mathrm{ft}^{3}$ & $\mathrm{~kg} / \mathrm{m}^{3}$ & $1 \mathrm{lb} / \mathrm{ft}^{3}=16.01846 \mathrm{~kg} / \mathrm{m}^{3}$ & CON_RHO \\
\hline Energy & Btu & $\mathrm{J}$ & $1 \mathrm{Btu}=1055.056 \mathrm{~J}$ & \\
\hline Enthalpy & $\mathrm{Btu} / \mathrm{lb}$ & $\mathrm{J} / \mathrm{kg}$ & $1 \mathrm{Btu} / \mathrm{lb}=2326.00 \mathrm{~J} / \mathrm{kg}$ & CON_H \\
\hline Heat Flux & $\mathrm{Btu} /\left(\mathrm{hr} \cdot \mathrm{ft}^{2}\right)$ & $\mathrm{W} / \mathrm{m}^{2}$ & $1 \mathrm{Btu} /\left(\mathrm{hr} \cdot \mathrm{ft}^{2}\right)=3.1545906 \mathrm{~W} / \mathrm{m}^{2}$ & CON_Q \\
\hline $\begin{array}{l}\text { Heat Transfer } \\
\text { Coefficient }\end{array}$ & $\mathrm{Btu} /\left(\mathrm{hr} \cdot \mathrm{ft}^{2}{ }^{\circ} \mathrm{F}\right)$ & $\mathrm{W} /\left(\mathrm{m}^{2} \cdot \mathrm{K}\right)$ & $\begin{array}{l}1 \quad \mathrm{Btu} /\left(\mathrm{hr} \cdot \mathrm{ft}^{2}{ }^{\circ} \mathrm{F}\right)=5.678263 \\
\mathrm{~W} /\left(\mathrm{m}^{2} \cdot \mathrm{K}\right)\end{array}$ & CON_HT \\
\hline Length & $\mathrm{ft}$ & $\mathrm{m}$ & $1 \mathrm{ft}=0.3048 \mathrm{~m}$ & CON_L \\
\hline Mass Flow Rate & $\mathrm{lb} /\left(\mathrm{hr} \cdot \mathrm{ft}^{2}\right)$ & $\mathrm{kg} /\left(\mathrm{s} \cdot \mathrm{m}^{2}\right)$ & $1 \mathrm{lb} /\left(\mathrm{hr} \cdot \mathrm{ft}^{2}\right)=1.35623 \cdot 10^{-3} \mathrm{~kg} /\left(\mathrm{s} \cdot \mathrm{m}^{2}\right)$ & CON_MF \\
\hline Power & $\mathrm{Btu} / \mathrm{hr}$ & MW & $1 \mathrm{MW}=3412141.2 \mathrm{Btu} / \mathrm{hr}$ & \\
\hline Pressure & psi & $\mathrm{Pa}$ & $1 \mathrm{psi}=6894.757 \mathrm{~Pa}$ & CON_P \\
\hline $\begin{array}{l}\text { Specific } \\
\text { volume }\end{array}$ & $\mathrm{ft}^{3} / \mathrm{lbm}$ & $\mathrm{m}^{3} / \mathrm{kg}$ & $1 \mathrm{ft}^{3} / \mathrm{lbm}=6.242797 \cdot 10^{-2} \mathrm{~m}^{3} / \mathrm{kg}$ & CON_V \\
\hline Viscosity & $\mathrm{lb} /(\mathrm{ft} \cdot \mathrm{hr})$ & $\mathrm{Pa} \cdot \mathrm{s}$ & $1 \mathrm{lb} /(\mathrm{ft} \cdot \mathrm{hr})=4.133789 \cdot 10^{-4} \mathrm{~Pa} \cdot \mathrm{s}$ & CON_VIS \\
\hline $\begin{array}{l}\text { Volumetric } \\
\text { Heat Capacity } \\
\left(\rho C_{p}\right)\end{array}$ & $\mathrm{Btu} /\left(\mathrm{ft}^{3} \cdot{ }^{\circ} \mathrm{F}\right)$ & $\mathrm{J} /\left(\mathrm{m}^{3} \cdot \mathrm{K}\right)$ & $\begin{array}{l}1 \quad \mathrm{Btu} /\left(\mathrm{ft}^{3} \cdot{ }^{\circ} \mathrm{F}\right) \\
6.706611 \cdot 10^{4} \mathrm{~J} /\left(\mathrm{m}^{3} \cdot \mathrm{K}\right)\end{array}$ & CON_RCP \\
\hline Specific Heat & $\mathrm{Btu} /\left(\mathrm{lb}^{\circ} \mathrm{F}\right)$ & $\mathrm{J} /(\mathrm{kg} \cdot \mathrm{K})$ & $1 \mathrm{Btu} /\left(\mathrm{lb} \cdot{ }^{\circ} \mathrm{F}\right)=4186.80 \mathrm{~J} /(\mathrm{kg} \cdot \mathrm{K})$ & $1.8 * \mathrm{CON} \_\mathrm{H}$ \\
\hline
\end{tabular}

Table 11.2 Constants defined and used by PARET/ANL

\begin{tabular}{|l|l|}
\hline Quantity & Value \\
\hline Gravitational constant & $\mathrm{G}=9.80665 \mathrm{~m} / \mathrm{s}^{2}$ \\
\hline
\end{tabular}




\section{Appendix II Empirical Correlations}

Several empirical correlations for the heat transfer at the clad-coolant interface are implemented in PARET/ANL. Table 12.1 lists which correlations are available for each coolant regime. The remainder of this appendix defines the empirical correlations.

Table 12.1 Heat Transfer Phenomena for the PARET/ANL options

\begin{tabular}{|l|l|l|}
\hline $\begin{array}{l}\text { Mode } \\
\text { Number } \\
\text { IBOIL) }\end{array}$ & Heat Transfer Phenomena & Correlations \\
\hline 0 & Single-phase liquid, no boiling & $\begin{array}{l}\text { Dittus-Boelter [27], Petukhov [29], } \\
\text { Sieder-Tate [28], Colburn [30], } \\
\text { Russian [undocumented], CIAE [31], } \\
\text { ANL-modified Dittus-Boelter }\end{array}$ \\
\hline 1 & Nucleate boiling & Jens-Lottes [14], McAdams [34] \\
\hline 2 & Transition boiling & Dittus-Boelter [16] \\
\hline 3 & Film boiling & \\
\hline 4 & Bulk boiling & \\
\hline-1 & Pure vapor & \\
\hline & & \\
\hline
\end{tabular}

\section{SINGLE-PHASE Liquid Heat Flux Correlations}

The first item on card 1112 (IONEP, see Section 5.4) determines the heat transfer correlation at the clad-coolant interface when the coolant is in single phase liquid regime. In the following relationships

- $\quad$ Re is the Reynolds number

- Pr is the Prandtl number

- $\mathrm{L}$ is the characteristic length of the channel

- De is the hydraulic diameter

- $\mathrm{Nu}$ is the Nusselt number

- $\mathrm{h}$ is the heat transfer coefficient

- $\mathrm{k}$ is the thermal conductivity of the fluid

The relationship between the Nusselt number and the heat transfer coefficient is

$$
\mathrm{Nu}=\frac{h L}{k}
$$

Dittus Boelter [27]

The Dittus-Boelter equation for the Nusselt number is: 


$$
\mathrm{Nu}=0.023 \operatorname{Re}^{0.8} \operatorname{Pr}^{0.4}
$$

This relationship is valid as long as

- $\quad 0.7<\operatorname{Pr}<160$ (i.e. valid for water at any temperature or pressure)

- $\mathrm{L} / \mathrm{D}>60$, where $\mathrm{D}$ is the outer diameter of the pin

- $\operatorname{Re}>6000$

\section{Dittus-Boelter Modified by ANL [27]}

The modified Dittus-Boelter equation for the Nusselt number is:

$$
\mathrm{Nu}=0.023 \operatorname{Re}^{0.8} \operatorname{Pr}^{0.4}\left(\frac{\mu_{b}}{\mu_{w}}\right)^{0.11}
$$

This relationship is valid as long as

- $\quad 0.7<\operatorname{Pr}<160$ (i.e. valid for water at any temperature or pressure)

- $\mathrm{L} / \mathrm{D}>60$, where $\mathrm{D}$ is the outer diameter of the pin

- $\operatorname{Re}>6000$

\section{Sieder-Tate [28]}

The Sieder-Tate Eq. for the Nusselt number is

$$
\mathrm{Nu}=0.027 \operatorname{Re}^{0.8} \operatorname{Pr}^{1 / 3}\left(\frac{\mu_{b}}{\mu_{w}}\right)^{0.14}
$$

This relationship is valid as long as

- $\mathrm{L} / \mathrm{D}>60$, where $\mathrm{D}$ is the outer diameter of the plate

- $\operatorname{Re}>10000$

\section{Petukhov \& Popov [29] AND [37]}

The Darcy friction factor $f_{D}$ of a rectangular channel or an annulus is approximated as

$$
f_{D}=\frac{1.0875-0.1125\left(\frac{b}{s}\right)}{(1.82 \log \operatorname{Re}-1.64)^{2}}
$$

where

$\mathrm{b}$ is the gap of a rectangular channel or annulus (in $\mathrm{m}$ )

$\mathrm{s}$ is the span of the channel (in $\mathrm{m}$ )

The numerator term, 1.0875-0.1125(b/s), is a correction term accounting for the rectangular shape. This factor should be 1.0 for a round tube.

Then the forced-convection heat transfer coefficient is:

$$
h_{\mathrm{FC}}=\frac{\frac{k_{b}}{\mathrm{De}} \frac{f_{D}}{8} \operatorname{Re} \operatorname{Pr}\left(\frac{\mu_{b}}{\mu_{w}}\right)^{0.11}}{\left(1+3.4 f_{D}\right)+\left(11.7+\frac{1.8}{\operatorname{Pr}^{1 / 3}}\right)\left(\frac{f_{D}}{8}\right)^{\frac{1}{2}}\left(\operatorname{Pr}^{2 / 3}-1.0\right)}
$$

where 
$\mu_{b}$ and $\mu_{w}$ are liquid kinematic viscosities, $\left(\mathrm{m}^{2} / \mathrm{s}\right)$, for the bulk coolant and for the coolant at the wall temperature

$k_{b}$ is the coolant conductivity, $\mathrm{w} / \mathrm{m} \mathrm{K}$

De is hydraulic diameter, $\mathrm{m}$

subscript b refers to bulk coolant

subscript w refers to coolant at the wall temperature

Practical Range and Conditions

Single-phase, fully developed, turbulent flow

Water + various other fluids

Friction factor corrected for rectangular channels

Corrected for temperature-dependent viscosity

Accuracy is $1 \%$ for Re from 1E4 to 5E5 and Pr from 0.5 to $200 ; 1-2 \%$ for Re from 5E5 to $5 E 6$ and Pr from $200-2000$

Range for variable physical properties correction is $\mu_{\mathrm{w}} / \mu_{\mathrm{b}}=0.08$ to 40 , Re from $1 \mathrm{E} 4$ to $1.25 \mathrm{E} 5$, and Pr from 2-140.

The resulting heat transfer coefficient is valid away from entrance effects.

Based on the Petukhov-Popov correlation, Gnielinski proposed a similar correlation that is valid down to the laminar flow transition at $\mathrm{Re}=2300$. It is not yet available in PARET. The Gnielinski correlation is:

(V. Gnielinski, New equations for heat and mass transfer in turbulent pipe and channel flow. Int. Chemical Engineering, 16:359-368, 1976)

$$
\mathrm{H}=(\mathrm{f} / 8)(\operatorname{Re}-1000) \mathrm{Pr} /\left[1+12.7\left(\mathrm{f}_{\mathrm{D}} / 8\right)^{1 / 2}\left(\mathrm{Pr}^{2 / 3}-1.0\right)\right]
$$

It is valid for Re from 2300 to $5 \cdot 10^{6}$.

\section{Russian}

The "Russian" equation for the Nusselt number is

$$
\mathrm{Nu}=0.021 \operatorname{Re}^{0.8} \operatorname{Pr}^{0.43}\left(\frac{\mu_{b}}{\mu_{w}}\right)^{0.25}
$$

\section{Colburn [32]}

The Colburn equation for the Nusselt number is

$$
\mathrm{Nu}=0.023 \operatorname{Re}^{0.8} \operatorname{Pr}^{0.3}
$$

This Eq. uses Tfilm $=($ Tsurf + Tbulk $) / 2$ when obtaining fluid properties.

It is valid for fully developed turbulent flow.

\section{CIAE [33]}

The CIAE equation for the Nusselt number is 


$$
\begin{cases}\mathrm{Nu}=0.68(\mathrm{Gr} \cdot \mathrm{Pr})^{1 / 4} & , \text { when } \mathrm{Gr} \cdot \operatorname{Pr}<6 \cdot 10^{6} \\ \mathrm{Nu}=0.174(\mathrm{Gr} \cdot \operatorname{Pr})^{1 / 3} & \text {, when } \mathrm{Gr} \cdot \operatorname{Pr} \geq 6 \cdot 10^{6}\end{cases}
$$

This equation is valid for $\operatorname{Re}<2300$

\section{Churchill-Chu Correlation [41]}

(for vertical fluid flow under natural convection for flat plates and cylinders)

Given $\mathrm{Ra}=$ Rayleigh number, Gr x Pr

Pr $=$ Prandtl number

$\mathrm{Gr}=$ Grashof number

$$
\mathrm{Gr}_{\mathrm{L}}=\mathrm{g} \beta\left(\mathrm{T}_{\mathrm{w}}-\mathrm{T}_{\mathrm{b}}\right) \mathrm{L}^{3} / v^{2} \quad \text { for vertical flat plates }
$$

where:

$g$ is acceleration due to Earth's gravity

$\beta$ is the coefficient of thermal expansion

$L$ is the vertical length or natural convection length

$v$ is the kinematic viscosity

$\mathrm{T}_{\mathrm{w}}$ is the wall temperature

$\mathrm{T}_{\mathrm{b}}$ is the bulk temperature

$\mathrm{Cp}=$ fluid specific heat at constant pressure

$\mathrm{k}=$ thermal conductivity

$\rho=$ fluid density

Define the following four terms:

term $1=0.825 ;$ term $2=0.387(\mathrm{Ra})^{1 / 6}$; term $3=\left[1+(0.492 / \mathrm{Pr})^{9 / 16}\right.$

$$
\text { term } 4=(\text { term } 3)^{8 / 27}
$$

Then $\mathrm{Nu}=[\text { term } 1+\text { term } 2 / \text { term } 4]^{2}$

There are no restrictions on use of this correlation for flat plates. For vertical cylinders, it applies when D/L $\geq 35 / \mathrm{Gr}^{1 / 4}$.

\section{CHEN CORRELATION [43]}

This correlation is used for saturated nucleate boiling. It contains a macroscopic convection term and a microscopic boiling term:

Heat flux q" $=\mathrm{h}_{\operatorname{mac}}(\mathrm{Tw}-\mathrm{Tspt}) \mathrm{F}+\mathrm{h}_{\text {mic }}(\mathrm{Tw}-\mathrm{Tspt}) \mathrm{S}$

$\mathrm{F}$ is a Reynolds number factor for the convective term $\mathrm{h}_{\mathrm{mac}}$

$\mathrm{S}$ is a suppression factor for the boiling part.

$\mathrm{h}_{\text {mac }}$ is obtained from the Dittus-Boelter correlation 
$\mathrm{h}_{\text {mic }}$ is obtained from the Forster-Zuber equation:

$$
\mathrm{h}_{\text {mic }}=0.00122[\mathrm{~A} / \mathrm{B}](\Delta \mathrm{Tw})^{0.24} \Delta \mathrm{P}^{0.75}
$$

where $\mathrm{A}=\mathrm{k}^{0.79}(\mathrm{Cp})^{0.45} \rho^{0.49}$

and $\mathrm{B}=\sigma^{0.5} \mu_{\mathrm{f}}^{0.29} \mathrm{~h}_{\mathrm{fg}} 0.24\left(\rho_{\mathrm{g}}\right)^{0.24}$

Note that subscript $\mathrm{w}$ denotes wall, $\mathrm{f}$ denotes liquid, and g means vapor/gas. Tspt is vapor saturation temperature based on total pressure. The pressure based on wall temperature minus total pressure defines $\Delta \mathrm{P}$.

\section{TWO-PHASE NUCLEATE BOILING HEAT FLUX CORRELATIONS}

The second item on card 1112 (ITWOP, see Section 5.4) determines the two phase nucleate boiling correlation for the heat transfer at the clad coolant interface.

\section{Original Jens-Lottes [16]}

$$
\left(q_{\mathrm{NB}}^{\prime \prime}\right)^{m+1}=\left(q_{\mathrm{NB}}^{\prime \prime}\right)^{m}\left[1+\frac{4\left(u_{s}^{m+1}-u_{s}^{\prime m}\right)}{u_{s}^{\prime m}-u_{\mathrm{sat}}}\right]
$$

where the superscript $\mathrm{m}$, refers to the $\mathrm{m}^{\text {th }}$ time node This boundary condition is based on the Jens-Lottes correlation [14]

$$
u_{s}^{\prime}=u_{\text {sat }}+60 \exp \left(-\frac{p}{900}\right)\left(\frac{q^{\prime \prime}}{10^{6}}\right)^{\frac{1}{4}}
$$

McAdams [34]

$$
q^{\prime \prime}=0.074\left(T_{w}-T_{\text {sat }}\right)^{3.86}
$$

Quantities are in United States Customary units (q" in BTU $/ \mathrm{hr} / \mathrm{ft}^{2}$. and temperatures in ${ }^{\circ} \mathrm{F}$ ).

This correlation is valid for 2.06 - 6.21 Bar (30 - 90 psia), velocities from $0.3-11 \mathrm{~m} / \mathrm{s}(1-36 \mathrm{ft} / \mathrm{s}$ ), equivalent hydraulic diameter from 4.3 - $13.2 \mathrm{~mm}$ (0.17 - $0.52 \mathrm{in}$.), and subcooling from $11.1-83.3 \mathrm{C}$ $\left(20-150^{\circ} \mathrm{F}\right)$. The constant 0.074 varies with the extent of degassing of the water. It was found to be 0.074 at $0.06 \mathrm{ml}$ of air at standard conditions per liter of water.

\section{Critical Heat Flux and flow instability Correlations}

The fourth item on card 1112 (ICHF, see Section 5.4) determines the critical heat flux correlations used by PARET. In the following relationships

- $\mathrm{q}_{\mathrm{c}}$ is the critical heat flux in $\mathrm{MW} / \mathrm{m}^{2}$

\section{ICHF=0: Original DNB}

\section{ICHF=1: Bernath DNB [9]}

The Bernath equation is 


$$
q_{c}=h_{c}\left[\left(T_{w}\right)_{c}-\left(T_{b}\right)_{c}\right]
$$

where

$$
\begin{gathered}
h_{c}=\frac{0.067 D}{D+\frac{\xi}{\pi}}+0.65 \times 10^{-4} \frac{U}{D^{0.6}} \\
\left(T_{w}\right)_{c}=57 \ln (14.5 P)-\frac{54 P}{P+1.034214}-\frac{U}{1.2192}
\end{gathered}
$$

$\mathrm{hc}$ is the (critical) heat transfer coefficient at burnout $\left(\mathrm{MW} / \mathrm{m}^{2} / \mathrm{C}\right)$

$\left(\mathrm{T}_{\mathrm{w}}\right)_{\mathrm{c}}$ is the (critical) wall temperature $\left({ }^{\circ} \mathrm{C}\right.$ )

$\left(\mathrm{T}_{\mathrm{b}}\right)_{\mathrm{c}}$ is the (critical) bulk coolant temperature $\left({ }^{\circ} \mathrm{C}\right.$ )

$D$ is the hydraulic diameter, $m$

$\xi$ is the heated perimeter, $\mathrm{m}$

$\mathrm{U}$ is the coolant velocity, $\mathrm{m} / \mathrm{s}$

$\mathrm{P}$ is the absolute pressure (bar)

This correlation is valid for $0<\mathrm{V} \leq 54 \mathrm{ft} / \mathrm{s} ; 23<\mathrm{P}<3000$ psia; $0.143<\mathrm{D}<0.66$ in

\section{ICHF=2: Mirshak-Durant-Towell [[DNB [33]}

The Mirshak-Durant-Towell equation is

$$
q_{c}=1.51(1+0.1198 U)\left(1+0.00914 \Delta T_{\text {sub }}\right)(1+0.19 P)
$$

where

$\Delta T_{\text {sub }}$ is the subcooling at the channel exit (C)

$U$ is the coolant velocity, $\mathrm{m} / \mathrm{s}$

$P$ is the absolute pressure (bar) at the channel exit

This correlation is valid for downflow and

$1.5 \mathrm{~m} / \mathrm{s}<\mathrm{U}<13.7 \mathrm{~m} / \mathrm{s}$

$5^{\circ} \mathrm{C}<\Delta \mathrm{T}_{\text {sub }}<75^{\circ} \mathrm{C}$

1.72 bar $<\mathrm{P}<5.86$ bar

$2.84<\mathrm{q}_{\mathrm{c}}<10.22 \mathrm{Mw} / \mathrm{m}^{2}$

Fitting error $\pm 16 \%$, Standard deviation $8 \%$, Downward flow, Based on 65 tests.

ICHF=3: FORGAN \& WHITTLE FIR

ICHF=4: CEA FIR

ICHF=5: LUND DNB (CYLINDRICAL PINS)

ICHF=6: LUND DNB (CYLINDRICAL PINS

ICHF=7: GROENEVELD 2006 CHF LOOKUP TABLE 


\section{Comment on "ATHENA" Options}

ORNL created special heat transfer options for the RELAP code to use for the design of the Advanced Neutron Source Reactor (ANSR). The geometry of the coolant channel in the ANSR has an aspect ratio of about 68 in the inner fuel annulus and 55 in the outer fuel annulus. The heavy water coolant flow velocity is very high: $27.4 \mathrm{~m} / \mathrm{s}$. The inlet and outlet pressures are 3.7 and $1.9 \mathrm{MPa}$, respectively. The average and peak heat fluxes are 6.1 and $16.6 \mathrm{MW} / \mathrm{m}^{2}$. The stated range and conditions for CHF or Departure from Nucleate Boiling are [35]:

- $\quad$ subcooled water or heavy water

- $\quad \mathrm{Al}$ or SS, tubes, annular or rectangular channels

- $\quad$ pressure of $0.1-8.4 \mathrm{MPa}$

- mass flux of $1.2-67.7 \mathrm{Mg} / \mathrm{m}^{2} \mathrm{~s}$

- velocity of $1.1-61.9 \mathrm{~m} / \mathrm{s}$

- subcooling of $0.6-170.4 \mathrm{C}$

- heat flux of $3.2-130 \mathrm{MW} / \mathrm{m}^{2}$

- equivalent hydraulic dia. of 2.1 - $25.4 \mathrm{~mm}$

- $\quad$ L/D ratio of 6.56 - 191.0

For Turbulent Forced Convection, the stated range and conditions are:

- $\quad$ single-phase, fully developed, turbulent flow

- various fluids, including water

- friction factor corrected for rectangular channels

- corrected for variable properties

The accuracy of original correlation is

- $1 \%$ for Re of 10,000 to 500,000 and Pr $0.5-200$

- $1-2 \%$ for Re 500,000 to 5,000,000 and Pr $200-2000$

The range for variable physical properties is: $\mu_{\mathrm{w}} / \mu_{\mathrm{b}}=0.08$ to $40, \operatorname{Re} 10,000$ to 125,000 and $\operatorname{Pr}=2$ 140.

For Laminar Flow, the ANS option is made available by IMODE=2 or 3. It uses $\mathrm{Nu}=7.63$ instead of 4.36 from the Sellars Correlation [50]. The Sellars correlation is for fully developed laminar flow in a tube with a uniform wall heat flux and constant thermal properties. It is an exact solution. It is an option made available by IMODE= 4 or 5 .

For Natural Convection, the ANS option uses the Elenbaas [47] correlation instead of correlations by Churchill-Chu [41] or by McAdams. For subcooled and saturated nucleate boiling, the Athena options use the Chen [43] correlation. For subcooled and for saturated film boiling, the Bromley [46] correlation could be used but is not yet implemented. For film condensation in turbulent flow, the Shah [51] correlation is used. 


\section{Churchill-Chu Correlation}

(for vertical fluid flow under natural convection)

Given $\mathrm{Ra}=$ Rayleigh number, $\mathrm{Gr} \times \mathrm{Pr}$

$\operatorname{Pr}=$ Prandtl number

$\mathrm{Gr}=$ Grashof number

$\mathrm{M}=$ fluid viscosity

$\mathrm{Cp}=$ fluid specific heat at constant pressure

$\mathrm{k}=$ thermal conductivity

$\rho=$ fluid density

$\beta=$ coefficient of thermal expansion

$\mathrm{g}=$ gravitational constant

$\mathrm{L}=$ natural convection length

$\mathrm{Tw}=$ wall temperature

$\mathrm{Tb}=$ bulk temperature

Define the following four terms:

term $1=0.825$; term $2=0.387(\mathrm{Ra})^{1 / 6}$; term $3=\left[1+(0.492 / \mathrm{Pr})^{9 / 16}\right.$ term $4=(\text { term } 3)^{8 / 27}$

Then $\mathrm{Nu}=[\text { term } 1+\text { term } 2 / \text { term } 4]^{2}$

\section{Chen Correlation [43]}

This correlation is used for subcooled nucleate boiling and for saturated nucleate boiling. It contains a macroscopic convection term and a microscopic boiling term:

Heat flux q" $=h_{\text {mac }}(T w-T s p t) F+h_{\text {mic }}(T w-T s p t) S$

$\mathrm{S}$ is a suppression factor for the boiling part.

$$
\begin{array}{ll}
S=\left(1+0.12 \operatorname{Re}_{\mathrm{tp}}{ }^{1.14}\right)^{-1} & \mathrm{Re}_{\mathrm{tp}}<32.5 \\
\mathrm{~S}=\left(1+0.42 \operatorname{Re}_{\mathrm{tp}} 0.8\right)^{-1} & 32.5 \leq \operatorname{Re}_{\mathrm{tp}}<70 \\
\mathrm{~S}=0.0797 & \operatorname{Re}_{\mathrm{tp}} \geq 70
\end{array}
$$

Where

$$
\begin{aligned}
& \operatorname{Re}_{t p}=\operatorname{Min}\left[70,10^{-4} \operatorname{Re}_{\mathrm{f}} F^{1.25}\right] \\
& \operatorname{Re}_{\mathrm{f}}=\mathrm{G}_{\mathrm{f}} \mathrm{D} / \mu_{\mathrm{f}} \\
& \mathrm{G}_{\mathrm{f}}=\text { mass flux of liquid } \\
& \mathrm{F}=2.35\left(\chi \mathrm{tt}^{-1}+0.213\right)^{0.736} ; \text { note that if } \mathrm{F}<0.1 \text {, it is set to } 1.0 . \\
& \chi \mathrm{tt}^{-1}=\left(\mathrm{G}_{\mathrm{g}} / \mathrm{G}_{\mathrm{f}}\right) 0.9\left(\rho_{\mathrm{f}} / \rho_{\mathrm{g}}\right) 0.5\left(\mu_{\mathrm{g}} / \mu_{\mathrm{f}}\right) 0.1 \text {; note that } \chi \mathrm{tt}^{-1} \text { is limited to } 100 .
\end{aligned}
$$

Subscript $\mathrm{g}$ is gas (vapor) and $\mathrm{f}$ is liquid. 
$\mathrm{h}_{\text {mac }}$ is obtained from the Dittus-Boelter correlation.

$\mathrm{h}_{\text {mic }}$ is obtained from the Forster-Zuber equation:

$$
\mathrm{h}_{\text {mic }}=0.00122[\mathrm{~A} / \mathrm{B}](\Delta \mathrm{Tw})^{0.24} \Delta \mathrm{P}^{0.75}
$$

where $\mathrm{A}=\mathrm{k}^{0.79} \mathrm{Cp}^{0.45} \rho^{0.49}$

and $\mathrm{B}=\sigma^{0.5} \mu_{\mathrm{f}}^{0.29} \mathrm{~h}_{\mathrm{fg}}{ }^{0.24}\left(\rho_{\mathrm{g}}\right)^{0.24}$

\section{Chen Transition Boiling Model}

This model accounts for wall heat transfer to the liquid, and a second term describing the wall heat transfer to the vapor/gas. Radiative heat transfer from wall to fluid is not explicitly included, because it is estimated to be less than $10 \%$ and is lumped into the given two components.

$$
\mathrm{q}_{\mathrm{tb}}=\mathrm{q}_{\mathrm{wf}} A_{\mathrm{f}}+\mathrm{hw}_{\mathrm{gg}}\left(\mathrm{T}_{\mathrm{w}}-\mathrm{T}_{\mathrm{g}}\right)\left(1-\mathrm{A}_{\mathrm{f}}\right)
$$

Where

$\mathrm{q}_{\mathrm{tb}}=$ transition boiling heat flux

$A_{f}=$ fractional wall wetted area

$\mathrm{h}_{\mathrm{wgg}}=$ heat transfer coefficient from the wall to vapor/gas, using Dittus-Boelter

$\mathrm{A}_{\mathrm{f}}$ is obtained from an empirical correlation:

$\mathrm{A}_{\mathrm{f}}=\operatorname{Exp}\left[-\lambda\left(\mathrm{T}_{\mathrm{w}}-\mathrm{T}_{\mathrm{spt}}\right)^{0.5}\right]$

$\lambda=\operatorname{Max}\left[\lambda_{1}, \lambda_{2}\right]$

$\lambda_{1}=\mathrm{C}_{1}-\mathrm{C}_{2} \mathrm{G} / 10^{5}$

$$
\lambda_{2}=\mathrm{C}_{3} \mathrm{G} / 10^{5}
$$$$
\mathrm{C}_{1}=2.4 \mathrm{C}_{2}
$$

$\mathrm{C}_{2}=0.05 /\left(1-\alpha_{\mathrm{g}}{ }^{40}\right)+0.075 \alpha_{\mathrm{g}} ; \alpha_{\mathrm{g}}$ is vapor/gas volume; a limit is applied for numerical stability that $\alpha_{\mathrm{g}}=\operatorname{Min}\left[\alpha_{\mathrm{g}}, 0.99\right]$ when evaluating constant $\mathrm{C}_{2}$.

$$
\mathrm{C}_{3}=0.2 \mathrm{C}_{2}
$$

Note that $\mathrm{f}$ denotes liquid, and $\mathrm{g}$ denotes vapor/gas. $\mathrm{T}_{\mathrm{spt}}$ is vapor saturation temperature based on total pressure. The pressure based on wall temperature minus total pressure defines $\Delta \mathrm{P}$.

\section{Sha Correlation [51]}

This correlation is used for film condensation in turbulent flow.

$$
\mathrm{h}_{\text {Shah }}=\mathrm{h}_{\mathrm{sf}}\left[1+3.8 \mathrm{Z}^{-0.95}\right]
$$

where

$\mathrm{Z}=\left[\mathrm{X}^{-1}-1\right]^{0.8} \mathrm{P}_{\mathrm{red}}{ }^{0.4}$

$\mathrm{X}=$ static quality

$\mathrm{h}_{\mathrm{sf}}=$ superficial heat transfer coefficient $=\mathrm{h}_{1}(1-\mathrm{X})^{0.8}$ 
$\mathrm{h}_{1}=$ Dittus-Boelter heat transfer coefficient assuming all fluid is liquid

$$
=0.023\left(\mathrm{k} / \mathrm{D}_{\mathrm{h}}\right) \operatorname{Re}_{1}{ }^{0.8} \operatorname{Pr}^{0.4}
$$

$\mathrm{P}_{\text {red }}=$ reduced bulk pressure, $\mathrm{P} / \mathrm{P}_{\text {critical; }}$ where the critical pressure is $22.064 \mathrm{MPa}$ for light water, and $21.671 \mathrm{MPa}$ for heavy water

$\operatorname{Re}_{1}=\mathrm{G}_{\mathrm{total}} \mathrm{D}_{\mathrm{h}} / \mu_{\mathrm{f}}$

$\mathrm{D}_{\mathrm{h}}$ is hydraulic diameter

$\mu_{\mathrm{f}}=$ viscosity of fluid

Subscript $\mathrm{f}$ is fluid

$\mathrm{G}_{\mathrm{total}}$ is total mass flux.

There is a second correlation based on laminar flow for condensation from Nusselt [52].

$$
\mathrm{h}_{\text {Nusselt }}=\mathrm{k}_{\mathrm{f}} / \delta
$$

where the film thickness is $\delta=\left[3 \mu_{\mathrm{f}} \Gamma /\left(g \rho_{\mathrm{f}}\left(\rho_{\mathrm{f}}-\rho_{\mathrm{g}}\right)\right]^{1 / 3}\right.$

The final value used is the $\operatorname{Max}\left[\mathrm{h}_{\text {Shah }}, \mathrm{h}_{\text {Nusselt }}=\mathrm{k}_{\mathrm{f}} / \delta\right]$

\section{Flow instability}

The flow instability ratios (ICHF $=3$ and 4 ) are defined as follows:

$$
\begin{aligned}
& \mathbf{F I R}=\mathbf{q}_{\mathbf{F I}} / \overline{\mathbf{q}} \\
& \mathbf{q}_{\mathbf{F I}}=\mathbf{R} \frac{\rho \mathbf{C} \mathbf{p}}{4} \frac{\mathbf{D}_{\mathbf{H}}}{\mathbf{L}_{\mathbf{H}}} \mathbf{v}\left(\mathbf{T}_{\text {sat }}-\mathbf{T}_{\mathrm{in}}\right) \\
& \overline{\mathbf{q}}=\text { Average heat flux at normal steady-state power (QAVE) with } \\
& \text { peaking factors if the hot channel modeled. }
\end{aligned}
$$

- $\quad \mathrm{ICHF}=3$

$$
\mathbf{R}=\frac{1}{1+\eta \frac{\mathbf{D}_{H}}{L_{H}}}
$$

- $\quad \mathrm{ICHF}=4$

$$
\begin{aligned}
& R=\frac{1}{1+3.15(M F R)^{0.29} \frac{\text { De }}{L_{H}}} \\
& \rho \quad=\quad \text { Density of the coolant }\left[\mathrm{g} / \mathrm{cm}^{3}\right] \\
& \mathbf{C p}=\text { Specific heat of coolant }(\mathrm{CP})\left[\mathrm{J} / \mathrm{g}{ }^{\circ} \mathrm{C}\right] \\
& \mathbf{D}_{\mathbf{H}}=\text { Equivalent heated diameter }[\mathrm{cm}] \\
& \mathbf{L}_{\mathbf{H}} \quad=\quad \text { Heated length }[\mathrm{cm}] \\
& \mathbf{v}=\text { Coolant flow-velocity }[\mathrm{cm} / \mathrm{s}]
\end{aligned}
$$




$$
\begin{array}{lll}
\mathbf{T}_{\text {sat }} & = & \text { Saturation temperature }\left[{ }^{\circ} \mathrm{C}\right] \\
\mathbf{T}_{\text {in }} & = & \text { Inlet temperature }\left[{ }^{\circ} \mathrm{C}\right] \\
\mathbf{\eta} & = & \text { Bubble detachment parameter }(\mathrm{ETA})\left[\frac{\mathbf{c m}^{3}{ }^{\circ} \mathbf{C}}{\mathbf{J}}\right] \\
\mathbf{D e} & = & \text { Equivalent hydraulic wetted diameter }[\mathrm{cm}] \\
\mathbf{M F R} & = & \text { Absolute Value of Mass Flux }\left[\mathrm{g} / \mathrm{cm}^{2} \mathrm{~s}\right]
\end{array}
$$

This form of the average heat flux at the onset of flow instability, $\mathrm{q}_{\mathrm{FI}}$, assumes that $\eta$ is a minimum at the channel exit, and that the heat flux at the channel exit is representative of this average heat flux.

Table 12.2 Heat Transfer Phenomena for the ATHENA (RELAP) Options

\begin{tabular}{|l|l|l|}
\hline $\begin{array}{l}\text { Mode } \\
\text { (JHT) })\end{array}$ & Heat transfer phenomena & Correlations \\
\hline 0 & Noncondensable-vapor-liquid & $\begin{array}{l}\text { Dittus-Boelter[21], } \\
\text { Petukhov [23] } \\
\text { Churchill-Chu [41] } \\
\text { Elenbaas [44] }\end{array}$ \\
\hline 1 & $\begin{array}{l}\text { Single-phase liquid or } \\
\text { subcooled wall with void fraction }<0.1\end{array}$ & Same as mode 0 \\
\hline 2 & Single-phase liquid or & Churchill-Chu [41] \\
\hline 3 & Subcooled wall with void fraction $<0.1$ & Chen [43] \\
\hline 4 & Saturated nucleate boiling & Same as mode 3 \\
\hline 5 & Subcooled transition boiling & Chen-Sundaram-Ozkaynak [45] \\
\hline 6 & Saturated transition boiling & Same as mode 5 \\
\hline 7 & Subcooled film boiling & Bromley [46] \\
\hline 8 & Saturated film boiling & Same as mode 7 \\
\hline 9 & Single-phase vapor & Same as mode 0 \\
\hline 10 & Filmwise condensation with void fraction $<1.0$ & Shah [51] \\
\hline 11 & Condensation in vapor with void fraction $=1.0$ & Same as mode 10 \\
\hline 12 & Nucleate boiling & Samodes 3, 4 \\
\hline
\end{tabular}




\section{Appendix III 10 MW IAEA Benchmark Reactor HEU Model}

The purpose of this appendix is to clarify the meaning of some PARET/ANL input parameters. Input preparation for a typical PARET/ANL problem is discussed. A listing of input cards is provided along with a portion of the output.

The excursion model is a benchmark calculation of a reactivity insertion transient in an idealized, light-water, pool-type reactor [38, 42]. The transient is initiated by a linear ramp insertion of $1.5 \$$ excess reactivity in 0.5 seconds at an operating pressure of $1.7 \mathrm{bar}$, an initial power of $1 \mathrm{~W}$, an initial temperature of $38^{\circ} \mathrm{C}$ and a flow rate of $1000 \mathrm{~m}^{3} / \mathrm{hr}$.

\section{Preparation of input}

The input data entered into PARET/ANL for the analysis under discussion follows. The complete input file is shown in Figure 13.1.

General Information (1000-series CARDS)

1. The core is modeled with two channels (physical regions containing fuel meat, clad, and coolant), with one channel representing the hottest (highest power density) channel and the other channel representing the remainder of the active core. The number NCHN entered is negative because the quantity entered on the remainder of the input will be given in SI units if it is negative, or interpreted as in U.S. Customary units if positive.

2. There are 22 axial interfaces. The plate is divided into 21 axial zones.

3. There are 7 radial interfaces. The plate is divided into 6 radial zones.

4. The geometry code is 0 because the reactor contains plate-type fuel.

5. The operation code is 1 . This is a reactivity-specified transient (1.5\$ ramp insertion).

6. For the vapor fraction and quality option, option 1 was chosen. This allows the code to calculate values of vapor fraction and quality in both the subcooled and saturated regions.

7. Coolant pressure code. The 0 option is chosen since the pressure is to be specified at the inlet.

8. Kinetics time step parameter. Option 0 was chosen. The time step is reduced, when necessary, for the neutron kinetics calculation and then expanded to the input-specified or hydrodynamics-specified time-step, whichever controls.

9. The number of delayed neutron groups is six.

10. The print frequency. Since detailed printout was desired at the end of every time step, a - 1 is appropriate here.

11. Average temperature printout option. Since no printout of average temperature was desired, a zero was entered here.

12. The maximum number of heat transfer code iterations. A value of 10 was selected. From experience, it is rare to need more than 10 .

13. Initial reactor power. This transient is to be initiated from a power of 10-6 $\mathrm{MW}$.

14. Total volume of fuel meat in the core. The core contains $10.62214 \mathrm{E}-3 \mathrm{~m}^{3}$ of fuel meat.

15. Operating pressure is $1.7 \mathrm{bar}$. 
16. Enthalpy of inlet coolant. At 1.7 bar and $38^{\circ} \mathrm{C}$, the enthalpy of water is $1.58650 \mathrm{E}+5 \mathrm{~J} / \mathrm{kg}$.

17. Plate half-thickness is $0.635 \mathrm{~mm}$.

18. Fuel meat half-thickness is $0.255 \mathrm{~mm}$.

19. Half-distance to inner surface of clad. This is the same as item 18 , since there is no intermediate region between the fuel and clad.

20. Fuel plate width is $6.65 \mathrm{~cm}$.

21. Active fuel width is $6.30 \mathrm{~cm}$.

22. Active fuel length is $60 \mathrm{~cm}$.

23. Inlet non-fueled Section length. There is no inlet non-fueled Section in this model.

24. Outlet non-fueled Section length. Same as item 23.

25. Effective delayed neutron fraction is 0.0076071 .

26. Prompt neutron generation time is $5.5960 \mathrm{E}-5 \mathrm{~s}$.

27. Acceleration of gravity.

28. Heat source description for coolant. In specifying this parameter, it was assumed that $4.5 \%$ of the energy generated in the fuel is deposited promptly in the coolant.

where

$$
Q_{W}=0.045\left(V_{f} / V_{\text {mod }}\right)=0.00975
$$

$V_{f}$ is the volume of fuel in the core, $V_{\text {mod }}$ is the volume of coolant in the core.

29. Transient time. This transient will run for a duration of 0.8 seconds.

30. Vapor volume fraction generation constant. The vapor volume fraction will be evaluated with Eq. (86). The constant was given a value of 0.8 .

31. An exponent (dimensionless) used in Eq. (87), given a value of 1.0.

32. The coolant reference density at 1.7 bar and $38^{\circ} \mathrm{C}$ is $993.20 \mathrm{~kg} / \mathrm{m}^{3}$.

33. Doppler coefficient constant term. The Doppler reactivity feedback is constant with the temperature. It only affects the level of temperature feedback at time $t=0$.

34. Doppler coefficient term varying linearly with temperature.

35. Doppler coefficient term varying as the square of temperature.

36. Doppler coefficient term varying as $\mathrm{Tn}$.

37. Temperature offset used to select degrees $\mathrm{K}$ or $\mathrm{R}$ for temperature.

38. Doppler coefficient power, n, used with entry 36.

39. The upper limit for kinetics time step test, QH, was set to 0.001, as recommended in Section 3.2.1.

40. Transient DNB heat flux. A value of zero was entered for this parameter. The code will calculate a steady-state DNB heat flux for each axial node at each time node. 
41. Nucleate boiling bubble collapse time. Reliable values of this parameter cannot be predicted from fundamental considerations with any degree of assurance. Therefore, values should be derived from a parametric study of this parameter on a similar excursion experiment. A value of $0.5 \mathrm{~ms}$ is used.

42. Transition boiling bubble collapse time. A value of $0.001 \mathrm{~s}$ is used.

43. Fraction of the clad surface heat flux which is utilized in producing vapor in the subcooled nucleate boiling region. A value of 0.03 is used.

44. Fraction of the clad surface heat flux which is utilized in producing vapor in the subcooled transition boiling region. A value of 0.05 is used.

45. Fraction of the clad surface heat flux which is utilized in producing vapor in the subcooled film boiling region. A value of 0.05 is used.

46. Natural convection heat transfer constant. A value of 1.4 is given. The value used is of minor importance in this analysis, however, since the coolant is forced through the core at 1000 $\mathrm{m}^{3} / \mathrm{hr}$. The natural convection heat transfer correlation will be used only if the flow is reduced at some time to a Reynolds number less than 2300 .

47. Natural convection heat transfer constant. A value of 0.33 is given.

Additional general information (1100 series cards)

1. The total cross-sectional area of all heated flow channels in the core is $0.0857927 \mathrm{~m}^{2}$. This parameter is no longer used.

2. The flux weighting factor is set to 1.0 for both channels. These factors have no effect on calculations and results. Its physical significance is not clear and has been taken as unity in ANL calculations.

3. The single-phase correlation option is set to 1 . The Sieder-Tate correlation will be used.

4. The two-phase correlation option is set to 1 . The McAdams correlation will be used.

5. The transient two-phase scheme option is set to 1 . The transition model, single-phase to twophase will be used.

6. The DNB and flow instability correlations option is set to 0 . The original DNB correlation is used.

7. The single-phase heat transfer subroutine option is set to 0 . The original heat transfer subroutine is used. Therefore, entrance effects are included when the Reynolds is smaller than a specific threshold value. A function called ANUSSX computes the Nusselt Number, accounting for entrance effects due to simultaneously developing velocity and thermal profiles. Data was taken from Ref. [52]. This curve was used to estimate the difference between the fully developed value and that for the local point in the entrance region. Because the entrance length is 1-2 meters the entire core will usually be affected. The tabular data used is:

DATA GRAETZ/ 0., 120., 240., 360., 480.,

$$
\text { 600., 720., 1000./ }
$$

DATA NUINC / 0., 3.2, 5.5, 7.0, 7.9,

$$
8.4,8.7,8.9 /
$$


8. The constant rate for control rod movement is set to $1.2 \mathrm{~m} / \mathrm{s}$. The control rod travels $0.6 \mathrm{~m}$ in $0.5 \mathrm{~s}$ when the reactor reaches the scram trip point.

9. The delay time before rod starts in motion after trip is $25 \mathrm{~ms}$.

10. The overpower trip point is $12.0 \mathrm{MW}$.

11. The low-flow trip point is set to $0 \%$. This transient does not simulate a loss of flow accident.

12. The heights above and below the reactor fuel meat (for natural convection effects) are set to 0.0 .

Thermal properties of Fuel Element Materials

1. The thermal conductivity $(k)$ and volumetric heat capacity $(g)$ of the fuel are represented as a function of the temperature ( $T$ in Kelvin) by

$$
\begin{aligned}
& k=158.0 \mathrm{~W} / \mathrm{mK} \\
& g=1.0670 \cdot 10^{3} \mathrm{~T}+2.0721 \cdot 10^{6} \mathrm{~J} /\left(\mathrm{m}^{3} \mathrm{~K}\right)
\end{aligned}
$$

2. The thermal conductivity $(k)$ and volumetric heat capacity $(g)$ of the cladding are represented as a function of the temperature ( $T$ in Kelvin) by

$$
\begin{aligned}
& k=180.0 \mathrm{~W} / \mathrm{mK} \\
& g=1.0670 \cdot 10^{3} \mathrm{~T}+2.0721 \cdot 10^{6} \mathrm{~J} /\left(\mathrm{m}^{3} \mathrm{~K}\right)
\end{aligned}
$$

Half-Plate Thickness Description

In this problem the half-plate is divided into six radial intervals, four in the fuel and 2 in the cladding. A constant radial increment of $6.37510^{-5} \mathrm{~m}$ is used in the fuel (nodes 1 through 5) and of $1.910^{-4} \mathrm{~m}$ in the cladding (nodes 6 and 7).

The source description has a constant value of 0.955 in the fuel and 0.0 in the cladding. $95.5 \%$ of the prompt energy is deposited in the fuel and none in the clad. The rest is deposited directly in the coolant.

\section{Axial Description}

The length of the active core $(0.6 \mathrm{~m})$ is divided into 21 axial regions of equal size $\left(2.8571410^{-2} \mathrm{~m}\right)$

Individual channel information

In this analysis channel 1 represents the hottest plate in the core and channel 2 represents the remainder of the active core. They are both treated as flow-forced channels. The differences between the two channels are:

1. The value of BM. Channel 1 represents only one plate and its associated coolant channel. Therefore its fraction of meat volume is much smaller than for channel 2.

2. Void and temperature reactivity feedback coefficient (DVOID and DTEMP). There is a spatial effect to take into account.

3. The axial power profile (PFQ).

It was assumed that there was no axial dependence for the temperature reactivity feedback and the axial dependence is identical in both channels for the void reactivity feedback. The values entered in this Section are obtained with neutronics steady-state calculations using codes such as MCNP [36].

Delayed Neutron Information

Delayed neutron fractions and decay constant are entered in pairs on the 6000-series card. As specified on the 1000-series card, there are six delayed neutron groups for this problem. 
Reactivity vs. Time (Table 9)

Reactivity is inserted linearly from 0 seconds to $1.5 \$$ at 0.5 second. The $1.5 \$$ excess reactivity is not removed or changed at any time during the transient after $\mathrm{t}=0.5$ second.

Coolant Inlet Mass Flux vs. Time (Table 10)

The nominal flow rate of the coolant at the inlet is $1000 \mathrm{~m}^{3} / \mathrm{hr}$. It is constant throughout the transient. This is equivalent to a mass flux of $3.2158010^{3} \mathrm{~kg} / \mathrm{s} / \mathrm{m}^{2}$ at $38^{\circ} \mathrm{C}$ and $1.7 \mathrm{bar}$.

Linear Thermal Expansion of Clad vs. Temperature (Table 11)

In this problem we assume no thermal expansion of the clad, thereby ignoring a known reactivity feedback mechanism that can be represented by Table 11 .

Total pressure drop vs. Time (Table 12)

This is a flow-forced problem so we do not specify any pressure drop.

Time increment vs. Time (Table 14)

$5 \mathrm{~ms}$ time increments are specified for the kinetics time step until 0.55 seconds into the transient Then the time increment is reduced to $1 \mathrm{~ms}$ between $0.55 \mathrm{~s}$ and $0.75 \mathrm{~s}$. Finally the time increment is reset to $5 \mathrm{~ms}$ until the end of the transient.

Print frequency vs. Time (Table 16)

From 0.0 to 0.5 seconds, major output edits are printed every 0.10 seconds and intermediate output edits every 5 time steps. From $0.5 \mathrm{~s}$ to $0.6 \mathrm{~s}$, major output edits are printed every 0.05 seconds and intermediate output edits every 2 time steps. From $0.6 \mathrm{~s}$ to $0.7 \mathrm{~s}$, major output edits are printed every 0.05 seconds and intermediate output edits at every time step. From 0.7 seconds until the end of the reactor transient, major output edits are printed every 0.10 seconds and intermediate output edits every 5 time steps.

These settings will show the most output at the time of peak power, between $0.6 \mathrm{~s}$ and $0.7 \mathrm{~s}$ where variables of interest change most rapidly.

Pump mass flux vs. time

The pump has a constant mass flux throughout the transient.

Rod worth vs. Rod Location

Complete insertion of the control $\operatorname{rod}(\mathrm{s})$ will introduce $10 \$$ of negative reactivity. This reactivity will begin insertion starting when time equals the sum of the over-power trip time plus the over-power trip delay time. 
Figure 13.1 Input listing for the IAEA 10 MW Benchmark HEU Reactor Core

\section{$\odot$}

* HEU Benchmark 2 channel $\$ 1.50 / 0.5$ s ramp insertion

$\mathrm{HCC}=10$

Maximum iterations that the code should perform in the heat transfer

calculations. If the code detects that it should perform more iterations to achieve convergence, the temperature printout is accompanied by an asterix $\left({ }^{*}\right)$

POWER $=1.00000-6$

Initial reactor power is $1 \mathrm{~W}$

$\mathrm{PF}=.01062214$

Total volume of fuel meat in the core is $1.062214 \mathrm{E}-02 \mathrm{~m} \wedge 3$

PRESUR $=1.70000+5$

Inlet operating pressure is 1.7 bar (see IPOP)

ENTHIN $=1.58650+5$

The enthalpy of the inlet coolant is $1.58650 \mathrm{E}+5(\mathrm{~J} / \mathrm{kg})$. This is equivalent to a temperature of $38 \mathrm{C}$

$\mathrm{RS}=6.35000-4$

Plate half-thickness (including clad) is $0.635 \mathrm{~mm}$

$\mathrm{RF}=2.55000-4$

Fuel half-thickness is $0.255 \mathrm{~mm}$

$\mathrm{RC}=2.55000-4$

Half distance to inner surface of clad is $2.55 \mathrm{~mm}$. Same as RF because there is no intermediate zone between the fuel and cladding.

$\mathrm{PW}=6.65000-2$

Plate width is $6.65 \mathrm{~cm}$

$\mathrm{FW}=6.30000-2$

Fuel width is $6.3 \mathrm{~cm}$

$A L=0.6000$

Active fuel length is $0.6 \mathrm{~m}$

ALDDIN $=0.0$

Inlet non-fueled section length is $\odot . \odot \mathrm{m}$

ALDDEX $=0 . \odot$

Outlet non-fueled Section length is $0.0 \mathrm{~m}$

BBEFF $=0.0076071$

Effective delayed neutron fraction beta $=\odot .0076071$

$E L=55.960-6$

Prompt neutron generation time is 55.960E-06 s

GRAV $=9.80664$

Acceleration due to gravity is $9.80664 \mathrm{~m} / \mathrm{s}^{\wedge} 2$

$\mathrm{QW}=\odot .0 \odot 975$

Heat source description for coolant. It is the fraction of the heat generated in the coolant multiplied by the ratio of the fuel meat volume to the coolant volume (see card QR on card 3001 and 3002) 


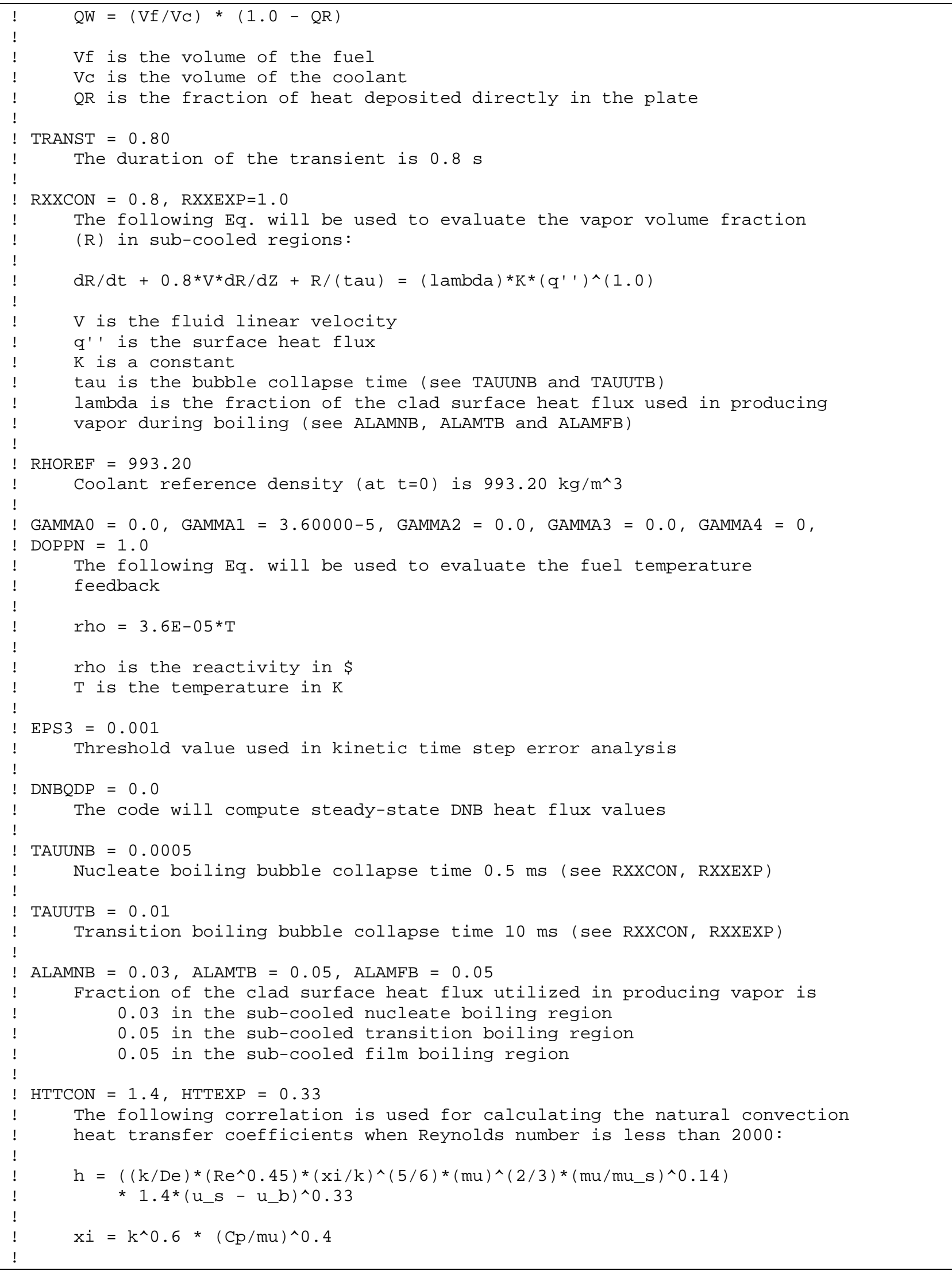




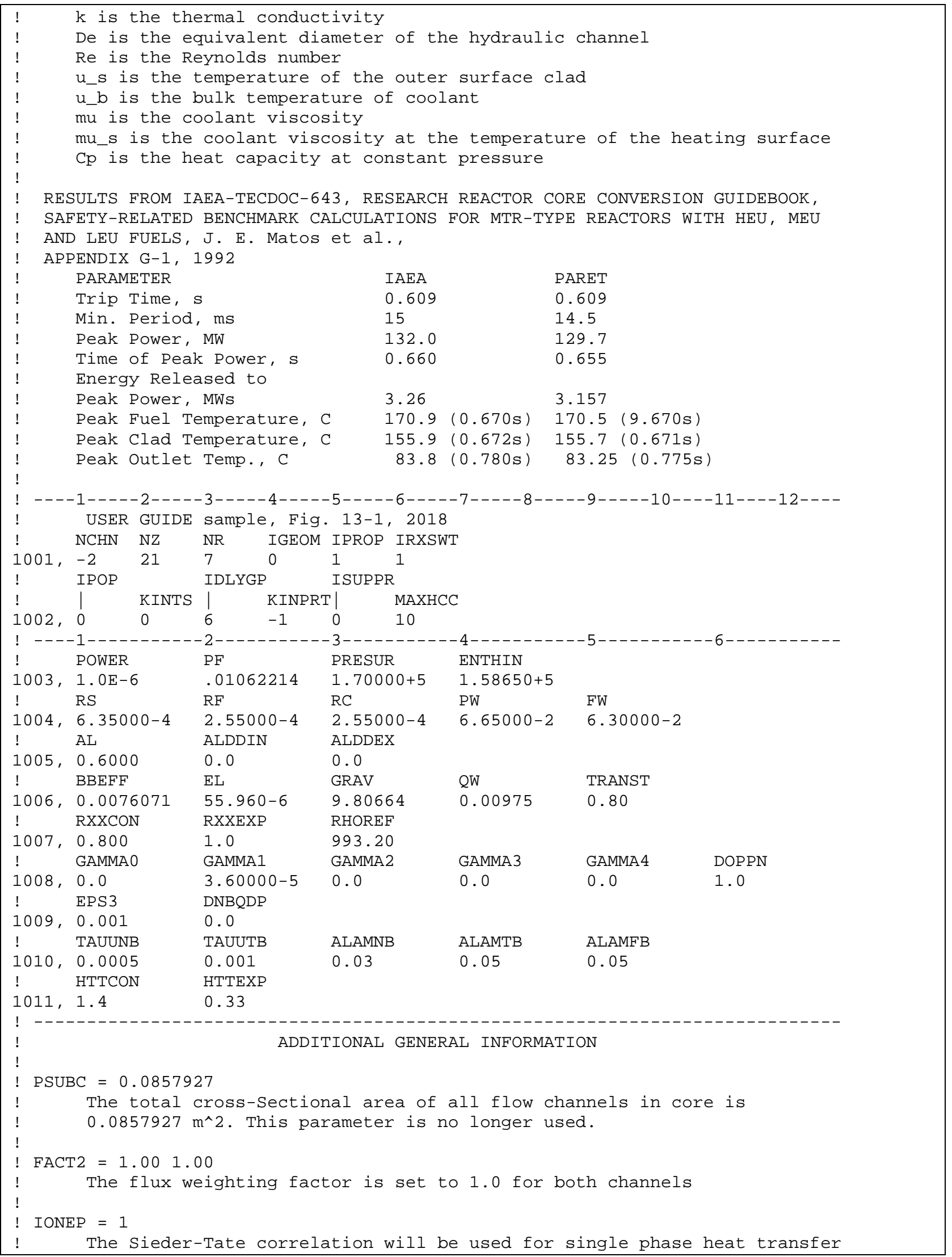




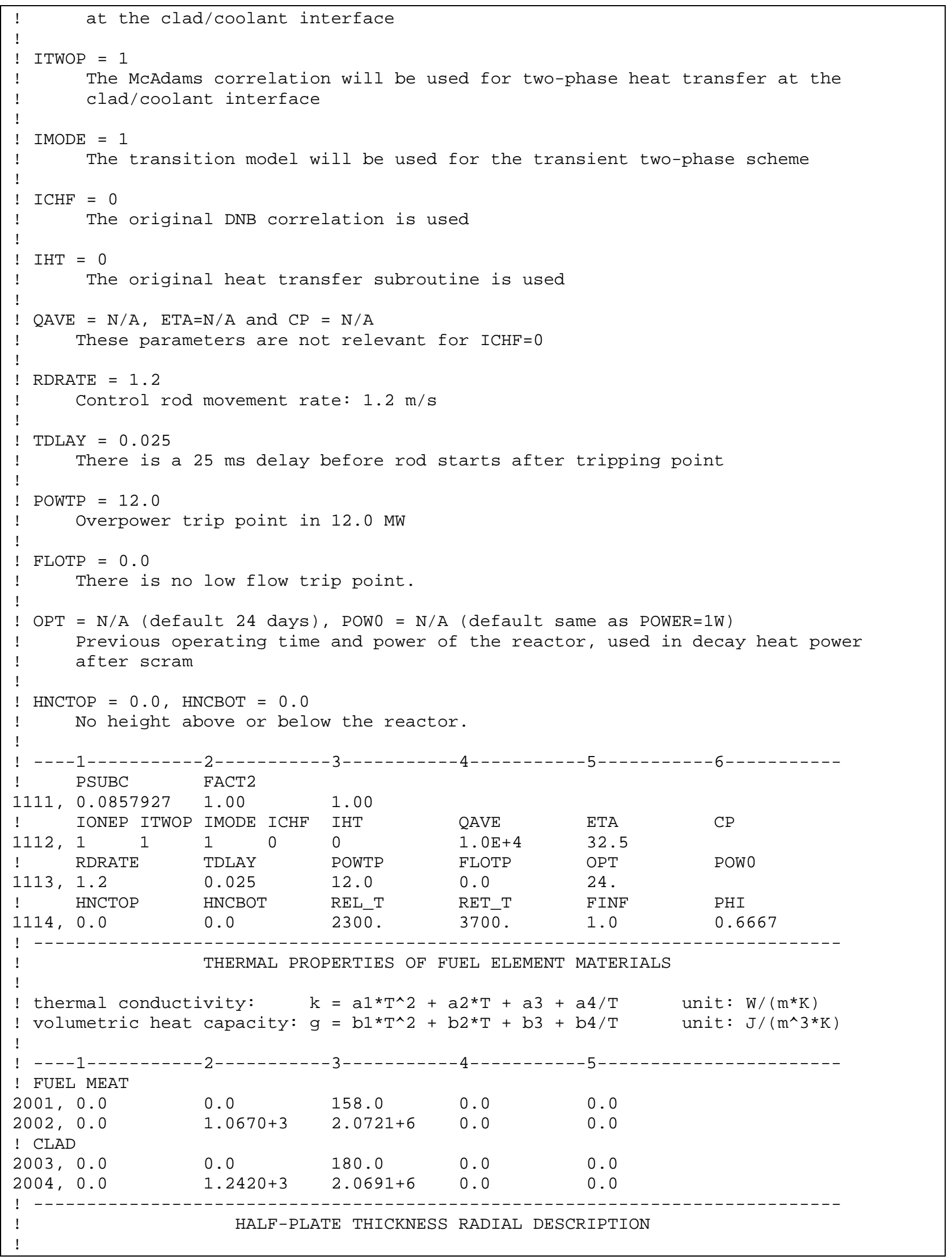




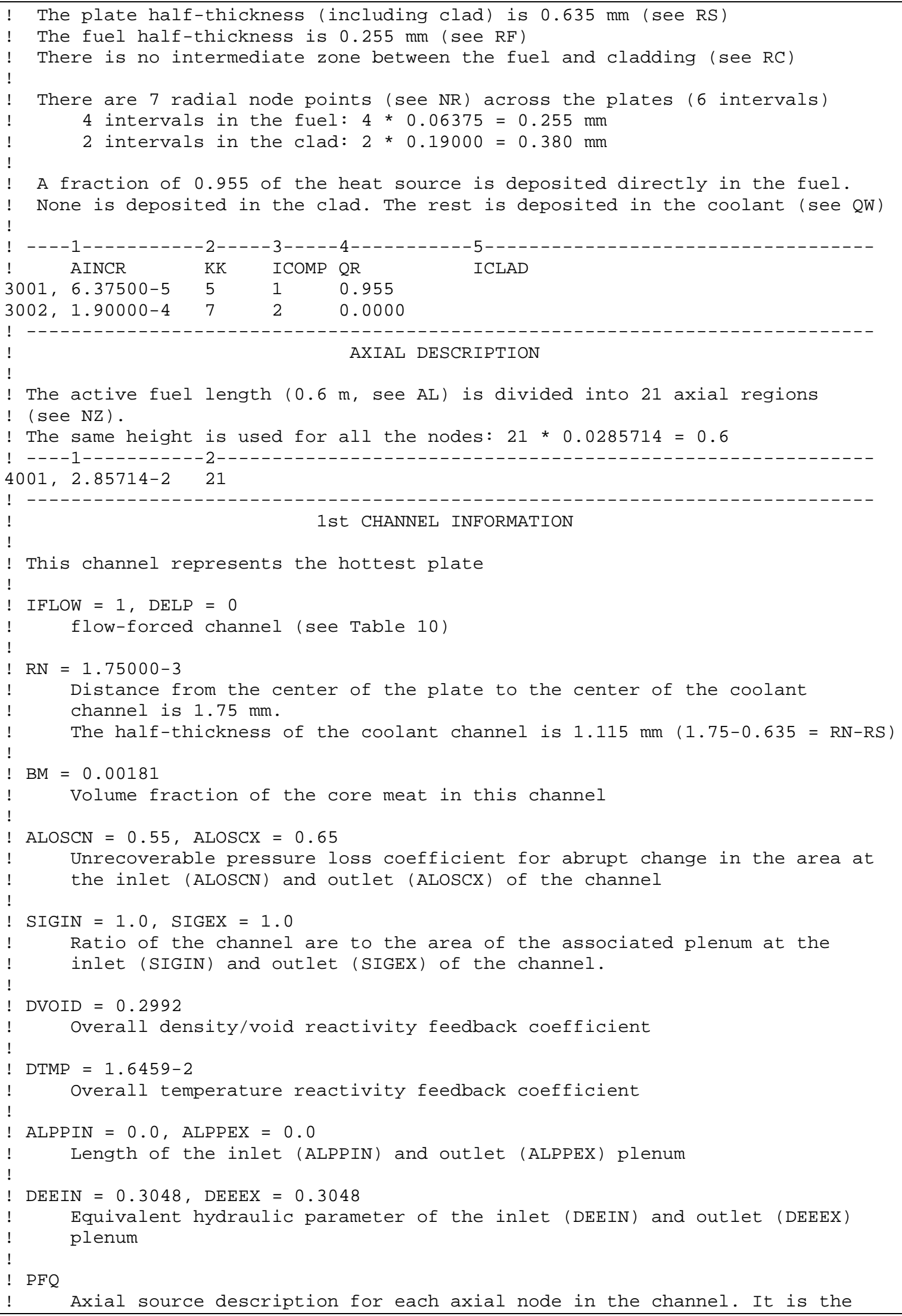




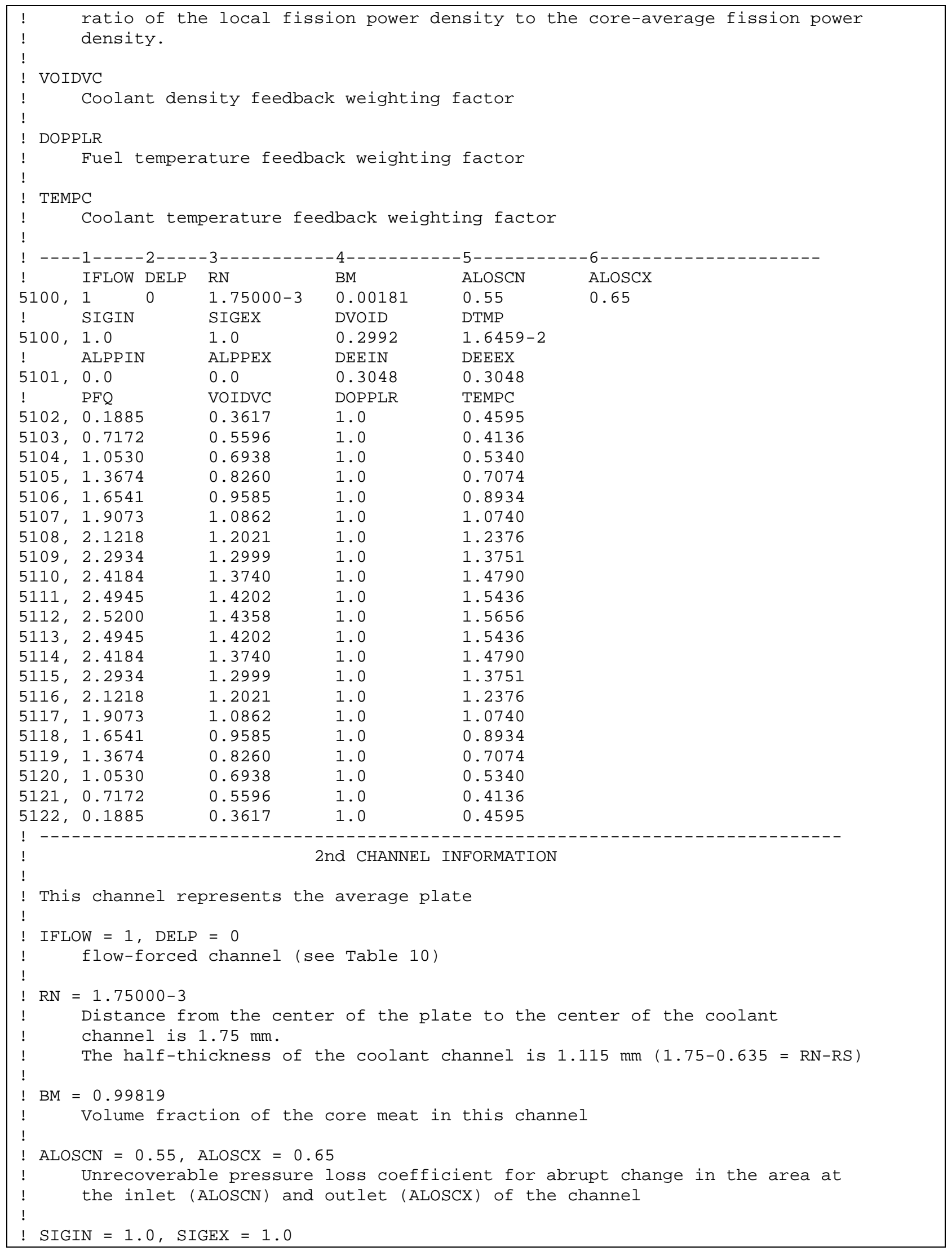




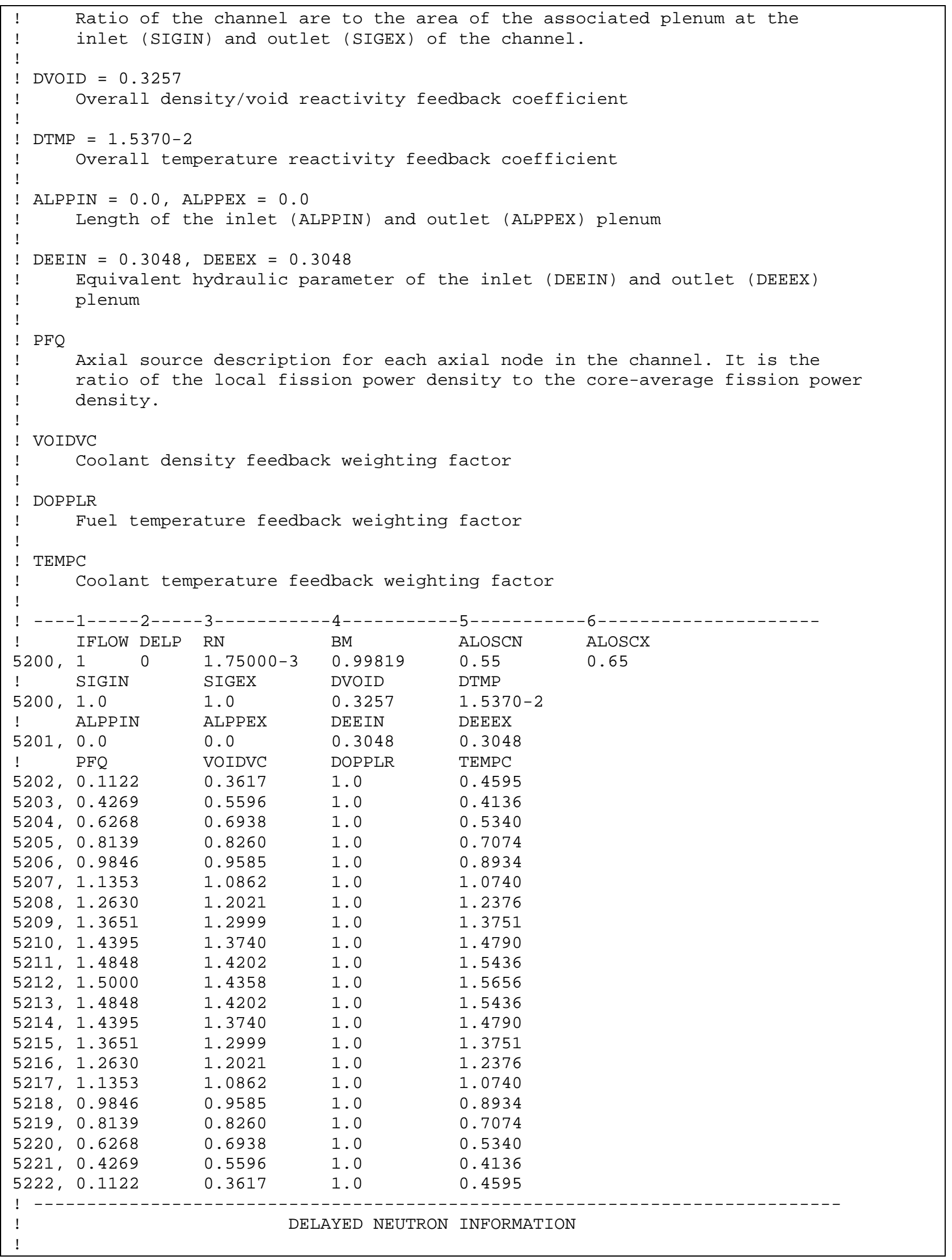




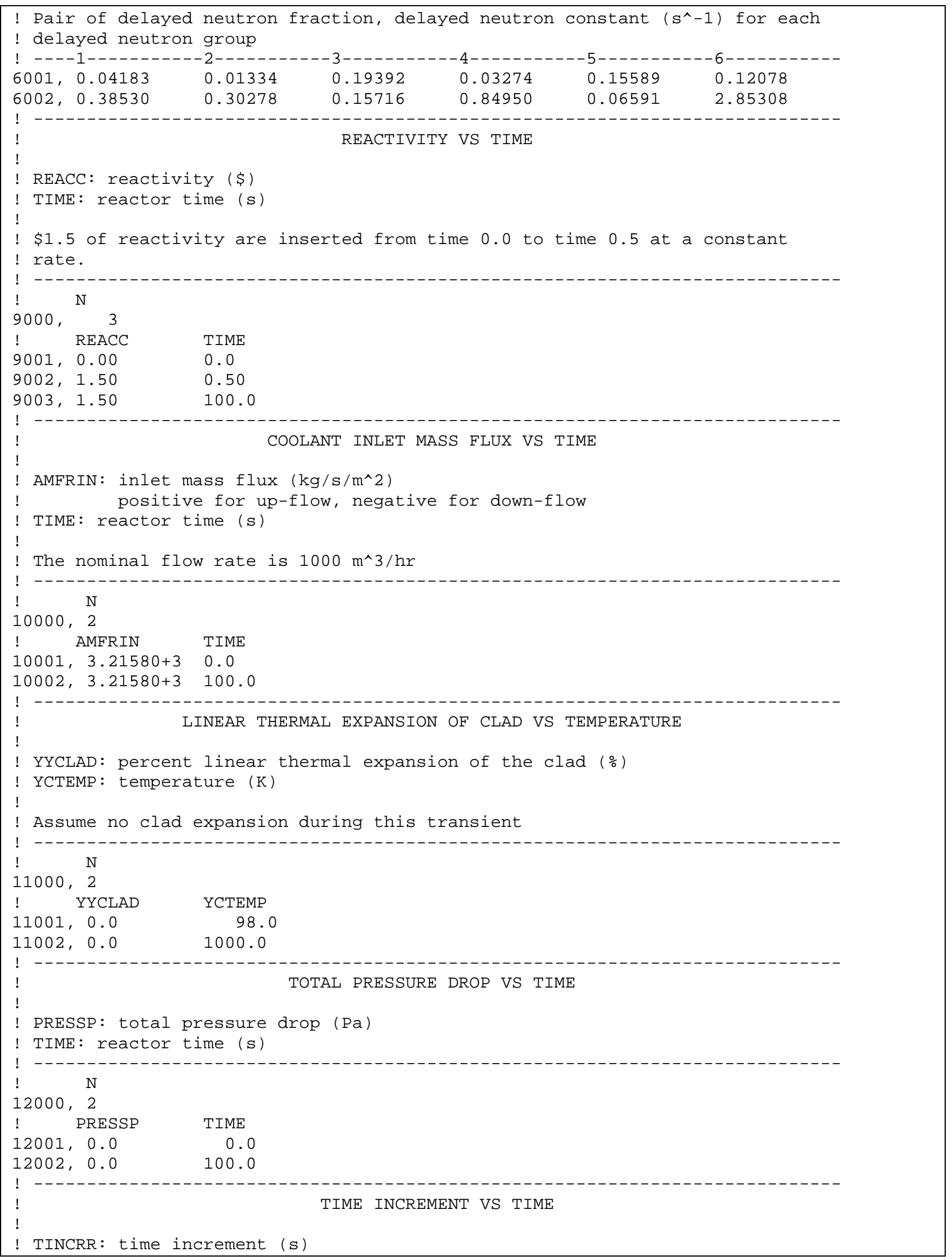




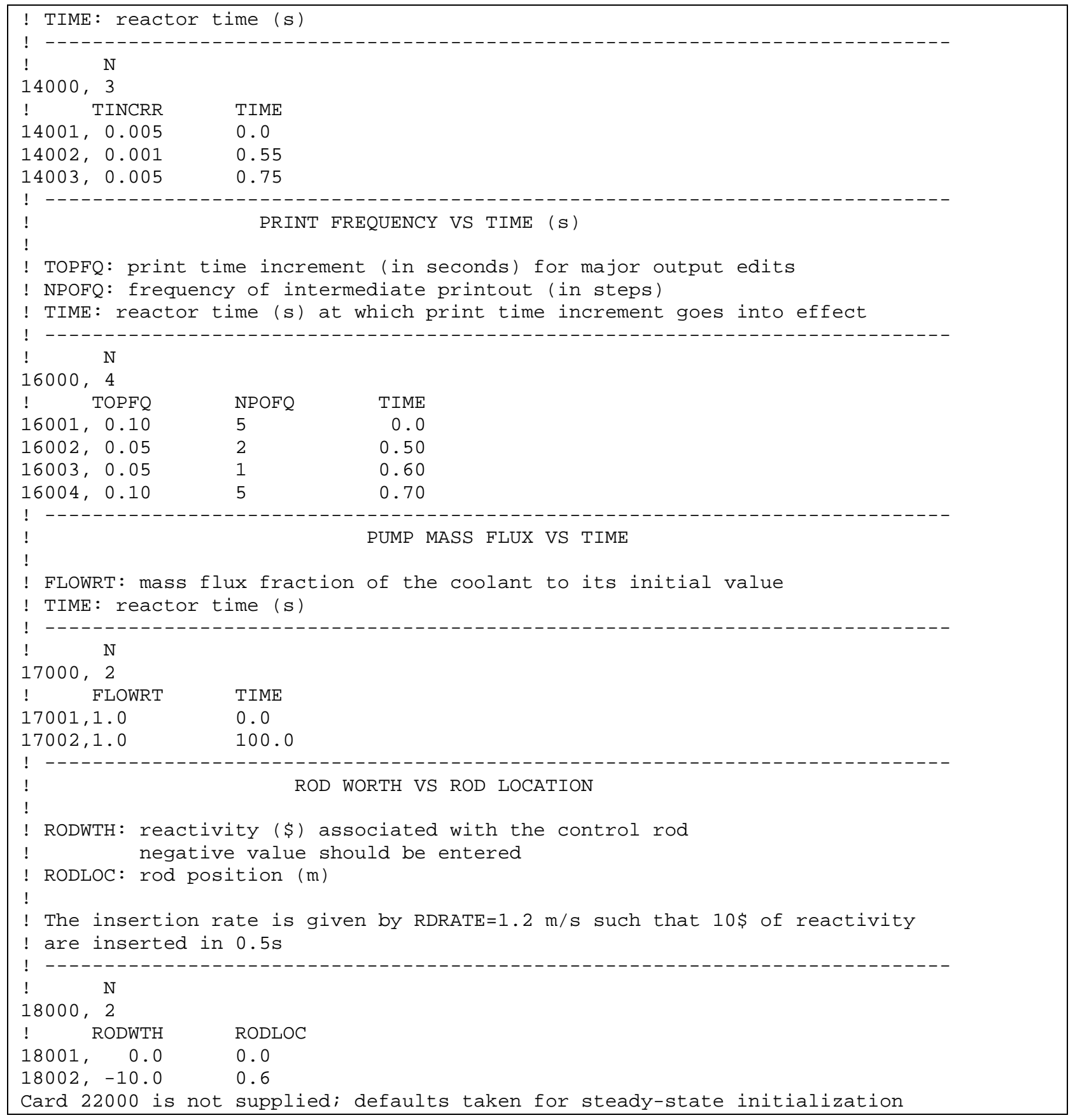




\section{Appendix IV Use of Axial Power Profiles in PARET}

Previous Users Guides for PARET, and the original Obenchain [1] document, do not state clearly where the axial power profile supplied on card types $5 \mathrm{k} 01$ is located (variable PFQ), or how it is used. The purpose of this appendix is to make it clear how the code uses axial power profile information. The purpose of Section 15 is to document the self-consistency of input data arrays used to specify the power distribution among PARET/ANL channels, across the thickness or radius of the meat, and among the axial nodes over the fueled length.

Edited Axial Mesh Information

When an input file is processed, the code edits axial profile location information under a centered title:

\section{AXIAL DESCRIPTION}

Here, one finds column headings of:
AXIAL NODE AXIAL LENGTH
CALC. INTERVAL
AXIAL INTERVAL

Values that follow under "AXIAL LENGTH" are the axial locations of the points in the z-direction at which the axial power profile is located. Also, the power that the code delivers to the coolant in each axial node is proportional to the average of the two interface values for PFQ at each end of that node.

If the mesh is optimal from the standpoint of numerical instability, then the fluid axial nodes will all be of the same length [AL/(NZ-1)]. The first and last fuel nodes will be half-sized, compared to all of the rest $[\mathrm{AL} /(2(\mathrm{NZ}-1)]$.

Test Problem

As an example, a 2-channel case with NZ=11 axial nodes and an axial fueled length of $0.6 \mathrm{~m}$ was tested using a linear power profile that ranged over 1.0 to 2.0 in channel 1.(See Table 14.1).

Table 14.1

Enthalpy Rise at time $\mathbf{t}=\mathbf{0 . 1}$ second for a null transient

\begin{tabular}{|l|l|l|l|l|l|l|}
\hline Node & Z, m & PFQ & $\begin{array}{l}\text { Enthalpy at } \\
\text { z, kJ } \\
\text { (up-flow) }\end{array}$ & $\begin{array}{l}\text { Enthalpy } \\
\text { rise in node, } \\
\text { kJ }\end{array}$ & $\begin{array}{l}\text { Enthalpy at } \\
\text { z, kJ } \\
\text { (downflow) }\end{array}$ & $\begin{array}{l}\text { Enthalpy } \\
\text { rise in node, } \\
\text { kJ }\end{array}$ \\
\hline 1 & 0 & 1.0 & 146.1001 & 7.1155 & 247.4601 & 7.1037 \\
\hline 2 & .06 & 1.1 & 153.2156 & 7.7914 & 240.3564 & 7.7567 \\
\hline 3 & .12 & 1.2 & 161.0070 & 8.4693 & 232.5997 & 8.4534 \\
\hline 4 & .18 & 1.3 & 169.4763 & 9.1436 & 224.1463 & 9.1126 \\
\hline 5 & .24 & 1.4 & 178.6199 & 9.8228 & 215.0337 & 9.8041 \\
\hline 6 & .30 & 1.5 & 188.4427 & 10.4869 & 205.2296 & 10.4678 \\
\hline 7 & .36 & 1.6 & 198.9296 & 11.1743 & 194.7618 & 11.1554 \\
\hline 8 & .42 & 1.7 & 210.1039 & 11.8311 & 183.6064 & 11.8226 \\
\hline 9 & .48 & 1.8 & 221.9350 & 12.5266 & 171.7838 & 12.5072 \\
\hline 10 & .54 & 1.9 & 234.4616 & 13.1796 & 159.2766 & 13.1765 \\
\hline
\end{tabular}




\begin{tabular}{|l|l|l|l|l|l|l|}
\hline 11 & .60 & 2.0 & 247.6412 & & 146.1001 & \\
\hline
\end{tabular}

Discussion

Even though the PARET/ANL code should treat this problem identically for up-flow or for downflow, there are small differences in the enthalpy rise in each node. One can ratio the enthalpy rise in various nodes, and compare that to the expected ratio, as shown in Table 14.2.

Table 14.2 Details of Enthalpy rise by node

\begin{tabular}{|c|c|c|c|}
\hline Node Ratio & $\begin{array}{l}\text { Enthalpy Rise } \\
\text { Ratio Supplied } \\
\text { and Expected }\end{array}$ & $\begin{array}{l}\text { PARET/ANL } \\
\text { edited } \\
\text { Enthalpy Rise } \\
\text { Ratio and \% error } \\
\text { (up-flow) }\end{array}$ & $\begin{array}{l}\text { PARET/ANL } \\
\text { edited } \\
\text { Enthalpy Rise } \\
\text { Ratio and \% error } \\
\text { (downflow) }\end{array}$ \\
\hline $10: 1$ & 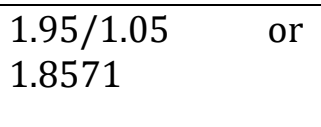 & $\begin{array}{l}1.8522 \\
-0.27 \%\end{array}$ & $\begin{array}{l}1.8549 \\
-0.12 \%\end{array}$ \\
\hline $9: 2$ & $\begin{array}{l}1.85 / 1.15 \\
1.6087\end{array}$ & $\begin{array}{l}1.6077 \\
-0.06 \%\end{array}$ & $\begin{array}{l}1.6124 \\
+0.23 \%\end{array}$ \\
\hline $8: 3$ & $\begin{array}{l}1.75 / 1.25 \\
1.4000\end{array}$ & $\begin{array}{l}1.39694 \\
-0.22 \%\end{array}$ & $\begin{array}{l}1.3986 \\
-0.10 \%\end{array}$ \\
\hline $7: 4$ & $\begin{array}{l}1.65 / 1.35 \\
1.2222\end{array}$ & $\begin{array}{l}1.2221 \\
-0.01 \%\end{array}$ & $\begin{array}{l}1.2242 \\
+0.16 \%\end{array}$ \\
\hline $6: 5$ & $\begin{array}{ll}1.55 / 1.45 & \text { or } \\
1.0690 & \end{array}$ & $\begin{array}{l}1.0676 \\
-0.13 \%\end{array}$ & $\begin{array}{l}1.0677 \\
-0.12 \%\end{array}$ \\
\hline
\end{tabular}

It is clear from Table 14.2 that PARET/ANL computes the enthalpy rise for this linear power profile as expected. If there were any unknown treatment of first and last nodes, then the listed enthalpy rise ratios would not agree with those in column 2. The edited "ENERGY GAIN" at 0.1 sec is 1.04042 for up-flow, and 1.03511 for downflow. The true power is $1.04000 \mathrm{MW}$. This comparison shows that the code is not exactly symmetric for up-flow vs. downflow. It is more accurate for up-flow, in this case. One possibility is that the fluid density variation with pressure and height should be implemented.

\section{CONCLUSION}

This investigation shows that the enthalpy rise calculation proceeds as expected for a linear power profile. There is a very minor difference between up-flow and downflow that is not necessarily indicative of any error in coding. This investigation also found that PARET/ANL does not compute fluid density using local pressure, as the Obenchain report claims (Section 4, p. 8). It appears to be relatively simple to implement that feature, because the local pressure at each axial level is periodically computed throughout the transient event, accounting for up-flow vs. downflow. 


\section{Appendix V Self-Consistency of Arrays BM and PFQ for PARETIANL Channels and Normalization of Power Density Distribution}

\subsection{Summary}

The reactor core is modeled by dividing it into a maximum of 120 PARET/ANL channels (see input card series 5100 and 5101), where a channel is a specific group of fuel pins/plates with the associated coolant. All channels are axially divided into a maximum of 96 mesh intervals here referred to as axial nodes (see input card series 5102, 5103, etc.). The same axial mesh structure is used in all channels. As shown in Fig. 1, each fuel pin is radially divided into an input number of radial increments in the fuel meat, an input number of radial increments in the fuel-cladding gap, and an input number of radial increments in the cladding (specified on the input card series 3000). The power density distribution in a fuel pin is assumed to be separable into a function of time, a function of intra-pin radius, and a function of axial position.

It is shown below that a consistent normalization of reactor-wide power density distribution requires that the input array $Q R$ must average to (1- $\left.F_{\text {cool }}\right)$ as shown by Eq. (15-16), and the input arrays $\mathrm{BM}_{\mathrm{k}}$ and $\mathrm{PFQ}_{\mathrm{k}, \mathrm{j}}$ must satisfy Eq. (15-26). The channel-wise power density in meat, $\mathrm{q}_{\mathrm{chan,k,j,n},}$ (excluding the power deposited directly in coolant) is shown to be related to the input data arrays by

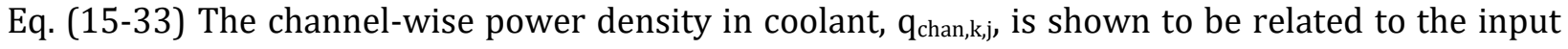
data arrays by Eq. (15-39). Here, $\bar{Q}$ is the core-average power density in meat assuming that all power is deposited in the meat, and Eq. (15-1) and (15-2) accounts for the fact that a fraction of power is deposited directly in the coolant.

$$
\begin{aligned}
& \mathrm{q}_{\text {chan, }, \mathrm{j}, \mathrm{n}}=\overline{\mathrm{Q}} \times \mathrm{PFQ}_{\mathrm{k}, \mathrm{j}} \times \mathrm{QR}_{\mathrm{n}} \\
& \mathrm{q}_{\mathrm{cool}, \mathrm{k}, \mathrm{j}}=\overline{\mathrm{Q}} \times \mathrm{PFQ}_{\mathrm{k}, \mathrm{j}} \times \mathrm{QW}
\end{aligned}
$$

\subsection{Demonstration Of The Self-Consistency Of Arrays BM And PFQ}

Let us assume a problem with NP fuel plates or pins discretized in NZ axial nodes, with (NN1-1) radial nodes in meat of each fuel pin as shown in Figure 15-1. From the physics-calculated power density distribution $Q_{i, j, n}$ in all fuel pins of the core, we need to calculate the channel-wise axial power density shapes $\mathrm{PFQ}_{\mathrm{k}, \mathrm{j}}$ and describe the distribution of the total reactor power $\mathrm{P}_{\text {tot }}$ (input variable POWER) among the channels. First, the core average power density in fuel meat is calculated by Eq. (15-3), assuming the total power is produced and deposited in the total meat volume in core. The total meat volume $V_{\text {tot }}$ is given by Eq. (15-4) as the sum of meat node volumes $\left(\Delta \mathrm{A}_{\mathrm{n}} \Delta \mathrm{Z}_{\mathrm{j}}\right)$ over all (NN1-1) nodes along meat thickness/radius, over all NP fuel plates/pins, and over all NZ axial nodes. The sum of all nodal powers $\mathrm{Q}_{\mathrm{i}, \mathrm{j}, \mathrm{n}} \times \Delta \mathrm{V}_{\mathrm{i}, \mathrm{j}, \mathrm{n}}$ (nodal power density $\times$ nodal volume) must be $\mathrm{P}_{\text {tot }}$ as shown by Eq. (15-5).

$$
\overline{\mathrm{Q}}=\frac{\mathrm{P}_{\text {tot }}}{\mathrm{V}_{\text {tot }}}
$$




$$
\begin{aligned}
& \mathrm{V}_{\text {tot }}=\sum_{\mathrm{j}=1}^{\mathrm{NZ}} \sum_{\mathrm{i}=1}^{\mathrm{NP}} \sum_{\mathrm{n}=1}^{\mathrm{NN1}-1} \Delta \mathrm{V}_{\mathrm{i}, \mathrm{j}, \mathrm{n}} \quad \text { where } \Delta \mathrm{V}_{\mathrm{i}, \mathrm{j}, \mathrm{n}}=\Delta \mathrm{A}_{\mathrm{n}} \Delta \mathrm{Z}_{\mathrm{j}} \\
& \mathrm{P}_{\text {tot }}=\sum_{\mathrm{j}=1}^{\mathrm{NZ}} \sum_{\mathrm{i}=1}^{\mathrm{NP}} \sum_{\mathrm{n}=1}^{\mathrm{NN} 1-1} \mathrm{Q}_{\mathrm{i}, \mathrm{j}, \mathrm{n}} \times \Delta \mathrm{V}_{\mathrm{i}, \mathrm{j}, \mathrm{n}}
\end{aligned}
$$

where

$\mathrm{n} \quad=$ Intra-pin radial mesh index, or mesh index across plate thickness.

$\mathrm{j}=$ = Axial segment index

$\mathrm{k} \quad=$ Channel number. Each channel models a different number of fuel pins of identical geometry, differing only in the coolant flow cross-sectional area.

The channel-wise flow area is determined by the coolant outer radius $\mathrm{RN}(\mathrm{K})$

(shown in Figure 17.1) that is entered on the input card series 5000.

$\mathrm{A}_{\text {cool }}=$ coolant flow area associated with a fuel plate $/ \mathrm{pin}$

$\mathrm{A}_{\text {meat }}=\sum_{\mathrm{n}=1}^{\mathrm{NN1}-1} \Delta \mathrm{A}_{\mathrm{n}}=$ fuel meat cross Sectional area in fuel plate $/ \mathrm{pin}$

$\Delta \mathrm{A}_{\mathrm{n}}=($ plate width $) \times \Delta \mathrm{X}_{\mathrm{n}}$ in slab geometry $($ IGEOM $=0)$ where $\Delta \mathrm{X}_{\mathrm{n}}$ is the $\mathrm{n}^{\text {th. }}$ mesh interval in the thickness of a fuel plate, or $=\pi\left(r_{n+1}^{2}-r_{n}^{2}\right)$ in cylindrical geometry (IGEOM $\left.=1\right)$ as shown in Fig. 1

$\mathrm{F}_{\text {cool }}=$ (input $\left.\mathrm{QW}\right) \times\left(\mathrm{A}_{\text {cool }} / \mathrm{A}_{\text {meat }}\right)=$ fraction of $\mathrm{P}_{\text {tot }}$ that is deposited directly in the coolant

$\mathrm{NZ} \quad=$ Number of axial node boundaries. (input card series 1000)

NN1 = Input radial node number out to which is fuel meat. The meat consists of the Radial mesh intervals $\mathrm{I}=1,2, \ldots$ (NN1-1). In the special case of Figure 17.1,

NN1 $=6$ and the meat consists of 5 mesh intervals. (input card series 3000)

NN2 = Input radial node number out to which is fuel-cladding gap. In Figure 17.1, NN2 = 8 . (input card series 3000)

NN3 = Input radial node number out to which is cladding. In Figure 17.1, NN3 $=10$. (input card series 3000)

$\mathrm{P}_{\text {tot }}=$ total reactor power (input variable POWER). It includes the power deposited directly into the coolant and directly into the fuel meat and clad.

$\mathrm{P}_{\text {tot,k }} \quad=$ total power in meat, clad, and coolant of PARET/ANL channel $\mathrm{k}$

$\mathrm{P}_{\mathrm{k}} \quad=\mathrm{P}_{\text {tot } \mathrm{k}}\left(1-\mathrm{F}_{\text {cool }}\right)=$ power in fuel meat in PARET $/$ ANL channel $\mathrm{k}$ (ignoring for simplicity direct heating to clad)

$\overline{\mathrm{Q}} \quad=$ core-average power density in meat assuming that all power is deposited in the meat

$\mathrm{Q}_{\mathrm{avg}, \mathrm{i}, \mathrm{j}}=$ power density averaged over fuel meat cross-Section in axial segment $\mathrm{j}$ of pin/plate i assuming that all power is deposited in the meat 
$\mathrm{q}_{\mathrm{i}, \mathrm{j}, \mathrm{n}}=$ nodal power density in fuel meat volume $\Delta \mathrm{V}_{\mathrm{i}, \mathrm{j}, \mathrm{n}}$. It does not include the power deposited directly in the coolant. It only includes the power deposited in the meat.

$\mathrm{q}_{\mathrm{chan}, \mathrm{k}, \mathrm{j}, \mathrm{n}}=$ channel-wise power density in fuel meat, excluding the power deposited directly in the coolant.

$\mathrm{q}_{\text {cool, }, \mathrm{ij}}=$ nodal power density in coolant volume $\mathrm{A}_{\text {cool }} \Delta \mathrm{Z}_{\mathrm{j}}$ of the $\mathrm{i}^{\text {th }} \mathrm{pin} / \mathrm{plate}$ in the $\mathrm{j}^{\text {th }}$ axial segment. It only includes the power deposited directly in the coolant.

$\mathrm{QW} \quad=\mathrm{q}_{\text {cool }, \mathrm{i}, \mathrm{j}} / \mathrm{Q}_{\mathrm{avg}, \mathrm{i}, \mathrm{j}}=$ Ratio of power density in coolant to the total power density averaged over fuel meat cross-section. (input card series 1000). The value of this input fraction must be such that [averaged value of $\mathrm{QR}(\mathrm{I})]+\mathrm{QW}$.(coolant volume) $/($ fuel meat volume $)=1$

$\mathrm{RF} \quad=$ Fuel meat outer radius, $\mathrm{m}$. (input card series 1000)

$\mathrm{RC} \quad=$ Cladding inner radius, $\mathrm{m}$. (input card series 1000)

RS = Cladding outer radius, $\mathrm{m}$. (input card series 1000)

$\mathrm{V}_{\mathrm{tot}}=$ total meat volume in core

$\Delta \mathrm{V}_{\mathrm{i}, \mathrm{j}, \mathrm{n}}=\Delta \mathrm{A}_{\mathrm{n}} \times \Delta \mathrm{Z}_{\mathrm{j}}=$ volume of meat in intra-meat radial node $\mathrm{n}$ of axial node $\mathrm{j}$ of fuel pin $\mathrm{i}$.

Eq. (15-6) defines a power density $Q_{\text {avg,i,j }}$ averaged over fuel meat cross-Section in axial segment $\mathrm{j}$ of $\mathrm{pin} /$ plate $\mathrm{i}$ assuming that all power is deposited in the meat.

$$
\begin{gathered}
\mathrm{Q}_{\mathrm{avg}, \mathrm{i}, \mathrm{j}}=\frac{\sum_{\mathrm{n}=1}^{\mathrm{NN} 1-1} \mathrm{Q}_{\mathrm{i}, \mathrm{j}, \mathrm{n}} \times \Delta \mathrm{A}_{\mathrm{n}}}{\sum_{\mathrm{n}=1}^{N N 1-1} \Delta \mathrm{A}_{\mathrm{n}}}=\frac{\sum_{\mathrm{n}=1}^{\mathrm{N} 1-1} \mathrm{Q}_{\mathrm{i}, \mathrm{j}, \mathrm{n}} \times \Delta \mathrm{A}_{\mathrm{n}}}{\mathrm{A}_{\text {meat }}} \\
\mathrm{Q}_{\mathrm{avg}, \mathrm{i}, \mathrm{j}} \mathrm{A}_{\text {meat }}=\sum_{\mathrm{n}=1}^{\mathrm{NN1} 1} \mathrm{Q}_{\mathrm{i}, \mathrm{j}, \mathrm{n}} \times \Delta \mathrm{A}_{\mathrm{n}}
\end{gathered}
$$

Eq. (15-3) for the core-average power density $\bar{Q}$ assuming that all power is deposited in the meat can be written as Eq. (15-8). Using Eq. (15-7), Eq. (15-8) can be written in terms of $Q_{a v g, i, j}$ as shown by Eq. (15-9).

$$
\begin{aligned}
& \bar{Q}=\frac{\sum_{j=1}^{N Z} \sum_{i=1}^{N P} \sum_{n=1}^{N N 1-1} \mathrm{Q}_{\mathrm{i}, \mathrm{j}, \mathrm{n}} \times \Delta \mathrm{A}_{\mathrm{n}} \Delta \mathrm{Z}_{\mathrm{j}}}{\sum_{\mathrm{j}=1}^{N Z} \sum_{\mathrm{i}=1}^{N P} \sum_{\mathrm{n}=1}^{N N 1-1} \Delta \mathrm{A}_{\mathrm{n}} \Delta \mathrm{Z}_{\mathrm{j}}}=\frac{\sum_{\mathrm{j}=1}^{N Z} \sum_{\mathrm{i}=1}^{N P} \Delta \mathrm{Z}_{\mathrm{j}} \sum_{\mathrm{n}=1}^{N N 1-1} \mathrm{Q}_{\mathrm{i}, \mathrm{j}, \mathrm{n}} \times \Delta \mathrm{A}_{\mathrm{n}}}{\sum_{\mathrm{j}=1}^{N Z} \sum_{\mathrm{i}=1}^{N P} \Delta \mathrm{Z}_{\mathrm{j}} \sum_{\mathrm{n}=1}^{N N 1-1} \Delta \mathrm{A}_{\mathrm{n}}} \\
& \overline{\mathrm{Q}}=\frac{\sum_{\mathrm{j}=1}^{N Z} \sum_{\mathrm{i}=1}^{N P} \Delta \mathrm{Z}_{\mathrm{j}} \mathrm{Q}_{\text {avg,i,j }} \mathrm{A}_{\text {meat }}}{\sum_{\mathrm{j}=1}^{N Z} \sum_{\mathrm{i}=1}^{N P} \Delta \mathrm{Z}_{\mathrm{j}} \mathrm{A}_{\text {meat }}}=\frac{\sum_{\mathrm{j}=1}^{N Z} \sum_{\mathrm{i}=1}^{N P} \Delta \mathrm{Z}_{\mathrm{j}} \mathrm{Q}_{\mathrm{avg}, \mathrm{i}, \mathrm{j}}}{\sum_{\mathrm{j}=1}^{N Z} \sum_{\mathrm{i}=1}^{N P} \Delta \mathrm{Z}_{\mathrm{j}}}
\end{aligned}
$$

The code makes the following two assumptions regarding the power split between the meat and the coolant: 
(1) It is assumed that the ratio $\mathrm{q}_{\text {cool, }, \mathrm{i}, \mathrm{j}} / \mathrm{Q}_{\mathrm{avg}, \mathrm{i}, \mathrm{j}}$ is constant. This assumption means that the nodal power density in the coolant associated with each pin/plate has the same axial shape as that of the total power density averaged over meat cross-Section.

$$
\frac{\mathrm{q}_{\text {cool, }, \mathrm{i}, \mathrm{j}}}{\mathrm{Q}_{\mathrm{avg}, \mathrm{i}, \mathrm{j}}}=\mathrm{QW}, \text { where } \mathrm{QW} \text { is an input datum }
$$

(2) It is assumed that the nodal power density $q_{i, j, n}$ deposited in meat is the product of array $Q_{a v g, i, j}$ and an input array $\mathrm{QR}_{\mathrm{n}}$ of intra-meat index $\mathrm{n}$, as shown by Eq. (8). The current code assumes a single intra-meat radial profile $\mathrm{QR}_{\mathrm{n}}$ for all pins/plates and for all axial nodes.

$$
\mathrm{q}_{\mathrm{i}, \mathrm{j}, \mathrm{n}}=\mathrm{Q}_{\mathrm{avg}, \mathrm{i}, \mathrm{j}} \times \mathrm{QR}_{\mathrm{n}}
$$

Multiplying Eq. (15-11) by nodal volume $\Delta \mathrm{A}_{n} \Delta \mathrm{Z}_{\mathrm{j}}$ and summing over the meat cross Section, the power $\left(\mathrm{P}_{\text {meat, }, \mathrm{i}, \mathrm{j}}\right)$ deposited in meat in the $\mathrm{j}^{\text {th }}$ axial segment of the $\mathrm{i}^{\text {th }}$ plate/pin is found as follows.

Here the average of array $\mathrm{QR}_{\mathrm{n}}$ is defined by $\sum_{\mathrm{n}=1}^{\mathrm{NN} 1-1} \mathrm{QR}_{\mathrm{n}} \Delta \mathrm{A}_{\mathrm{n}}=\mathrm{A}_{\text {meat }} \overline{\mathrm{QR}}$.

$$
\begin{aligned}
\mathrm{P}_{\text {meat }, \mathrm{i}, \mathrm{j}} & =\sum_{\mathrm{n}=1}^{\mathrm{NN} 1-1} \mathrm{q}_{\mathrm{i}, \mathrm{j}, \mathrm{n}} \Delta \mathrm{A}_{\mathrm{n}} \Delta \mathrm{Z}_{\mathrm{j}}=\mathrm{Q}_{\mathrm{avg}, \mathrm{i}, \mathrm{j}} \Delta \mathrm{Z}_{\mathrm{j}} \sum_{\mathrm{n}=1}^{\mathrm{NN} 1-1} \mathrm{QR}_{\mathrm{n}} \Delta \mathrm{A}_{\mathrm{n}} \\
\mathrm{P}_{\text {meat }, \mathrm{i}, \mathrm{j}} & =\mathrm{Q}_{\text {avg, }, \mathrm{j}, \mathrm{j}} \Delta \mathrm{Z}_{\mathrm{j}} \mathrm{A}_{\text {meat }} \overline{\mathrm{QR}}
\end{aligned}
$$

The sum of the power $\left(\mathrm{P}_{\text {meat,i,j }}\right)$ deposited in meat [given by Eq. (15-13)] and the power deposited directly in the coolant must equal the total power in an axial segment of each plate/pin, which is given by $\mathrm{P}_{\mathrm{i}, \mathrm{j}}=\mathrm{Q}_{\mathrm{avg}, \mathrm{i}, \mathrm{j}} \times \mathrm{A}_{\text {meat }} \Delta \mathrm{Z}_{\mathrm{j}}$. The power deposited directly in the coolant is given by $\mathrm{q}_{\text {cool, }, \mathrm{i}, \mathrm{j}} \times \mathrm{A}_{\text {cool }} \Delta \mathrm{Z}_{\mathrm{j}}$. This power balance is expressed as follows.

$$
\mathrm{Q}_{\text {avg, }, \mathrm{j}, \mathrm{Z}} \Delta \mathrm{Z}_{\mathrm{j}} \mathrm{A}_{\text {meat }} \overline{\mathrm{QR}}+\mathrm{q}_{\text {cool, }, \mathrm{j}, \mathrm{j}} \times \mathrm{A}_{\text {cool }} \Delta \mathrm{Z}_{\mathrm{j}}=\mathrm{Q}_{\text {avg, }, \mathrm{j}, \mathrm{j}} \times \mathrm{A}_{\text {meat }} \Delta \mathrm{Z}_{\mathrm{j}}
$$

Dividing this power balance equation by $A_{\text {meat }} \Delta Z_{j}$, and using Eq. (15-11), one obtains Eq. (15-15).

$$
\overline{\mathrm{QR}}+\mathrm{QW} \times\left(\frac{\mathrm{A}_{\text {cool }}}{\mathrm{A}_{\text {meat }}}\right)=1
$$

The PARET/ANL input data description specifies that Eq. (15-15) must be satisfied. This equation can be rewritten as a normalization condition for the input array $\mathrm{QR}_{\mathrm{n}}$, as given by Eq. (15-16). Here (input $\mathrm{QW}) \times\left(\mathrm{A}_{\text {cool }} / \mathrm{A}_{\text {meat }}\right)$ is the fraction of total power that is deposited in coolant.

$$
\overline{\mathrm{QR}}=\frac{\sum_{\mathrm{n}=1}^{\mathrm{NN1} 1} \mathrm{QR}_{\mathrm{n}} \Delta \mathrm{A}_{\mathrm{n}}}{\sum_{\mathrm{n}=1}^{\mathrm{NN1} 1} \Delta \mathrm{A}_{\mathrm{n}}}=1-\mathrm{F}_{\text {cool }} \quad \text { where } \mathrm{F}_{\text {cool }}=(\text { input } \mathrm{QW}) \times\left(\mathrm{A}_{\text {cool }} / \mathrm{A}_{\text {meat }}\right)
$$

PARET/ANL model requires the calculation of local-to-average power density ratios, $\mathrm{PFQ}_{\mathrm{k}, \mathrm{j}}$ for each channel k. So let us start with the local-to-average power density ratios for each nodal volume in the reactor. The local power density used in the ratio is the value averaged over meat cross Section. 


$$
\mathrm{f}_{\mathrm{i}, \mathrm{j}}=\frac{\mathrm{Q}_{\text {avg, }, \mathrm{j}}}{\overline{\mathrm{Q}}}
$$

For each channel of PARET/ANL model, the $P F Q_{k, j}$ of an axial node $j$ is the average of all the $\mathrm{f}_{\mathrm{i}, \mathrm{j}}$ at that axial location in fuel plates/pins represented by that channel. Let us assume that PARET/ANL channel $\mathrm{k}$ represents the fuel plates/pins 1 to $\mathrm{M}$.

$$
\mathrm{PFQ}_{\mathrm{k}, \mathrm{j}}=\frac{\sum_{\mathrm{l}=1}^{\mathrm{M}} \mathrm{f}_{\mathrm{i}, \mathrm{j}} \times \mathrm{A}_{\text {meat }} \Delta \mathrm{Z}_{\mathrm{j}}}{\mathrm{V}_{\mathrm{k}, \mathrm{j}}}
$$

where the denominator $\mathrm{V}_{\mathrm{k}, \mathrm{j}}=\sum_{\mathrm{i}=1}^{\mathrm{M}} \mathrm{A}_{\text {meat }} \Delta \mathrm{Z}_{\mathrm{j}}$ is the sum of all fuel volumes in channel $\mathrm{k}$ for a given axial node j. For that channel, the axially averaged PFQ is

$$
\overline{\mathrm{PFQ}}_{\mathrm{k}}=\frac{\sum_{\mathrm{j}=1}^{\mathrm{NZ}} \mathrm{PFQ}_{\mathrm{k}, \mathrm{j}} \times \mathrm{V}_{\mathrm{k}, \mathrm{j}}}{\mathrm{V}_{\mathrm{k}}}
$$

where the denominator $V_{k}=\sum_{j=1}^{N Z} V_{k, j}$ is the fuel meat volume in PARET/ANL channel $k$. The fuel meat volume fraction array $\mathrm{BM}_{\mathrm{k}}$ by channel (an input data) is defined in terms of $\mathrm{V}_{\mathrm{k}}$ as follows.

$$
\mathrm{BM}_{\mathrm{k}}=\frac{\mathrm{V}_{\mathrm{k}}}{\mathrm{V}_{\mathrm{tot}}}
$$

Using Eqs. (15-19) and (15-20), let us evaluate

$$
\overline{\mathrm{PFQ}}_{\mathrm{k}} \times \mathrm{BM}_{\mathrm{k}}=\frac{\sum_{\mathrm{j}=1}^{\mathrm{NZ}} \mathrm{PFQ}_{\mathrm{k}, \mathrm{j}} \times \mathrm{V}_{\mathrm{k}, \mathrm{j}}}{\mathrm{V}_{\mathrm{k}}} \times \frac{\mathrm{V}_{\mathrm{k}}}{\mathrm{V}_{\mathrm{tot}}}=\frac{\sum_{\mathrm{j}=1}^{\mathrm{NZ}} \mathrm{PFQ}_{\mathrm{k}, \mathrm{j}} \times \mathrm{V}_{\mathrm{k}, \mathrm{j}}}{\mathrm{V}_{\text {tot }}}
$$

Equation (15-18) can be rewritten as $\mathrm{PFQ}_{k, j} \times \mathrm{V}_{\mathrm{k}, \mathrm{j}}=\sum_{1=1}^{\mathrm{M}} \mathrm{f}_{\mathrm{i}, \mathrm{j}} \times \mathrm{A}_{\text {meat }} \Delta \mathrm{Z}_{\mathrm{j}}$. Using this in Eq. (15-21)

$$
\begin{aligned}
& \overline{\mathrm{PFQ}}_{\mathrm{k}} \times \mathrm{BM}_{\mathrm{k}}=\frac{\sum_{\mathrm{j}=1}^{\mathrm{NZ}} \mathrm{PFQ}_{\mathrm{k}, \mathrm{j}} \times \mathrm{V}_{\mathrm{k}, \mathrm{j}}}{\mathrm{V}_{\mathrm{k}}} \times \frac{\mathrm{V}_{\mathrm{k}}}{\mathrm{V}_{\text {tot }}}=\frac{\sum_{\mathrm{j}=1}^{\mathrm{NZ}} \mathrm{PFQ}_{\mathrm{k}, \mathrm{j}} \times \mathrm{V}_{\mathrm{k}, \mathrm{j}}}{\mathrm{V}_{\text {tot }}} \\
& \overline{\mathrm{PFQ}}_{\mathrm{k}} \times \mathrm{BM}_{\mathrm{k}}=\frac{\sum_{\mathrm{j}=1}^{\mathrm{NZ}} \sum_{\mathrm{i}=1}^{\mathrm{M}} \mathrm{f}_{\mathrm{i}, \mathrm{j}} \times \mathrm{A}_{\text {meat }} \Delta \mathrm{Z}_{\mathrm{j}}}{\mathrm{V}_{\text {tot }}}
\end{aligned}
$$

Replacing Eq. (15-17) in Eq. (15-23) 


$$
\overline{\mathrm{PFQ}}_{\mathrm{k}} \times \mathrm{BM}_{\mathrm{k}}=\frac{\sum_{\mathrm{j}=1}^{\mathrm{NZ}} \sum_{\mathrm{i}=1}^{\mathrm{M}} \mathrm{Q}_{\mathrm{avg}, \mathrm{i}, \mathrm{j}} \times \mathrm{A}_{\text {meat }} \Delta \mathrm{Z}_{\mathrm{j}}}{\mathrm{V}_{\text {tot }} \overline{\mathrm{Q}}}
$$

The denominator of Eq. (15-24) is $\mathrm{V}_{\text {tot }} \overline{\mathrm{Q}}=\mathrm{P}_{\text {tot }}$. The numerator is the total power (including the power in coolant) in PARET/ANL channel $k$, $P_{\text {tot,k }}$, as defined by Eq. (15-25). Replacing Eq. (15-25) in Eq. (15-24), we get Eq. (15-26) .

$$
\begin{aligned}
& \mathrm{P}_{\text {tot, } \mathrm{k}}=\sum_{\mathrm{j}=1}^{\mathrm{NZ}} \sum_{\mathrm{i}=1}^{\mathrm{M}} \mathrm{Q}_{\text {avg, }, \mathrm{j}, \mathrm{j}} \times \mathrm{A}_{\text {meat }} \Delta \mathrm{Z}_{\mathrm{j}} \\
& \overline{\mathrm{PFQ}}_{\mathrm{k}} \times \mathrm{BM}_{\mathrm{k}}=\frac{\mathrm{P}_{\text {tot }, \mathrm{k}}}{\mathrm{P}_{\text {tot }}}
\end{aligned}
$$

Eq. (15-26) indicates that in order for the input arrays $\mathrm{BM}_{\mathrm{k}}$ and $\mathrm{PFQ}_{\mathrm{k}, \mathrm{j}}$ to be self-consistent, the product of the axial average of $\mathrm{PFQ}_{\mathrm{k}, \mathrm{j}}$ in a PARET/ANL channel times its $\mathrm{BM}$ must equal the fraction of power in that channel. The axial average of $P_{F Q}$ in a PARET/ANL channel is found by Eq. (15-19) which can be rewritten as Eq. (15-27).

$$
\overline{\mathrm{PFQ}}_{\mathrm{k}}=\frac{\sum_{\mathrm{j}=1}^{\mathrm{NZ}} \mathrm{PFQ}_{\mathrm{k}, \mathrm{j}} \times \Delta \mathrm{Z}_{\mathrm{j}}}{\sum_{\mathrm{j}=1}^{\mathrm{NZ}} \Delta \mathrm{Z}_{\mathrm{j}}}
$$

\subsection{Channel-Wise Power Density In Fuel Meat}

The code uses channel-wise power density in meat, $\mathrm{q}_{\text {chan,k,j,n }}$, excluding the power deposited directly in the coolant. This is basically the average of pin-wise (or plate-wise) nodal power density in meat $\mathrm{q}_{\mathrm{i}, \mathrm{j}, \mathrm{n}}$, over all the pins/plates (i=1 to $\mathrm{M}$ ) constituting a channel $\mathrm{k}$.

$$
\mathrm{q}_{\text {chan }, \mathrm{k}, \mathrm{j}, \mathrm{n}}=\frac{\sum_{\mathrm{i}=1}^{\mathrm{M}} \mathrm{q}_{\mathrm{i}, \mathrm{j}, \mathrm{n}} \Delta \mathrm{A}_{\mathrm{n}} \times \Delta \mathrm{Z}_{\mathrm{j}}}{\sum_{\mathrm{i}=1}^{\mathrm{M}} \Delta \mathrm{A}_{\mathrm{n}} \times \Delta \mathrm{Z}_{\mathrm{j}}}
$$

Using Eq. (15-11) in Eq. (15-28) 


$$
\mathrm{q}_{\text {chan }, \mathrm{k}, \mathrm{j}, \mathrm{n}}=\frac{\sum_{\mathrm{i}=1}^{\mathrm{M}} \mathrm{Q}_{\text {avg, }, \mathrm{j}, \mathrm{j}} \times \mathrm{QR}_{\mathrm{n}} \Delta \mathrm{A}_{\mathrm{n}} \times \Delta \mathrm{Z}_{\mathrm{j}}}{\sum_{\mathrm{i}=1}^{\mathrm{M}} \Delta \mathrm{A}_{\mathrm{n}} \times \Delta \mathrm{Z}_{\mathrm{j}}}=\frac{\mathrm{QR}_{\mathrm{n}}}{\mathrm{M}} \sum_{\mathrm{i}=1}^{\mathrm{M}} \mathrm{Q}_{\text {avg,i,j }}
$$

Using Eq. (15-17) in Eq. (15-29)

$$
\mathrm{q}_{\text {chan, }, \mathrm{j}, \mathrm{n}}=\frac{\overline{\mathrm{Q}} \times \mathrm{QR}_{\mathrm{n}}}{\mathrm{M}} \sum_{\mathrm{i}=1}^{\mathrm{M}} \mathrm{f}_{\mathrm{i}, \mathrm{j}}
$$

The sum $\sum_{i=1}^{M} f_{i, j}$ is obtained from Eq. (15-18).

$$
\begin{aligned}
& \sum_{1=1}^{M} f_{i, j}=\frac{P F Q_{k, j} \times V_{k, j}}{A_{\text {meat }} \Delta Z_{j}}=\frac{P F Q_{k, j} \times \sum_{i=1}^{M} A_{\text {meat }} \Delta Z_{j}}{A_{\text {meat }} \Delta Z_{j}} \\
& \sum_{i=1}^{M} f_{i, j}=P F Q_{k, j} \times M
\end{aligned}
$$

Using Eq. (15-32) in Eq. 15-28, the channel-wise power density in meat is given by Eq. (15-33):

$$
\mathrm{q}_{\mathrm{chan}, \mathrm{k}, \mathrm{j}, \mathrm{n}}=\overline{\mathrm{Q}} \times \mathrm{PFQ}_{\mathrm{k}, \mathrm{j}} \times \mathrm{QR}_{\mathrm{n}}
$$

\subsection{Power Density In Coolant}

Eq. (15-33) can be used to find the pin/plate linear power in meat in axial node $\mathrm{j}$ of PARET/ANL channel $\mathrm{k}$, as shown by Eq. (15-34). Dividing this linear power by (1- $\mathrm{F}_{\text {cool }}$ ), one gets the total linear power (i.e., including the power deposited in coolant), as shown in Eq. (15-35). Multiplying the total linear power of Eq. (15-35) by $\mathrm{F}_{\mathrm{cool}}$, one gets the linear power in the coolant, as shown in Eq. (15-36). Dividing Eq. (15-36) by the coolant flow area associated with a pin/plate gives the power density in coolant, as shown by Eq. (15-37).

$$
\begin{aligned}
& \text { Pin/plate linear power in meat of channel } k=\sum_{n=1}^{N N 1-1} q_{c h a n, j, k, n} \times \Delta A_{n} \\
& \text { Pin/plate total linear power of channel } \mathrm{k}=\frac{1}{\left(1-\mathrm{F}_{\text {cool }}\right)} \sum_{\mathrm{n}=1}^{\mathrm{NN1}-1} \mathrm{q}_{\mathrm{chan}, \mathrm{j}, \mathrm{k}, \mathrm{n}} \times \Delta \mathrm{A}_{\mathrm{n}} \\
& \text { Pin/plate linear power in coolant of channel } k=\frac{F_{\text {cool }}}{\left(1-F_{\text {cool }}\right)} \sum_{n=1}^{N N 1-1} q_{c h a n, j, k, n} \times \Delta A_{n} \\
& \mathrm{q}_{\text {cool }, \mathrm{k}, \mathrm{j}}=\frac{\mathrm{F}_{\text {cool }}}{\mathrm{A}_{\text {cool }} \times\left(1-\mathrm{F}_{\text {cool }}\right)} \sum_{\mathrm{n}=1}^{\mathrm{NN1}-1} \mathrm{q}_{\text {chan }, \mathrm{j}, \mathrm{k}, \mathrm{n}} \times \Delta \mathrm{A}_{\mathrm{n}}
\end{aligned}
$$

Replacing Eqs. (15-33) and (15-16), Eq. (15-37) becomes Eq. (15-38). Noting that the input datum $\mathrm{QW}=\mathrm{F}_{\text {cool }} \times \mathrm{A}_{\text {meat }} / \mathrm{A}_{\text {cool }}$, Eq. (15-38) becomes Eq. (15-39). 


$$
\begin{aligned}
& \mathrm{q}_{\text {cool }, \mathrm{k}, \mathrm{j}}=\frac{\mathrm{F}_{\text {cool }} \times \overline{\mathrm{Q}} \times \mathrm{PFQ}_{\mathrm{k}, \mathrm{j}}}{\mathrm{A}_{\text {cool }} \times\left(1-\mathrm{F}_{\text {cool }}\right)} \sum_{\mathrm{n}=1}^{\mathrm{NN1}-1} \mathrm{QR}_{\mathrm{n}} \times \Delta \mathrm{A}_{\mathrm{n}}=\frac{\mathrm{F}_{\text {cool }} \times \overline{\mathrm{Q}} \times \mathrm{PFQ}_{\mathrm{k}, \mathrm{j}}}{\mathrm{A}_{\text {cool }} \times\left(1-\mathrm{F}_{\text {cool }}\right)} \mathrm{A}_{\text {meat }} \times\left(1-\mathrm{F}_{\text {cool }}\right) \\
& \mathrm{q}_{\text {cool }, \mathrm{k}, \mathrm{j}}=\frac{\mathrm{F}_{\text {cool }} \times \overline{\mathrm{Q}} \times \mathrm{PFQ}_{\mathrm{k}, \mathrm{j}}}{\mathrm{A}_{\text {cool }}} \mathrm{A}_{\text {meat }}=\overline{\mathrm{Q}} \times \mathrm{PFQ}_{\mathrm{k}, \mathrm{j}} \times \mathrm{QW}
\end{aligned}
$$

\subsection{Check That Eq. (15-33) Is Consistent With Eq. (15-27)}

To show this, the power in PARET/ANL channel $\mathrm{k}$ found from Eq. (15-33) will be shown to equal to $P_{\text {tot,k }}$ given by Eq. (15-27). The sum over indices $j$ and $n$ of Eq. (15-33) times the nodal meat volume in channel $\mathrm{k}$ equals the power in meat of channel $\mathrm{k}$, as shown by Eq. (15-40). The power in meat is not the total power in the channel given by Eq. (15-27), rather a fraction (1- $\left.F_{\text {cool }}\right)$ of $P_{\text {tot,k. }}$ To show the consistency, the right hand side of Eq. (15-40) should equal (1- $\left.F_{\text {cool }}\right) P_{\text {tot,k. }}$

$$
\begin{aligned}
& \text { Power in meat of channel } \mathrm{k}=\sum_{\mathrm{j}=1}^{\mathrm{NZ}} \sum_{\mathrm{n}=1}^{\mathrm{NN1} 1-1} \mathrm{M} \Delta \mathrm{A}_{\mathrm{n}} \Delta \mathrm{Z}_{\mathrm{j}} \times \mathrm{q}_{\text {chan, } \mathrm{k}, \mathrm{j}, \mathrm{n}} \\
& =\sum_{\mathrm{j}=1}^{\mathrm{NZ}} \sum_{\mathrm{n}=1}^{\mathrm{NN1}-1} \mathrm{M} \Delta \mathrm{A}_{\mathrm{n}} \Delta \mathrm{Z}_{\mathrm{j}} \times \overline{\mathrm{Q}} \times \mathrm{PFQ}_{\mathrm{k}, \mathrm{j}} \times \mathrm{QR}_{\mathrm{n}}
\end{aligned}
$$

Substituting Eq. (15-16) in Eq. (15-40)

$$
\begin{aligned}
& \text { Power in meat of channel } \mathrm{k}=\mathrm{M} \times \overline{\mathrm{Q}} \sum_{\mathrm{j}=1}^{\mathrm{NZ}} \Delta \mathrm{Z}_{\mathrm{j}} \times \mathrm{PFQ}_{\mathrm{k}, \mathrm{j}} \sum_{\mathrm{n}=1}^{\mathrm{NN1}-1} \Delta \mathrm{A}_{\mathrm{n}} \times \mathrm{QR}_{\mathrm{n}} \\
& = \\
& =\mathrm{M} \times \overline{\mathrm{Q}} \sum_{\mathrm{j}=1}^{\mathrm{NZ}} \Delta \mathrm{Z}_{\mathrm{j}} \times \mathrm{PFQ}_{\mathrm{k}, \mathrm{j}}\left(1-\mathrm{F}_{\text {cool }}\right) \mathrm{A}_{\text {meat }} \\
& \mathrm{M} \times \overline{\mathrm{Q}}\left(1-\mathrm{F}_{\text {cool }}\right) \mathrm{A}_{\text {meat }} \sum_{\mathrm{j}=1}^{\mathrm{NZ}} \Delta \mathrm{Z}_{\mathrm{j}} \times \mathrm{PFQ}_{\mathrm{k}, \mathrm{j}}
\end{aligned}
$$

Eq. (15-19) can be rewritten as $\overline{\mathrm{PFQ}}_{\mathrm{k}} \times \mathrm{L}_{\mathrm{h}}=\sum_{\mathrm{j}=1}^{\mathrm{NZ}} \mathrm{PFQ}_{\mathrm{k}, \mathrm{j}} \times \Delta \mathrm{Z}_{\mathrm{j}}$ where $\mathrm{L}_{\mathrm{h}}$ is fueled length of each plate/pin. Using this, Eq. (15-41) becomes Eq. (15-42). Using Eq. (15-3), Eq. (15-42) becomes Eq. (1543).

$$
\begin{aligned}
\text { Power in meat of channel } \mathrm{k} & =\mathrm{M} \times \overline{\mathrm{Q}}\left(1-\mathrm{F}_{\text {cool }}\right) \mathrm{A}_{\text {meat }} \times \mathrm{L}_{\mathrm{h}} \times \overline{\mathrm{PFQ}} \\
\text { Power in meat of channel } \mathrm{k} & =\mathrm{M} \times \frac{\mathrm{P}_{\text {tot }}}{\mathrm{V}_{\text {tot }}}\left(1-\mathrm{F}_{\text {cool }}\right) \mathrm{A}_{\text {meat }} \times \mathrm{L}_{\mathrm{h}} \times \overline{\mathrm{PFQ}}
\end{aligned}
$$

Noting that the volume of meat in channel $k$ is given by $V_{k}=M \times A_{\text {meat }} \times L_{h}$, Eq. (15-43) can be rewritten as Eq. (15-38). Using Eq. (15-20), Eq. (15-44) becomes Eq. (15-45). 
Power in meat of channel $\mathrm{k}=\mathrm{V}_{\mathrm{k}} \times \frac{\mathrm{P}_{\text {tot }}}{\mathrm{V}_{\text {tot }}}\left(1-\mathrm{F}_{\text {cool }}\right) \times \overline{\mathrm{PFQ}}$

Power in meat of channel $\mathrm{k}=\mathrm{P}_{\text {tot }}\left(1-\mathrm{F}_{\text {cool }}\right) \times \overline{\mathrm{PFQ}} \times \mathrm{BM}_{\mathrm{k}}$

$=\left(1-\mathrm{F}_{\text {cool }}\right) \times \mathrm{P}_{\text {tot }}$ given by Eq. (20)

The right hand side of Eq. (15-40) is shown to equal (1- $\left.F_{\text {cool }}\right) P_{\text {tot,k }}$ as required for consistency.

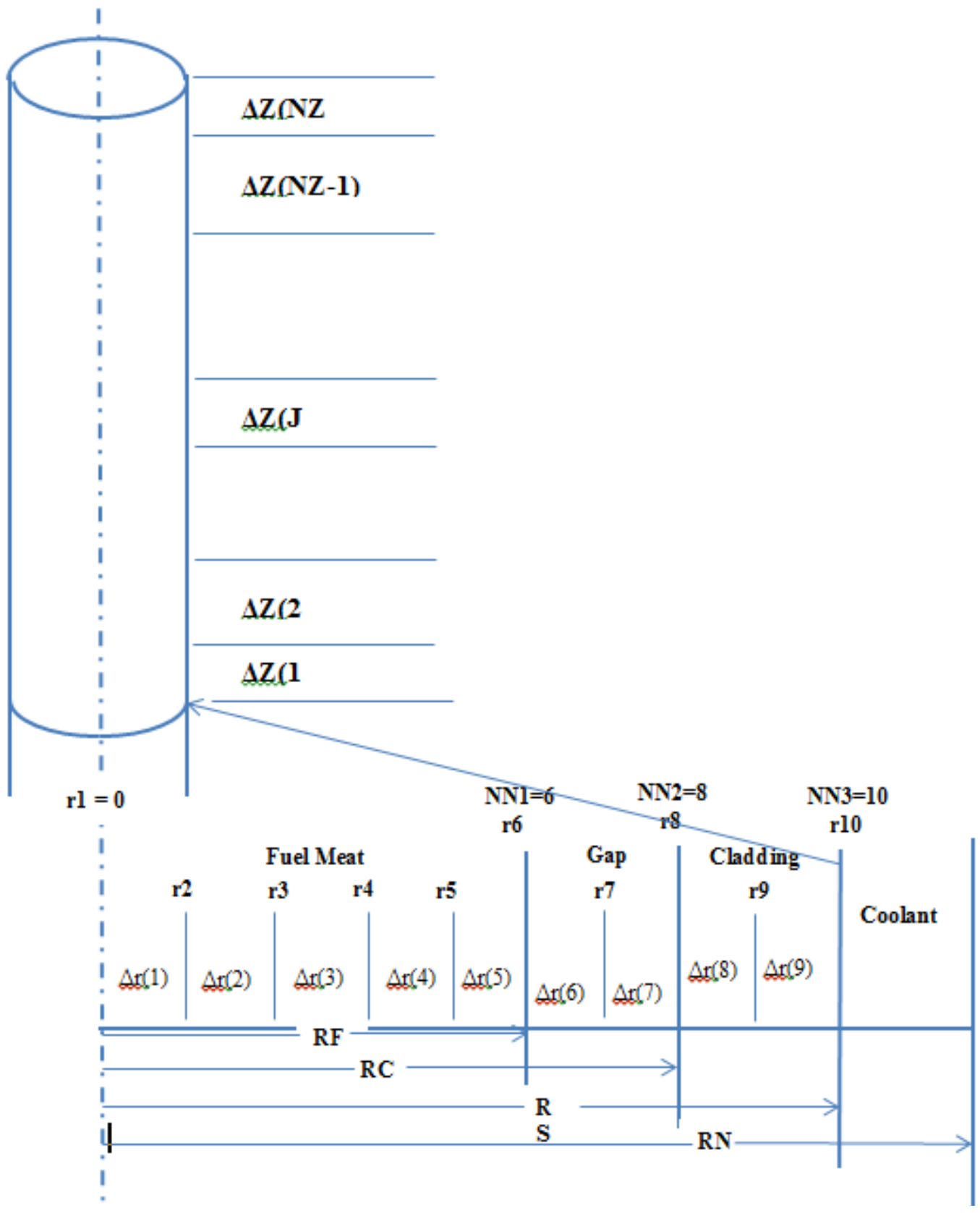

Figure 15.1 Radial and Axial Mesh structure used by PARET/ANL in a Fuel Pin 


\section{Appendix IV Energy Conservation in PARET}

P. Garner (ANL, private communication) provided a sample 2-channel case with complex axial power shapes. Now it will be shown that increasing the number of axial nodes, coupled with retaining the complex axial power shapes, leads to significant improvements in the accuracy of the energy gain in the coolant.

A Mathematica notebook was created that interpolated Garner's power shapes and edited new nodal powers for any desired number of axial mesh nodes. The number of axial nodes was increased from the original 11 to 21 , and then to 41 . These choices halved the mesh spacing, and halved it again.

Figure 16.1 shows the original 11-point power shape in the hot channel. Also shown is the fitted interpolated curve, and the 21 fitted points. Figure 16.2 is the same, but for a 41-node fit. Table 16.1 shows how the energy gain in the coolant varied in time over the first second of operation. The input model defines that there is no introduction of any change over the first second of time--hence in that interval it is a "null transient".

\section{CONCLUSIONS}

It can be seen that the numerical scheme for computing the energy gain in the coolant becomes very stable at all edited times during the first second of operation, when the number of axial nodes is increased to 41 . This problem is quite complex. For the 41-node case, one can see that the edit of "ENERGY GAIN IN THE COOLANT" is within $0.013 \%$ over $0.2 \leq \mathrm{t} \leq 1$ second. These results indicate that the energy gain edits are probably correct for this problem.

Table 16.1 Energy Gain for Real Axial Power Profile (from P. Garner)

\begin{tabular}{|l|l|l|}
\hline Time, s & 21 Axial Nodes: Gain, MW & 41 Axial Nodes: Gain, MW \\
\hline & & \\
\hline .1 & 1.03902 & 1.03900 \\
\hline .2 & 1.04053 & 1.03996 \\
\hline .3 & 1.03923 & 1.03987 \\
\hline .4 & 1.03931 & 1.03990 \\
\hline .5 & 1.03924 & 1.03994 \\
\hline .6 & 1.03919 & 1.03995 \\
\hline .7 & 1.03914 & 1.03997 \\
\hline .8 & 1.03910 & 1.03997 \\
\hline .9 & 1.03908 & 1.03998 \\
\hline 1.0 & 1.03905 & 1.03997 \\
\hline
\end{tabular}




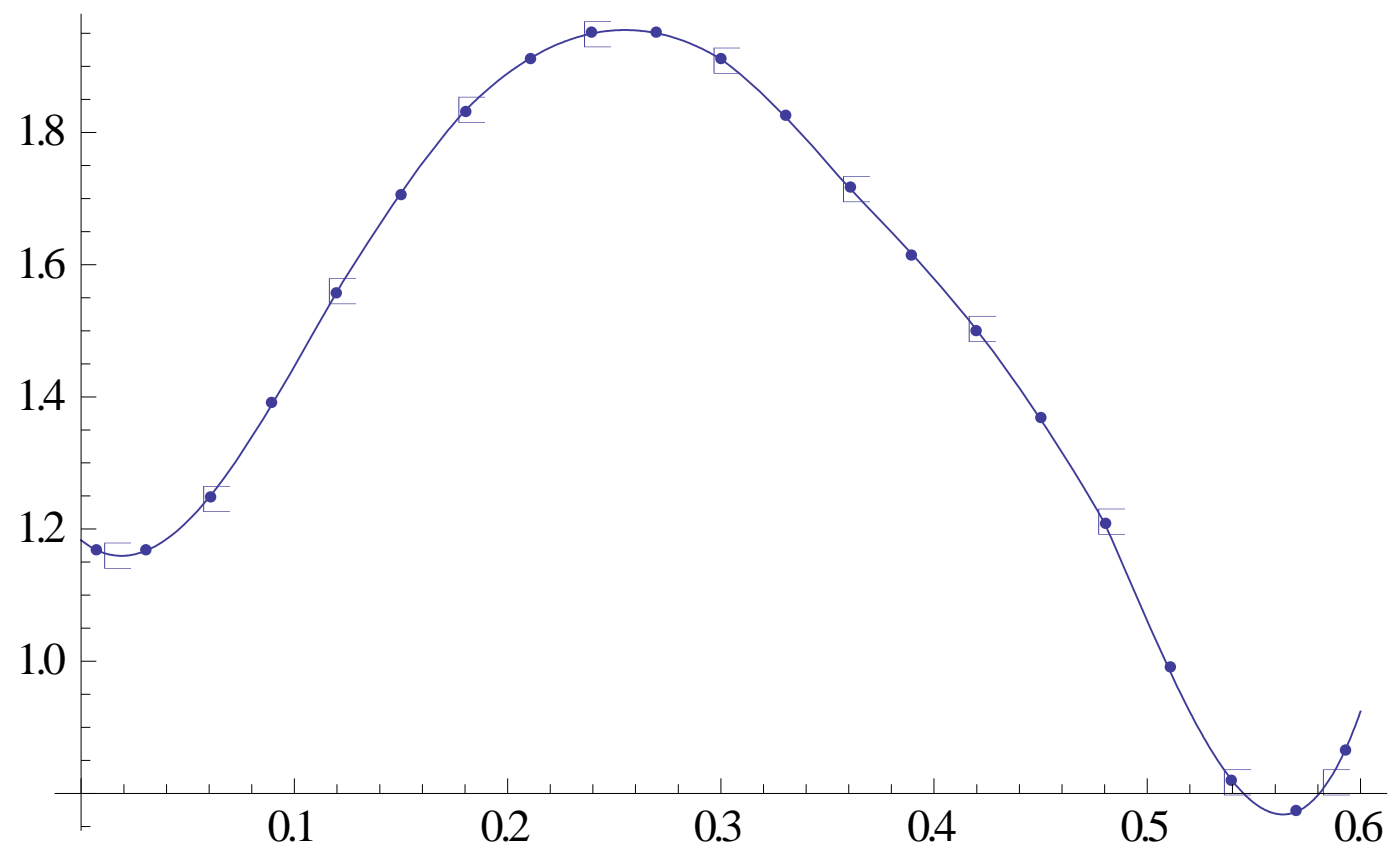

Figure 16.1 Axial Power Shape in the Hot Channel (21 nodes) Small dots are interpolated points on the fitted curve through the large dots.

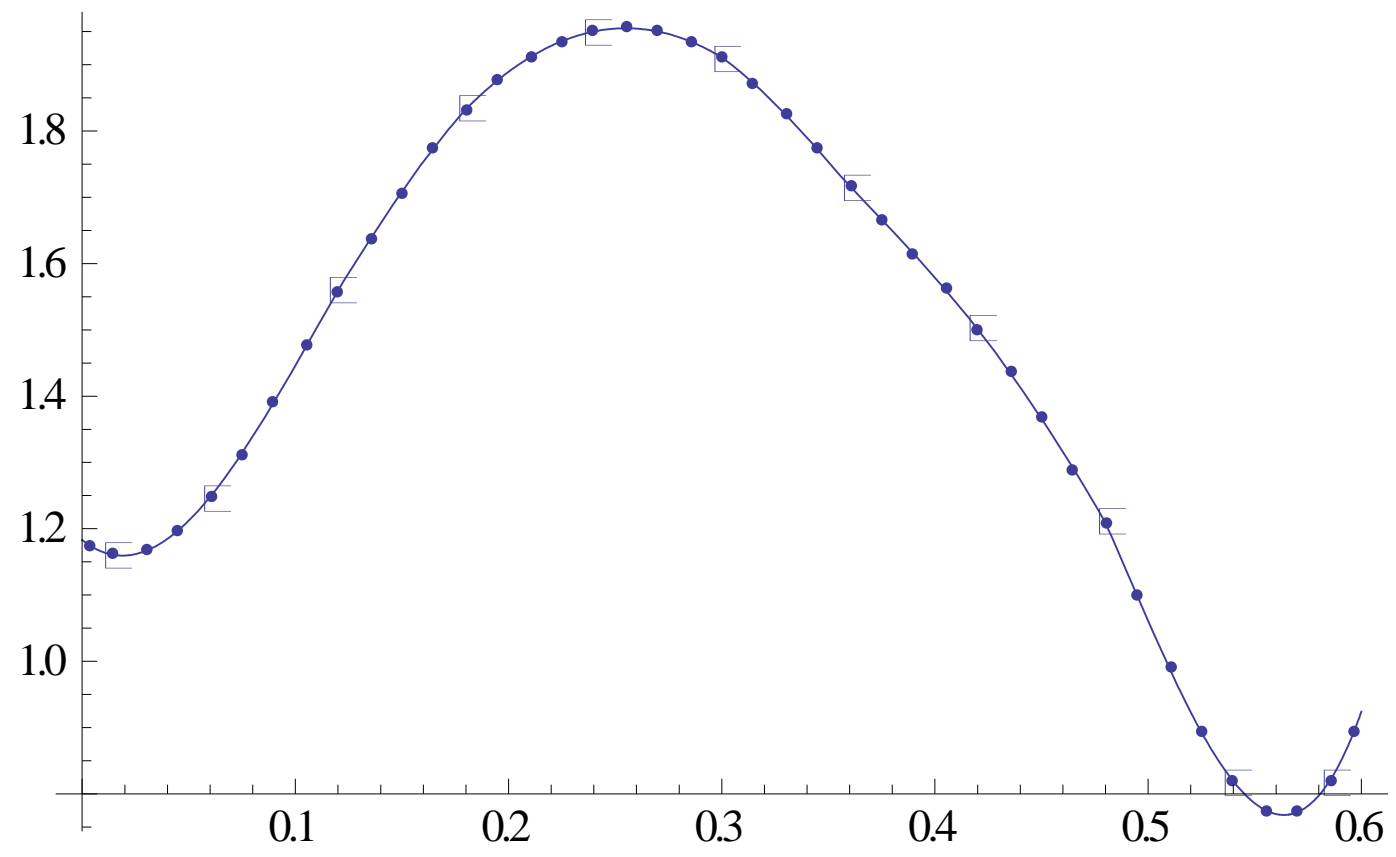

Figure 16.2 Axial Power Shape in the Hot Channel (41 nodes) Small dots are interpolated points on the fitted curve through the large dots. 


\section{Appendix VII Axial Nodalization}

PARET/ANL has always used two sets of axial nodes: the given set on card types 3000 (increments DZ in the code), and a fluid node set made from the first by placing mesh interfaces at the centers of all nodes $\mathrm{DZ}(\mathrm{j})$ for $1<\mathrm{j}<\mathrm{NZ}$. There are NZ axial nodes in the fuel for the heat source. The user normally specifies these to be of the same axial length. With this construction, there are NZ-1 axial nodes in the coolant, separated by distances DELZ(j). Note that the first and last axial nodes in the coolant are larger than the others: node 1 has $\Delta \mathrm{z}_{1}=\mathrm{DELZ}(1)=\mathrm{DZ}(1)+0.5^{*} \mathrm{DZ}(2)$, and node NZ-1 has $\Delta \mathrm{z}_{\mathrm{NZ}-1}=$ DELZ(NZ-1) $=\mathrm{DZ}(\mathrm{NZ})+0.5^{*} \mathrm{DZ}(\mathrm{NZ}-1)$. Enthalpy rise and fluid temperature edits by PARET/ANL are at the end points of the unequally-spaced nodes collected into vector DELZ. See Fig. 5 of the Obenchain document [1]. The conservation of energy equation is given in Eq. (107) by Obenchain. This equation uses DZ and $\Delta$ to identify spatial increments.

It was found that by replacing the usage of DZ by DELZ, the error in the energy conservation was greatly reduced. Results with and without this change are shown in Figure 17.1 for a simple 1-channel test. Similar behavior is obtained for a 12-channel test. As the number of axial nodes is increased, the error clearly diminishes. But there is an unexpected result that the trend is different for even numbers of nodes vs. odd numbers of nodes. In fact, the odd number choice is very much better than is the even number choice, for the revised V7.4, while the opposite is true for older uncorrected versions. This behavior most likely is associated with the "four point explicit" difference representation used to solve the energy conservation equation.

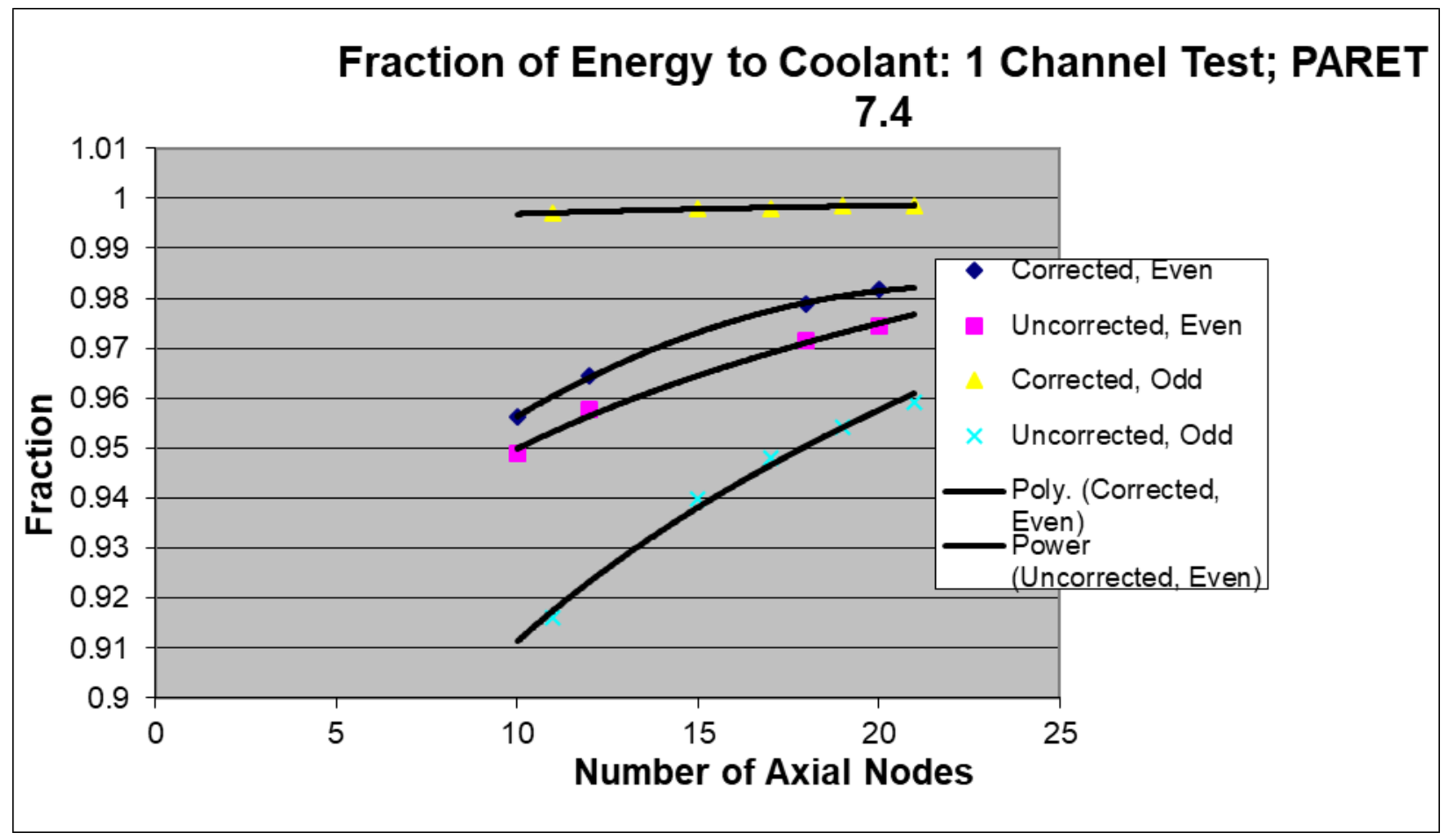

Figure 17.1

Effect of Increasing Axial Nodes on Energy Conservation

Table 17.1 and Table 17.2 show the effect of changing integration time step size, on the fraction of energy delivered to the coolant in a null transient. 
Table 17.1 Fraction of Energy to Coolant; 1 Channel Test, Flat Axial Profile

\begin{tabular}{|l||l|l|}
\hline Time step size, $s$ & Old Versions & Version 7.4 \\
\hline 0.002 & 0.954 & 0.987 \\
\hline 0.0001 & 0.9382 & 0.9966 \\
\hline \hline 0.00001 & 0.9398 & 0.9979 \\
\hline \hline & & \\
\hline
\end{tabular}

Table 17.2 Fraction of Energy to Coolant; 12 Channel Test, Flat Axial Profile

\begin{tabular}{|l|l|l|}
\hline Time step size, $\mathrm{s}$ & Old Versions & Version 7.4 \\
\hline \hline 0.0001 & 0.9383 & 0.9965 \\
\hline 0.00001 & 0.9341 & 0.9923 \\
\hline 0.000001 & 0.9398 & 0.9920 \\
\hline & & \\
\hline
\end{tabular}

\section{Choosing a "Best" Axial Mesh}

Within that subject, the issue of stability has undergone a great deal of research. PARET/ANL uses a standard criterion for stability to determine if the enthalpy calculations are to remain stable in time. If that criterion is violated at any axial node in any channel, at any time, the calculation terminates with an error message. This check takes care of instability in time only. The subjects of stability in time and monotonic error growth due to centered advection differencing are discussed by Roache in [37]. The latter is a so-called static instability, not in time, but in space. This type of error is introduced by changes in mesh node lengths. The comment is made by Roache that ".unless the mesh spacing is changed slowly, the formal truncation error is actually deteriorated, rather than improved." This comment was in the context of attempts to locally improve the quality of a solution by deviating from a uniform mesh.

The PARET/ANL user typically selects uniform length nodes for the heat source. PARET/ANL internally creates a fluid node set in which the first and last nodes are $50 \%$ larger than the others. One finds oscillations in the enthalpy solution. For example, the enthalpy rise across a set of interior nodes should always be the same, if the fluid remains single-phase liquid and the axial power profile is flat. And yet the code produces results that show a "pairing" effect where pairs of axial nodes have the correct total enthalpy rise, but one of the pair is too low, and the other is too high. This pairing effect occurs for both the old and for the revised coding in subroutine enthal. It shows an oscillating error about the true solution, where the magnitude of the oscillation is quite large.

The question that comes to mind is: What is the best mesh? What mesh is minimally subject to static instability? If the heat source nodes are selected to be of uniform length, what would happen if the fluid nodes were of equal length? The heat source nodes have to be chosen to assure that condition. One simply sets the heat source nodes to be of size

$$
\mathrm{L} /(\mathrm{NZ}-1), 1<\mathrm{j}<\mathrm{NZ} \text {; and } \mathrm{L} /[2(\mathrm{NZ}-1)] \text { for } \mathrm{j}=1 \text {, or } \mathrm{j}=\mathrm{NZ}
$$


Tests were run with various numbers of axial nodes, for the standard 1-channel case with a flat axial profile. The results obtained for energy conservation are amazing, as shown in Table 17.3. There is essentially no error at all, for any choice from 9 to 21 axial nodes! Furthermore, the enthalpy solution shows consistent heat additions to every node, whether the model has even or odd numbers of nodes. I believe this confirms the conclusion that the non-uniform fluid node spacing is the source of a static instability that does not damp out over time, but in fact grows to some limiting oscillatory error from node to node.

As for older versions of PARET, how will they perform with this special axial mesh? As it turns out, they will do just the same as Version 7.5 because the logical error in subroutine enthal is fortuitously corrected. Note, however, that in general the old PARET/ANL versions will perform substantially less accurately for any other choice of axial nodalization than does Version 7.4.

Table 17.3 Fraction of Energy to Coolant, 1 Channel Test, Flat Axial Profile; Uniform Fluid Node Spacing; PARET/ANL 7.4

\begin{tabular}{|l|l|}
\hline Number of Axial Nodes & $\begin{array}{l}\text { Error in Energy Conservation, } \\
\%\end{array}$ \\
\hline 9 & -0.0021 \\
\hline 10 & +0.0019 \\
\hline 15 & -0.0015 \\
\hline 20 & -0.0012 \\
\hline 21 & -0.0014 \\
\hline
\end{tabular}




\section{Appendix VIII Users' Guidelines}

The purpose of this chapter is to help PARET/ANL users by providing:

1. an overview of the code and the information needed to determine its applicability to model a given reactor and/or transients of interest (Section 1818.1),

2. a summary of the lessons learned from comparisons with reactivity insertion experiments (SPERT-III and SPERT-I reactors) and with the RELAP5 [34] code (Section 1818.2 and 18.3),

3. recommendations and guidelines about modeling choices based on the experience of the developers and various experienced users (Sections 18.4 to 18.11),

4. clarifications about some input options (Sections 18.12 to 18.15)

\subsection{General Overview of PARETIANL}

The original PARET code was designed for predicting the course of nondestructive (events in which fuel or structural deformation does not occurs) reactivity accidents in small reactor cores in which there are no space-time effects on the neutron flux (i.e., point-kinetics where only the neutron flux magnitude changes with time) [18-1]. More specifically, the code was designed to analyze reactivity insertion transients in the light-water-cooled plate-type and rod-type cores tested in the SPERT-III reactor. Since then, PARET/ANL has been used routinely to analyze transients in research reactor cores with similar fuel designs (flat plate, curved plate, tube, and pin) using light or heavy water coolant.

PARET/ANL models the fuel assemblies of a reactor core as one or more channels. Each of these channels consists of a half fuel plate or a pin (which can be composed of multiple layers/rings to represent cladding, gap, oxide layer, and other laminated fuel designs) and a half coolant channel. Each channel is thermal-hydraulically independent but coupled through reactivity feedback effects (from coolant density and temperature changes as well as fuel temperature changes and fuel plate thermal expansion) to the whole core. The code also contains logic models for automatic trips on period, power, and flow as well as models for decay heat after shutdown and control rod reactivity versus time or position. More details about PARET/ANL's one-dimensional hydrodynamic momentum integral model, heat transfer models and point-kinetics model can be found in [18-1].

PARET/ANL core representation by channels is adequate for the simulation of transients affecting mainly the core region. System transients requiring the simulation of coolant regions other than the core cannot be modeled with PARET/ANL due to the lack of representation of components such as valves, piping, heat exchangers, etc. However, three simplified models have been implemented in PARET/ANL to approximate three types of transients under specific conditions: two different models to estimate buoyancy-driven flow in pool-type reactors, and a loss-of-flow model.

To evaluate the applicability of PARET/ANL to model a given reactor and/or transient, the user should take into consideration the assumptions used in the thermal-hydraulics and point-kinetics solutions as well as in the various other models. Therefore the remainder of this Section discusses these assumptions.

The main assumptions in the PARET/ANL thermal-hydraulic solution are:

1. A thermal-hydraulic solution is obtained for each PARET/ANL channel independently

2. The radial heat conduction is modeled (axial and lateral heat conduction are neglected). 
3. The radial heat flux is assumed symmetric, i.e., half of the heat goes out of each side of the plate

4. Each coolant channel is assumed heated by two half-plates at the same power

5. Core internal structures cannot be modeled (grid plate, side plates, core shroud, fuel assembly cans or channel walls, solid coolant or reflector).

6. The use of steady-state heat transfer correlations, a simplified boiling model considered in the developmental stage and an incompressible hydrodynamic model.

A few comments about the impact of the thermal-hydraulics assumptions on the simulation of typical events in research reactors:

1. For longer transients and for steady-state, the user should review the implications of neglecting the thermal-hydraulic coupling between channels. For most transient events lasting up to a few seconds, the channels are effectively thermal-hydraulically decoupled since the event is terminated before any potential coupling could take place. Reactor designs using fuel pins can be modeled as long as there is no significant cross-flow between the subchannels.

2. Axial heat conduction is typically important only for transients which involve steep axial temperature gradients due to large differences in coolant voiding conditions. Lateral conduction near the fuel plate unheated edge can be important if the power peak occurs in the same region. However, both the lateral and axial heat conduction can conservatively be ignored.

3. The heat flux is nearly symmetric for fuel assemblies using flat or slightly curved thin fuel plates when the flow conditions on each side of a fuel plate are similar. For a fuel assembly design with different flow conditions in both channels, this assumption is conservative when modeling the hot side of a fuel plate. The symmetry assumption is less accurate for tubes when the ratio of tube radius to tube thickness is less than 10 . Note that variations in that symmetry are typically of the order of a few percent, i.e., small compared to the other uncertainties associated with modeling transients.

4. The heat flux symmetry assumption is always conservative when modeling the hot plate/channel.

5. The importance of modeling internal core structures depends on their contributions to heat removal and/or reactivity feedback for a transient in a given reactor. For most transients, the heat removal contribution of these structures can be conservatively ignored. For slow transients, the user should pay attention to the potential reactivity feedback of heating the reflector region.

6. The prediction by PARET/ANL of a thermal and/or hydraulic crisis should be interpreted as a qualitative indication rather than a reliable quantitative prediction [18-1].

Based on the various assumptions discussed up to this point, PARET/ANL can model adequately reactivity insertions resulting in limiting voiding. These assumptions also imply that the code cannot be recommended for quantitative analyses of reactivity insertions resulting in significant voiding of the coolant channels since modeling accurately such events requires good predictive capabilities of phenomena such as: 1) the impact of the void distribution in the various fuel assemblies on the power shapes and reactivity feedback coefficients, 2) the onset of thermalhydraulic crises and possibly the resulting cladding and/or fuel melting, and 3) fuel deformation including the impact of reflooding ("quenching"). The user should read Section 18.2.2 to understand 
the level of agreement between calculation and measurements that have been historically achieved for this type of events.

The rest of this Section provides a description of the approximate system-type transient models and their assumptions. These models are designed to simulate the expected stable, dominant core flow pattern of upflow everywhere in the heated channels, at all times.

The first model (IFLOW=4, NLUP2=0) is designed to estimate buoyancy-driven flow in a reactor submerged in an infinite pool (good assumption when the pool water's heat capacity is very large compared to the energy release of the event). The model assumes that the coolant flows only through the fuel assembly inlets and outlets which are opened directly to the pool. The coolant is assumed to be drawn only from the pool which remains at constant temperature throughout the transient. This model does not take into account any return flow path other than through the pool.

The second model (IFLOW=4, NLUP2=1) is designed to estimate the buoyancy-driven flow in a Miniature Neutron Source Reactor (MNSR). The reactor core is contained in a closed tank which is submerged in a very large but not infinite pool. In an MNSR, when operating at power, the coolant flows though the core and returns to the inlet by a complex downcomer between the core inner tank and the outer tank wall. The model approximates this flow path using an equivalent hydraulic resistance. It assumes that this region is unheated (no gamma heating or conduction through the inner tank). In the model, the coolant entering the downcomer is the same as the coolant exiting the core. The initial unheated water in the downcomer flows over time to the core inlet and is followed by the heated water. The small heat exchange through the tank wall between the coolant in the downcomer and the pool water is taken into account. The flow resistance in the downcomer region is approximated through the use of inlet and outlet unrecoverable pressure loss coefficients. The model also has provision for representing heat removal from the pool by air flow over the pool. The variation in the pool water temperature is accounted for by a simple enthalpy balance.

The loss-of-flow model (IFLOW=3, NLUP2=0) combines the forced flow from a pump coast-down with the estimated buoyancy-driven flow (calculated like in option IFLOW=4). If a flow reversal is detected (coolant mass flux sign switching from negative to positive), the channel outlet becomes the inlet and time-dependent coolant mixing fractions are used. These coolant mixing fractions approximate the transition period when hot water from the outlet plenum is mixed with the colder pool water and drawn back into the core.

\subsection{Lessons Learned From Comparisons With Reactivity Insertion Experiments In the SPERT Cores}

One of the objectives of the SPERT program was to determine experimentally the maximum equivalent step reactivity that could be inserted safely, i.e., relying only on the self-limiting behavior of the core to halt the excursion and stabilize the power to a level limited by feedback without damaging the fuel. Comparison of PARET/ANL predictions with measurements from the SPERT-III transients was part of the original validation [18-1] of the code performed in 1969. This validation was later extended [18-2] to include comparisons with SPERT-I experimental data. These comparisons studied the applicability of the code to model feedback effects in a wide variety of transients performed without scram (unprotected transients). A discussion about the use of PARET/ANL to model protected transients (i.e. with a reactor trip followed by a scram) is presented in Section 18.3.

It is recommended that the user review the discussions presented below in order to get a sense of the type of uncertainties that are expected when modeling reactivity insertion transients. 


\subsubsection{SPERT-III Reactor Transients}

The SPERT-III cores and experiments were designed to measure the effects of changing the following parameters on the core behavior following various reactivity insertions: initial power, coolant inlet temperature and pressure, and coolant velocity. The range of these parameters covered the operating environment found in a typical unborated PWR (of that era) without fission products. Therefore many of these tests were performed at operating conditions relatively far from those of most typical research reactors. The operating regimes were: coolant temperature up to $260^{\circ} \mathrm{C}\left(500^{\circ} \mathrm{F}\right)$, pressure up to $10.34 \mathrm{MPa}$ (1500 psig), coolant velocity up to $7.31 \mathrm{~m} / \mathrm{s}(24 \mathrm{ft} / \mathrm{sec})$ and initial power up to 20 MW. The initial periods associated with the reactivity insertions ranged from 2.26 sec to $9.7 \mathrm{msec}$. These experiments covered a major part of the range of reactor accident severity that is of interest in reactor analyses.

Two types of cores were studied as part of this validation [18-1, 18-5, 18-6]: the E-cores and the Ccores. The E-cores used fuel rods with $4.8 \%$ enriched $\mathrm{UO}_{2}$ pellets clad in stainless steel with a heliumfilled gap. The reactivity insertions for the E-core ranged from 0.5 to $1.3 \$$. For the E-core, 129 of 256 total tests were for initial pressures not exceeding 200 psig. The C-cores [18-7] used fuel plates with 93\% enriched $\mathrm{UO}_{2}$ dispersed in stainless steel and also clad in stainless steel. However, application of PARET to the SPERT-III C-cores was not as extensive as for the E-cores in this study. It should also be mentioned that this validation study performed no comparisons with E-cores' transients in which boiling occurred. Only limited boiling occurred in C-core transients.

One of the first lessons drawn from the comparison between PARET and SPERT-III measurements is that the code requires the calibration of its boiling model parameters: (1) an exponent (input option RXXEXP), (2) a dimensionless constant (input option RXXCON), the bubble collapse times in the subcooled and transition boiling regimes (input options TAUUNB, and TAUUTB) as well as the fractions of the heat transfer area contributing to producing bubbles in the sub-cooled, transition and film boiling regimes (input options ALAMNB, ALAMTB and ALAMFB.

These boiling model parameters were obtained through a parametric study in order to represent the experimental results of a given SPERT-III C-19/52 core transients since no values was available from theory or experimental measurements. Note that the topic of boiling and bubble formation remains a topic of much research to this day. The selected values for those parameters remain the basis for the current recommended values in the manual. (RXXEXP=1, RXXCON=0.8, TAUUNB $=$ TAUUTB $=0.001$, ALAMNB $=$ ALAMTB $=$ ALAMFB $=0.05$ )

The overall time-dependent behavior of the power, peak clad temperature and the energy generation was well predicted by the code. For the LEU oxides cores, discrepancies of $10 \%$ to $30 \%$ between the predicted and measured values were observed. The calculated results from PARET (ID0-17270, June 1968) required a good estimate of the helium gap conductance in order to best match experiment. In addition, it was found that direct heating by gammas to clad and water was important. For plate-type cores, discrepancies of $20 \%$ to $40 \%$ have been observed. To put these discrepancies into context, some of the reported experimental errors were: $\pm 10 \%$ on the power calibration, $\pm 7-10 \%$ on the reproducibility of the power for a given reactivity insertion, $\pm 5 \%$ due to the dynamic error of the temperature response, and $\pm 4 \%$ on the initial reactivity insertion. Similarly, Ref. 18- 6 reports that the PARET results were within $30 \%$ or less for the SPERT-III experiments.

\subsubsection{SPERT-I Reactor Transients}

The SPERT-I experimental facility used pool-type cores without forced circulation or pressurization other than the static pressure head. The SPERT-I cores used plate-type fuel assemblies using 93\% enriched uranium-aluminum alloy meat clad in aluminum. Two of the SPERT-I B-series cores (B- 
24/32 and B-12/64) as well as the D-12/25 core (used in the final destructive test) were analyzed using PARET/ANL. All transients were initiated at $20^{\circ} \mathrm{C}$ and from a nominal power level of $5 \mathrm{~W}$. The initial periods associated with the reactivity insertions ranged from $930 \mathrm{~ms}$ to $3.2 \mathrm{~ms}$ (destructive test).

A two-channel model was developed [18-2] to compare PARET/ANL predictions with measured data from these tests. A ramp of $70 \mathrm{~ms}$ was used to insert the specified amount of reactivity (same assumption as in the analysis of the SPERT-III tests discussed in Section 18.2.1). The experimental time taken to fully insert the reactivity is not clearly defined. The transient rod drop time is given [18-6] as 0.2 seconds, for a 45" maximum drop, from initiation of scram signal to full travel. In general, the tests did not require a maximum drop therefore the drop time should be less. However, the evolution of the transient is not sensitive to the ramp duration or profile since the initial power is very low and the insertion time is short. A forced flow problem was specified with an inlet velocity of $0.3 \mathrm{~cm} / \mathrm{s}$ to approximate the expected steady-state buoyancy-driven flow at the beginning of the event. More details about the modeling choices used in these analyses can be found in Ref. 18-2.

In this analysis, the Rosenthal and Miller [18-3] approximation of the heat transfer coefficient was selected in order to obtain better cladding temperature in the natural circulation regime $(\operatorname{Re}<2000)$.

It was found that the energy release and clad temperatures were the most sensitive to the choice of the void generation model parameters. To obtain better agreement for transients reaching the nucleate boiling regime, the bubble collapse time and the fraction of the heat transfer area contributing to producing bubbles were changed for that regime (TAUUNB=0.0005 and ALAMNB=0.03).

For these tests, the overall time-dependent behavior of the power, peak clad temperature and the energy generation were predicted well by the code.

For the SPERT-I B-24/32 core, comparisons between the PARET/ANL predictions and the measurements showed that:

- Discrepancies between $10 \%$ and $40 \%$ (on average $20 \%$ ) for the peak power for most transients were observed. Peak powers were overestimated for events with initial periods less than $0.02 \mathrm{sec}$ and underestimated for the other events.

- Discrepancies of up to $30 \%$ (on average 10\%) for the energy release at the time of peak power were observed. The largest discrepancy was observed for an event with an initial period of about 0.01 second. Transients with initial periods larger than 0.15 seconds have discrepancies around 20\%. For this core, the predicted energies releases were both underestimated and overestimated.

- Discrepancies of up to $20 \%$ (on average $10 \%$ ) in the peak cladding temperatures were observed. For events with initial periods larger than 0.15 seconds and smaller than 0.05 second, the discrepancies were typically of the order of $15 \%$. The peak clad temperatures were overestimated for events with initial periods larger than 0.15 second and smaller than 0.02 seconds. For the other events, the peak clad temperatures were underestimated.

- For one of the events (initial period greater than 0.5s), the discrepancy in the peak power was larger than $80 \%$ but the peak cladding temperature and energy released agreed within $20 \%$.

For the SPERT-I B-12/64 core, comparisons between the PARET/ANL predictions and the measurements showed that:

- Discrepancies of about $10 \%$ for the peak power for most transients were observed. The peak powers were typically overestimated. 
- Discrepancies of up to $50 \%$ (on average 20\%) for the energy release at the time of the peak power were observed. For transients with an initial period below about $20 \mathrm{~ms}$, the energies released at the time of the power peak were overestimated. For the other transients, the energy released was underestimated.

- Discrepancies of up to $30 \%$ (on average 10\%) in the peak cladding temperatures were observed. Peak clad temperatures were typically overestimated.

- For one of the events (initial period of about $50 \mathrm{~ms}$ ), the peak power and energy released were overestimated by about $70 \%$ and $50 \%$ respectively. For that event, the peak cladding temperature was overestimated by about $20 \%$.

For the SPERT-I D-12/25, the following observations about the comparisons between PARET/ANL predictions and the measurements can be made:

- Discrepancies of up to $60 \%$ (on average 30\%) for the peak power for most transients were observed. The peak powers were all overestimated.

- Discrepancies of up to $80 \%$ (on average 30\%) for the energy release at the time of the peak power were observed. Most of the energies released were overestimated.

- Discrepancies of up to $50 \%$ (on average $30 \%$ ) in the peak cladding temperatures were observed. Peak clad temperatures were almost all overestimated.

- For one event with an initial period near $50 \mathrm{~ms}$, the peak power and energy released were overestimated by about $110 \%$ and $90 \%$ respectively. For that event, the peak cladding temperature was overestimated by about $30 \%$.

It should be noted that numerical difficulties in the hydraulic solution were experienced for reactivity insertions large enough to result in significant void generation. For those cases, significant shortlived unphysical oscillations ${ }^{2}$ in the mass flux resulted in an unphysical enthalpy calculation. Consequently, the simulations of many of the shortest period transients failed at or slightly after the power peak.

Mass flux oscillations can be prevented, to some extent, by reducing the time step size (see Section 18.7). However, results may differ significantly since in those cases, stable transition or film boiling can be predicted by the code even though it is questionable that such stable conditions actually occurred during the experiments based on the measured cladding temperatures. It was found that the selection of the heat transfer correlations as well as the correlation used to define the boundaries of the various regimes (including DNB) affects significantly the prediction of the code for those types of events.

\subsubsection{Summary}

The analyses of SPERT-III and SPERT-I experiments showed that the boiling model parameters for the nucleate boiling regime may need to be calibrated to reflect the operating conditions of the core. In absence of reactor-specific experiments, it is recommended that the user select values based on the analysis of the SPERT core most similar to their reactor: SPERT-I for reactors with natural circulation and near atmospheric pressure and SPERT-III for reactors with forced flow and pressurized. The values selected for the boiling model parameters will affect the

\footnotetext{
${ }^{2}$ Mass fluxes orders of magnitude larger than steady-state values fluctuating between upflow and downflow at each time step
} 
predictions of the code for transients where the presence of void is a significant feedback effect. It is recommended that a sensitivity study be performed to understand the impact of those parameters for a given reactor and transients of interest.

The comparisons with measurements performed for a wide range of reactivity insertions in five SPERT cores have shown that the overall time-dependent behavior of the power, peak clad temperature and the energy released were adequately predicted by the code. For these same three parameters, the discrepancies between the predictions from the code and the measurements were generally between $10 \%$ and $50 \%$. For the SPERT-I cores, about one tenth of the events modeled have shown discrepancies between 50\%-80\%.

For the 2-channel model used in the SPERT-I transient analyses, most of the measured parameters (peak power, energy release at time of peak power and peak clad surface temperature) were overestimated and therefore conservative.

\subsection{Lessons Learned From Comparisons With RELAP5}

Many comparisons between RELAP5 and PARET/ANL have been performed over the years. This section presents several to illustrate the lessons learned.

Reference 18-4 performed a comparison between PARET/ANL and RELAP5/MOD3 for the following events in an idealized reactor (IAEA 10MW benchmark reactor):

- fast and slow loss-of-flow followed by a flow reversal

- fast and slow reactivity insertion followed by an overpower scram at $120 \%$ of full power

Comparisons of the flow reversal events showed that:

- the results were nearly identical while the pump coast-down curve dominated the buoyancy effects,

- the time of flow reversal as well as the peak clad temperatures at time of flow reversal agreed relatively well: within 1 or 2 seconds for the time of flow reversal and within a few degrees for peak clad temperature,

- PARET/ANL predicted a slightly higher coolant temperature,

- Small discrepancies of $5^{\circ} \mathrm{C}$ were observed after flow reversal when buoyancy effects drive the flow solution.

Comparisons for reactivity insertion events followed by an overpower scram at $120 \%$ showed that the results were nearly identical for the slow reactivity insertion event studied. For the fast reactivity insertion event, the largest discrepancy in peak cladding temperature was about $12^{\circ} \mathrm{C}$.

It was concluded that for the IAEA benchmark reactor, the overall agreement between the codes was generally good.

Reference (18-4] compared RELAP5 and PARET/ANL simulations of IAEA benchmark reactor transients. Note that the Rosenthal and Miller correlation was implemented in an ANL test version of RELAP5 for this analysis.

The comparisons showed that:

- Up to $1.2 \$$ reactivity insertion, the two codes agrees well when the same natural circulation heat transfer correlation is used (i.e., Rosenthal and Miller). 
- For reactivity insertion above $1.2 \$$ (point at which significant nucleate boiling occurs), the discrepancy between the two codes increases significantly due to different predicted void fraction, flow regimes and reactivity feedback. For those higher reactivity events, PARET/ANL predictions were closer to the experimental values.

\subsection{Recommendations For Selecting An Axial Nodalization}

Due to the numerical scheme used within PARET/ANL, it is best to use axial nodes with the first and last nodes defined to be half the length in the inner nodes. By this means, the fluid nodes are all of the same length, which is advantageous for numerical accuracy and stability of the enthalpy solution in space and time. See APPENDICES VI and VII for more discussion about axial nodalization in PARET/ANL).

A sensitivity study is recommended in order to study the convergence of key results such as the number of axial nodes. It is recommended that the user select as many axial nodes as necessary to adequately capture the axial power peak.

\subsection{Recommendations For Steady-State Initialization}

At the beginning of a PARET/ANL transient, thermal-hydraulics properties are initialized to their steady-state values. In recent versions of the code, this initialization was improved such that reactivity insertion could be defined starting a time zero. However, it is still recommended to perform a "null" transient (i.e., no reactivity insertion) for the first second of the simulation in order to verify that the steady-state conditions (flow and temperatures) are as expected and remain stable.

The user should look for the message of "STEADY-STATE INITIALIZATION CONVERGED AT MPASS= NNN" where NNN is the number of passes needed to ensure that the steady-state initialization was successful.

Note that the initialization process during the steady-state calculation assumes that the coolant will not enter into any boiling process. The code will fail in unexpected ways if there is insufficient coolant flow rate for the requested power, to keep the coolant subcooled.

It is also recommended that the steady-state conditions be compared with either experimental data or a more detailed steady-state thermal-hydraulic code if possible.

\subsection{Recommendations For Flow-Forced, Pressure-Drop- Forced Or Buoyancy Driven Calculations}

When possible, it is recommended that the user select IFLOW=1 (forced flow calculation) since the other flow options have not received as much verification.

IFLOW=2 (pressure-drop flow calculation) should not be used as it is known to fail to converge (see Section 18.9).

IFLOW=3 (buoyancy driven with pump coast downflow superimposed) received some verification but is not fully qualified yet.

Therefore, for events terminated before the buoyancy effects can change significantly the flow conditions, it is recommended that a forced flow calculation (IFLOW=1) be performed even for 
reactors cooled by natural circulation. The value of the mass flux should correspond to the expected steady-state natural circulation values (experimental data or other values obtained from another code). The buoyancy-driven flow rate for a given steady-state power can be approximated using IFLOW=4 without reactivity feedback by setting the Doppler, coolant void and coolant temperature feedback coefficients to zero and specifying a null transient or by setting IPROP=0 to perform a power-level specified calculation. A long "transient" time should be specified (possibly of the order of 100 seconds) to allow for the convergence of the flow solution.

If the assumptions used in the buoyancy-driven flow model (see Section 18.1) are appropriate, the user can also select IFLOW=4 (and NLUP2=0) to approximate the response of the flow conditions during a slow event. Note that this utilization of IFLOW $=4$ has received limited verification at this time. For MNSRs (NLUP2=1), slower events are modeled more accurately due to the reactor-specific natural circulation model in the code.

\subsection{Recommendations For Selecting The Time Step Size}

It is important to understand that the hydrodynamics and point-kinetics solutions from PARET/ANL are sensitive to time step size. PARET/ANL uses a simple algorithm to control the time step to ensure the numerical stability of the enthalpy solutions. Special attention should be given to the selection of the time step size.

If computing time constraints permit, it is recommended that the user specify a uniform time step sufficiently small to model adequately the kinetics and hydraulics transient behaviors. This will simplify the use of the following guidelines since it may be necessary to run the simulation multiple times.

PARET/ANL ensures that the time step is at or below 0.8* the Courant limit. All fluid nodes are checked to locate the smallest value of:

$$
\Delta t \leq \min \left(\frac{\rho_{i, m} \cdot \Delta z_{i}}{\left|\dot{m}_{i, m}\right|}\right)
$$

The above criterion is theoretically necessary but not sufficient to ensure a well-behaved solution. It is recommended that the user set the time step size to about $\Delta t$ / 5 .

Moreover, this version of the code does not have an algorithm to adjust the time step size to prevent the fluid density from changing too drastically over a time step. If it does, it can result in stability issues when significant boiling occurs. In that event, further reduction in the time step size is required. For example, the occurrence of "BULK BOILING" and "FILM BOILING" involves the creation of significant steam void and can challenge the PARET/ANL hydraulic solution. Should numerical stability fail, the error message "ENTH<0" (i.e., that the fluid enthalpy of a given node has been computed in error) may be generated. The code terminates the run at that time. The onset of numerical instability is typically preceded by large mass flux oscillations.

To select an appropriate time step size based on Eq. (18-1), it is helpful to proceed as follows. The first calculation should be performed with a time step size evaluated from Eq. (18-1) using the initial conditions (input parameters). The results from that calculation should be inspected to evaluate the minimum time step size for the whole transient using Eq. (18-1). The calculation can then be repeated with the new time step size. If significant oscillations are observed in the flow solution, it is 
recommended that the time step size be further reduced based on the above criterion evaluated using the unphysical values. This should help prevent the onset of these instabilities.

Secondly, it is recommended to use option KINTS $=-1$ to force the code to use the same time steps for both the thermal-hydraulic and point-kinetics solutions, to prevent extrapolation of the reactivity over a time step and warn the user that the time step has to be reduced to meet the point-kinetics solution error criterion [ 18-1]. In that case, the user should look for "NEXT TIME-STEP WAS FORCED" statements in the output. If they occur, the user should reduce the time step size in half and rerun the simulation. This process should be repeated until no such statement appears in the output.

Finally, PARET/ANL assumes that all clad surface temperatures must satisfy a relative change of less than 0.001 within MAXHCC iterations in order to consider the thermal solution converged. Issues with the thermal solution are flagged in the output file and preceded by the label "HEAT2". For convergence problems, the time, channel, axial node, and radial node numbers where the convergence was worst are printed. Note that any issue with the thermal solution can be an indication that the time step size is inappropriate, or that MAXHCC needs to be larger.

If PARET/ANL cannot obtain a converged thermal solution within MAXHCC iterations, the code relaxes the convergence criterion to 0.008 for $1 \%$ of the transient time requested, and then restores the original criterion. However, if possible, it is recommended that the user try to avoid this type of relaxation of the convergence criterion by reducing the time step size further and rerunning the problem.

\subsection{Recommendations About Output Verification}

Errors in processing the supplied input are sometimes fatal, and sometimes not. Not all card type sequence numbers within a given card type such as 14000 cards, are checked. But input is checked for integer vs. floating point, for complete pairs of data when it should be in pairs, and for the correct number of data values for a given card type. Detected errors will cause various messages, including the word "DUMP" when an input line image is edited that does not conform to expectations

The user can search for the label "ERROR" in the output file in order to identify the source of the problem.

If a job fails to complete, it is recommended that the user look at the last time step by searching up from the end of the output file for "THUS FAR" in order to diagnose the issue.

In general, it is good practice to look for the label "WARNING" in the output file to see if any questionable conditions were detected.

One such warning relates to PARET/ANL renormalization of the power distribution if normalization discrepancy larger than $0.1 \%$ is detected. The user should always look for that warning since it might be due to a user input error rather than a round-off error.

Channel files provide an output for the peak properties only. It is recommended to review/study/plot the properties (clad and fuel properties as well as coolant temperature and density) in the whole channel using the information in the main output file to verify that a stable/physical solution was obtained.

The power peaks can be identified by searching for "PERIOD=-" in the output file. The first occurrence of a negative period marks the power peak. Subsequent peaks can also be located in the same way.

Review the average Reynolds number of each channel, which is printed at the end of every major edit. Heat transfer correlations have limits of applicability, such as the Reynolds number, L/D, pressure, coolant velocity, up-flow or downflow, or the Prandtl number. A warning is printed to 
informs the user when a limit of applicability has been violated. APPENDIX II provides those limits where known. The user should use caution when the known limits of applicability of a selected correlation are violated during the transient.

\subsection{Recommendations About The Developmental Options}

A number of options in PARET/ANL are in their developmental state and/or have received incomplete testing. Consequently, users cannot utilize the following options:

- IFLOW=2 (pressure drop driven flow solution)

- Capability 11 (nested tube modeled as two half-plates per tube)

- IMODE=2, 3, 4 and 5 (transient two-phase schemes)

- The following option is known to be less accurate in determining the flow solution:

- INORM=1 and 2 (power distribution renormalization options that are less accurate)

The following option should be used only for laminar flow, for IGEOM=1 only

- IONEP=5 (CIAE MNSR natural circulation correlation)

The manual also specifies that the option IGEOM=2 allows for different meat and coolant channel dimensions as well as for different forced flow rate in each channel. If the user needs to specify different types of fuel assemblies in the same core, it is recommended that the user check his IGEOM= 2 model results by using the IGEOM=0 option. Each type of fuel assembly in the core can be simulated as a separate run using IGEOM=0. Various approaches can be used to partition the core into "PARET" channels for each type of fuel. Appropriate power fraction and feedback coefficients are needed for each "channel". The following reference contains an example of an analysis for two different fuel types in the same core:

P.L. Garner and N. A. Hanan, "Transient Analyses for the Uzbekistan VVR-SM Reactor with IRT-3M HEU Fuel and IRT-4M LEU Fuel: Independent Verification Results,"ANL-07/26, Argonne National Laboratory, (2007).

\subsection{Recommendations For Mass Flow Specification Using IGEOM=0 or 1}

The recommended geometry options in PARET/ANL V7.5 (IGEOM=0 or 1 ) with IFLOW=1 use a single mass flux for all channels. It is recommended to use the best estimate of the coolant mass flux in the hot channel in order to better reflect the peak clad temperature. If the mass flux in the hot channel is significantly different than that in the other channels, it is recommended that a sensitivity study be performed to evaluate the impact of the coolant mass flux on the transient behavior due to change in the coolant feedback.

For IFLOW=3, 4, and 5, the flow in each channel may depend on buoyancy forces.

\subsection{Recommendations For Multi-Channel Core Partitioning}

It is recommended that a PARET/ANL model have at least 2 channels, i.e., one channel representing the hot coolant channel (typically the coolant channel where the peak clad temperature 
occurs at steady-state) and one other channel representing the remainder of the core to model the core average feedback.

It is expected that 2-channel models will provide a conservative estimate of the peak clad temperatures. Engineering judgment suggests that the overall reactivity insertion from the coolant and fuel feedback could be better represented by modeling core regions with similar power as different equivalent PARET/ANL channels. In theory, this should allow for high power regions to introduce negative reactivity feedback earlier during the transient and possibly improve comparisons to experiments. However, absent of detailed and successful comparisons to experimental data for different nodalizations, it is difficult to recommend an appropriate level of detail. Note that, as mentioned in Section 18.1, the predicted clad temperatures in channels other than the hot channel may not be conservative.

It is useful to perform a nodalization sensitivity study analyzing the impact of the number of the channels. If the number of channels in the model has a large impact on the predicted transient behavior, it is possible that the core for this specific transient has a strong space-time dependency for the coolant and fuel reactivity feedback. This can potentially invalidate the approximations used in the point-kinetics model that predicts the power excursion. The user should be very careful when relying on the code predictions for cases where the channel nodalization has a strong impact on the results.

The user should also be aware that increasing the number of PARET/ANL channels affects only the evaluation of the effective core feedback and not the thermal-hydraulics solution since, as noted previously, the channels are not thermal-hydraulically coupled.

\subsection{Clarification About Using The Decay Heat Model}

PARET/ANL has a recommended decay heat model based on the ANSI/ANS 2005 Standard. It also has an older decay heat model based on the ANS-5.1-1973 draft decay heat standard.

If a decay power contribution from prior operation at a given power (card POW0) for a given number of days (card OPT) is specified, it assumed that this contribution is part of the initial steady-state power (card POWER) and is not updated based on the change in power during the transient. This last assumption is valid for all transients except the very long events involving a major change in power. For such cases, the decay power contribution after scram can be modeled by adjusting the cards POW0 and OPT to reflect the conditions at the time of the trip. One can also introduce a shutdown time (TSHUT0) between the end of prior operation, and the start of the PARET/ANL simulation.

In addition to providing the proper cards to input previous operating time and power, it is necessary to set up trip points and control rod reactivity insertion cards in order activate the decay heat model. The decay heat contribution will be added to the residual neutronics power once a trip is detected $\left(\mathrm{T}_{\text {trip }}\right)$ and a scram is initiated following a user-specified control system response delay $\left(\mathrm{T}_{\text {delay }}\right)$.

\subsection{Clarification About Water Property Tables}

The water properties tables (used for interpolated properties during the simulation of a transient) are automatically generated for a fixed number of 27 pressure points, one of which is now always the user input pressure. As a result, there is no interpolation error introduced by interpolation between pressure tables. This table was originally based on a limited range of pressure (14.7 to $50 \mathrm{psi}$ ). Version 7.5 r82160803 allows for the use of any pressure but the user should be aware that the table of properties will contain the same number of pressure points no matter the range of pressure specified. The library is extended to higher pressure as needed, automatically. The nominal limits are 
16.608 $\mathrm{MPa}$ for $\mathrm{H}_{2} \mathrm{O}$, and 16.327 $\mathrm{MPa}$ for $\mathrm{D}_{2} \mathrm{O}$. Verification up to $40 \mathrm{MPa}$ is satisfactory. A Validation and Verification document is in preparation which will document the fluid properties.

It should also be noted that pressure drop calculations reported by PARET/ANL are not used to evaluate the water properties at different axial locations in the coolant channel. The water properties are always evaluated at the initial pressure specified by the input variable PRESUR. Note that the change in pressure due to the change in static pressure head and friction loss along a fuel assembly has only a negligible impact on the water properties in research reactors.

\subsection{Clarification on PARETIANL Axial Nodalization Convention}

The convention used in PARET/ANL is that axial node 1 is always located at the bottom of the fuel assemblies. This convention is used anytime axially dependent properties need to be specified in the 5000 -series cards (5kXX cards with $\mathrm{XX} \geq 02$ ) as well as in the output file.

\subsection{Clarification About Specifying Flow Conditions}

Some comment is appropriate regarding orientation of PARET/ANL input/output (sign conventions for gravity and mass flux) and the axial source distribution sequence. PARET/ANL models either up flow or downflow by user input specifications for Table 10, i.e., the Coolant Inlet Mass flux vs. Time data supplied on cards 10000 and 10XXX. Positive values for input variable AMFRIN denote up flow, while negative values denote downflow. The acceleration of gravity, GRAV, should be $>0$ regardless of flow direction, to account correctly for static pressure head changes.

\subsection{Discussion About Two-Phase Flow Heat Transfer Correlations And Transition Models}

The boiling transition models (IMODE=0 or IMODE=1) are used to evaluate the two-phase heat transfer coefficients in the partial boiling regime (after onset of nucleate boiling but before fully developed boiling occurs) and smoothly transition from one heat transfer mode to the other. At this point, it is recommended that the user select IMODE = 1 to use the approach developed by Bergles \& Rosenhow. A generic recommendation for the selection of a two-phase heat transfer correlation (ITWOP $=0$ or ITWOP $=1$ ) cannot be made. The user should be careful to select a correlation that was developed for pressures close to their operating pressure (see comments for the ITWOP option written in the 1112 Card) and perform a sensitivity study of the impact of this selection. For transients with limited boiling, the impact of selecting either the Jens-Lottes correlation (ITWOP $=0$ ) or the McAdams (ITWOP $=1$ ) is expected to be small (the single-phase heat transfer coefficient still dominates the overall two-phase heat transfer coefficient obtained through the transition formula).

\subsection{References for Appendix VIII}

[18-1] C. F. Obenchain, PARET-A PROGRAM FOR THE ANALYSIS OF REACTOR TRANSIENTS, AEC Research and Development Report, Reactor Technology, IDO-17282, Phillips Petroleum Company, Idaho, January 1969.

[18-2] William L. Woodruff, The PARET Code and the Analysis of the SPERT I Transients, ANL/RERTR/TM-4 (1982). 
[18-3] M.W. Rosenthal and R.L. Miller, "An Experimental Study of Transient Boiling”, ORNL-2294, Oak Ridge National Laboratory, April 29, 1957.

[18-4] W.L. Woodruff, N.A. Hanan, R.S. Smith and J.E. Matos, "A Comparison of the PARET/ANL and RELAP5/MOD3 Codes for the Analysis of IAEA Benchmark Transients," Proceedings of the 1996 International Meeting on Reduced Enrichment for Research and Test Reactors, Seoul, Republic of Korea, October 7-10, Argonne National Laboratory, (1996).

[18-5] R. K. McCardell, D. I. Herborn, and J. E. Houghtaline, Reactivity Accident Test Results and Analyses for the SPERT-III E-Core-A Small, Oxide-Fueled, Pressurized-Water Reactor, AEC Research and Development Report IDO-17281, TID-4500, March 1969.

[18-6] ID0-17036, SPERT-III Reactor Facility: E-Core Revision, J. Dugone, Editor, TID=4500, Nov. 1965, p. 101.

[18-7] R. Scott, Jr., C. L. Hale, R. N. Hagen, Transient Tests of the Fully Enriched Uranium-Oxide Stainless Steel Plate-Type C-Core in the SPERT III Reactor: Data Summary Report, IDO-17223, February 1967. 


\section{Appendix IX Coolant Properties Generators For PARETIANL}

This section documents how the coolant properties subroutines used in PARET/ANL V7.5 were obtained from original PARET/ANL Version 5 software. The original stand-alone coolant properties generators in PARET/ANL are:

light water source code: proph2og.for, dated 8/12/2004

heavy water source code: propd2og.for, dated 12/6/2001

The saturation pressure of light water was taken from [19-1]. Other water properties (thermal conductivity, valid from 0-500 bar and 0-350 C) came from [19-2]. Viscosity came from [19-3]. For heavy water, the thermal-hydraulic properties came from [19-4] and [19-5].

There is also a readable text version of the library for heavy water called propd2o.prt which was created when the code was executed. The FORTRAN source file proph2og.for was changed to a subroutine. This stand-alone code had no PROGRAM statement, so it was only necessary to add a SUBROUTINE statement to make it useable by PARET. The actual statement is:

\section{SUBROUTINE PROPH2O(N8)}

The argument N8 is the unit number of the binary file to be created. The PARET/ANL main program opens this file and calls either PROPH2O or PROPD2O, as directed by input parameter IFLUID.

The same process was applied for heavy water, using file propd2og.for as the starting point for PARET/ANL file propd2o.f. The actual statement is:

\section{SUBROUTINE PROPD2O(N8)}

The coding involved to make the binary library was unchanged. Tests were performed at that time to assure that the new library from PARET/ANL was the same as before, and that sample problems produced identical results. Similar tests were conducted in December 2009 to verify that the code produced identical results with different libraries.

The heavy water library is generated by functions that are valid from 0-100 MPa, and 0-800 C.

The light water library is set up to create the default library that goes from 14.6959 psia to 50.304 psia. In Version 7.6, the code checks the operating pressure supplied and generates a library structured accordingly. Note that the accuracy of interpolation within the library is relatively unaffected as the pressure range is increased. 
Table 19.1 Saturation Temperature of Light and Heavy Water between NIST Data and the PARET/ANL Version 7.6 Code

\begin{tabular}{|l|l|l|l|l|l|l|}
\hline \multirow{2}{*}{$\begin{array}{l}\text { Pressure } \\
\text { Bar }\end{array}$} & \multicolumn{4}{|l}{ Saturation Temperature, ${ }^{0} \mathrm{C}$} & \multicolumn{2}{l|}{ Coolant Outlet Temp., ${ }^{0} \mathrm{C}^{*}$} \\
\cline { 2 - 7 } & \multicolumn{2}{|l|}{ Light Water } & Neavy Water & Light Water & Heavy Water \\
\hline \multirow{2}{*}{ Code } & NIST & Code & NIST & Code & Code \\
\hline 2 & 99.632 & 99.606 & 101.065 & 101.05 & 58.68 & 59.23 \\
\hline 5 & 120.231 & 120.21 & 121.408 & 121.41 & 58.67 & 59.20 \\
\hline 10 & 151.849 & 151.83 & 152.642 & 152.65 & 58.69 & 59.21 \\
\hline 20 & 179.883 & 179.88 & 180.367 & 180.38 & 58.71 & 59.22 \\
\hline 30 & 212.369 & 212.38 & 212.516 & 212.51 & 58.73 & 59.24 \\
\hline 40 & 250.333 & 250.35 & 250.098 & 250.07 & 58.78 & 59.28 \\
\hline 50 & 263.914 & 263.94 & 263.542 & 263.51 & 58.77 & 59.30 \\
\hline 75 & 290.512 & 290.54 & 289.846 & 289.81 & 58.85 & 59.36 \\
\hline 100 & 310.960 & 311.00 & 310.074 & 310.04 & 58.89 & 59.41 \\
\hline 125 & 327.780 & 327.81 & 326.689 & 326.67 & 58.95 & 59.46 \\
\hline 150 & 342.122 & 342.16 & 340.852 & 340.85 & 59.00 & 59.51 \\
\hline
\end{tabular}

* For the cylindrical geometry test problems with a reactor power of $10 \mathrm{MW}$ and a mass flux of $425.8 \mathrm{~kg} / \mathrm{m}^{2}-\mathrm{s}$. 
Table 19.2 Comparison of Thermal Properties of $\mathrm{H}_{2} \mathrm{O}$ over 1 to 145 bar Pressure and 4 to $372^{\circ} \mathrm{C}$ Temperature between PARET Version 7.6_r152_181129 and the NIST Data

\begin{tabular}{|c|c|c|c|c|c|}
\hline $\begin{array}{c}\text { Phase } \boldsymbol{\&} \\
\text { Pressure }\end{array}$ & $\begin{array}{c}\text { \% Diff. } \\
\mathbf{H}\end{array}$ & \% Diff. K & \% Diff. Cp & \% Diff. $\boldsymbol{~}$ & \% Diff. $\boldsymbol{\mu}$ \\
\hline Liquid, 1 bar & 0.53 & 2.14 & 1.18 & 0.07 & 3.02 \\
\hline Vapor, 1 bar & 0.22 & 0.93 & 3.79 & 0.62 & 1.92 \\
\hline Liquid, 2 bar & 0.52 & 2.06 & 1.07 & 0.10 & 3.59 \\
\hline Vapor, 2 bar & 0.24 & 2.70 & 3.83 & 0.64 & 1.22 \\
\hline Liquid, 5 bar & 0.51 & 2.02 & 1.00 & 0.11 & 3.51 \\
\hline Vapor, 5 bar & 0.26 & 5.08 & 5.29 & 0.68 & 0.65 \\
\hline Liquid, 10 bar & 0.50 & 2.09 & 0.99 & 0.11 & 3.38 \\
\hline Vapor, 10 bar & 1.27 & 5.84 & 14.84 & 4.14 & 0.65 \\
\hline Liquid, 20 bar & 0.46 & 1.97 & 2.99 & 0.11 & 3.09 \\
\hline Vapor, 20 bar & 0.41 & 6.02 & 6.16 & 1.27 & 1.77 \\
\hline Liquid, 30 bar & 0.43 & 1.85 & 14.77 & 0.11 & 3.42 \\
\hline Vapor, 30 bar & 0.09 & 5.11 & 13.26 & 0.23 & 2.90 \\
\hline Liquid, 40 bar & 0.39 & 1.73 & 3.28 & 0.11 & 3.85 \\
\hline Vapor, 40 bar & 0.34 & 3.95 & 17.31 & 0.99 & 4.02 \\
\hline Liquid, 50 bar & 0.36 & 1.67 & 2.98 & 0.11 & 4.05 \\
\hline Vapor, 50 bar & 0.51 & 2.80 & 20.06 & 1.52 & 5.14 \\
\hline Liquid, 75 bar & 0.30 & 1.57 & 2.76 & 0.11 & 4.42 \\
\hline Vapor, 75 bar & 0.64 & 0.82 & 23.43 & 1.99 & 8.04 \\
\hline Liquid, 100 bar & 0.26 & 1.47 & 2.09 & 0.11 & 6.75 \\
\hline Vapor, 100 bar & 0.47 & 3.13 & 23.87 & 1.52 & 10.99 \\
\hline Liquid, 125bar & 0.21 & 1.37 & 1.30 & 0.11 & 14.33 \\
\hline Vapor, 125bar & 0.41 & 4.49 & 17.51 & 0.86 & 14.01 \\
\hline Liquid, 145 bar & 0.18 & 1.58 & 3.58 & 0.13 & 27.16 \\
\hline Vapor, 145 bar & 0.61 & 4.91 & 15.95 & 1.63 & 16.07 \\
\hline Max. \% Diff., All & 1.27 & 6.02 & 23.87 & 4.14 & 27.16 \\
\hline Pressures & 1.27 & & & \\
\hline
\end{tabular}


Table 19.3 Comparison Between ASME Steam Tables and NIST Data for $C_{p}$ and Viscosity of $\mathrm{H}_{2} \mathrm{O}$

\begin{tabular}{|l|l|l|l|l|l|l|l|}
\hline \multicolumn{4}{|l|}{$\mathbf{C}_{\mathbf{p}}$ of $\mathbf{H}_{2} \mathbf{O}$ (Btu/lb-F) at 15 psia } & \multicolumn{4}{l|}{ Viscosity of $\mathbf{H}_{2} \mathbf{O}$ (lbf-s/ft ${ }^{2}$ ) at 20 psia } \\
\hline Temp., of & ASME Data & NIST Data & \% Diff. & Temp., -F & ASME Data & NIST Data & $\%$ Diff. \\
\hline 40 & 1.004 & 1.0053 & 0.129 & & & & \\
\hline 80 & 0.998 & 0.99921 & 0.121 & 50 & $2.73 \mathrm{E}-05$ & $2.727 \mathrm{E}-05$ & 0.021 \\
\hline 120 & 0.999 & 0.99929 & 0.029 & 100 & $1.42 \mathrm{E}-05$ & $1.423 \mathrm{E}-05$ & 0.019 \\
\hline 160 & 1.001 & 1.0016 & 0.060 & 150 & $8.98 \mathrm{E}-06$ & $8.978 \mathrm{E}-06$ & 0.028 \\
\hline 200 & 1.005 & 1.0058 & 0.080 & 200 & $6.32 \mathrm{E}-06$ & $6.325 \mathrm{E}-06$ & 0.073 \\
\hline 400 & 0.473 & 0.47257 & 0.091 & 400 & $3.4 \mathrm{E}-07$ & $3.414 \mathrm{E}-07$ & 0.413 \\
\hline 600 & 0.482 & 0.48303 & 0.213 & 600 & $4.4 \mathrm{E}-07$ & $4.372 \mathrm{E}-07$ & 0.639 \\
\hline 800 & 0.498 & 0.49874 & 0.148 & 800 & $5.3 \mathrm{E}-07$ & $5.338 \mathrm{E}-07$ & 0.708 \\
\hline 1000 & 0.515 & 0.51627 & 0.246 & 1000 & $6.3 \mathrm{E}-07$ & $6.290 \mathrm{E}-07$ & 0.162 \\
\hline Max \% Diff & & & 0.246 & Max \% Diff & & & 0.708 \\
\hline
\end{tabular}




\subsection{References for Appendix IX}

[19-1] Report NASA TN D-7391, National Aeronautics and Space Administration (1973).

[19-2] UK Steam Tables in SI Units 1970, United Kingdom Committee on the Properties of Steam, Edward Arnold (Publishers) Ltd, London, 1970.

[19-3] International Association for the Properties of Steam, H. J. White, Secretary, Release on Thermal Conductivity of Water Substance, National Bureau of Standards, Washington, D.C. (1977, revised 1983).

[19-4] Heavy Water - Thermophysical Properties, Kernforschungsanlage (KFA), Julich GMBH. These functions span 0-100 MPa, and 0-800 C.

[19-5] Lester Haar, John S. Gallagher, and George S. Kell, NBS/NRC Steam Tables, Thermodynamic and Transport Properties and Computer Program for Vapor and Liquid States of Water in SI Units, Hemisphere Publishing Corporation, Washington D.C., 1984. 


\section{Other Useful References}

The following references are provided should the user wish to locate scientific works not referenced, but of value to a thermal-hydraulic analyst.

[20-1] For the Moody friction factor: L. F. Moody, Trans. ASME, 66, 671 (1944).

[20-2] R. J. Weatherhead, "Nucleate Boiling Characteristics and the Critical Heat Flux Occurrence in Subcooled Axial-flow Water Systems,” ANL-6675, 1963.

[20-3] W. L. Woodruff and K. Mishima, "Neutronics and Thermal-Hydraulics Analysis of KUHFR,”ANL/RERTR/TM-3, CONF-801144, p. 579, 1980.

[20-4] K. Mishima, H. Nishihara, and T. Shibata, “CHF Correlations Related to the Core Cooling of a Research Reactor,” Proc. International Meeting on Reduced Enrichment for Research and Test Reactors, 24-27 October, 1983, Tokai, Japan, JAERI-M-84-073, 311 (1983).

[20-5] K. Mishima, K. Kanda and T. Shibata, “Thermal-Hydraulic Analysis for Core Conversion to the Use of Low-enrichment Uranium Fuels in the KUR," KURRI-TR-258, Research Reactor Institute, Kyoto University, Dec. 7, 1984.

[20-6] K. Mishima, K. Kanda and T. Shibata, “Thermal-Hydraulic Analysis for Core Conversion to the Use of Low-Enriched Uranium Fuels in the KUR,” ANL/RERTR/TM-6, CONF-8410173, p. 375, 1984.

[20-7] For condensation: J. Kestin, J. V. Sengers, B. Kamgar-Parsi, and J. M. H. Levelt Sengers, “Thermophysical Properties of Fluid H2O,” J. Phys. Chem. Ref. Data, Vol. 13, No. 1, 1984, pp. 175-183.

[20-8] W. L. Woodruff, "Some Neutronics and Thermal-hydraulics Codes for Reactor Analysis Using Personal Computers," Proc. Int. Mtg. on Reduced Enrichment for Research and Test Reactors, Newport, RI, Sept. 23-27, 1990, CONF-9009108 (ANL/RERTR/TM-18), Argonne National Laboratory (1993).

[20-9] For 1995 look-up table: D. C. Groeneveld, L. K. H. Leung, P. L. Kirillov, V. P. Bobkov, I. P. Smogalev, V. N. Vinogradov, X.C. Huang, E. Royer, "The 1995 look-up table for critical heat flux in tubes,” Nuclear Engineering and Design, 163 (1996) 1-23. For film boiling: C. Groeneveld, L.K.H Leung, A.Z. Vasic, Y. J. Guo, S.C. Cheng, "A look-up table for fully-developed filmboiling heat transfer,” Nuclear Engineering and Design 225, 83-97 (2003). Tables are marked: Version September 2001.

[20-10] W. L. Woodruff, J. R. Deen and C. Papastergiou, "Transient Analyses and Thermalhydraulic Safety Margins for the Greek Research Reactor (GRR1)," Proc. Int. Mtg. on Reduced Enrichment for Research and Test Reactors, Williamsburg, VA, Sept. 19-23, 1994, CONF9409107 (ANL/RERTR/TM-20), Argonne National Laboratory (1997).

[20-11] Ibrahim Babelli and Mamoru Ishii, "Flow Excursion Instability in Downward Flow Systems. Part I. Single-phase Instability,” Nucl. Eng. Design, 206, 91 (2001).

[20-12] Ibrahim Babelli and Mamoru Ishii, "Flow Excursion Instability in Downward Flow Systems. Part II. Two-phase Instability,” Nucl. Eng. Design, 206, 97 (2001). 
(This page left intentionally blank) 


\section{Argonne}

\section{Nuclear Science and Engineering Division}

Argonne National Laboratory

9700 South Cass Avenue, Bldg. 208

Argonne, IL 60439-4842

www.anl.gov

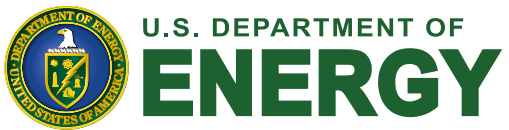

Argonne National Laboratory is a U.S. Department of Energy laboratory managed by UChicago Argonne, LLC 